\title{
WestVirginiaUniversity
}

THE RESEARCH REPOSITORY @ WVU

Graduate Theses, Dissertations, and Problem Reports

2015

\section{Thermal Stress Analysis for Early Age Mass Concrete Members}

Yun Lin

Follow this and additional works at: https://researchrepository.wvu.edu/etd

\section{Recommended Citation}

Lin, Yun, "Thermal Stress Analysis for Early Age Mass Concrete Members" (2015). Graduate Theses, Dissertations, and Problem Reports. 6090.

https://researchrepository.wvu.edu/etd/6090

This Dissertation is protected by copyright and/or related rights. It has been brought to you by the The Research Repository @ WVU with permission from the rights-holder(s). You are free to use this Dissertation in any way that is permitted by the copyright and related rights legislation that applies to your use. For other uses you must obtain permission from the rights-holder(s) directly, unless additional rights are indicated by a Creative Commons license in the record and/ or on the work itself. This Dissertation has been accepted for inclusion in WVU Graduate Theses, Dissertations, and Problem Reports collection by an authorized administrator of The Research Repository @ WVU.

For more information, please contact researchrepository@mail.wvu.edu. 


\title{
Thermal Stress Analysis for Early Age Mass Concrete Members
}

\author{
Yun Lin \\ Dissertation submitted \\ to the Benjamin M. Statler College of Engineering and Mineral Resources \\ at West Virginia University \\ in patial fulfillment of the requirements for the degree of \\ Doctor of Philosophy in \\ Civil and Environmental Engineering \\ Roger H.L. Chen, Ph.D., Chair \\ Karl E. Barth, Ph.D., P.E. \\ Hailin Li, Ph.D. \\ Fei Dai, Ph.D. \\ Thirimachos Bourlai, Ph.D. \\ Seung Ho Hong, Ph.D. \\ Department of Civil and Environmental Engineering
}

Morgantown, West Virginia

2015

Keywords: Mass Concrete; Heat of hydration; Thermal stress; Early age concrete; ABAQUS. 


\title{
ABSTRACT \\ Thermal Stress Analysis for Early Age Mass Concrete Members
}

\author{
Yun Lin
}

Research findings in the past have demonstrated that the heat of hydration can induce thermal cracking in early age concrete. The disproportionate thermal expansion can cause considerable tensile stresses at concrete surfaces. The minimum size of mass concrete has remained unsolved due to the complexity of the problem. In this study, a way to predict early age concrete temperature and associated thermal stresses is described, including the needed experimental testing and finite element modeling technique.

In thermal analysis, an adiabatic calorimeter was designed and built to measure the adiabatic temperature rise of the concrete. The measured adiabatic temperature rise was converted into a mathematical formulation for finite element modeling. Thermal properties including specific heat and thermal conductivity were considered to be degree of hydration dependent and determined individually for each element in the model. The interface conductance between concrete and steel formwork was determined experimentally and put in place to account for the thermal resistance from the concrete-formwork interface. External surface convection for formwork-air interface was used to calculate surface heat loss.

In order to calculate the thermal stresses, the degree of hydration was utilized to estimate the elastic modulus development. Concrete tensile creep and compressive creep behaviors were included using a step-by-step incremental calculation algorithm. Influences from loading age and temperature effect were considered in each time increment of the creep models. Based on test results from concrete cubes, the modeling method and experimental procedures used in this study were validated to exhibit reasonable accuracy in terms of temperature and strain predictions. The thermal and stress analysis models can be used to calculate the temperature profile and thermal stress development histories for early age concrete. 


\section{Acknowledgements}

I would like to thank all of the people helped me to make this dissertation a reality. First, I would like to express the deepest appreciation to my committee chair Professor Hung-Liang (Roger) Chen for his advices, encouragements and supports. He continuously conveyed a spirit of adventure in regard to research and teaching. Without his guidance and persistent help, this dissertation would not have been possible.

I am appreciative of the West Virginia Department of Transportation Highway Division for funding this study (Research Project RP \#257). I would also like to extend my gratitude to Donald Williams, Mike Mance, Ryan Arnold and others who provided assistants and supports throughout the project.

I am further indebted to Joseph sweet, Alper Yikici, Zhanxiao Ma and Jared Hershberger. They generously helped me with my research work so that I can make today's achievement. I would also like to thank Jim Fichtelman and Rusty Stout for their assistants on my laboratory experiments.

Finally, I would like to thank my parents, Jinsong Lin, Xinmin Liu, and my girlfriend, Limian Fang. Thank you all for the endless love and support. 


\section{Table of Contents}

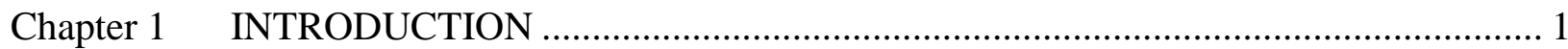

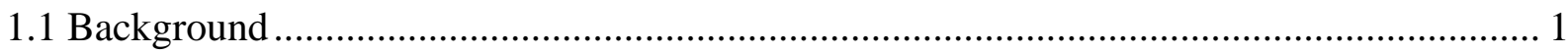

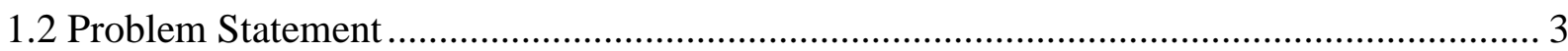

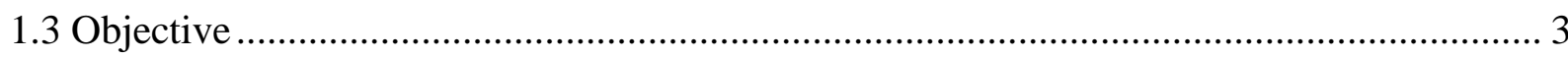

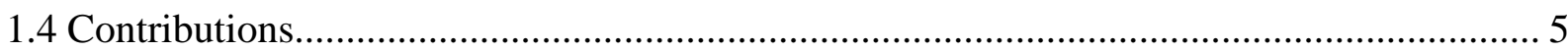

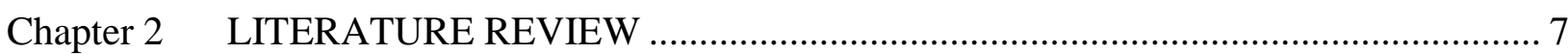

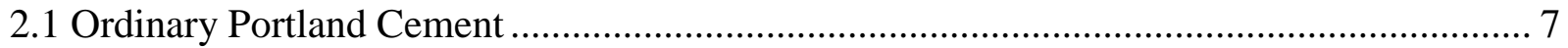

2.2 Effect of Compound Composition on Heat of Hydration ..................................................... 8

2.3 Effect of Cement Fineness on Heat of Hydration ......................................................... 10

2.4 Total Heat of Hydration ...................................................................................... 10

2.4.1 Cement hydration stages ……………….................................................. 12

2.4.2 Adiabatic calorimetry for concrete hydration ...................................................... 13

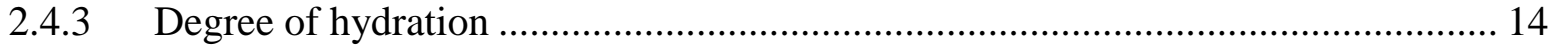

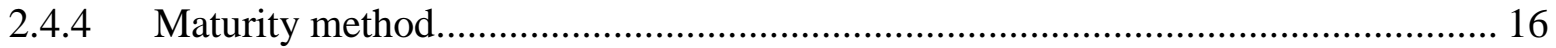

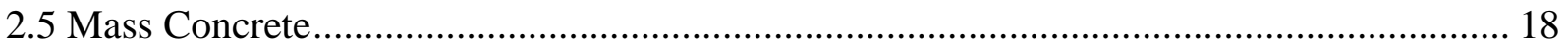

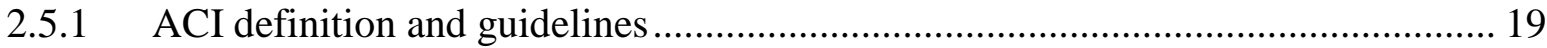

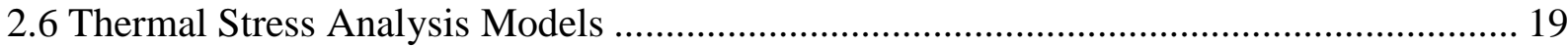

Chapter 3 ADIABATIC CALORIMETRY FOR EARLY AGE CONCRETE ........................ 21

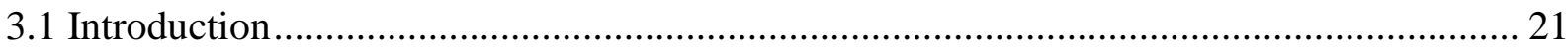

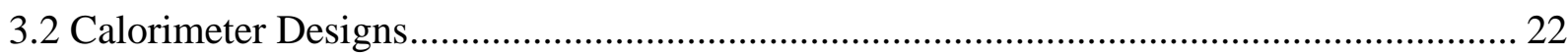

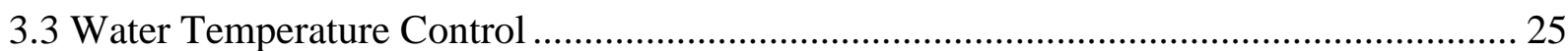

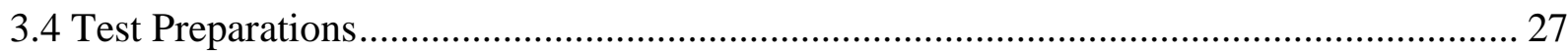

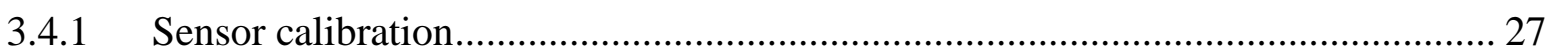

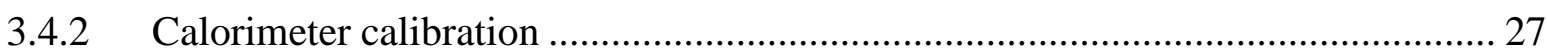

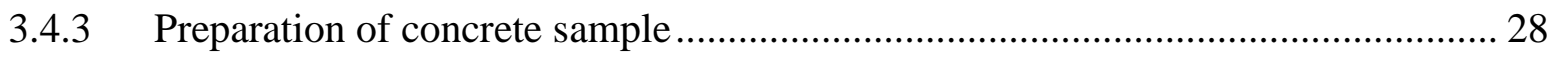

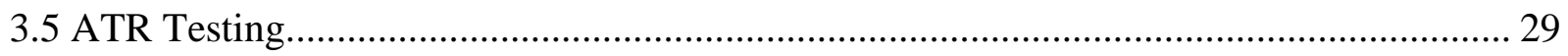

3.5.1 Concrete mix design and cement chemical composition ....................................... 29

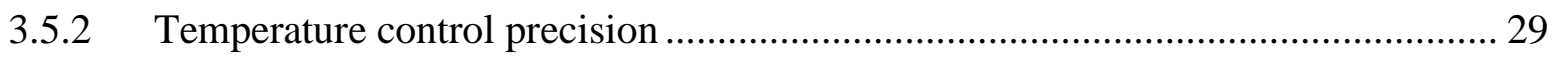

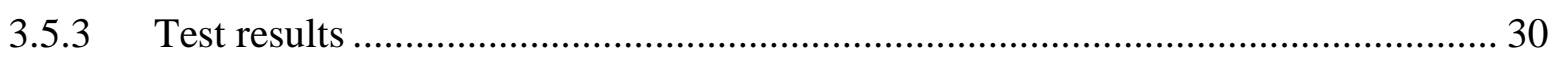

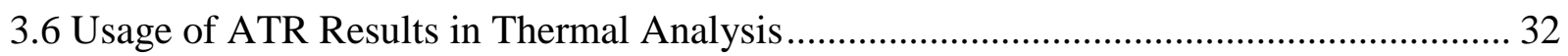

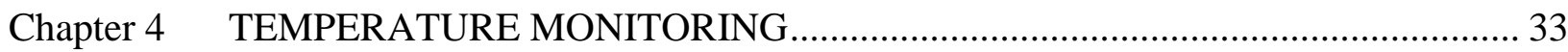

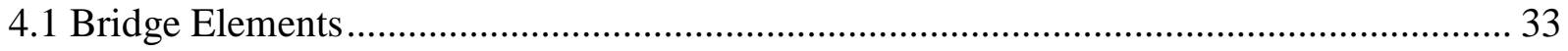




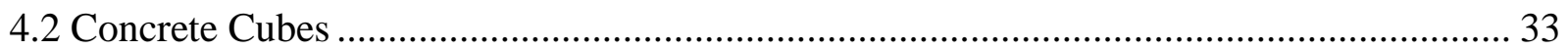

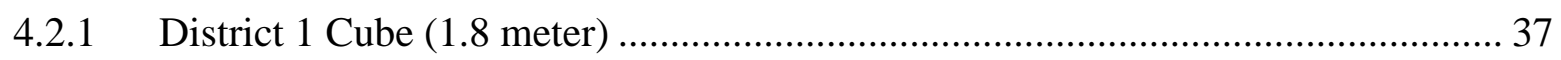

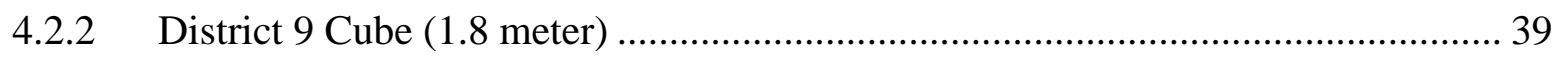

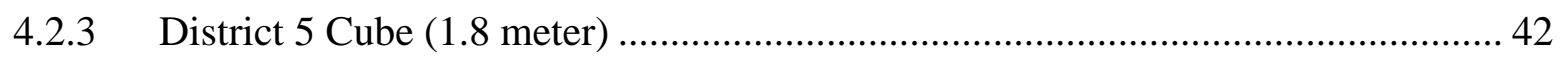

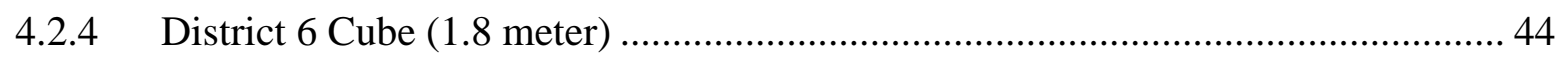

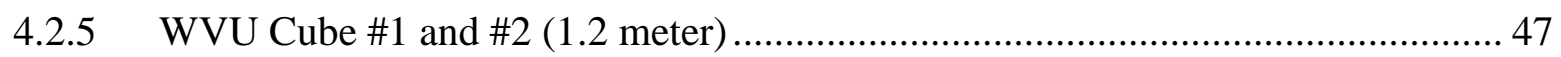

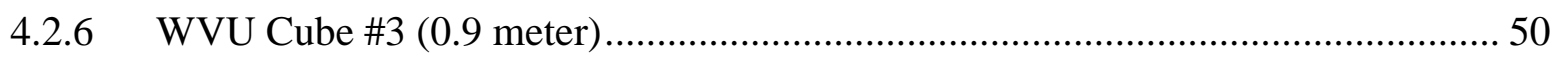

4.3 Discussions of the Temperature Monitoring Results.................................................... 52

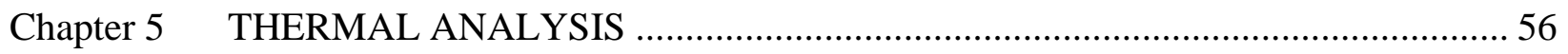

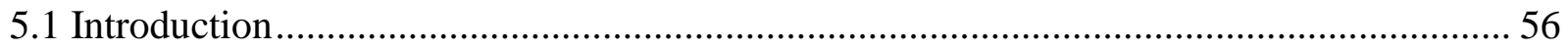

5.2 Hydration Heat and Thermal Loading Function .......................................................... 58

5.2.1 Mix designs, OPC chemical compositions and ATR results .................................. 58

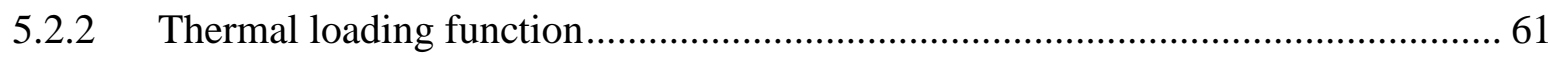

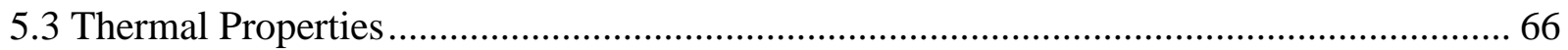

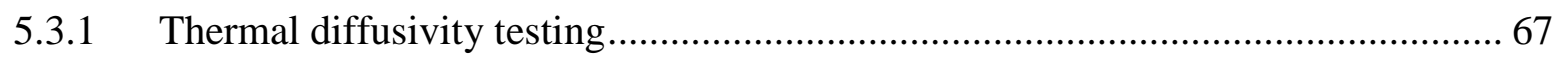

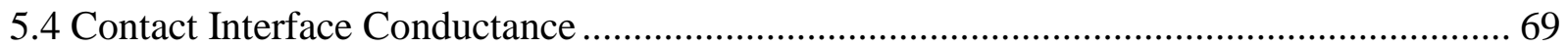

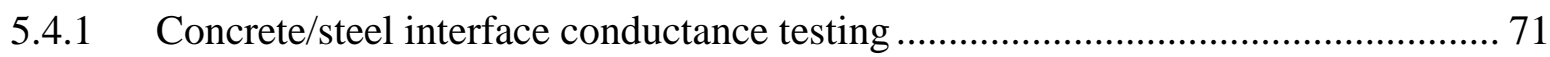

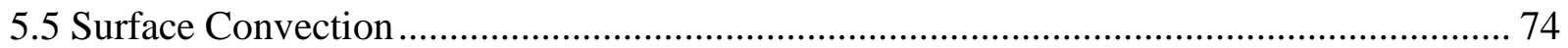

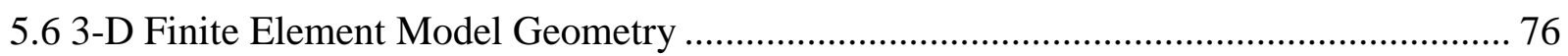

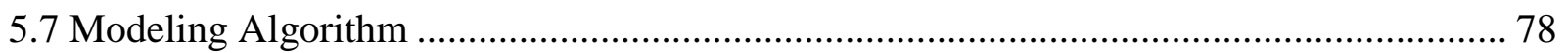

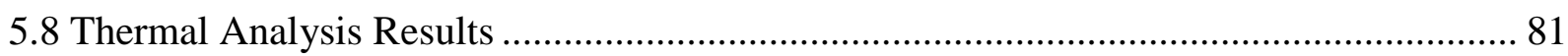

5.9 A Case Study of a Real World Concrete Element ........................................................... 93

5.10 Statistical Analysis of the Thermal Analysis Results ....................................................... 96

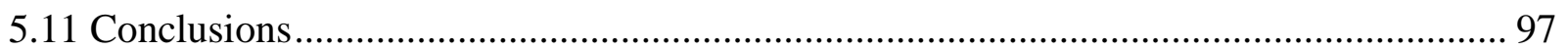

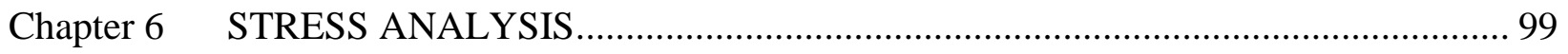

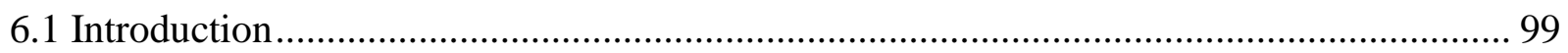

6.2 Sensor Installation in WVU Cube \#1 and \#2 ............................................................ 102

6.3 Mechanical Properties of Early age Concrete................................................................ 104

6.3.1 Concrete strength testing............................................................................... 105

6.3.2 Elastic modulus testing ............................................................................... 107

6.3.3 Coefficient of thermal expansion (CTE) testing ................................................ 110

6.4 Viscoelasticity of Early Age Concrete Viscoelasticity ..................................................... 112

6.4.1 Basic tensile creep testing ........................................................................... 113

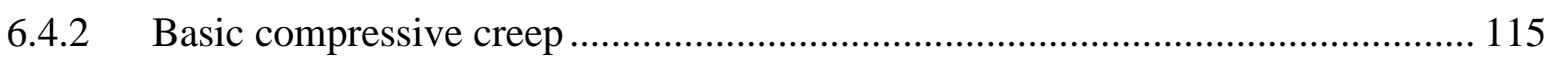




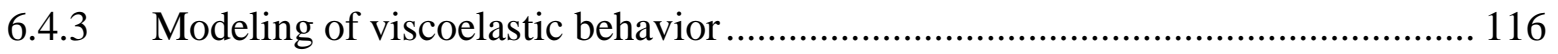

6.5 Discussion of Maturity Method on this Application..................................................... 120

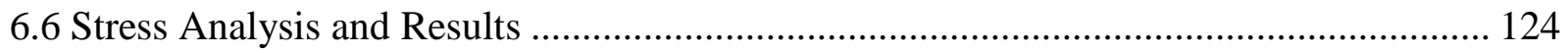

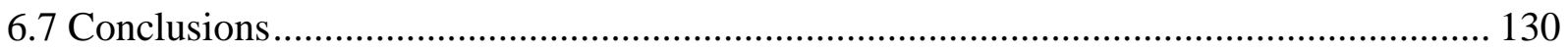

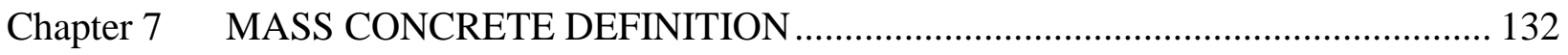

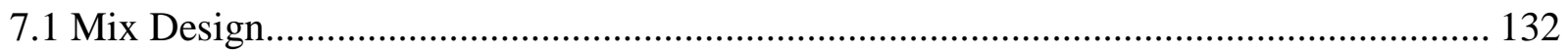

7.2 Ambient Temperature and Minimum Surface Cover ……………………………....... 133

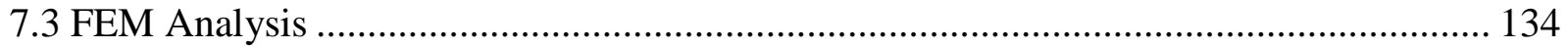

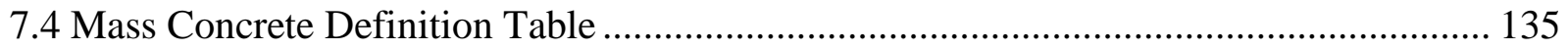

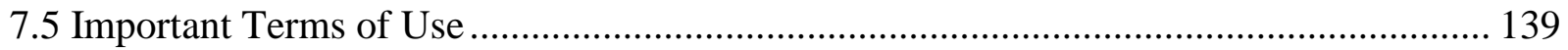

7.6 Preliminary Analysis Results with Additional Insulation................................................ 139

Chapter 8 GROUND GRANULATED BLAST-FURNACE SLAG ………………….......... 141

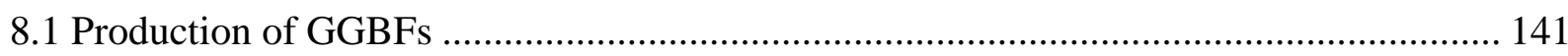

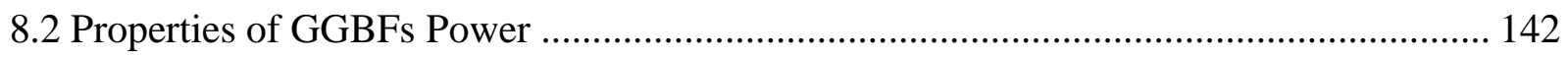

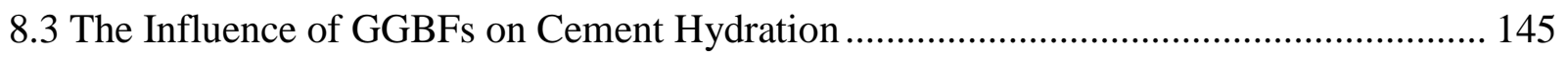

8.4 The Effect of GGBFs on Heat and Strength Development of Concrete........................... 146

8.5 The Effect of GGBFs on the Viscoelasticity of Concrete.............................................. 150

8.6 The Effect of GGBFs on the Autogenous and Drying Shrinkage of Concrete.................. 151

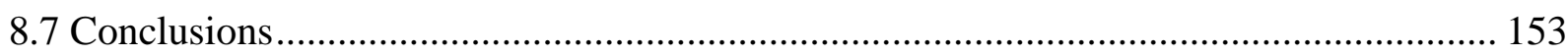

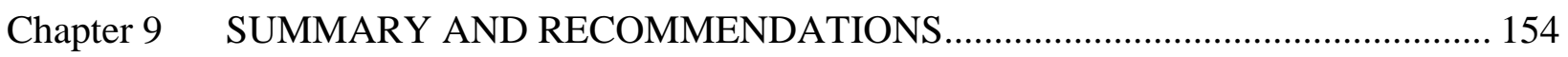

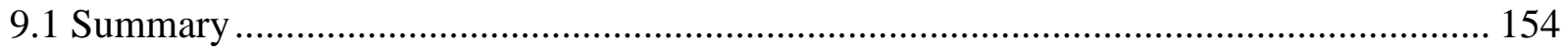

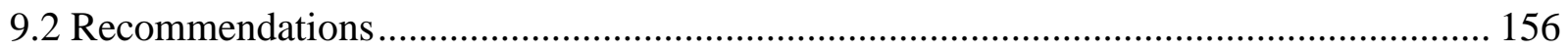

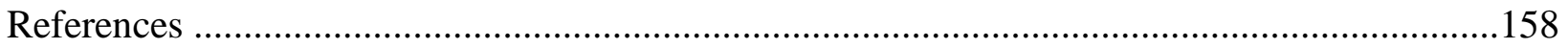




\section{List of Figures}

Figure 1-1: Behavior of hydrating early age mass concrete …………….................................. 1

Figure 1-2: Behavior of hydrating early age mass concrete ……………………..................... 2

Figure 2-1: Influence of $\mathrm{C}_{3} \mathrm{~S}$ content on heat evolution (Neville, 1995) .................................... 9

Figure 2-2: Influence of $\mathrm{C}_{3} \mathrm{~A}$ content on heat evolution (Neville, 1995) ……………................. 9

Figure 2-3: Heat of hydration for different cement types (Neville, 1995).................................... 10

Figure 2-4: Five Stages of the hydration process (Byfors, 1980) …………………………....... 13

Figure 2-5: The effect of increasing $\alpha_{u}$ (Folliard et al. 2008) ..................................................... 14

Figure 2-6: The effect of increasing $\tau$ (Folliard et al. 2008) ..................................................... 15

Figure 2-7: The effect of increasing $\beta$ (Folliard et al. 2008) ...................................................... 15

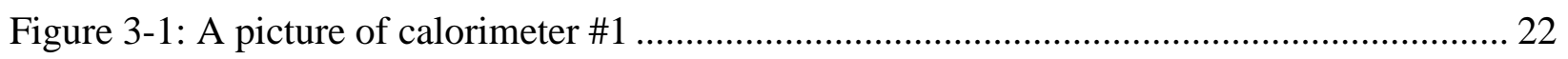

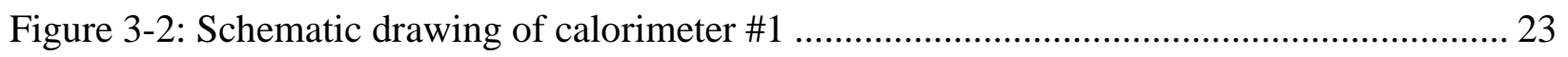

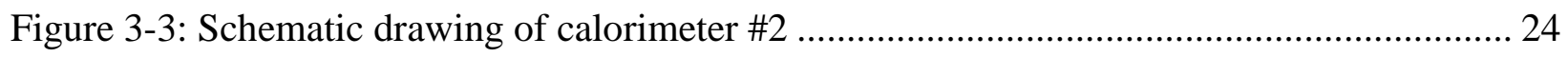

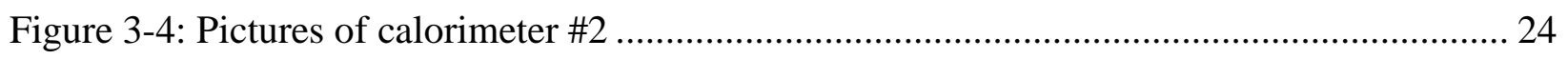

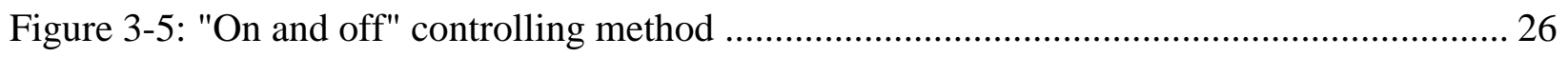

Figure 3-6: The controlled water temperature under a varying set temperature........................... 26

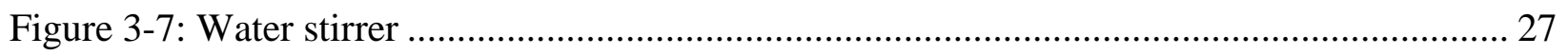

Figure 3-8: Temperature matching between water and hydration concrete ................................. 29

Figure 3-9: Measured ATR results for mix design in Table 3-1................................................. 31

Figure 3-10: Measured ATR compared with simulated ATR using VCCL (NIST, 2014)........... 31

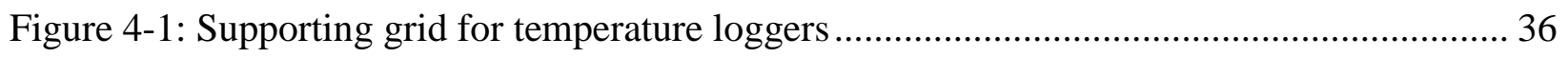

Figure 4-2: Sensor locations of the 6-ft cubes (center cross-sectional cut) .................................... 36

Figure 4-3: Intellirock temperature logger and data collection system ........................................ 37

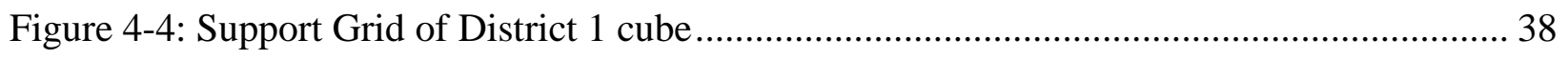

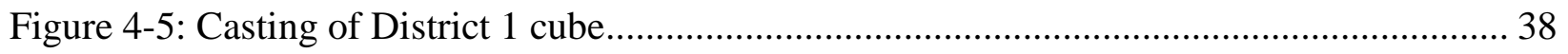

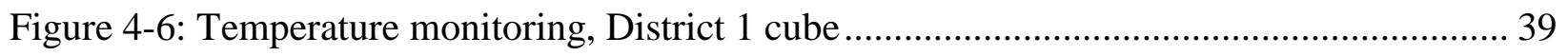

Figure 4-7: Support Grid of District 9 cube ......................................................................... 40

Figure 4-8: Casting of District 9 cube....................................................................................... 41

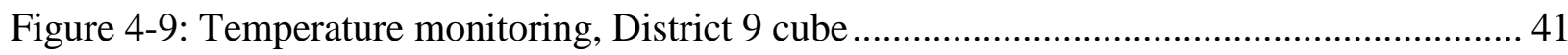

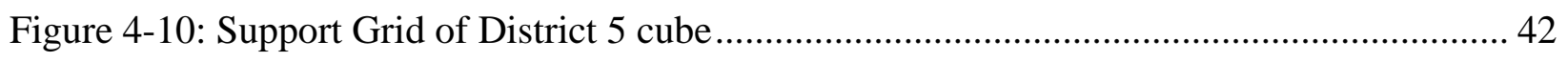

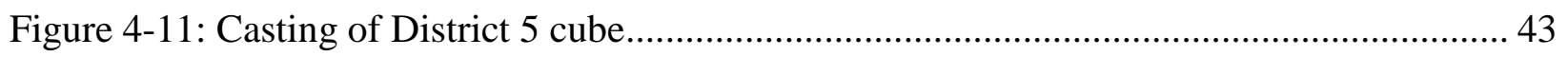




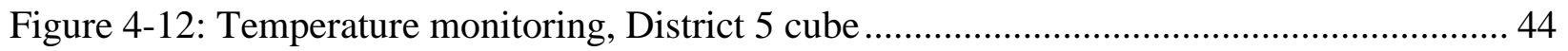

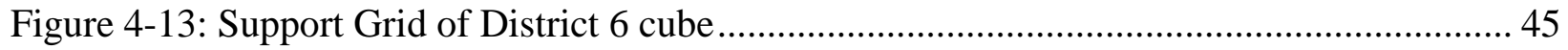

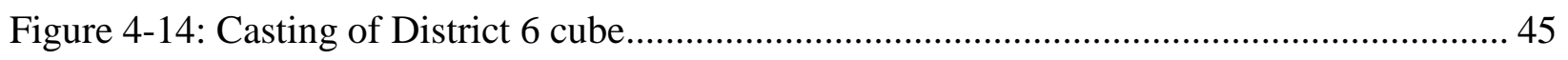

Figure 4-15: Temperature monitoring, District 6 cube ....................................................... 46

Figure 4-16: Support Grid of 1.2-meter cubes ................................................................... 47

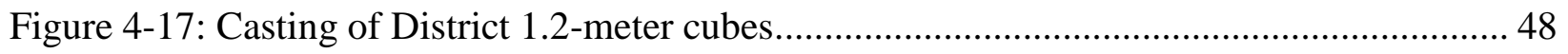

Figure 4-18: Finished WVU Cube \#1 and \#2 ................................................................... 48

Figure 4-19: Temperature monitoring, WVU Cube\# 1 ......................................................... 49

Figure 4-20: Temperature monitoring, WVU Cube\# 2 .................................................... 49

Figure 4-21: Support Grid of WVU Cube \#3 (0.9 meter) ................................................ 51

Figure 4-22: Casting of District of WVU Cube \#3 (0.9 meter) ............................................ 51

Figure 4-23: Temperature monitoring, WVU Cube \#3 ...................................................... 52

Figure 4-24: Temperature differential of the 1.8-meter cubes........................................... 54

Figure 4-25: Temperature differential of the 1.2-meter and 0.9-meter cubes .......................... 54

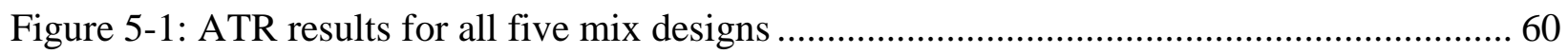

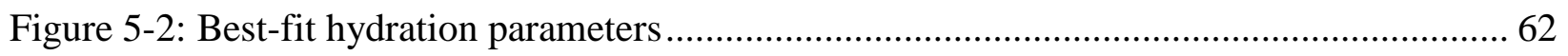

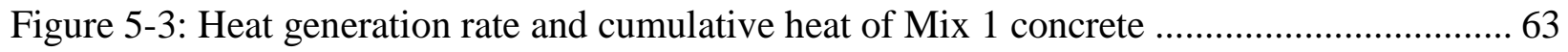

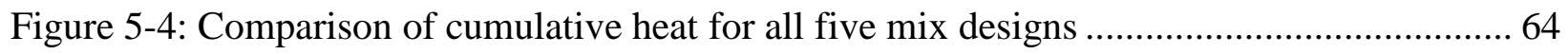

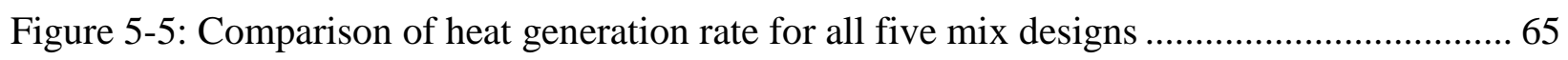

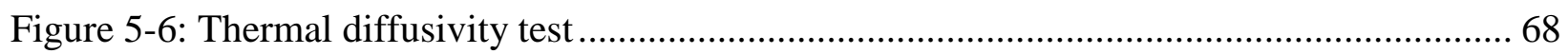

Figure 5-7: The measured temperature differences between concrete and water..................... 68

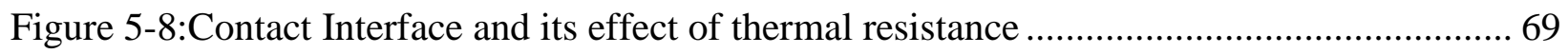

Figure 5-9:Temperature distribution accross the contact plane ............................................ 70

Figure 5-10:Schematic diagram of the interface conductance test set up............................... 72

Figure 5-11:Pictures of the interface conductance test set up............................................ 73

Figure 5-12:Temperature histories from all sensors in thermal conductance test .................... 73

Figure 5-13:Measured temperature distribution of interface conductance test ........................ 74

Figure 5-14:Convection heat transfer (Thomas, 1908) ..................................................... 75

Figure 5-15:Ambient temperature record for 1.8-meter cubes located in District1, 5 and $6 \ldots . . . .75$

Figure 5-16:Ambient temperature record for 1.2-meter and 0.9-meter cubes located in WVU... 76

Figure 5-17: Dissembled parts of the concrete cube model.................................................. 77 


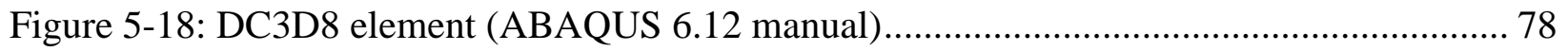

Figure 5-19: The algorithm of the thermal analysis model................................................ 79

Figure 5-20: Temperature distribution from the cube center to the external air at early age ....... 80

Figure 5-21: Temperature distribution of the center cross-sectional cut of Cube \#2 at 29 hours. 81

Figure 5-22: Experimental and FEM results of center and side temperatures (District 1 cube) .. 82

Figure 5-23: Experimental and FEM results of center and side temperatures (District 5 cube) .. 83

Figure 5-24: Experimental and FEM results of center and side temperatures (District 6 cube) .. 83

Figure 5-25: Experimental and FEM results of center and side temperatures (WVU Cube \#1) .. 84

Figure 5-26: Experimental and FEM results of center and side temperatures (WVU Cube \#2).. 84

Figure 5-27: Experimental and FEM results of center and side temperatures (WVU Cube \#3) .. 85

Figure 5-28: Experimental and FEM results of temperature differentials (District 1 cube)........ 86

Figure 5-29: Experimental and FEM results of temperature differentials (District 5 cube)........ 86

Figure 5-30: Experimental and FEM results of temperature differentials (District 6 cube)........ 87

Figure 5-31: Experimental and FEM results of temperature differentials (WVU Cube \#1) ........ 87

Figure 5-32: Experimental and FEM results of temperature differentials (WVU Cube \#2) ........ 88

Figure 5-33: Experimental and FEM results of temperature differentials (WVU Cube \#3) ........ 88

Figure 5-34: Center to surface temperature distribution (District 1 cube) ............................... 89

Figure 5-35: Center to surface temperature distribution (District 5 cube).............................. 90

Figure 5-36: Center to surface temperature distribution (District 6 cube)................................90

Figure 5-37: Center to surface temperature distribution (WVU Cube \#1) .............................. 91

Figure 5-38: Center to surface temperature distribution (WVU Cube \#2) ............................... 91

Figure 5-39: A picture of constructed Ices Ferry Bridge Pier-cap........................................... 94

Figure 5-40: Geometry of the Ices Ferry Bridge Pier-cap ..................................................... 94

Figure 5-41: Temperature distribution of the center cross-sectional cut at 33 hours ................. 95

Figure 5-42: Experimental and FEM results of center and side temperatures (pier-cap)............ 95

Figure 6-1: Thermal stress and tensile strength development (Tia et. al., 2010)..................... 101

Figure 6-2: Geokon embedment strain gage Model 4200 .................................................. 102

Figure 6-3: The internal structure of the strain gage ........................................................ 102

Figure 6-4: A pictures of the support grid and sensors before casting ................................. 103

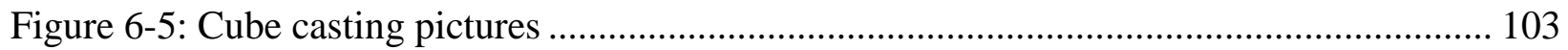

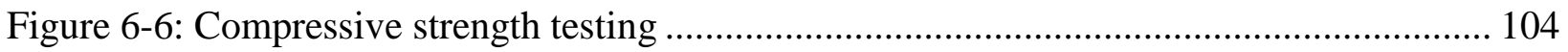




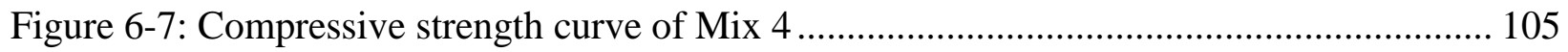

Figure 6-8: Relationship between compressive strength and degree of hydration ..................... 106

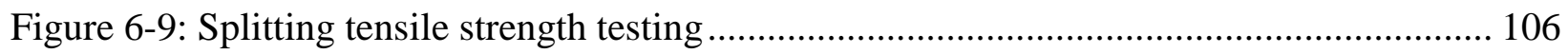

Figure 6-10: Splitting tensile strength test results in comparison with Wight \& Macgregor (2009)

Figure 6-11: Dog-bone sample for tensile modulus testing ........................................................ 108

Figure 6-12: Elastic tensile modulus testing ……………................................................... 109

Figure 6-13: Tensile modulus development of Mix 4 ......................................................... 109

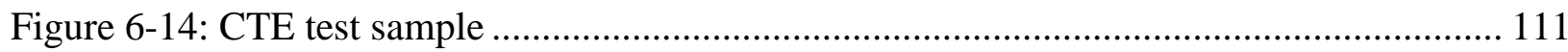

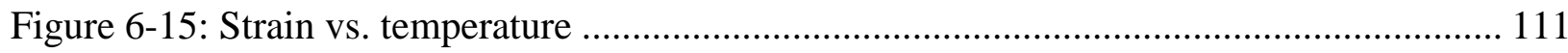

Figure 6-16:Comparison of creep compliance between experimental results and Eq. (6.8) ...... 115

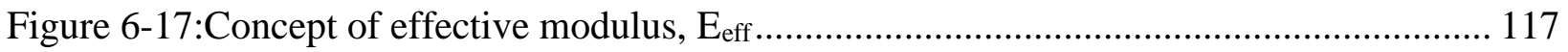

Figure 6-18:Creep behavior of early age concrete ................................................................... 117

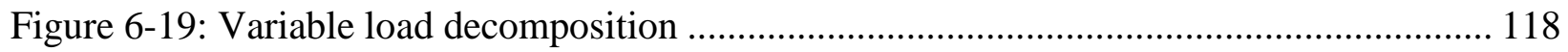

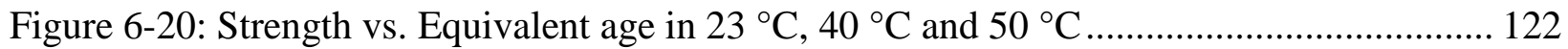

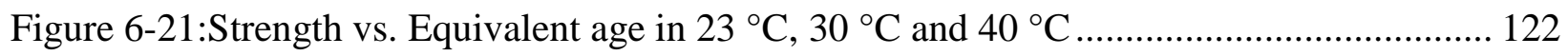

Figure 6-22:Concrete surface temperature of Cube \#1 and \#2 and curing temperature .............. 123

Figure 6-23: Measured compressive strength of the samples cured differently ........................ 123

Figure 6-24: The algorithm of the stress analysis ............................................................... 127

Figure 6-25: Predicted surface stress field and crack locations for WVU Cube \#1 ................... 127

Figure 6-26: Comparison of calculated thermal stress and estimated tensile strength for Cube \#1 128

Figure 6-27: Comparison of calculated thermal stress and estimated tensile strength for Cube \#2 128

Figure 6-28: Comparison of calculated and measured strain changes at the locations near the concrete surfaces (a) Cube \#1 - Location A, (b) Cube \#2 - Location A, (c) Cube \#2 - Location B

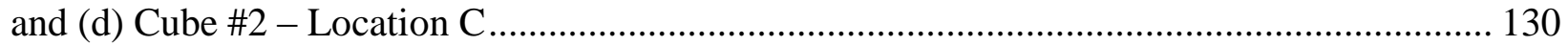

Figure 7-1: Assumed ambient temperature ............................................................................... 133

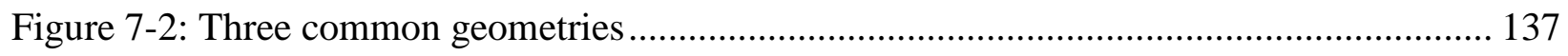

Figure 7-3: Stress and strength comparison from FEM results of the $1.07 \mathrm{~m}$ square column.... 137

Figure 7-4: Stress and strength comparison from FEM results of the $0.91 \mathrm{~m}$ square column.... 138 
Figure 8-1The raw and final product of GGBFs (Gordon Anderson, 2009) .......................... 142

Figure 8-2: Physical appearances of GGBFs and OPC (Siddiqui 2008) ................................ 143

Figure 8-3: SEM image of cement and slag particles (Metla et al., 2014) ............................. 144

Figure 8-4: Chemical reaction of OPC and GGBFs (Anderson, 2009) .................................. 145

Figure 8-5: Rate of heat evolution at various GGBFs levels (Nasir et al., 2014) .................... 146

Figure 8-6: Total of heat evolution at various GGBFs levels (Robbins, 2007) ....................... 147

Figure 8-7: Total of heat evolution at various GGBFs levels (WVU lab testing) .................... 147

Figure 8-8: Influence of varying GGBFs contents in strength (Khatib and Hibbert, 2005) ....... 149

Figure 8-9: Comparison of compressive strength development (WVU lab) .......................... 149

Figure 8-10: Effect of slag on basic creep of sealed concrete samples (Brooks et al. 1992) ..... 150

Figure 8-11: Effect of slag on autogenous shrinkage with different W/C (Lee et al., 2005) ..... 151 


\section{List of Tables}

Table 2-1: Typical compound composition of Portland Cement (Mindess and Young, 1981)...... 8

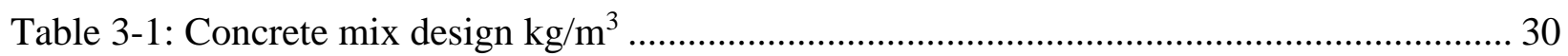

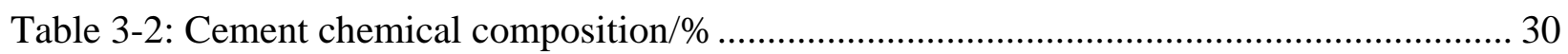

Table 4-1: Bridge element summary (Chen et al., 2015) ....................................................... 35

Table 4-2: Maximum center temperature $\left(\mathrm{T}_{\max }\right)$ and the influencing factors ................................ 53

Table 5-1: The mix design number for the six concrete cubes ................................................. 59

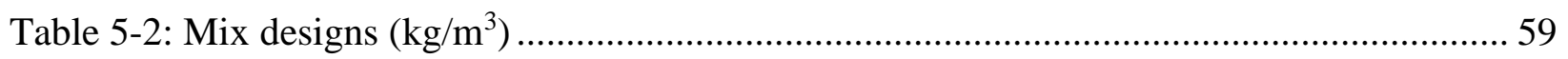

Table 5-3: Chemical compositions of each mix design ............................................................. 60

Table 5-4: Heat Properties for the five mix designs ................................................................ 62

Table 5-5: Details of the parts from each modeled cube ........................................................... 77

Table 5-6: The comparison of $\mathrm{T}_{\max }$ and $\Delta \mathrm{T}_{\max }$ between the experiment and FEM analysis results 92

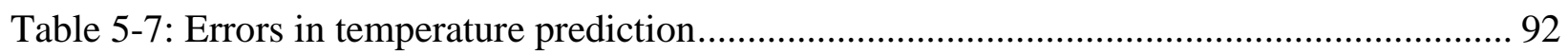

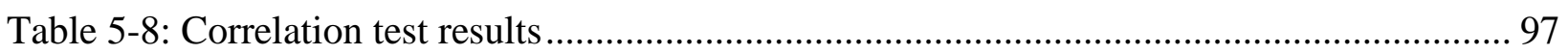

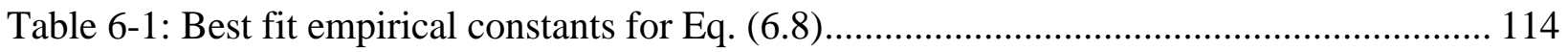

Table 7-1: Mass Concrete Member Definition Table (80\% Strength Limit)............................... 138

Table 7-2: Reference Table (100\% Strength Limit) ................................................................ 138

Table 7-3: Reference Table (additional R values and $80 \%$ Strength Limit).............................. 140

Table 8-1: Chemical composition of GGBFs from US and France........................................... 144

Table 8-2: Effect of GGBFs on drying shrinkage of concrete (a summary of findings from literature) 


\section{CHAPTER 1 INTRODUCTION}

\subsection{Background}

During the hydration of early age concrete, a large amount of heat is liberated due to a number of chemical reactions. The external heat loss of the trapped heat inside of the concrete body can create a large temperature differential between the center and surface. The temperature differential can cause considerable tensile stresses at the concrete surfaces due to non-uniform thermal expansion. This surface tensile stresses are widely referred as thermal stresses or thermally induced stresses. The thermal stress can exceed the tensile strength while the concrete strength is not fully developed and cause thermal cracking (Figure 1-1). Figure 1-2 shows a thermal cracking found in Shenandoah River Bridge in Martinsburg, West Virginia.

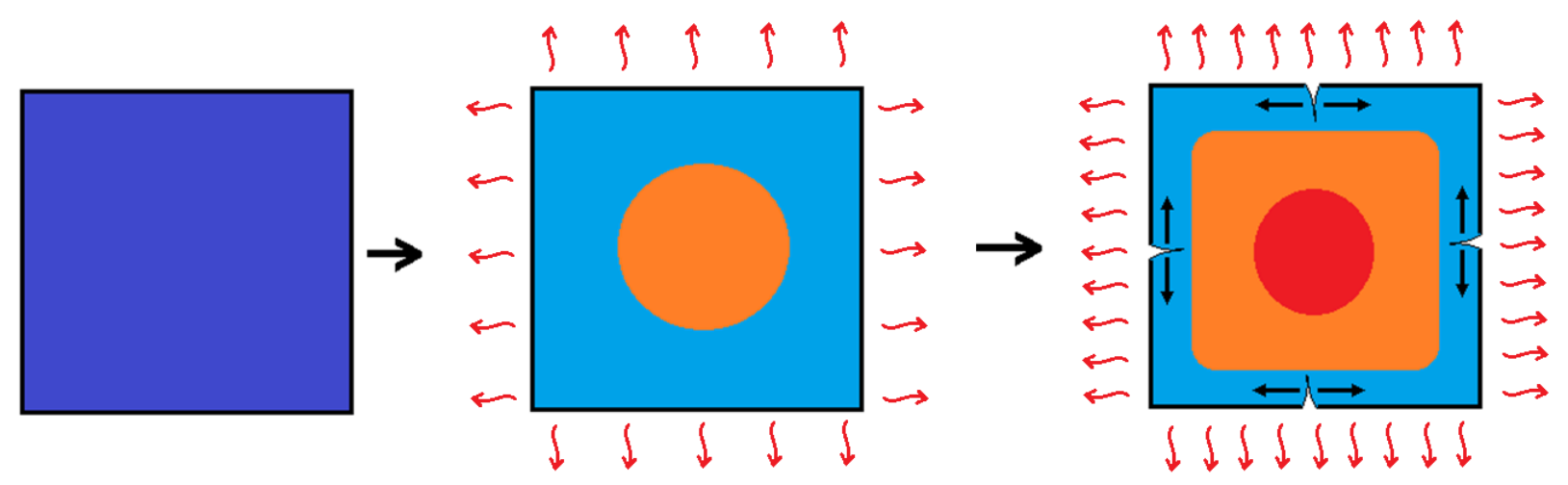

Figure 1-1: Behavior of hydrating early age mass concrete

Concrete members with larger dimensions are generally more in danger of having thermal cracks and often referred as mass concrete. The definition of mass concrete was made by the American Concrete Institute (ACI 301-10) as: "Any volume of concrete with dimensions large enough to require that measures be taken to cope with generation of heat from hydration of cement and attendant volume change to minimize cracking." No exact dimension for mass 
concrete is stated by ACI. The minimum size of mass concrete varies from $0.6 \mathrm{~m}(2 \mathrm{ft})$ to $2 \mathrm{~m}(7$ ft) among U.S. transportation agencies.

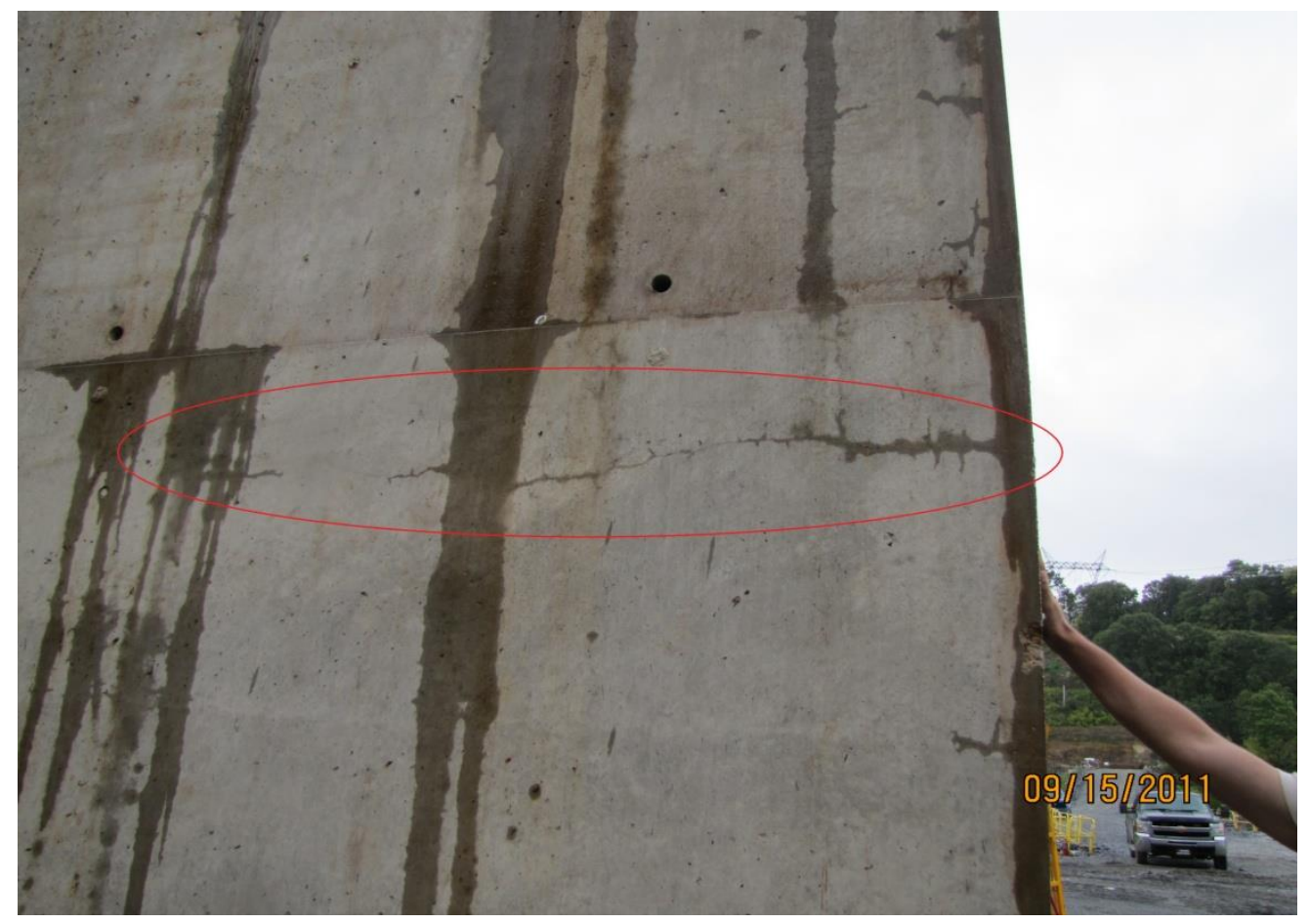

Figure 1-2: Behavior of hydrating early age mass concrete

Determining the minimum size of mass concrete is a difficult problem, because thermal stress is difficult to predict. Concrete expands and contracts due to temperature changes. Any restraint against the expansion or contraction movements creates thermal stresses. There are two types of restraint: external restraint and internal volume restraint. Any thermal cracking close to the external support is mainly due to external restraint such as a long wall structure fixed to the ground. However, the effect of internal volume restraint can be more critical when the volume of object is relatively large. The focus of this study is to analyze thermal stresses due to volume restraint. Figure 1-1 is a good representation of an early age concrete subjected to a large center to surface temperature differential and thermal stresses due to internal volume restraint. 


\subsection{Problem Statement}

A thermal control plan for mass concrete members is required for quality control purposes. A thermal control plan is necessary in order to lower the center maximum temperature and the temperature differential between the center and the surface of the early age concrete member. Generally speaking, a unit bid price of the mass concrete is significantly higher versus non-mass concrete. In West Virginia, the maximum allowable center temperature and temperature differential are $70{ }^{\circ} \mathrm{C}\left(158^{\circ} \mathrm{F}\right)$ and $20^{\circ} \mathrm{C}\left(35^{\circ} \mathrm{F}\right)$. For any violation, a penalty, such as $\$ 100$ per excessive degree Fahrenheit per cubic yard of concrete poured into the structure can also be charged. The extra costs of mass concrete are very significant. The estimation of material cost becomes very difficult to make without a clear definition of mass concrete to identify the mass concrete members prior to the construction. In West Virginia, the current minimum mass concrete dimension is $1.2 \mathrm{~m}(4 \mathrm{ft})$ excluding drilled Caissons, tremie seals and Class D concrete (WVDOT Special Provision, 2010, Section 601). In reality, many other things can also influence the minimum size of mass concrete such as mix design, geometry, surface protection, ambient temperature and so on. For example, concrete members over $1.2 \mathrm{~m}$ can exhibit no thermal cracking in the ideal conditions, while concrete members less than $0.6 \mathrm{~m}$ can have thermal cracking if not properly protected. Therefore, a scientific approach is needed to address the mass concrete definition. In order to determined the minimum size for mass concrete, a series of experimental testing procedures and finite element modeling will be described to predict the temperature profile history and the associated thermal stresses in early age concrete.

\subsection{Objective}

The primary objective of this dissertation is to study the actual behaviors of the early age concrete, including the temperature development and the associated thermal stresses. Finite 
element models were developed to calculate the temperature profile and the thermal stress development histories. Thermal stress and estimated tensile strength were evaluated and compared based on the experimental measurement and modeling results. After that, a preliminary mass concrete definition was developed based on the modeling results on concrete members with various sizes and geometries. This study has a total of four phases.

1. Conduct a literature review.

- Understand the behaviors of early age concrete under variable and non-uniform temperature distributions.

- Understand the related thermal and mechanical properties of early age concrete.

- Design for the needed experimental testing and analytical modeling.

2. Carry out field experiments and material property testing.

- Perform a few case studies by using concrete cubes with different sizes, mix designs and locations. Collect temperature profile and strain data from the embedded sensors in the concrete cubes.

- Test the related thermal and mechanical properties of different mix designs including adiabatic temperature rise, thermal diffusivity, mass density, activation energy, elastic modulus, compressive strength, tensile strength, thermal expansion coefficient and viscoelasticity.

3. Create analytical models and obtain thermal stress predictions for early age concrete.

- Create a thermal analysis model to predict the temperature profile histories. 
- Create a stress analysis model to predict the thermal stress development based on the predicted temperature profile histories.

- Validate the analytical results with experimental measurements.

4. Develop preliminary mass concrete definitions for concrete bridge pier-stems.

- Evaluate the thermal stress to strength relationship from finite element modeling results for three common pier stem geometries using a mix design which represents a thermally worst case scenario.

\subsection{Contributions}

In this study, a way to predict early age concrete temperature and associated thermal stresses is described, including the needed experimental testing and finite element modeling technique. To maximize the modeling accuracy, all the material related parameters were addressed in details. Finite element models of thermal and stress analysis were created using an ABQUS CAE program with the aid of subroutines created in this study to maximize modeling accuracy.

For thermal analysis, the adiabatic temperature rise of the concrete was determined experimentally using the adiabatic calorimeter developed in this study and converted into a mathematical formulation for finite element modeling. Thermal properties including specific heat and thermal conductivity were considered to be degree of hydration dependent and determined individually for each element in the model. The interface conductance between concrete and steel formwork was determined experimentally and implemented to account for the thermal resistance provided by the interface. External surface convection for formwork-air interface was used on the formwork surface. 
For stress analysis, the degree of hydration was used to estimate the elastic modulus developments. Concrete tensile creep and compressive creep behaviors were included using a step-by-step incremental calculation algorithm. The influences from loading age and temperature effect were considered in each time increment in the creep models.

Based on the test results from concrete cubes, the modeling method and experimental procedures used in this study were validated to exhibit reasonable accuracy in terms of temperature and strain predictions. The thermal and stress analysis models can be used to calculate the temperature profile and thermal stress development histories for early age concrete. 


\section{CHAPTER 2 LITERATURE REVIEW}

Concrete hydration produces heat and causes a temperature rise within the concrete body. It is known as the heat of hydration which is liberated from the chemical reactions between cement and water (Dusinberre 1945; Wilson 1968). Cement hydration can produce up to a total of 500 Joules per gram of cement while concrete is a poor thermal conductor (Neville, 1995). Heat of hydration and external heat loss can cause excessive temperature differentials between the core and the surface of concrete. Nonuniform thermal expansion can cause large tensile stresses on the concrete surfaces before reaching its full tensile strength. Thermal cracking is

likely to occur when the thermal stress exceeds the tensile strength. Early age thermal cracking due to hydration heat has been a problem since the beginning of $20^{\text {th }}$ century Lange and Altoubat, 2003). In modern concrete member constructions, the cement content is often raised to accelerate strength gain so that the formwork can be removed earlier. However, this action increases the heat of hydration which leads to higher risks of thermal cracking. In modern concrete constructions, thermal cracking can develop even for small concrete members such as 0.5 meters in size.

\subsection{Ordinary Portland Cement}

Ordinary Portland Cement (OPC) is the most commonly used cementitious material in concrete structures. OPC is primarily composed of $\mathrm{C}_{3} \mathrm{~S}$ (alite), $\mathrm{C}_{2} \mathrm{~S}$ (belite), $\mathrm{C}_{3} \mathrm{~A}$ (aluminate) and $\mathrm{C}_{4} \mathrm{AF}$ (aluminoferrite). According to ASTM C 150, there are five different types of cement: general purpose (Type I), moderate sulfate resistance (Type II), high early strength (Type III), low heat of hydration (Type IV) and high sulfate resistance (Type V). The typical compound compositions of the five types of OPC are shown in Table 2-1. 
Table 2-1: Typical compound composition of Portland Cement (Mindess and Young, 1981)

\begin{tabular}{lccccc}
\hline & \multicolumn{5}{c}{ Cement Type } \\
\cline { 2 - 6 } & I & II & III & IV & V \\
\hline $\mathrm{C}_{3} \mathrm{~S}$ & 55 & 55 & 55 & 42 & 55 \\
$\mathrm{C}_{2} \mathrm{~S}$ & 18 & 19 & 17 & 32 & 22 \\
$\mathrm{C}_{3} \mathrm{~A}$ & 10 & 6 & 10 & 4 & 4 \\
$\mathrm{C}_{4} \mathrm{AF}$ & 8 & 11 & 8 & 15 & 12 \\
Fineness (Blaine, $\mathrm{m} 2 / \mathrm{kg})$ & 365 & 375 & 550 & 340 & 380 \\
\hline
\end{tabular}

\subsection{Effect of Compound Composition on Heat of Hydration}

The cement type influences the heat of hydration due to different compound compositions. $\mathrm{C}_{3} \mathrm{~S}$ and $\mathrm{C}_{3} \mathrm{~A}$ have the highest contributions to heat generation during hydration. Type IV cement (low heat of hydration) replaces part of $\mathrm{C}_{3} \mathrm{~S}$ and $\mathrm{C}_{3} \mathrm{~A}$ with $\mathrm{C}_{3} \mathrm{~A}$ and $\mathrm{C}_{4} \mathrm{AF}$ to reduce heat generation in the early age. Based on Neville's (1995) research, the influences of $\mathrm{C}_{3} \mathrm{~S}$ and $\mathrm{C}_{3} \mathrm{~A}$ on heat evolution are shown in Figure 2-1 and Figure 2-2. He also showed the differences in heat generations of the five types of cement (Figure 2-3). In general, the increase of $\mathrm{C}_{3} \mathrm{~S}$ and $\mathrm{C}_{3} \mathrm{~A}$ content has an increasing effect on the heat of hydration. The samples used for experiments in Neville (1995) were cured at $21^{\circ} \mathrm{C}$ with a water cement ratio of 0.4. 


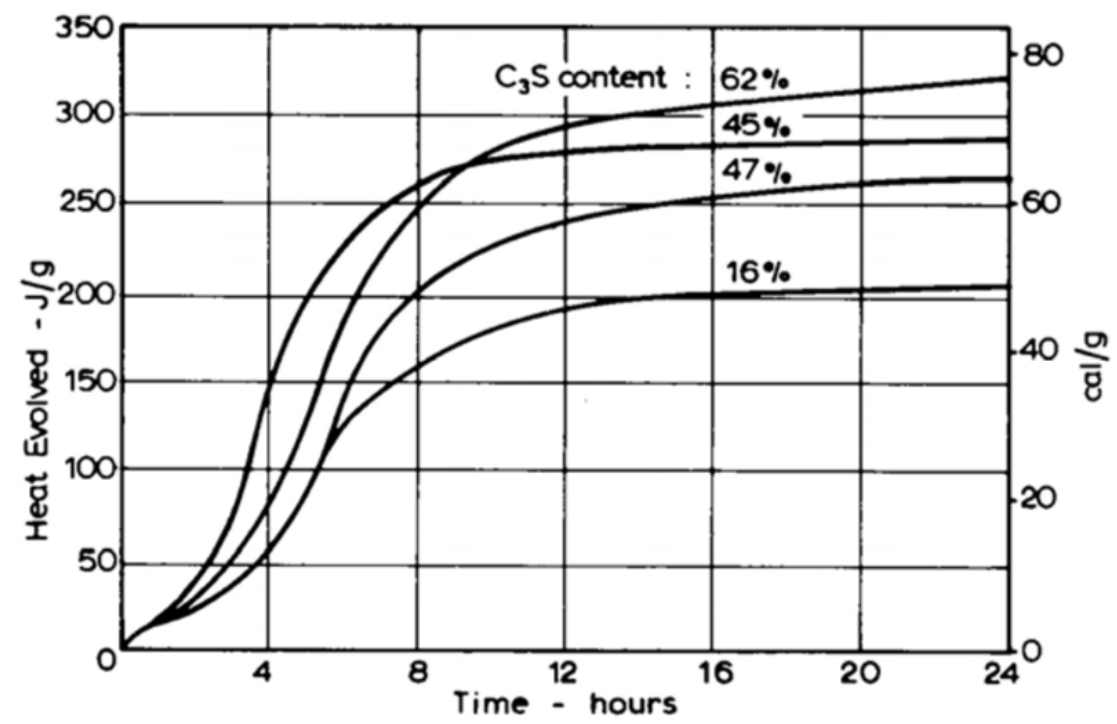

Figure 2-1: Influence of $\mathrm{C}_{3} \mathrm{~S}$ content on heat evolution (Neville, 1995)

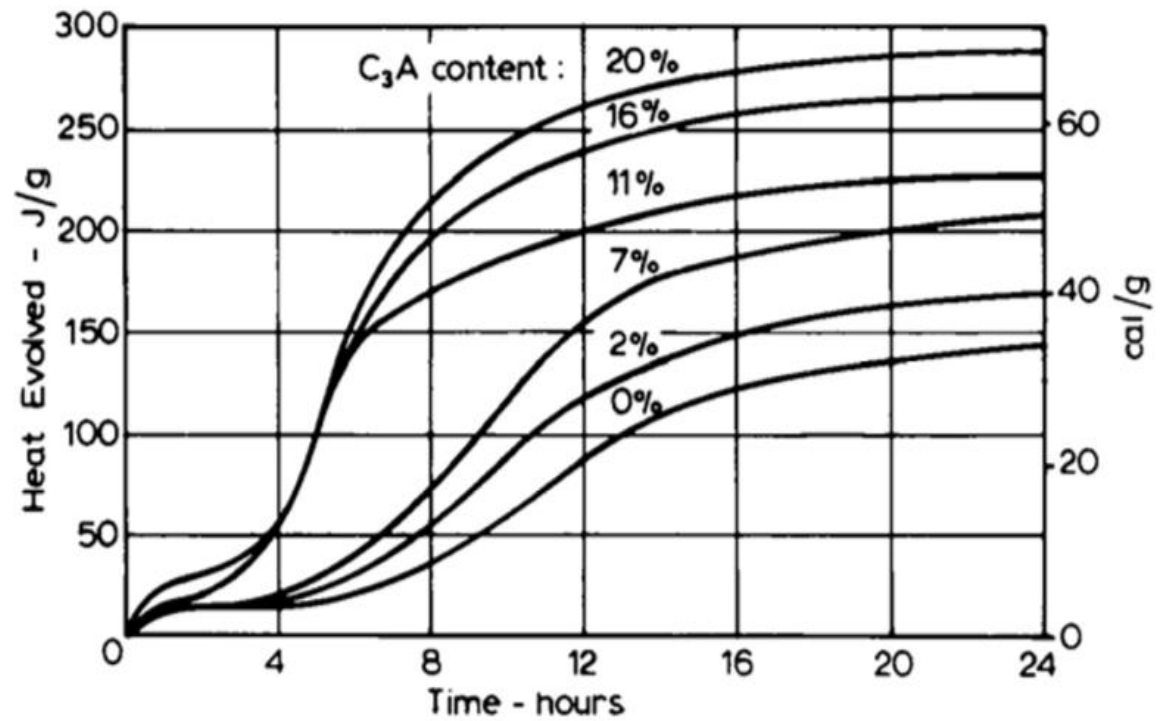

Figure 2-2: Influence of $\mathrm{C}_{3} \mathrm{~A}$ content on heat evolution (Neville, 1995) 


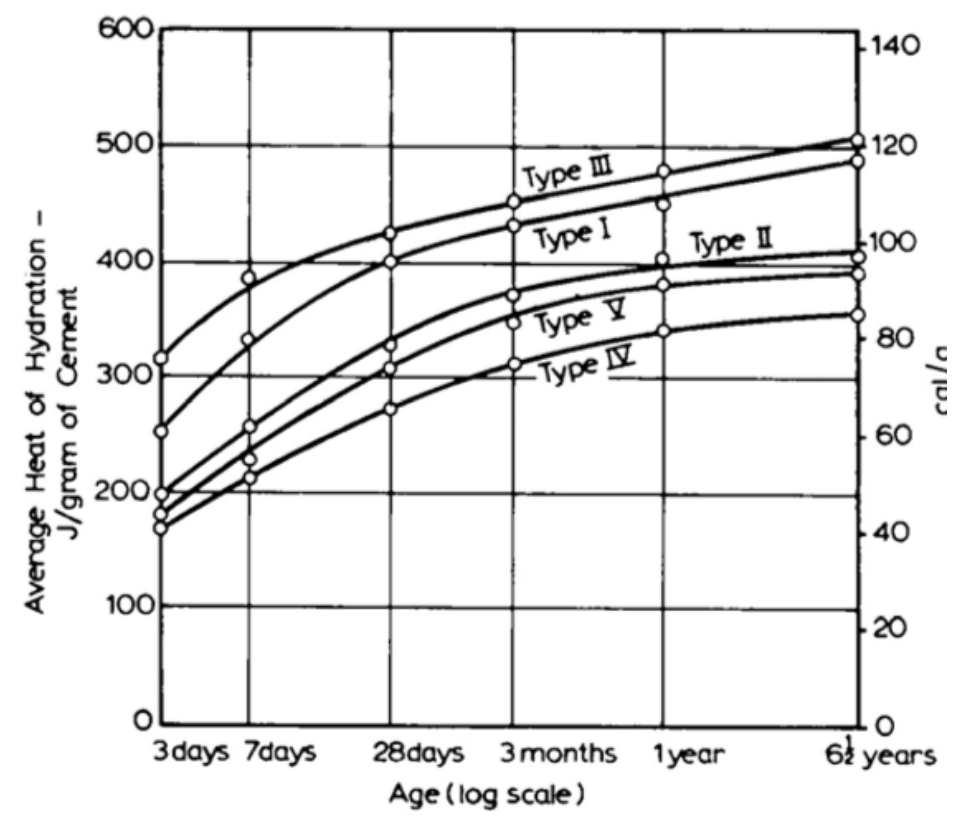

Figure 2-3: Heat of hydration for different cement types (Neville, 1995)

\subsection{Effect of Cement Fineness on Heat of Hydration}

The fineness of the cement can change the rate of hydration and heat generation (Bush et al. 1995). The rate of chemical reactions can be increased by increasing the fineness of cement due to enlarged surface areas of cement particles. Thus, heat generation and strength gain are accelerated. As shown in Table 2-1, Type I cement (general purpose) has a typical fineness of $365 \mathrm{~m}^{2} / \mathrm{kg}$, while the fineness of Type III cement (high early strength) is $550 \mathrm{~m}^{2} / \mathrm{kg}$. In fact, the compound composition is very similar between Type I and Type III cement. The only major difference is the fineness (Table 2-1). However, the cement fineness can only affect the rate of hydration in the early age, while the total heat of hydration remains unaffected by cement fineness according to Mindess and Young (1981).

\subsection{Total Heat of Hydration}

The total heat of hydration is the total released thermal energy when hydration is fully completed. The total heat of hydration of the cement $\left(\mathrm{H}_{\mathrm{cem}}\right)$ is the summation of each individual 
compound. $\mathrm{H}_{\mathrm{cem}}$ in Joules per gram of cement can be calculated using Bogue's calculation as shown in Eq. 2.1 (Neville, 1995). The P values in Eq. (2.1) present the percentages of the chemical components.

$\mathrm{H}_{\mathrm{cem}}=570 \mathrm{P}_{\mathrm{C} 3 \mathrm{~S}}+260 \mathrm{P}_{\mathrm{C} 2 \mathrm{~S}}+840 \mathrm{P}_{\mathrm{C} 3 \mathrm{~A}}+126 \mathrm{P}_{\mathrm{C} 4 \mathrm{AF}}$

Later, a more comprehensive version of this approach was published which account for the presence of free calcium, sulfur and magnesium oxide (Eq. 2.2) (Schindler and Folliard, 2005; ASTM C 150). The Bogue composition ( $\mathrm{P}_{\mathrm{C} 3 \mathrm{~S}}, \mathrm{P}_{\mathrm{C} 2 \mathrm{~S}}, \mathrm{P}_{\mathrm{C} 3 \mathrm{~A}}$ and $\left.\mathrm{P}_{\mathrm{C} 4 \mathrm{AF}}\right)$ can be calculated using the Eq. (2.3) to Eq. (2.6) (ASTM C 150). Note that these equations only work for Portland Cement. If one or both of Ground Granulated Blast-Furnace slag (GGBFs) and Fly Ash (FA) are added to the concrete mixture, the total energy $\mathrm{H}_{\mathrm{u}}$ can be calculated using Eq. (2.7) (Schindler \& Folliard, 2005).

$$
\begin{aligned}
\mathrm{H}_{\mathrm{cem}}= & 500 \mathrm{P}_{\mathrm{C} 3 \mathrm{~S}}+260 \mathrm{P}_{\mathrm{C} 2 \mathrm{~S}}+866 \mathrm{P}_{\mathrm{C} 3 \mathrm{~A}}+420 \mathrm{P}_{\mathrm{C} 4 \mathrm{AF}}+624 \mathrm{P}_{\mathrm{SO} 3} \\
& +1186 \mathrm{P}_{\mathrm{FreeCaO}}+850 \mathrm{P}_{\mathrm{MgO}} \\
\mathrm{C}_{3} \mathrm{~S}= & 4.071 \mathrm{CaO}-7.6 \mathrm{SiO}_{2}-6.718 \mathrm{Al}_{2} \mathrm{O}_{3}-1.43 \mathrm{Fe}_{2} \mathrm{O}_{3}-2.852 \mathrm{SO}_{3}-5.188 \mathrm{CO}_{2} \\
\mathrm{C}_{2} \mathrm{~S}= & 2.867 \mathrm{SiO}_{2}-0.754 \mathrm{C}_{3} \mathrm{~S} \\
\mathrm{C}_{3} \mathrm{~A}= & 2.65 \mathrm{Al}_{2} \mathrm{O}_{3}-1.692 \mathrm{Fe}_{2} \mathrm{O}_{3} \\
\mathrm{C}_{4} \mathrm{AF}= & 3.043 \mathrm{Fe}_{2} \mathrm{O} 3 \\
H_{u}= & H_{\text {cem }} P_{\text {cem }}+461 P_{\text {GGBS }-100}+1800 P_{F A-C a O} P_{F A}
\end{aligned}
$$




\subsubsection{Cement hydration stages}

Hydration starts when Portland Cement is in contact with water. Over time, the paste passes from a fluid state to a solid state. Heat release and strength gain occur simultaneously during the hydration process. As shown in Figure 2-4, a typical cement hydration can be grouped into five different stages (Byfors, 1980; Mindess and Young, 1981). Stage I takes place as soon as the cement is in contact with water. Heat release starts immediately, but only last for 15 to 30 minutes. This amount of heat influences the initial temperature of fresh concrete prior to the concrete placement. In Stage II, the chemical reactions are mostly inactive while almost no heat release can be observed. At the beginning of Stage III, after the initial set time is reached, both heat release and strength gain rapidly accelerate. The final set time is also reached during Stage III when the penetration resistance of the cement paste reaches $27.6 \mathrm{MPa}$ (4000 psi) (ASTM C 150). The rate of chemical reaction decelerates in stage IV and reaches a steady state in Stage V.

The chemical reactions of cement hydration are complicated, but can be generalized into a few chemical reactions from the four main types of components: $\mathrm{C}_{3} \mathrm{~S}, \mathrm{C}_{2} \mathrm{~S}, \mathrm{C}_{3} \mathrm{~A}$, and $\mathrm{C}_{4} \mathrm{AF}$. The chemical reactions of calcium silicates $\left(\mathrm{C}_{3} \mathrm{~S}\right.$ and $\left.\mathrm{C}_{2} \mathrm{~S}\right)$ are described in Eq. (2.8) and Eq. (2.9). As the primary reaction product, the main function of calcium silicate hydrate $\left(\mathrm{C}_{3} \mathrm{~S}_{2} \mathrm{H}_{8}\right.$ or $\mathrm{C}-\mathrm{S}-\mathrm{H})$ is to serve as a binder contributing to the concrete strength and durability. The ultimate strength increases as the C-S-H content increases. As shown in Eq. (2.10) and Eq. (2.11), both tri-calcium aluminate $\left(\mathrm{C}_{3} \mathrm{~A}\right)$ and tetra-calcium aluminoferrite $\left(\mathrm{C}_{4} \mathrm{AF}\right)$ produce similar hydration products. The precipitation of ettringite contributes to setting and early age strength development. The difference between $\mathrm{C}_{3} \mathrm{~A}$ and $\mathrm{C}_{4} \mathrm{AF}$ is that the chemical reaction of $\mathrm{C}_{3} \mathrm{~A}$ happens much more rapidly (Byfors, 1980). 

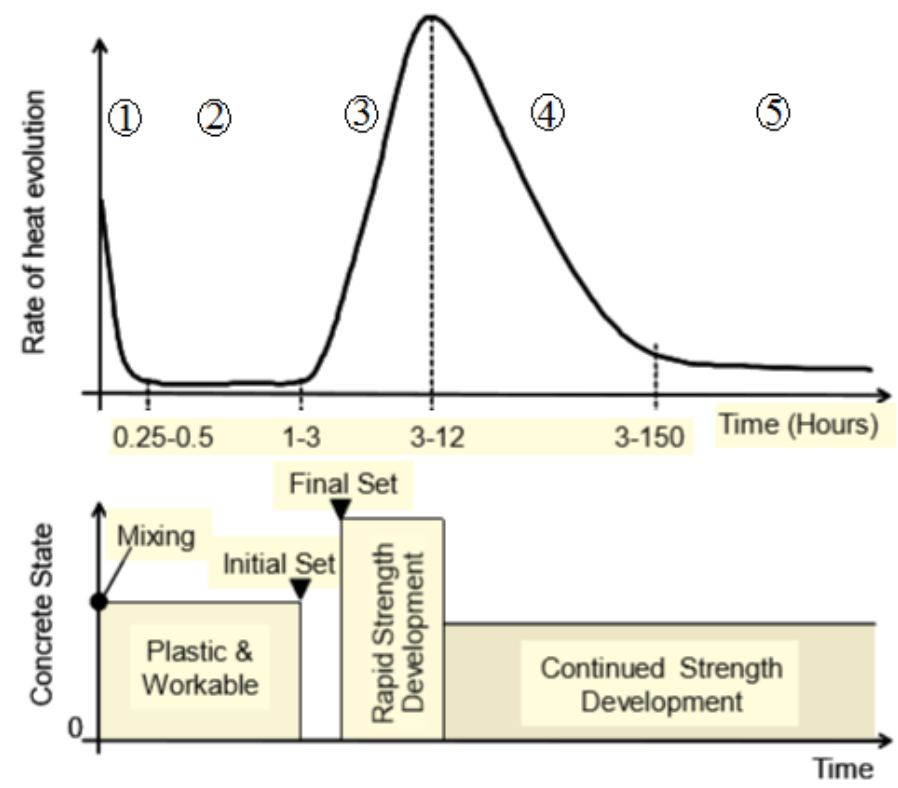

Figure 2-4: Five Stages of the hydration process (Byfors, 1980)

$2 \mathrm{C}_{3} \mathrm{~S}+11 \mathrm{H} \rightarrow \mathrm{C}_{3} \mathrm{~S}_{2} \mathrm{H}_{8}+3 \mathrm{CH}$

$2 \mathrm{C}_{2} \mathrm{~S}+9 \mathrm{H} \rightarrow \mathrm{C}_{3} \mathrm{~S}_{2} \mathrm{H}_{8}+\mathrm{CH}$

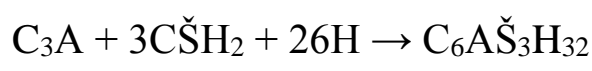

$\mathrm{C}_{4} \mathrm{AF}+3 \mathrm{C} \check{S}_{\mathrm{H}}+21 \mathrm{H} \rightarrow \mathrm{C}_{6}(\mathrm{~A}, \mathrm{~F}) \check{\mathrm{S}}_{3} \mathrm{H}_{32}+(\mathrm{F}, \mathrm{A}) \mathrm{H}_{3}$

\subsubsection{Adiabatic calorimetry for concrete hydration}

Accurately monitoring the concrete heat of hydration is crucial in order to compute the temperature development inside a concrete body. Adiabatic calorimetry is an accurate way to measure the adiabatic temperature rise (ATR) of concrete samples. The basic concept of adiabatic calorimeter design is to match the curing temperature as close as possible to the concrete sample. Gibbon (1997) described a design of an adiabatic calorimeter. In Gibbon's design, the concrete sample is cured at a large water tank with controlled water temperature. The water temperature is controlled to match the concrete sample based on the readings of two temperature probes (Figure 2-5). The same approach was also used in Ballim and Graham 
(2003). RILEM (1998) described another adiabatic calorimeter design using circulated water and thermal jacket. In this study, Gibbon's approach was adopted in the adiabatic calorimeter design to measure the adiabatic temperature rise of concrete samples.

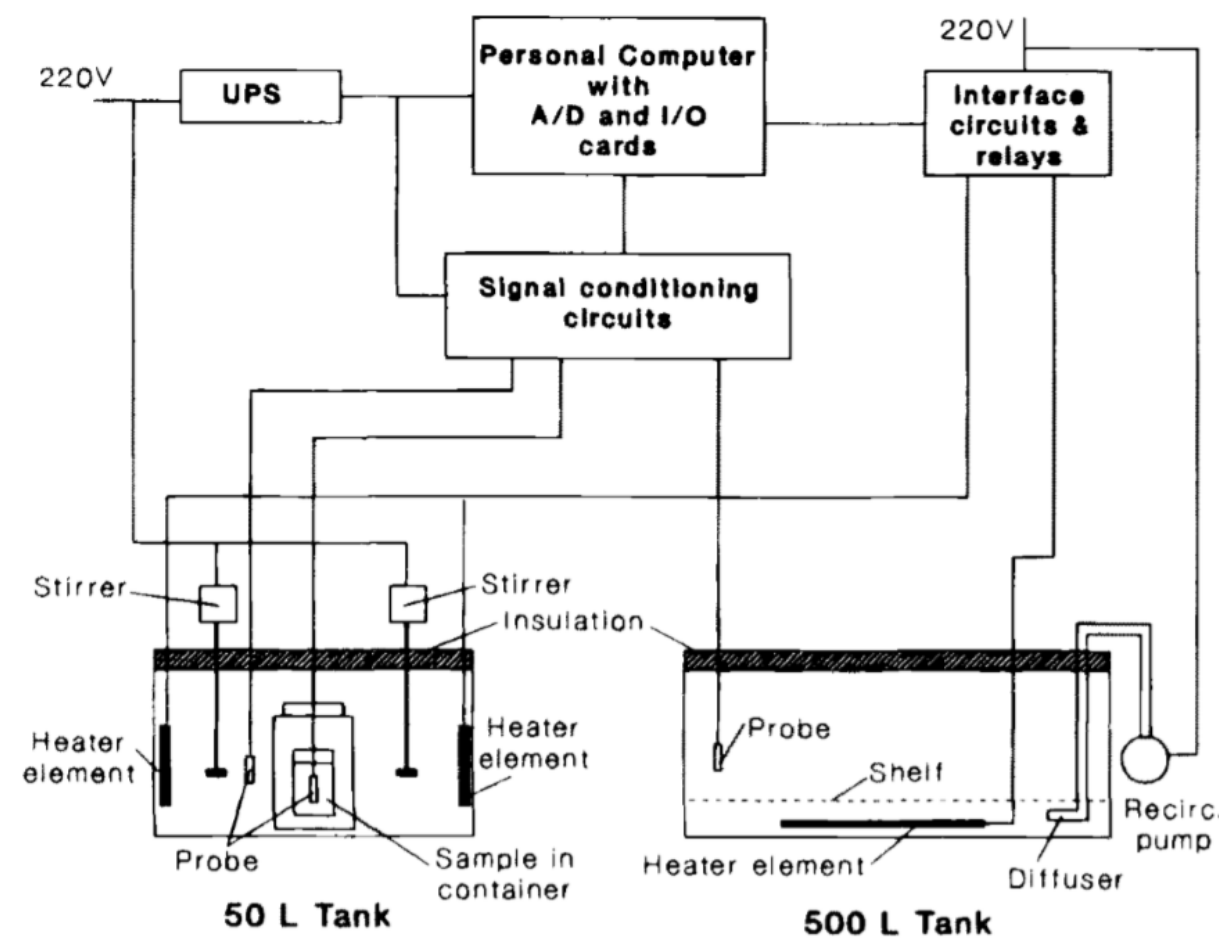

Figure 2-5: Schematic arrangement of the adiabatic calorimeter (Gibbons ,1997).

\subsubsection{Degree of hydration}

The degree of hydration $(\alpha)$ is the ratio of the quantity of hydrated and total cementitious material ranging from $0 \%$ to $100 \%$ (Van Breugel, 1998). The degree of hydration can be determined based on the heat generation. At any time $(t)$, the degree of hydration $(\alpha(t))$ is the ratio of heat generated $(\mathrm{H}(\mathrm{t}))$ and the total available heat $\left(\mathrm{H}_{\mathrm{u}}\right)\left(\right.$ Eq. 2.12). For OPC, $\mathrm{H}_{\mathrm{u}}$ is equal to $\mathrm{H}_{\mathrm{cem}}$. Mills (1966) noted that hydration can never reach $100 \%$, but stops at an ultimate degree of hydration. The ultimate degree of hydration $\left(\alpha_{\mathrm{u}}\right)$ is influenced by the water cement ratio (w/c). $\alpha_{\mathrm{u}}$ can be calculated using Eq. (2.13) (Mills, 1966). 
$a(t)=\frac{H(t)}{H_{u}}$

$\alpha_{u}=\frac{1.031 \cdot w / c}{0.194+w / c}$

An exponential equation (Eq. 2.14) was developed to describe the "S" shape of the hydration curve (Freiesleben Hansen and Pedersen, 1985; Pane and Hansen, 2005). Equivalent age or maturity $\left(\mathrm{t}_{\mathrm{e}}\right)$ is used to account for the temperature effect on concrete hydration. Ultimate degree of hydration $\left(\alpha_{u}\right)$ and Hydration parameter $(\tau$ and $\beta$ ) are used to control the shape of the hydration curve. The effects of each individual parameter $\left(\alpha_{\mathrm{u}}, \tau\right.$ and $\left.\beta\right)$ on the hydration curve are illustrated in Figure 2-6, Figure 2-7 and Figure 2-8 (Folliard et al. 2008).

$\alpha\left(t_{e}\right)=\alpha_{u} \exp \left(-\left[\frac{\tau}{t_{e}}\right]^{\beta}\right)$

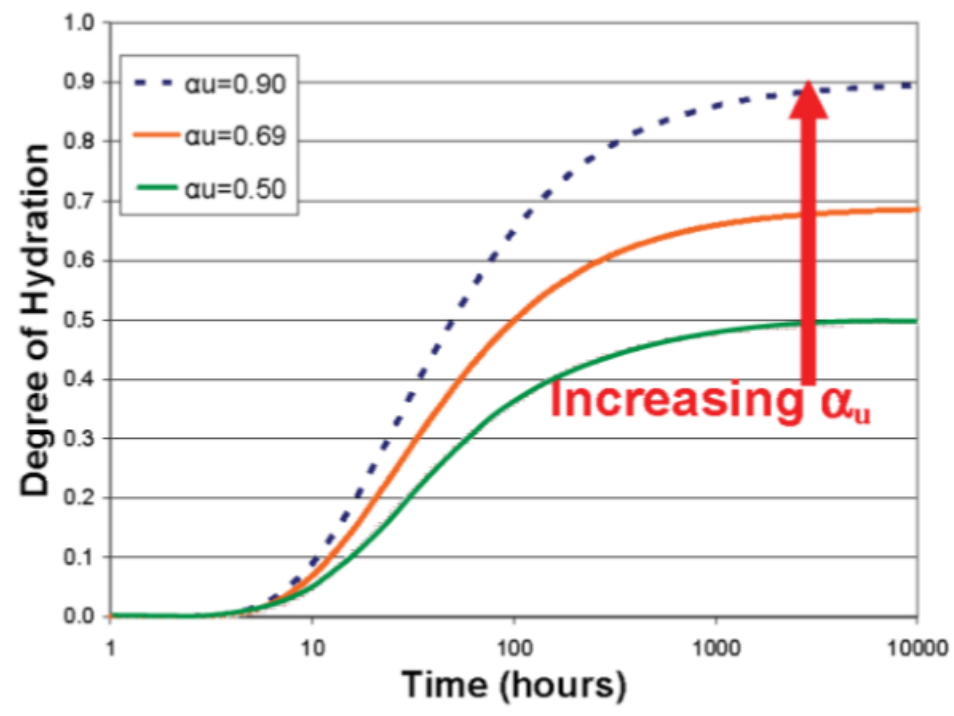

Figure 2-6: The effect of increasing $\alpha_{u}$ (Folliard et al. 2008) 


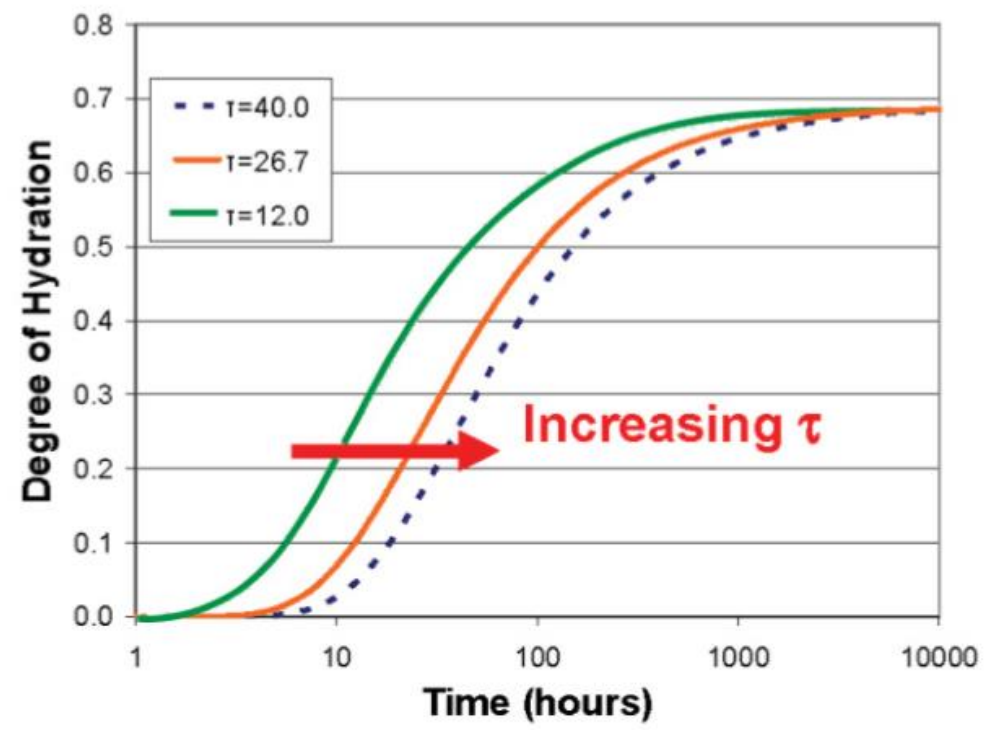

Figure 2-7: The effect of increasing $\tau$ (Folliard et al. 2008)

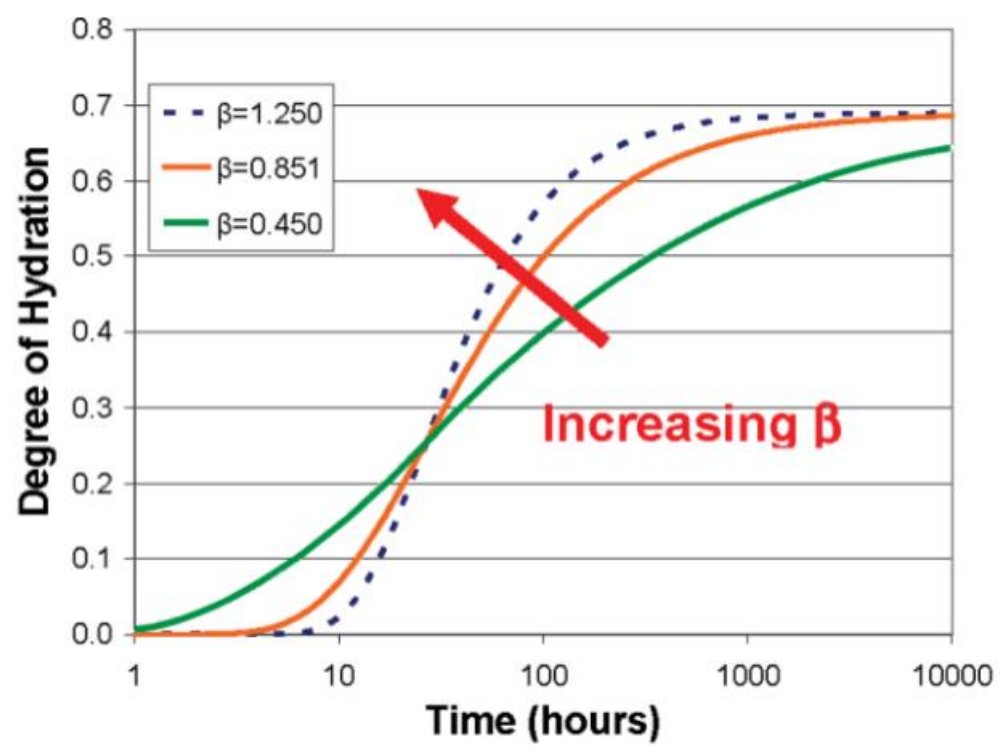

Figure 2-8: The effect of increasing $\beta$ (Folliard et al. 2008)

\subsubsection{Maturity method}

The strength development of early age concrete is highly depending on the curing temperature. For example, a concrete sample cured at $40{ }^{\circ} \mathrm{C}$ for one day can be more than twice as strong as an identical sample cured at $20^{\circ} \mathrm{C}$ for the same period of time. The maturity method has been used since the 1950 s to account for the combined effect of the concrete temperature and aging on the strength development of hardening concrete. McIntosh (1949) first published the 
idea that the rate of concrete strength gain is a function of time and temperature. The "maturity rule" (Saul 1951) states that "Concrete of the same mix at the same maturity (reckoned in temperature time) has approximately the same strength, whatever combination of temperature and time go to make up that maturity."

Nurse (1949) and Saul (1951) assigned the term "maturity" to be the product of time and temperature. Saul (1951) also suggests the use of datum temperature within the maturity calculation. The Nurse-Saul maturity method was interpreted by Carino (1984) and implemented in ASTM C 1074 (Eq. 2.15).

$M=\sum\left(T_{C}-T_{0}\right) \Delta t$

where, $\mathrm{M}=$ Nurse-Saul maturity index at age $\mathrm{t}\left({ }^{\circ} \mathrm{C} \cdot\right.$ hours $)$

$$
\begin{aligned}
& \mathrm{T}_{\mathrm{C}}=\text { average concrete temperature during the } \Delta \mathrm{t}\left({ }^{\circ} \mathrm{C}\right) \\
& \mathrm{T}_{0}=\text { datum temperature }\left({ }^{\circ} \mathrm{C}\right) \\
& \Delta \mathrm{t}=\text { time interval (hours) }
\end{aligned}
$$

Copeland et al. (1962) suggested that the Arrhenius equation can be used to calculate the nonlinear rate of cement hydration while considering the temperature effect. Freiesleben Hansen and Pederson (1977) published the Arrhenius maturity function which was also included in ASTM C 1074 (Eq. 2.16). The Arrhenius maturity function (Eq. 2.16) has its advantage over Eq. (2.15) because the activation energy (Ea) was included. The activation energy is a measure of sensitivity to temperature of a specific cementitious material.

$$
t_{e}=\int_{0}^{t} \exp \left(\frac{E_{a}}{R}\left(\frac{1}{T_{r}}-\frac{1}{T_{c}(t)}\right)\right) d t
$$


where, $t_{\mathrm{e}}=$ Equivalent age at $\mathrm{T}_{\mathrm{r}}$ (hours)

$$
\begin{aligned}
& \mathrm{T}_{\mathrm{C}}=\text { average concrete temperature during } \Delta \mathrm{t}\left({ }^{\circ} \mathrm{C}\right) \\
& \mathrm{T}_{\mathrm{r}}=\text { reference temperature }\left({ }^{\circ} \mathrm{C}\right) \\
& \mathrm{Ea}=\text { activation energy }(\mathrm{J} / \mathrm{mol}) \\
& \mathrm{R}=\text { universal gas constant, } 8.3144 \mathrm{~J} /(\mathrm{mol} \bullet \mathrm{K}) \text {. }
\end{aligned}
$$

\subsection{Mass Concrete}

Originally, mass concrete refers to concrete members with massive size such as dam structures. Different methods were used to reduce temperature differentials in early age mass concrete. Pre-cooling and post-cooling were implemented in dam constructions to reduce temperature differentials. Pre-cooling is performed before concrete placement by using cold aggregates, chilled water or any other way to reduce the temperature of fresh concrete. Postcooling is performed by installing cooling pipes to reduce the internal concrete temperature. In the early 1930s, the first major use of post-cooling was documented in the construction of Hoover Dam (Wilbur et al. 1933). Pre-cooling was first used in the construction of Norfork Dam in the early 1940s. Later on, Researchers realized that thermal cracking can also occur in smaller concrete members such as a bridge pier-stem. Instead of only paying attention to temperature control, researchers began to study the thermal stress to strength relationship. In general, thermal stress can be approximated by quantifying the temperature distribution (thermal gradient), coefficient of thermal expansion, modulus of elasticity, creep or relaxation and degree of restraint (Ross and Bray, 1949; Rhodes 1978; Polivka and Wilson, 1976). If the tensile stress exceeds the tensile strength of the concrete, cracking will occur (Houghton 1972; Houghton 1976; Dusinberre 1945). 


\subsubsection{ACI definition and guidelines}

As mentioned in Chapter 1, ACI does not specify the minimum dimensions for mass concrete. In ACI 301-10, mass concrete is defined as any volume of structural concrete that needs a thermal control plan due to elevated temperatures from hydrating concrete. To minimize thermal cracking, ACI 301-10 limits the center maximum temperature $\left(<70{ }^{\circ} \mathrm{C}\right.$ or $\left.158{ }^{\circ} \mathrm{F}\right)$ and maximum temperature differential $\left(<20{ }^{\circ} \mathrm{C}\right.$ or $\left.35^{\circ} \mathrm{F}\right)$. Concrete temperatures should be measured hourly from the time the concrete is placed until the differential between internal concrete temperatures and the average daily ambient temperatures is below the maximum value, after the peak temperature has been reached. At a minimum, two temperature sensors should be placed at the center of the mass concrete and two temperature sensors on the closest exterior face, $5 \mathrm{~cm}(2 \mathrm{in})$ from the surface.

\subsection{Thermal Stress Analysis Models}

In the late 1960s, researchers made a few attempts to calculate the thermal stresses due to early age hydration heat. At that time, the considerations were the concrete temperature and stiffness when the concrete mixture turns from semi-liquid state to solid state. The major difficulty was that the degree of restraint in a 3-D body could not be calculated using the conventional method (Springenschmid, 1998). More recently, 3-D stress modeling became easier using the modern computer technology.

In recent years, researchers attempted to solve the problem using various computer programs. ConcreteWork is a free software to predict both temperature profile and cracking index for mass concrete members (Riding, 2007; Poole, 2007; Folliard et al., 2008). In ConcreteWork analysis, heat of hydration can be calculated by providing the mix design details such as ingredient proportions, cement type and aggregate type. The heat of hydration results is 
based on the test results using a semi-adiabatic calorimeter. However, the temperature profile predictions were found to be inaccurate by Bobko et al. (2012), Jinxin (2012), Jacob Shaw (2012) and Chen et al. (2015). Robins (2007) pointed out large errors were found between ConcreteWork model and experimental measurement in the heat of hydration. In addition, ConcreteWork is incapable of performing 3D stress analysis (Bobko et al., 2012).

Both Florida and North Carolina Department of Transportation carried out research programs to evaluate thermal stress in mass concrete using TNO DIANA software (Tia et al. 2010; Bobko et al. 2012). TNO DIANA provided a module specifically designed for thermal stress analysis. However, modeling of creep behavior of early age concrete was not documented in their report. Lee et al. (2014) published their thermal stress analysis results using Midas Civil; however, the results may not be accurate due to the following two reasons. The temperature effect on material properties was not considered. The temperature effect on heat of hydration was not considered. Wu et al. (2011) created a model using ANSYS, which considers the property changes during concrete hydration as well as the temperature effect on the heat of hydration. A surface convection model was also used to simulate the surface heat loss. However, improvement was still needed for modeling the contact properties of the interfaces (e.g. formwork to concrete interface) and the creep behavior of early age concrete. 


\section{CHAPTER 3 ADIABATIC CALORIMETRY FOR EARLY AGE CONCRETE}

\subsection{Introduction}

The most reliable method to determine the heat of hydration for a concrete sample is to use the calorimetry method. The adiabatic temperature rise (ATR) is often measured and used to describe the concrete heat of hydration. There are three testing methods to obtain the adiabatic temperature rise (ATR): isothermal, semi-adiabatic and adiabatic. Isothermal test (ASTM C1679) provides a constant curing temperature of the test sample. The heat of hydration is directly measured by monitoring the heat flow out of the sample. The sample size is usually limited to a few grams, therefore only cement or cement mortar paste can be used. The test duration is limited to seven days due to the limitation on the sensitivity level of the heat flow sensor. Semiadiabatic test (RILEM, 1998) allows a small rate of heat loss $(100 \mathrm{~J} / \mathrm{K} / \mathrm{hr})$ by providing adequate insulation. A heat loss compensation is required to obtain the ATR curve. In addition, a time axis correction is required, because the concrete would be hydrating in a different rate if there was no heat loss. The use of maturity concept and the value of activation energy are required for the heat loss compensation and time axis correction. Adiabatic test (Gibbon, 1997; RILEM, 1998) provides an adiabatic environment for the test sample and directly measures the ATR. The limitation of the heat loss is set to be $0.02 \mathrm{~K} / \mathrm{hr}$. Among the three methods, adiabatic calorimeter is conceptually the simplest but the most difficult to conduct. Adiabatic calorimetry also has the highest accuracy among the three testing methods (Radjy, 2007). 


\subsection{Calorimeter Designs}

The basic concept of an adiabatic calorimeter is to eliminate the heat transfer by matching the temperature of the surrounding medium with the concrete sample. The surrounding medium can be water, air or heated containers (RILEM, 1998). Two adiabatic calorimeters were designed and built in this study. The first design is shown in Figure 3-2. A water insulated container (A) with concrete sample (15 cm x $15 \mathrm{~cm}$ cylinder, C) was completely submerged into a much larger steel water tank (B). Container A is carefully sealed to prevent water leakage. 5$\mathrm{cm}$ thick lightweight foam layer was used to stabilize the temperature of the concrete sample. The thermal capacity of the foam layer is negligible in comparison with the concrete sample. Two 1000-watt heaters and two water stirrers were placed inside of the water in Container B. Two resistance temperature detectors (RTD) were used to measure the temperatures of the concrete sample and the surrounding water. A temperature controller and a solid state relay (SSR) were used to control the two heaters. A picture of Calorimeter \#1 is shown in Figure 3-1.

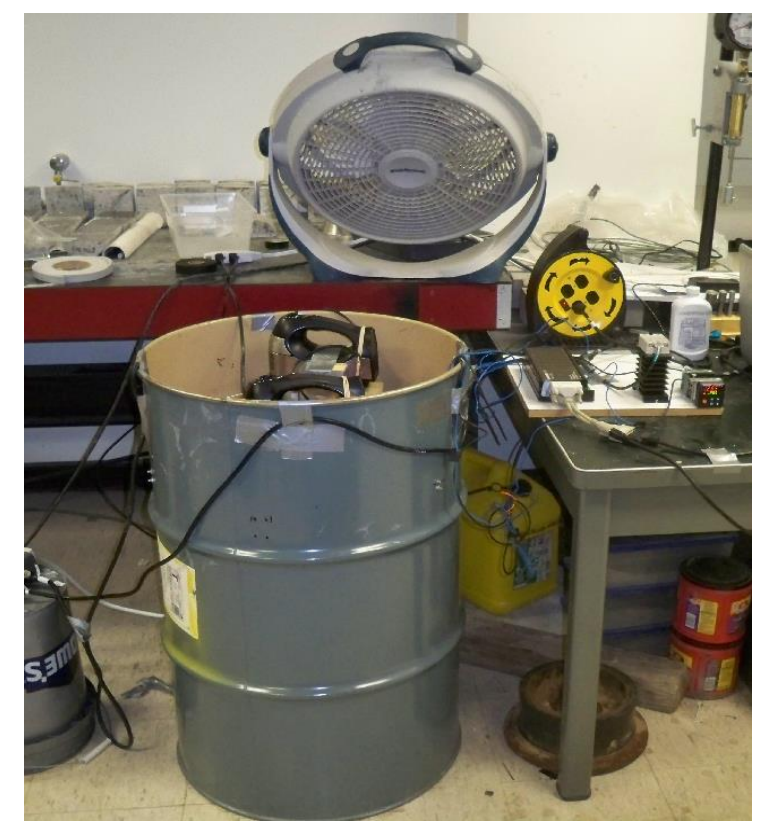

Figure 3-1: A picture of calorimeter \#1 


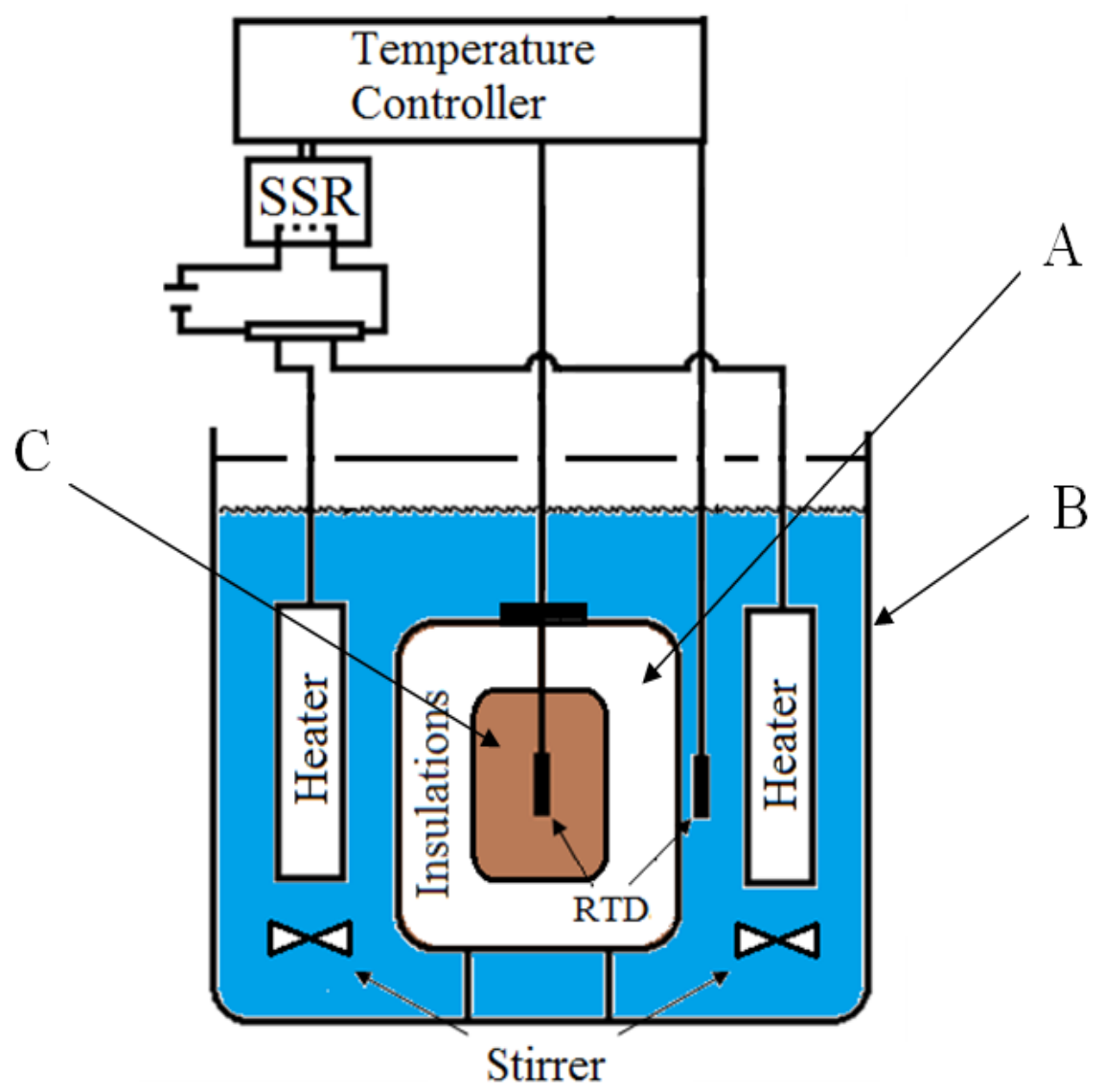

Figure 3-2: Schematic drawing of calorimeter \#1

Two major problems of the first design were observed. Firstly, a large energy input is required due to lack of insulation of the outer container. Secondly, sealing of the inner container become problematic due to the deterioration of the rubber seal under high temperature. A second design (Calorimeter \#2) was made for three major improvements (Figure 3-3). 1. A much more insulated outer container was used to increase the stability of water temperature. 2. The top of the inner container was above the water surface to completely eliminate the water leakage. A thick insulation layer was added to minimize the heat loss from the top surface. 3. The outer container can be sealed during operation to minimize the water loss due to evaporation. The actual Calorimeter \#2 is shown in Figure 3-4. An external water level indicator was added to 
indicate water level without opening the lid during operation. Due to the increased insulation and top cover of the outer container, the required rate of energy input is much less. Therefore, only one heater and one water stirrer were used as shown in (Figure 3-3).

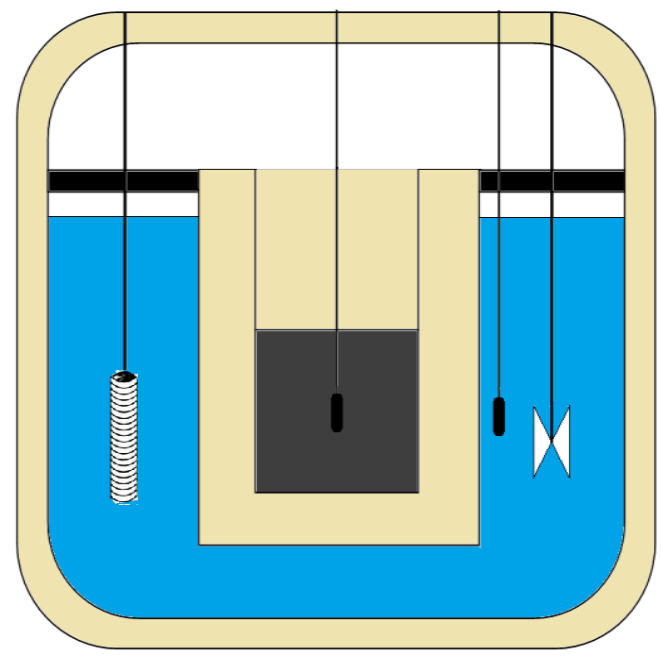

Figure 3-3: Schematic drawing of calorimeter \#2
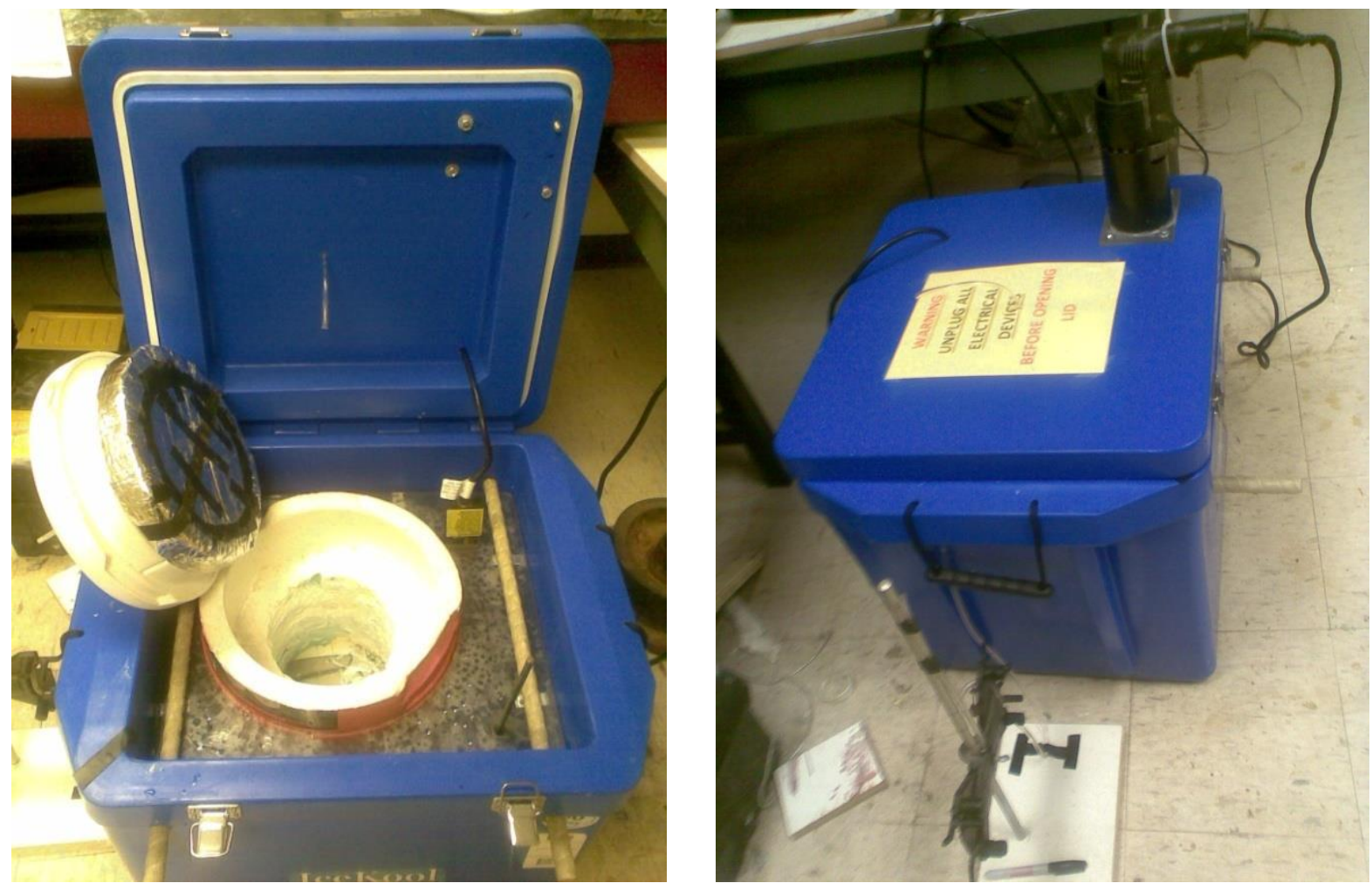

Figure 3-4: Pictures of calorimeter \#2 


\subsection{Water Temperature Control}

In order to provide an adiabatic environment for the test sample, the curing temperature was controlled to match concrete sample during the test period (Gibbon, 1997). A simple "on and off" method was adopted to control the heater switch. Figure 3-5 shows the water temperature using a constant set temperature under the "on and off" controlling method. The heater switch is automatically controlled based on the measured water and concrete temperatures by turning "on and off" of the heater. The water temperature is naturally cooled when the heater is switched to "off". As the water temperature is being monitored, water temperature is continuously being adjusted to match the set temperature. The "on and off" switch may be triggered too often due to the oscillation of the water temperature. It may cause damage to the temperature controller and heater units. A hysteresis was included to separate the "on" and "off" triggers. The hysteresis is shown in Figure 3-6 and further explained in the following paragraph.

Instead of using a constant set temperature, the calorimeter uses a remote set point. The temperature of the concrete sample inside of the calorimeter is under continuous monitoring and used as the set temperature. A measured variable set temperature is often referred as a remote set point. Figure 3-6 shows the controlled water temperature under a variable set temperature. A hysteresis is included to separate heating starting point "on" and stopping point "off", so that it lowers the frequency of the "on and off" switch. With a smaller hysteresis, the temperature control accuracy is increased, but switch frequency is also increased. The hysteresis needs to be at least larger than the noise level of the measurement to avoid false triggers due to electric noises. In this application, high matching accuracy is required; therefore a small hysteresis of $0.04{ }^{\circ} \mathrm{C}$ was used without having false triggering by noise. 


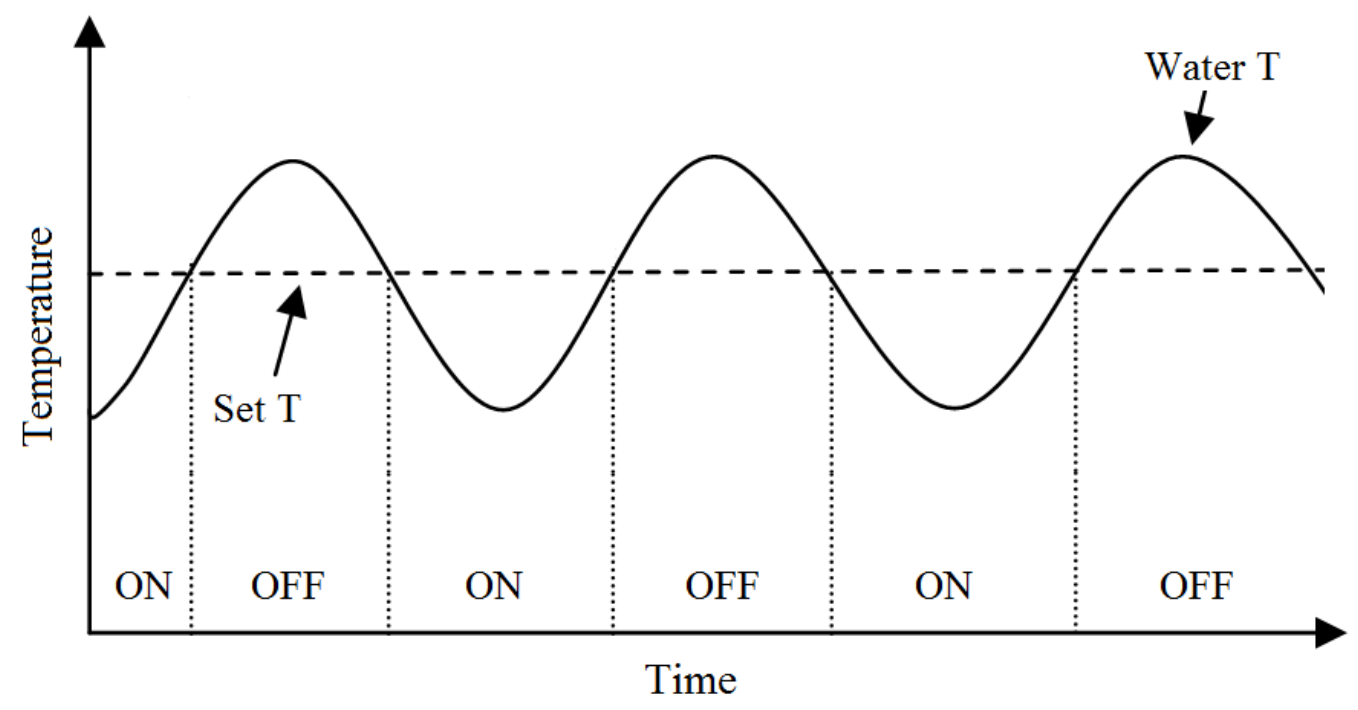

Figure 3-5: "On and off" controlling method

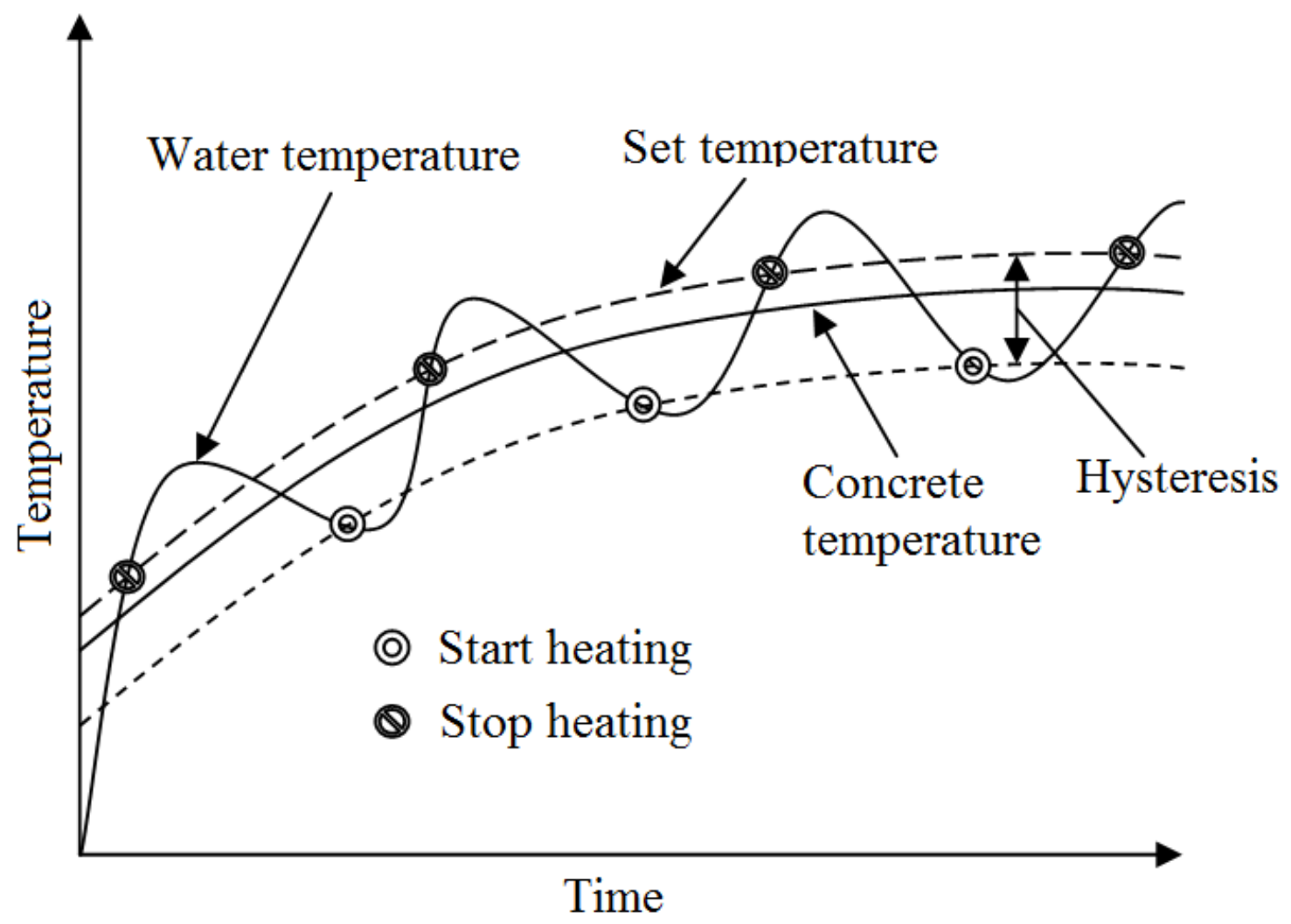

Figure 3-6: The controlled water temperature under a varying set temperature 
Sufficient mixing should be provided continuously during the entire testing period to ensure the uniform water temperature in the outer container. The maximum temperature differential at any two locations of the surrounding water does not exceed $0.1{ }^{\circ} \mathrm{C}$. An electric drill was used to drive the water stirrer as shown in Figure 3-7.

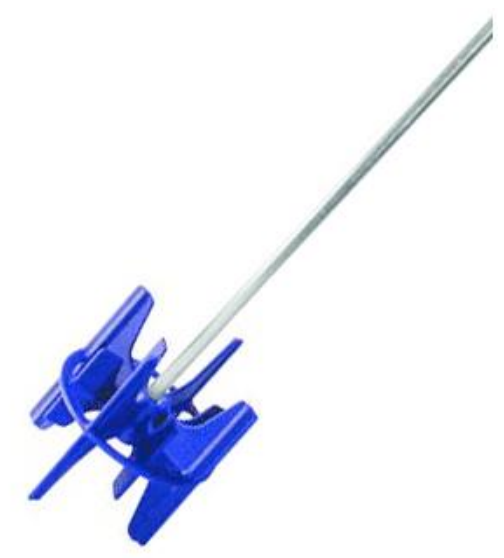

Figure 3-7: Water stirrer

\subsection{Test Preparations}

\subsubsection{Sensor calibration}

Two RTD sensors with an accuracy of $0.1{ }^{\circ} \mathrm{C}$ were used to measure the water temperature and concrete temperature simultaneously. Prior to testing, the two sensors were calibrated at 0 ${ }^{\circ} \mathrm{C}$ and $100{ }^{\circ} \mathrm{C}$ to ensure the same accuracy within the entire testing range. Ice-water mixture and boiling water was used to provide approximate $0{ }^{\circ} \mathrm{C}$ and $100^{\circ} \mathrm{C}$ for the sensor calibration.

\subsubsection{Calorimeter calibration}

Prior to the adiabatic temperature rise testing, the following procedures were performed to calibrate the system to ensure the adiabatic curing temperature. It is recommended to perform 
the calorimeter calibration every time before the ATR test. A recommended calibration procedures are shown below.

1. Preheat a fully hydrated concrete sample to $70{ }^{\circ} \mathrm{C}$ or above and placed it into the adiabatic calorimeter.

2. Turn on the adiabatic calorimeter system and let the water temperature and sample temperature converge.

3. Leave the system on for an additional 5 hours and continue monitoring the temperatures.

4. Adjust the set temperature sensor reading if the sample temperature does not stay constant under the adiabatic condition.

5. Repeat the procedures above until the sample remains constant for a recommended period of 5 hours.

\subsubsection{Preparation of concrete sample}

Theoretically, the sample size should not influence the ATR of homogeneous test sample. However, concrete is not truly homogeneous, especially due to the presence of coarse aggregates. The sample size should be sufficiently larger than the coarse aggregate used in the mix design. In this study, \#57 coarse aggregates are the largest group ever used with an aggregate size ranging from $1.25 \mathrm{~cm}$ to $3.8 \mathrm{~cm}$. The concrete samples for ATR testing are $15 \mathrm{~cm} \times 15 \mathrm{~cm}$ cylinders. In addition, it is important to store all of the ingredients including water in a room with the intended starting temperature at least 24 hours before mixing. Therefore, the initial temperature can be close to the desired value. 


\subsection{ATR Testing}

\subsubsection{Concrete mix design and cement chemical composition}

The concrete mix shown in Table 3-1 is a typical Class B concrete mix approved for West Virginia highway and infrastructure constructions. $335 \mathrm{~kg} / \mathrm{m}^{3}$ of OPC is the maximum quantity allowed in Class B mix designs by West Virginia Department of Transportation (WVDOT). The OPC was produced by ESSROC company. As shown in Table 3-2, the chemical composition of the OPC was tested by WVDOT.

\subsubsection{Temperature control precision}

With careful pre-test calibration, the adiabatic calorimeter was able to match the water temperature within a small error (less than $0.2^{\circ} \mathrm{C}$ ). Figure $3-8$ shows a typical recording of temperature match when a fresh concrete sample was being tested for ATR.

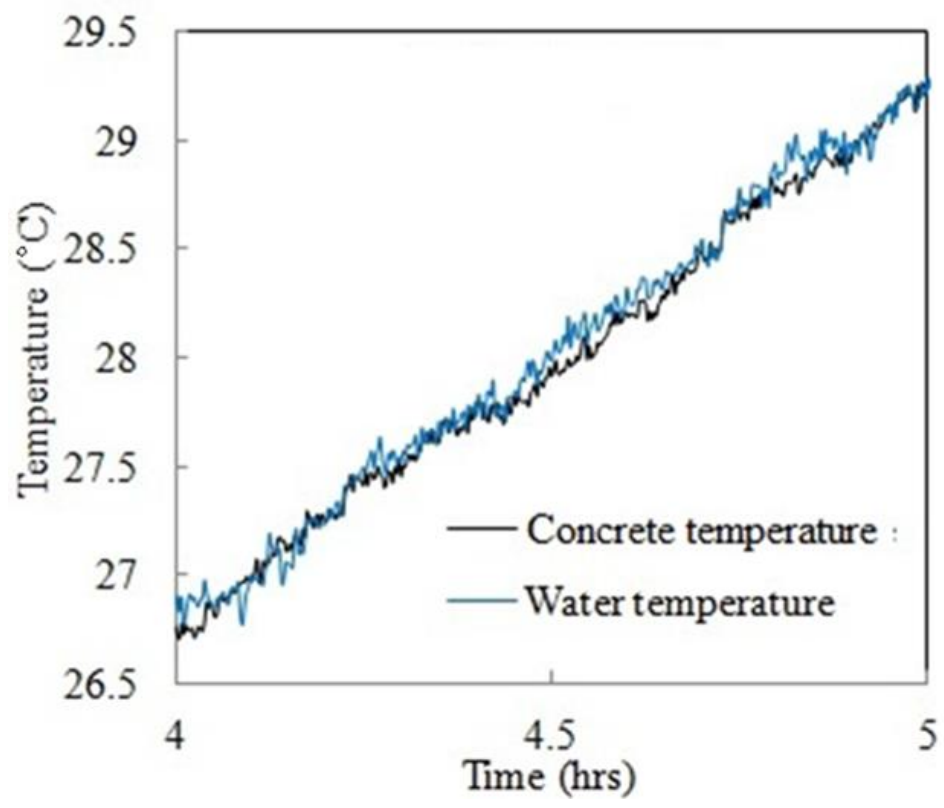

Figure 3-8: Temperature matching between water and hydration concrete 


\subsubsection{Test results}

The ATR of this particular concrete mixture shown in Table 3-1 was tested four times. The initial concrete temperatures of the four different tests were between 22.3 ${ }^{\circ} \mathrm{C}$ and $25.6^{\circ} \mathrm{C}$. The average temperature rise during the 120 -hour testing period was 48 ${ }^{\circ} \mathrm{C}$. The measured ATR histories of these four tests are plotted in Figure 3-9. The ATR results were compared with the simulation using Virtual Cement and Concrete Testing Laboratory software (VCCL) (NIST, 2014) with the above mix design information and an initial concrete temperature of $23^{\circ} \mathrm{C}$ and $26^{\circ} \mathrm{C}$ (Figure 3-10).

It was noted that the maximum ATR difference of the measured curves was approximately $4{ }^{\circ} \mathrm{C}$ amongst these tests. The differences in maximum ATR were mainly due to the sampling from four different concrete castings; although they were produced using the same mix design, the concrete samples collected from the ready-mix truck during field casting could still have substantial differences. However, this ATR deviation will not have a significant influence on the analysis. Only the shape of the measured ATR curve will be used to build the hydration curve, while the magnitude of the thermal loading is determined according to ASTM C150. Details of the thermal loading function will be described later in Chapter 5.

Table 3-1: Concrete mix design $\mathrm{kg} / \mathrm{m}^{3}$

\begin{tabular}{ccccccc}
\hline Material & Cement & Water & CA & FA & AE $/ L m^{-3}$ & $\mathrm{WR} / L m^{-3}$ \\
\hline Quantity & 335 & 139 & 969 & 844 & 0.067 & 1.0 \\
\hline
\end{tabular}

CA: coarse aggregates; FA: fine aggregates; AE: air entraining agent; WR: High-range water reducer Table 3-2: Cement chemical composition/\%

\begin{tabular}{ccccccccc}
\hline Components & $\mathrm{CaO}$ & $\mathrm{SiO}_{2}$ & $\mathrm{Al}_{2} \mathrm{O}_{3}$ & $\mathrm{Fe}_{2} \mathrm{O}_{3}$ & $\mathrm{MgO}$ & $\mathrm{SO}_{3}$ & $\mathrm{Na}_{2} \mathrm{O}$ & $\mathrm{K}_{2} \mathrm{O}$ \\
\hline Percentages & 62.3 & 20.22 & 4.8 & 3.1 & 2.51 & 3.0 & 0.034 & 0.76 \\
\hline
\end{tabular}




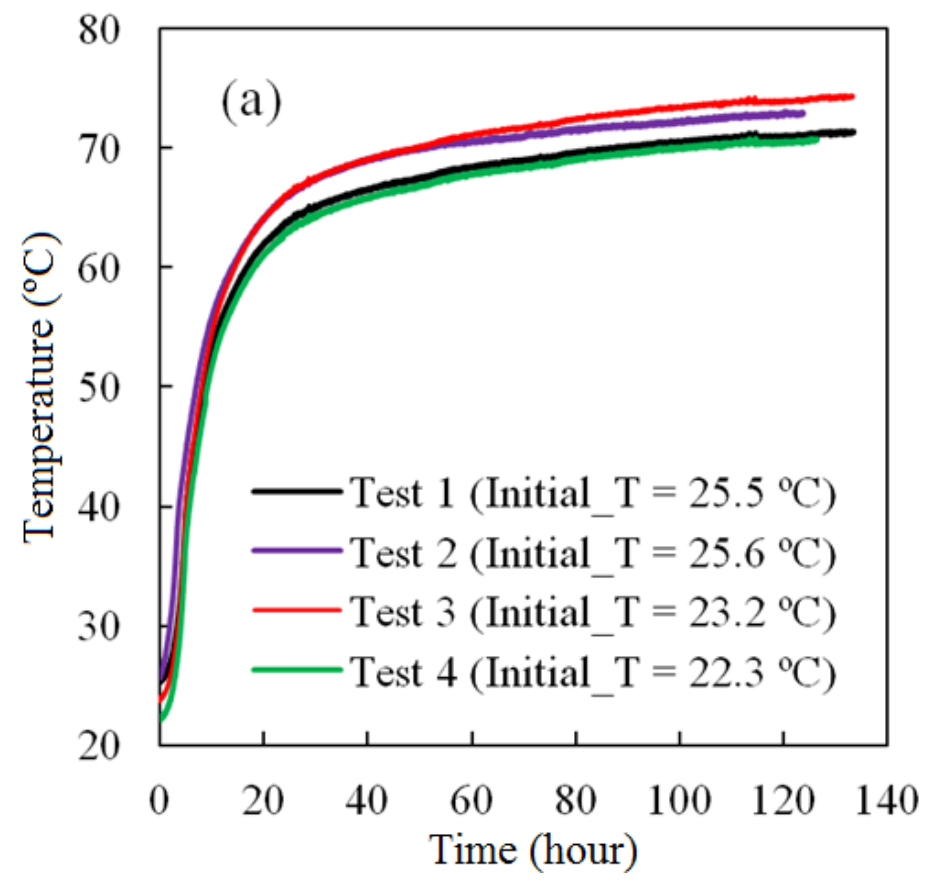

Figure 3-9: Measured ATR results for mix design in Table 3-1

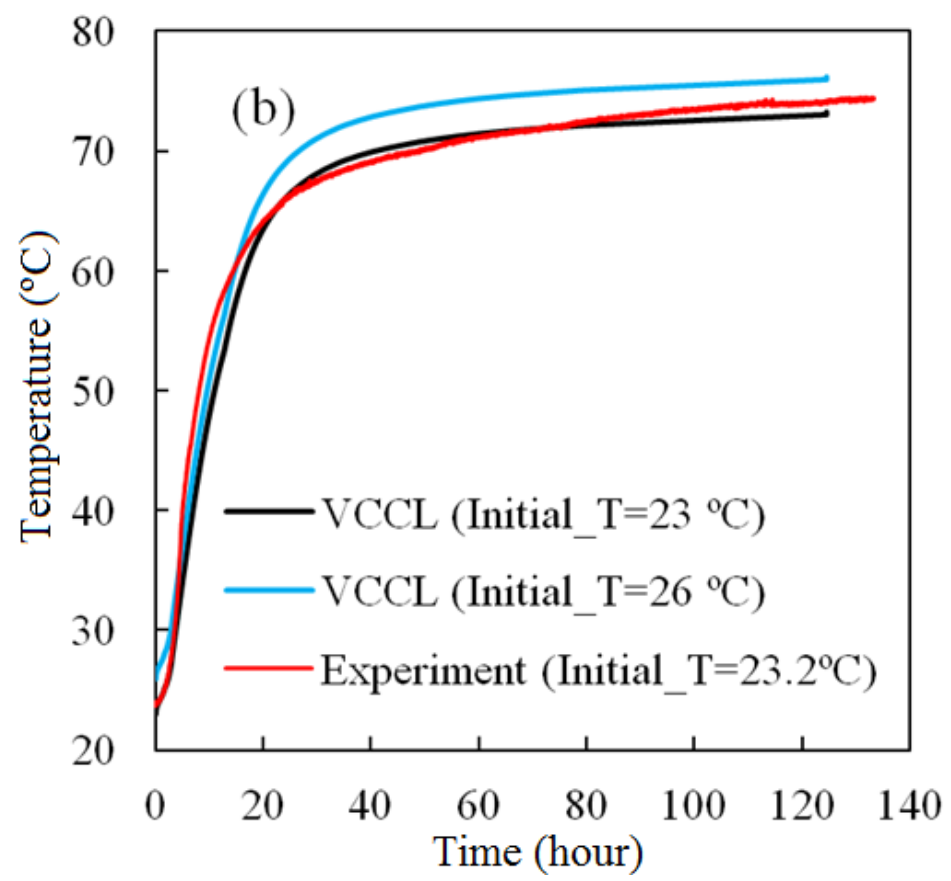

Figure 3-10: Measured ATR compared with simulated ATR using VCCL (NIST, 2014) 


\subsection{Usage of ATR Results in Thermal Analysis}

The degree of hydration curve (Eq. 2.13) will be used to describe the shape of the thermal loading function. The experimentally measured ATR results will be used to calibrate the shape of degree hydration curve using the curve fitting method. Hydration parameters, $\tau$ and $\beta$ (Figure

2-7 and Figure 2-8) can be determined from curve fitting. As shown in Figure 3-9, all four ATR measurements have a very similar shape, although the maximum ATRs were not exactly matched. The total thermal energy output will be determined using Bogue's calculation according to ASTM C 150. More details can be found in Chapter 5. 


\section{CHAPTER 4 TEMPERATURE MONITORING}

\subsection{Bridge Elements}

As mentioned in Section 2.5.1, ACI 301-10 limits the maximum center temperature $\left(70{ }^{\circ} \mathrm{C}\right.$ or $\left.158{ }^{\circ} \mathrm{F}\right)$ and the maximum temperature differential $\left(20^{\circ} \mathrm{C}\right.$ or $\left.35^{\circ} \mathrm{F}\right)$. From 2010 to 2012, a temperature monitoring program was conducted in West Virginia on a five different bridges under construction, including: Lucille Stalnaker Bridge (District 7), $5^{\text {th }}$ Avenue Bridge (District 2), Clear Fork Arch Bridge (District 10), South Mineral Wells Bridge (District 3) and Ices Ferry Bridge (District 4). A total of fourteen bridge elements was selected for temperature monitoring of the five bridges stated above (Chen et al., 2015).

Table 4-1 shows the summary of all bridge structures and the temperature monitoring results. Out of the fourteen bridge elements using, eleven ( $79 \%$ of the bridge elements) exceeded the allowable temperature differential. The maximum temperature differential is monitored as $41.7^{\circ} \mathrm{C}\left(75^{\circ} \mathrm{F}\right)$ in the pier-cap $\# 2$ of the $5^{\text {th }}$ Ave Bridge. The center maximum temperature of the same bridge element (pier-cap \#2 of the $5^{\text {th }}$ Ave Bridge) was measured to be $72.8^{\circ} \mathrm{C}\left(163{ }^{\circ} \mathrm{F}\right)$ which also exceeded the limitation of $70^{\circ} \mathrm{C}\left(158^{\circ} \mathrm{F}\right)$.

\subsection{Concrete Cubes}

Concrete cubes in different dimensions were constructed for more temperature monitoring. Four 1.8-meter (6-foot) Cubes were constructed at four different WVDOH districts, including Charleston (District 1), Martinsburg (District 5), Wheeling (District 6) and Lewisburg (District 9). Two 1.2-meter (4-foot) and one 0.9-meter (3-foot) cubes were constructed in front

of the Concrete Material Testing Lab in Morgantown at West Virginia University (WVU). Local 
ready-mix concrete plant (Central Supply Company in Morgantown, WV) provided the fresh concrete deliveries for the all the cube constructions.

A supporting grid was made for sensor installations for each concrete cube. Figure 4-1 shows a sketch of the supporting grid and a complete sensor location plan. This study uses the temperature measurements from the four sensors in the red circles. Figure 4-2 shows the center cross-section of the 1.8-meter cube and the location of those four sensors (A, B, C, and D). The center (A) and side (D, $5 \mathrm{~cm}$ or 2 in away from the surface) sensor measurements are important and extensively used in this study according to ACI 301-10. Other temperature measurements at other locations (Figure 4-1) were used for concrete maturity analysis. Details of the concrete maturity analysis can be found in of Alper Yikici's Ph.D. dissertation (2015) and Chen et al. (2015).

Intellirock temperature logger system (Figure 4-3) was used for temperature monitoring. The temperature loggers can record hourly temperature data for a period of 28 days. The sensors were coded with the robber for protections. The accuracy of the temperature logger is $1{ }^{\circ} \mathrm{C}$. The temperature logger can also directly provide concrete maturity history using Nurse-Saul maturity function. The default datum temperature is $0{ }^{\circ} \mathrm{C}$. However, the Arrhenius Function (Eq. (2.16)) was always used to calculate concrete maturity based on the measured temperature history in this study (Freiesleben Hansen and Pederson, 1977). 
Table 4-1: Bridge element summary (Chen et al., 2015)

\begin{tabular}{|c|c|c|c|c|c|c|c|c|}
\hline \multirow{2}{*}{ Place } & \multirow{2}{*}{ Element } & \multirow{2}{*}{$\begin{array}{l}\text { Min. } \\
\text { Size }\end{array}$} & \multirow{2}{*}{$\begin{array}{c}\text { Mix } \\
\text { Design }\end{array}$} & \multirow{2}{*}{$\begin{array}{c}\text { Casting } \\
\text { Time } \\
\text { Date }\end{array}$} & \multirow{2}{*}{$\frac{\mathrm{T}_{0}}{{ }^{\circ} \mathrm{F}}$} & \multirow{2}{*}{$\begin{array}{c}\text { Max. } \\
\text { Temp. } \\
{ }^{\circ} \mathrm{F} @ \mathrm{hrs}\end{array}$} & \multicolumn{2}{|c|}{$\begin{array}{l}\text { Max. Temp. } \\
\text { Differential }\end{array}$} \\
\hline & & & & & & & ${ }^{\circ} \mathrm{F} @ \mathrm{hrs}$ & Location \\
\hline $\begin{array}{l}\text { Lucille } \\
\text { Stalnaker }\end{array}$ & $\begin{array}{c}\text { Pier Stem } \\
\quad \# 1\end{array}$ & 6'dia. & $\begin{array}{c}6 \mathrm{Bag} \\
\mathrm{w} / 13 \% \\
\mathrm{FA} \\
\end{array}$ & $\begin{array}{l}\text { 11/1/2010 } \\
\text { 9:55 AM }\end{array}$ & 65 & $129 @ 20$ & $\begin{array}{l}35 @ 16 \\
40 @ 20\end{array}$ & side surface \\
\hline $\begin{array}{l}\text { Lucille } \\
\text { Stalnaker }\end{array}$ & Pier Cap \#1 & 4' & $\begin{array}{c}6 \mathrm{Bag} \\
\mathrm{w} / 13 \% \\
\mathrm{FA}\end{array}$ & $\begin{array}{l}\text { 1/17/2011 } \\
8: 45 \text { AM }\end{array}$ & 52 & $118 @ 28$ & $36 @ 15$ & side surface \\
\hline $\begin{array}{l}\text { Lucille } \\
\text { Stalnaker }\end{array}$ & $\begin{array}{l}\text { Abutment } \\
\quad \# 2\end{array}$ & $3^{\prime}-9 "$ & $\begin{array}{c}6 \mathrm{Bag} \\
\mathrm{w} / 13 \% \\
\mathrm{FA}\end{array}$ & $\begin{array}{l}\text { 3/30/2011 } \\
\text { 10:00 AM }\end{array}$ & 59 & $118 @ 21$ & $34 @ 16$ & $\begin{array}{l}\text { bottom } \\
\text { surface }\end{array}$ \\
\hline $5^{\text {th }} \mathrm{A}$ & Footer \#2 & 4 ' & $\begin{array}{c}6 \mathrm{Bag} \\
\text { w/45\% } \\
\text { Slag }\end{array}$ & \begin{tabular}{|c} 
2/3/2011 \\
10:00 AM
\end{tabular} & 62 & 99 @ 57 & $\begin{array}{c}18 @ 18 \\
40 @ 137\end{array}$ & side surface \\
\hline $5^{\text {th }}$ Avenue & Pier Stem\#2 & 8'dia. & 7 Bag & \begin{tabular}{|c|}
$2 / 11 / 2011$ \\
$1: 00 \mathrm{PM}$
\end{tabular} & 68 & $158 @ 37$ & $\begin{array}{l}41 @ 90 \\
52 @ 88 \\
\end{array}$ & $\begin{array}{l}\text { Center/side } \\
\text { Bottom/side }\end{array}$ \\
\hline $5^{\text {th }}$ Avenue & Pier Cap \#2 & 5 ' & 7 Bag & \begin{tabular}{|l|} 
3/28/2011 \\
11:00 AM
\end{tabular} & 69 & $163 @ 35$ & $\begin{array}{r}59 @ 35 \\
75 @ 66 \\
\end{array}$ & side surface \\
\hline $5^{\text {th }}$ Avenue & $\begin{array}{c}\text { Abutment } \\
\quad \# 2\end{array}$ & $3^{\prime}-9 "$ & $\begin{array}{c}6 \mathrm{Bag} \\
\mathrm{w} / 45 \% \\
\text { Slag } \\
\end{array}$ & $\begin{array}{c}\text { 4/1/2011 } \\
\text { 10:00 AM }\end{array}$ & 65 & 99 @ 30 & $20 @ 24$ & side surface \\
\hline $\begin{array}{c}\text { Clear Fork } \\
\text { Arch \#2 }\end{array}$ & $\begin{array}{c}\text { Abutment\#1 } \\
\text { Footing }\end{array}$ & $\begin{array}{c}3^{\prime} \\
(\min )\end{array}$ & $\begin{array}{c}6 \mathrm{Bag} \\
\mathrm{w} / 14 \% \\
\mathrm{FA}\end{array}$ & $\begin{array}{l}\text { 1/18/2011 } \\
\text { 9:10 AM }\end{array}$ & 55 & $122 @ 23$ & $\begin{array}{l}35 @ 28 \\
52 @ 41\end{array}$ & side surface \\
\hline $\begin{array}{c}\text { Clear Fork } \\
\text { Arch \#2 }\end{array}$ & $\begin{array}{c}\text { Abutment } \# 2 \\
\text { Stem }\end{array}$ & $3^{\prime}-0 "$ & $\begin{array}{c}6 \mathrm{Bag} \\
\mathrm{w} / 14 \% \\
\mathrm{FA} \\
\end{array}$ & $\begin{array}{l}\text { 2/15/2011 } \\
12: 50 \mathrm{PM}\end{array}$ & 56 & $115 @ 27$ & $\begin{array}{l}35 @ 17 \\
40 @ 22\end{array}$ & top surface \\
\hline $\begin{array}{c}\text { Clear Fork } \\
\text { Arch \#1 }\end{array}$ & $\begin{array}{c}\text { Abutment } \\
\# 2\end{array}$ & 3 ' & $6 \mathrm{Bag}$ & 1/4/2011 & 56 & $97 @ 18$ & $25 @ 15$ & $\begin{array}{l}\text { bottom } \\
\text { surface }\end{array}$ \\
\hline $\begin{array}{l}\text { S. Mineral } \\
\text { Wells }\end{array}$ & $\begin{array}{l}\text { Pier\#2 } \\
\text { Stem\#2 }\end{array}$ & 7'dia. & $\begin{array}{c}6 \mathrm{Bag} \\
\mathrm{w} / 14 \% \\
\mathrm{FA} \\
\end{array}$ & $\begin{array}{l}\text { 7/20/2011 } \\
6: 10 \text { AM }\end{array}$ & 78 & $156 @ 25$ & $38 @ 47$ & side surface \\
\hline $\begin{array}{l}\text { S. Mineral } \\
\text { Wells }\end{array}$ & Pier Cap \#2 & 5 , & $\begin{array}{c}6 \mathrm{Bag} \\
\mathrm{w} / 14 \% \\
\mathrm{FA} \\
\end{array}$ & $\begin{array}{l}\text { 8/22/2011 } \\
7: 30 \text { AM } \\
\end{array}$ & 81 & $145 @ 23$ & $31 @ 23$ & side surface \\
\hline $\begin{array}{l}\text { S. Mineral } \\
\text { Wells }\end{array}$ & Abutment\#2 & 3 ' & $\begin{array}{c}6 \mathrm{Bag} \\
\mathrm{w} / 14 \% \\
\mathrm{FA} \\
\end{array}$ & \begin{tabular}{|c|}
$11 / 02 / 201$ \\
$112: 30$ \\
$\mathrm{PM}$ \\
\end{tabular} & 68 & $116 @ 17$ & $32 @ 12$ & $\begin{array}{l}\text { bottom } \\
\text { surface }\end{array}$ \\
\hline Ices Ferry & Pier Cap \#2 & 6 ' & $\begin{array}{c}7 \mathrm{Bag} \\
\mathrm{w} / 12 \% \\
\mathrm{FA} \\
\end{array}$ & \begin{tabular}{|c}
$10 / 20 / 201$ \\
$112: 30$ \\
$\mathrm{PM}$
\end{tabular} & 65 & $135 @ 21$ & $31 @ 22$ & side surface \\
\hline
\end{tabular}




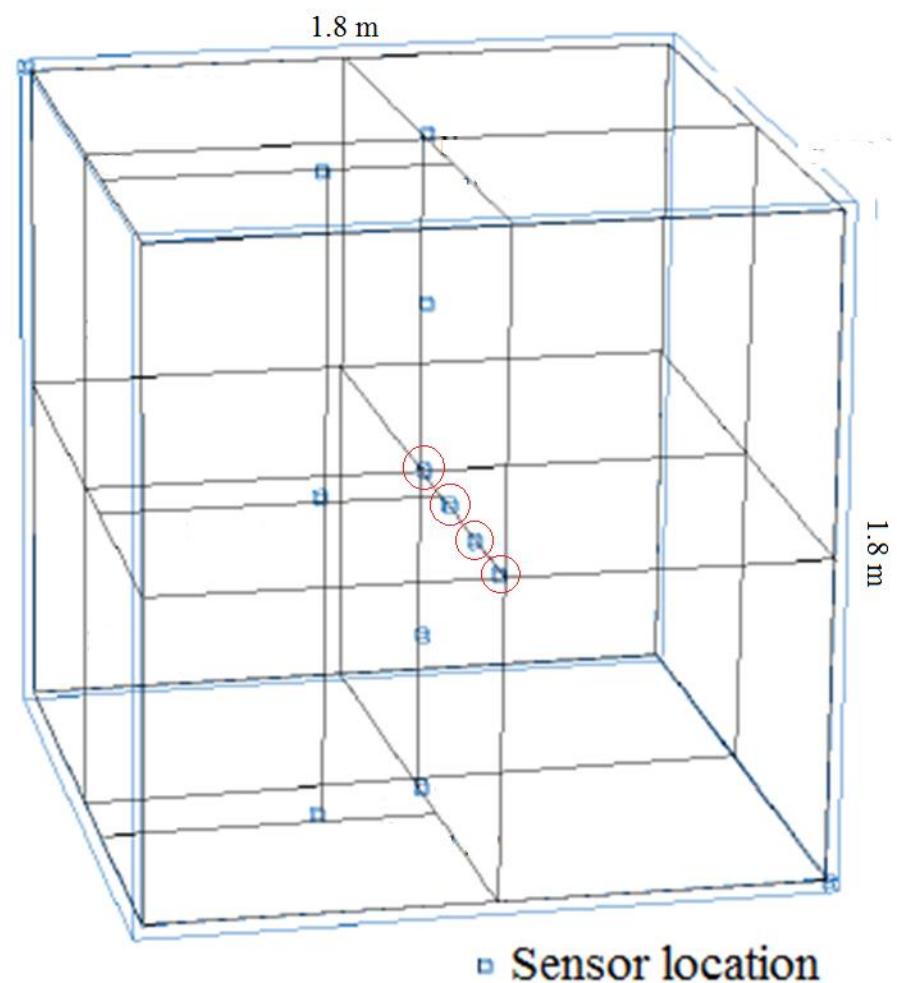

Figure 4-1: Supporting grid for temperature loggers

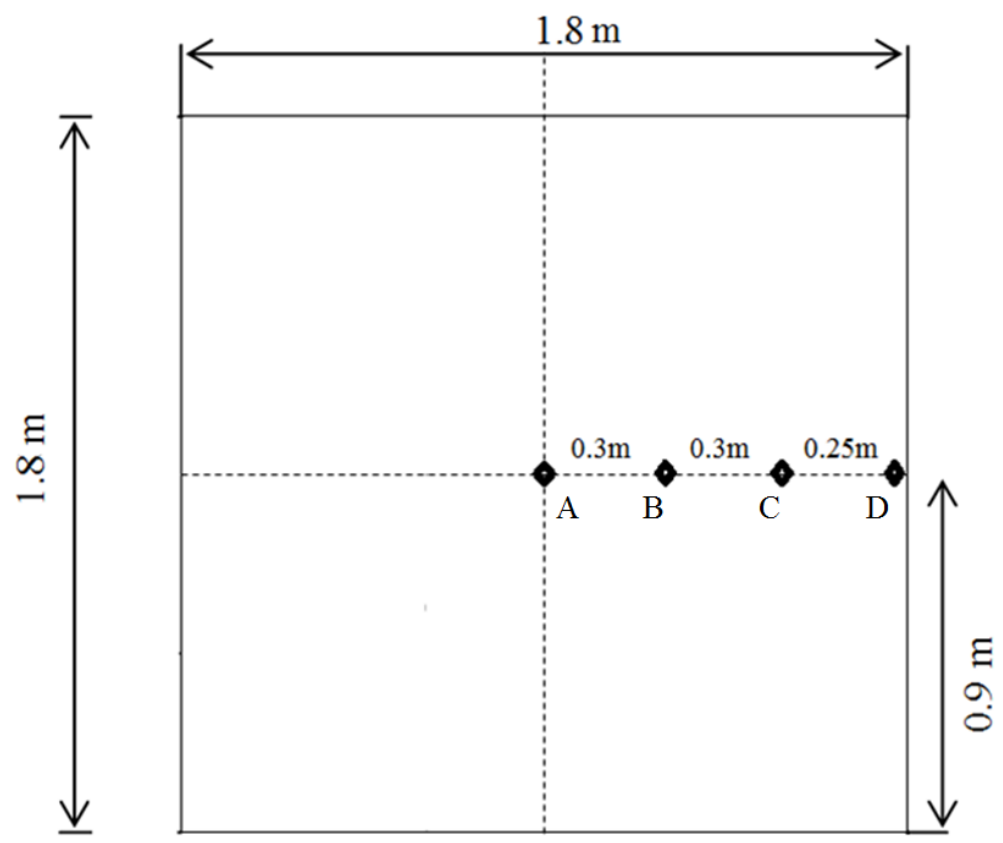

Figure 4-2: Sensor locations of the 6-ft cubes (center cross-sectional cut) 


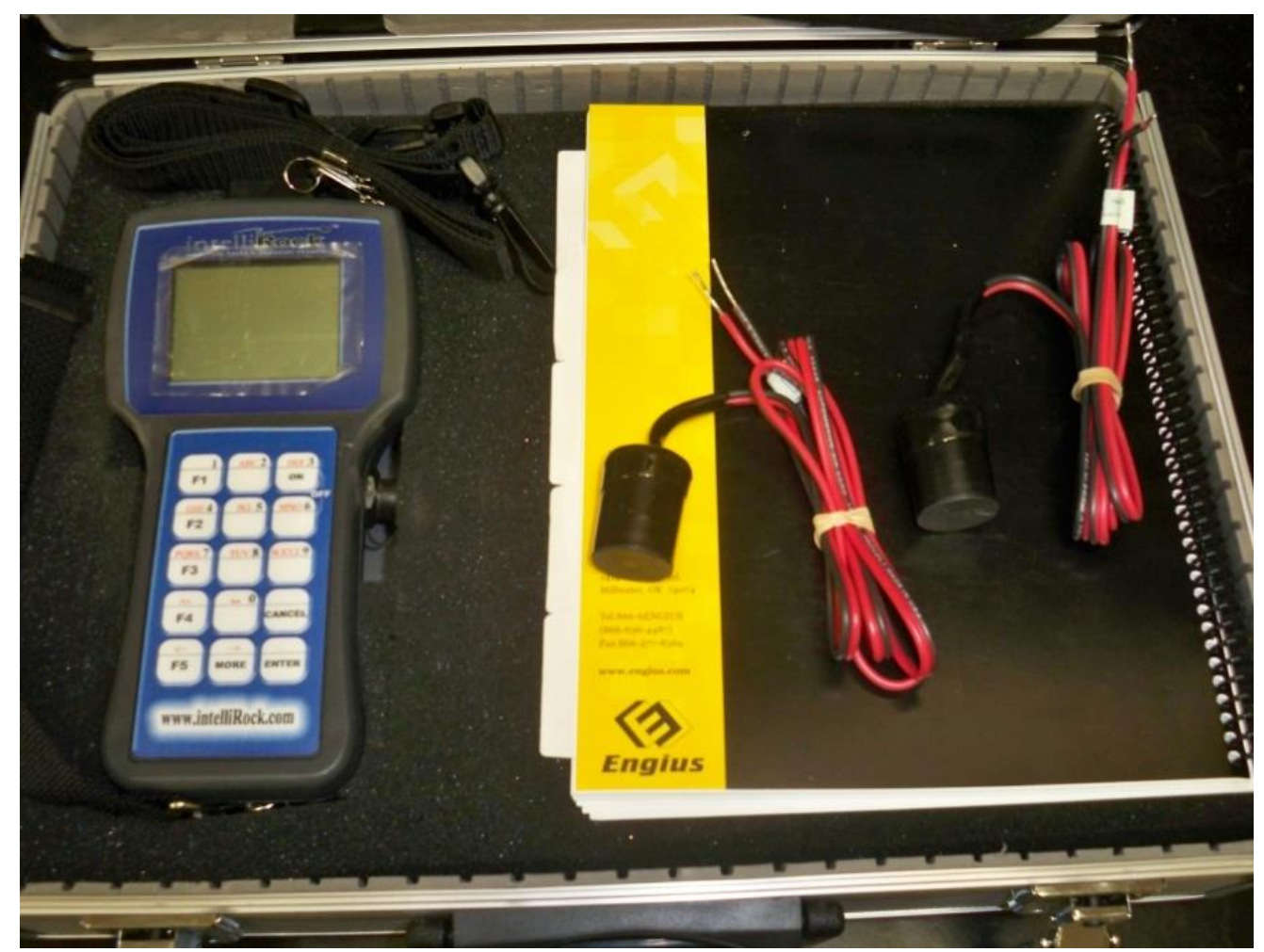

Figure 4-3: Intellirock temperature logger and data collection system

\subsubsection{District 1 Cube (1.8 meter)}

On August 15, 2011, a 1.8-meter cube was constructed in Charleston (District 1), West Virginia. The concrete used in District 1 cube contains $279 \mathrm{~kg} / \mathrm{m}^{3}$ of Ordinary Portland Cement (OPC) and $44 \mathrm{~kg} / \mathrm{m}^{3}$ of Fly Ash (FA). The concrete mixture was measured to have a 6.3-cm (2.5 inch) slump, $6.5 \%$ air and $29{ }^{\circ} \mathrm{C}\left(84{ }^{\circ} \mathrm{F}\right)$ initial temperature at the job site prior to casting. The concrete casting started 1:00 PM. Figure 4-4 shows the support grid of District 1 cube with mounted temperature loggers. Figure 4-5 shows concrete casting of District 1 cube. Wood formwork was used for concrete casting on top of a soil bottom surface. Figure 4-6 shows the 120 hour temperature record at A, B, C and D locations (Figure 4-2) and the ambient temperature histories for District 1 cube. 


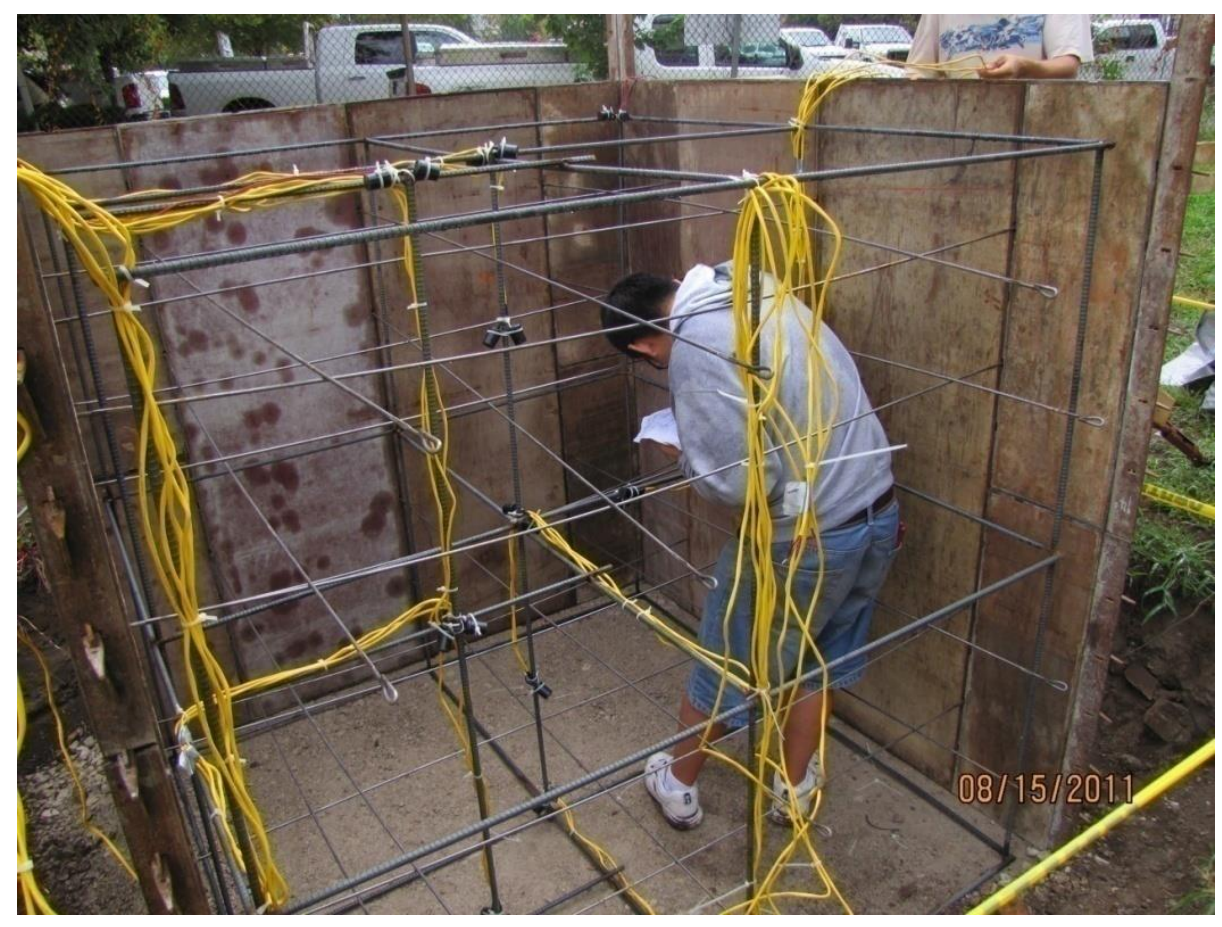

Figure 4-4: Support Grid of District 1 cube

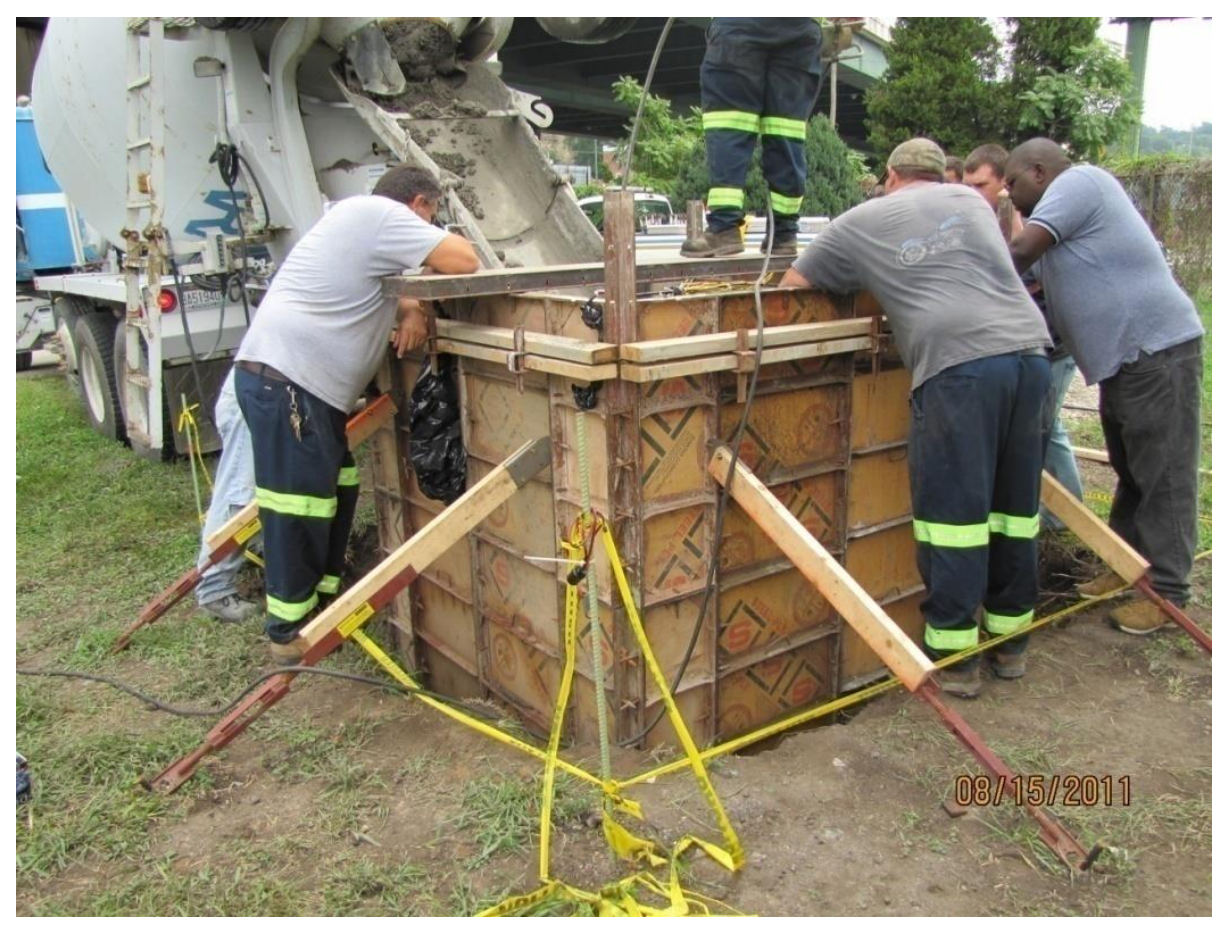

Figure 4-5: Casting of District 1 cube 
The maximum temperature observed was $63{ }^{\circ} \mathrm{C}\left(145^{\circ} \mathrm{F}\right)$ at 25 hours after casting in the center (A) location of the District 1 cube. The maximum temperature differential was $18{ }^{\circ} \mathrm{C}$ $\left(32{ }^{\circ} \mathrm{F}\right)$ at 43 hours between the center (A) and the side surface (D) of the cube. The measured maximum center temperature (less than $70{ }^{\circ} \mathrm{C}$ ) and maximum temperature differential (less than $20^{\circ} \mathrm{C}$ ) were within the ACI limitations.

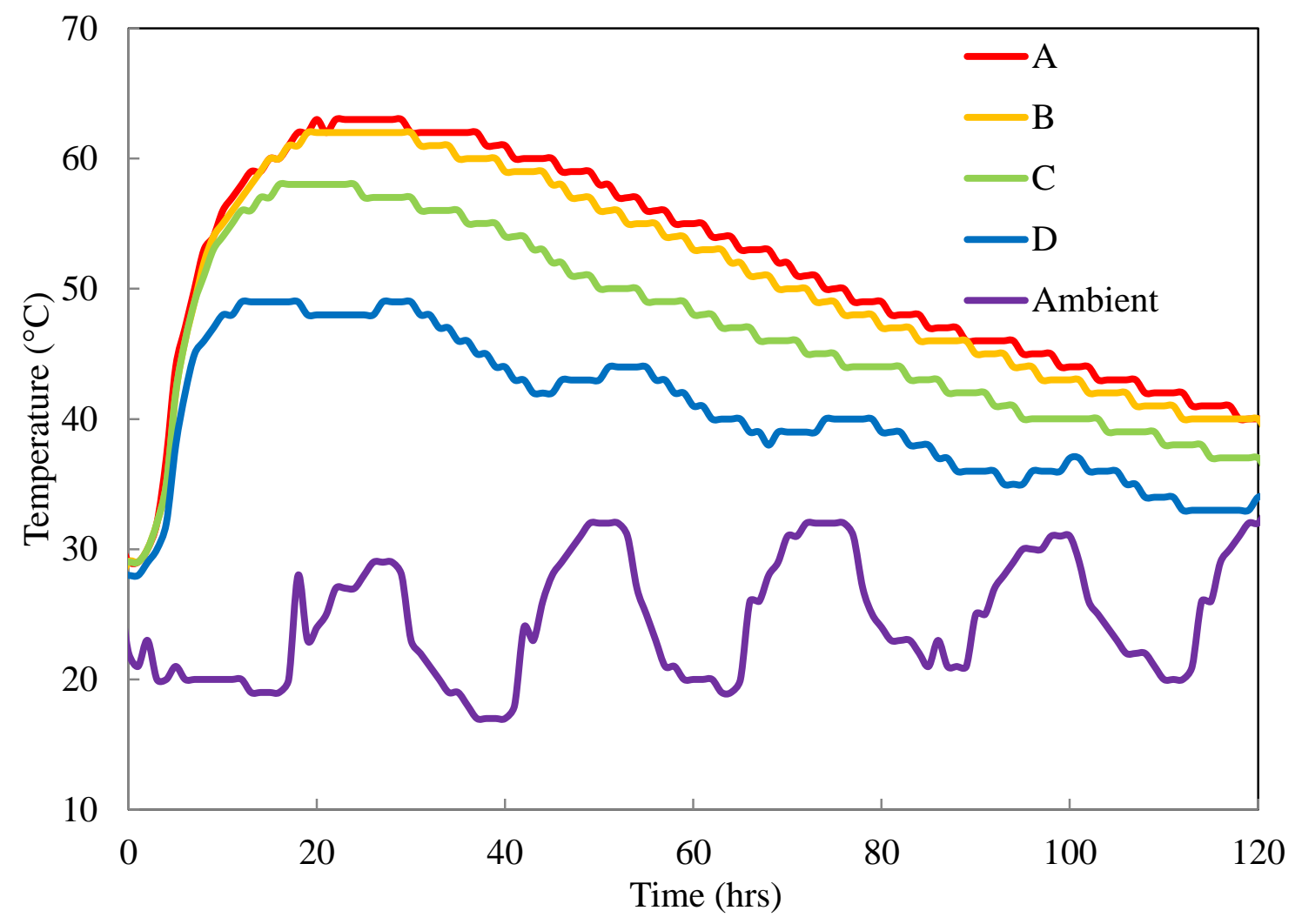

Figure 4-6: Temperature monitoring, District 1 cube

\subsubsection{District 9 Cube (1.8 meter)}

On August 26, 2011, a 1.8-meter cube was constructed in Lewisburg (District 9), West Virginia. The concrete used in District 9 cube contains $334 \mathrm{~kg} / \mathrm{m}^{3}$ of OPC. The concrete mixture was measured to have a $12.6 \mathrm{~cm}\left(5\right.$ inch) slump, $9.5 \%$ air and $27{ }^{\circ} \mathrm{C}\left(81{ }^{\circ} \mathrm{F}\right)$ initial 
temperature at the job site prior to casting. The concrete casting started 1:00 PM. Figure 4-7 shows the support grid of District 9 cube with mounted temperature loggers. Figure 4-8 shows concrete casting of District 9 cube. Wood formwork was used for concrete casting on top of a soil bottom surface. Figure 4-9 shows the 120 hour temperature record at A, B, C and D (Figure 4-2) locations and the ambient temperature history for District 9 cube.

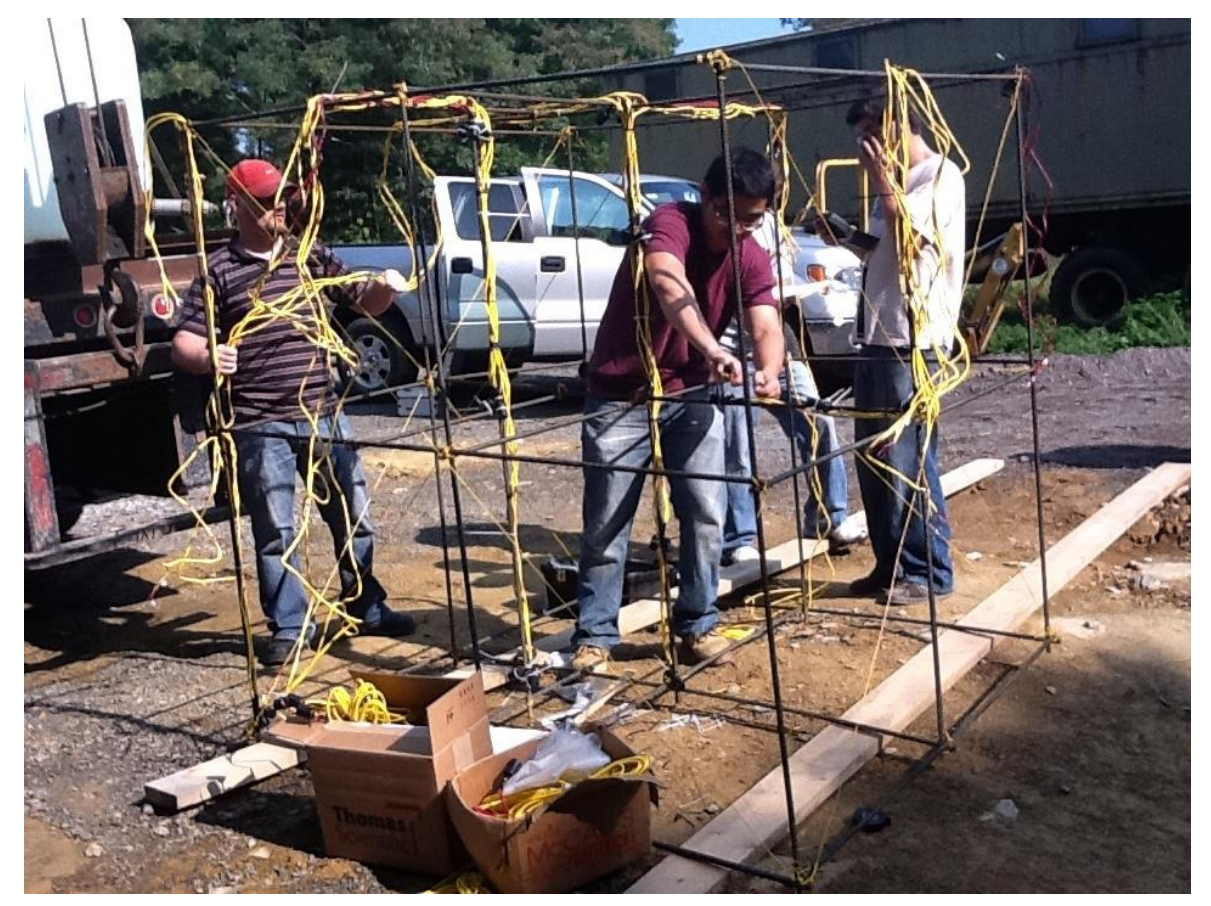

Figure 4-7: Support Grid of District 9 cube

The maximum temperature observed was $74^{\circ} \mathrm{C}\left(165^{\circ} \mathrm{F}\right)$ at 30 hours after casting in the center (A) location of the District 9 cube. The maximum temperature differential was $20{ }^{\circ} \mathrm{C}$ $\left(35^{\circ} \mathrm{F}\right)$ at 43 hours after casting between the center (A) and the side (D) of the cube. The measured maximum center temperature exceeded $70{ }^{\circ} \mathrm{C}$. The maximum temperature differential was equal to the ACI limitation of $20^{\circ} \mathrm{C}$. 


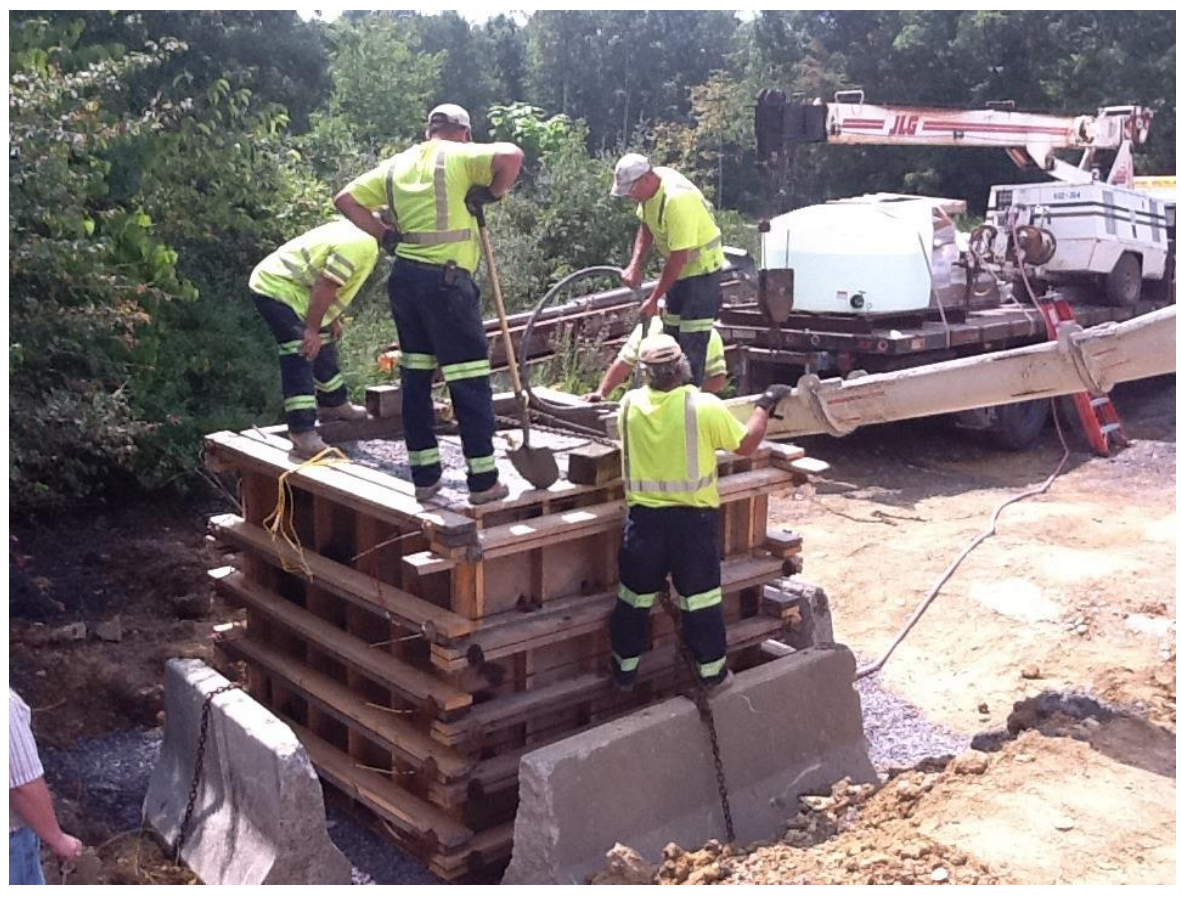

Figure 4-8: Casting of District 9 cube

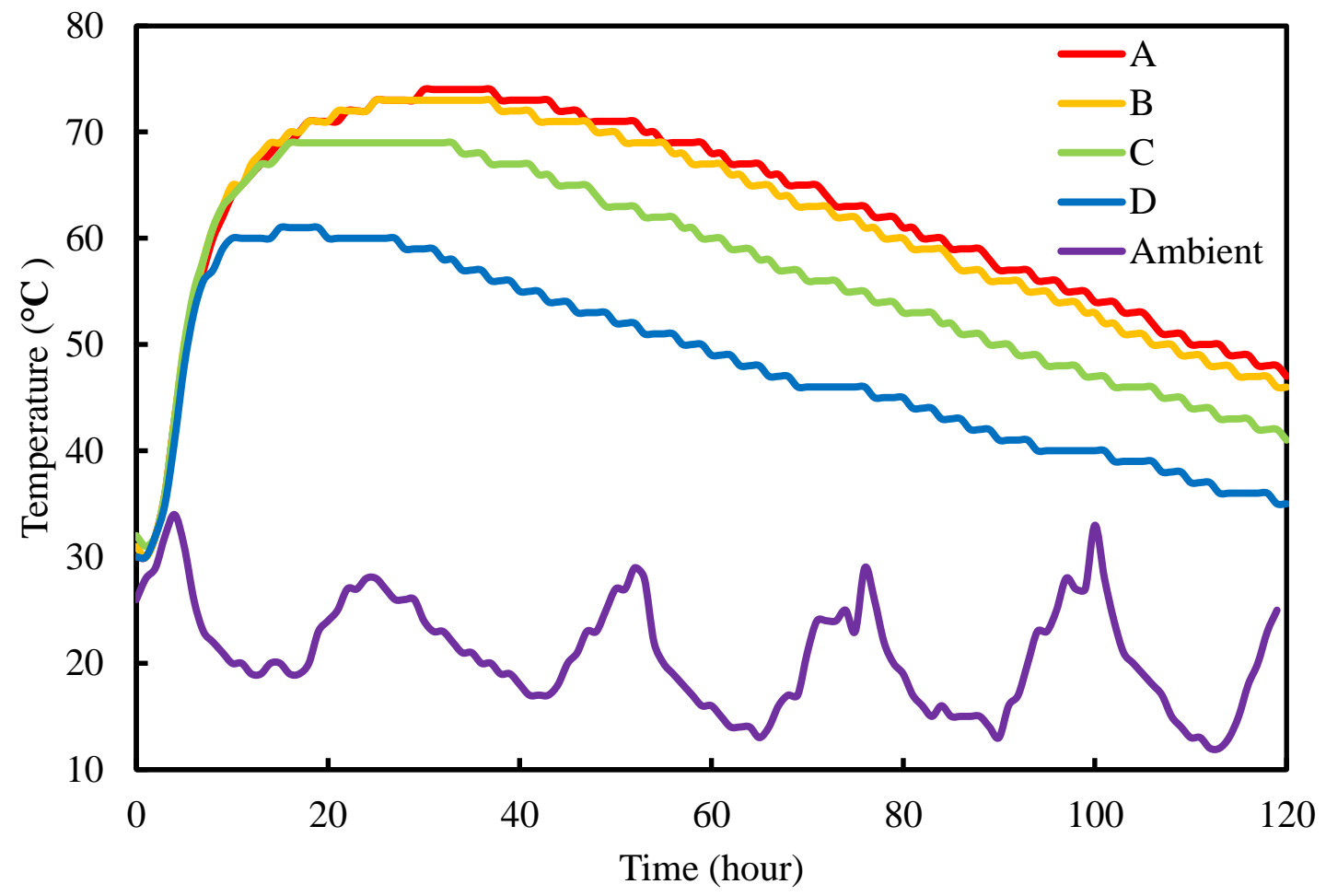

Figure 4-9: Temperature monitoring, District 9 cube 


\subsubsection{District 5 Cube (1.8 meter)}

On September 15, 2011, a 1.8-meter cube was constructed in Martinsburg (District 5), West Virginia. The concrete used in District 5 cube contains $251 \mathrm{~kg} / \mathrm{m}^{3}$ of OPC and $84 \mathrm{~kg} / \mathrm{m}^{3}$ of slag. The concrete mixture was measured to have a $6.3 \mathrm{~cm}(2.5 \mathrm{inch})$ slump, $5.6 \%$ air and $27{ }^{\circ} \mathrm{C}$ $\left(81^{\circ} \mathrm{F}\right)$ initial temperature at the job site prior to casting. The concrete casting started 1:00 PM. Figure 4-10 shows the support grid of District 5 cube with mounted temperature loggers. Different from other 1.8 meter cubes, steel formwork was used for concrete casting on top of a gravel bottom surface. Figure 4-11 shows concrete casting of District 5 cube. Figure 4-12 shows the 120 hour temperature record at A, B, C and D (Figure 4-2) locations and the ambient temperature history for District 5 cube.

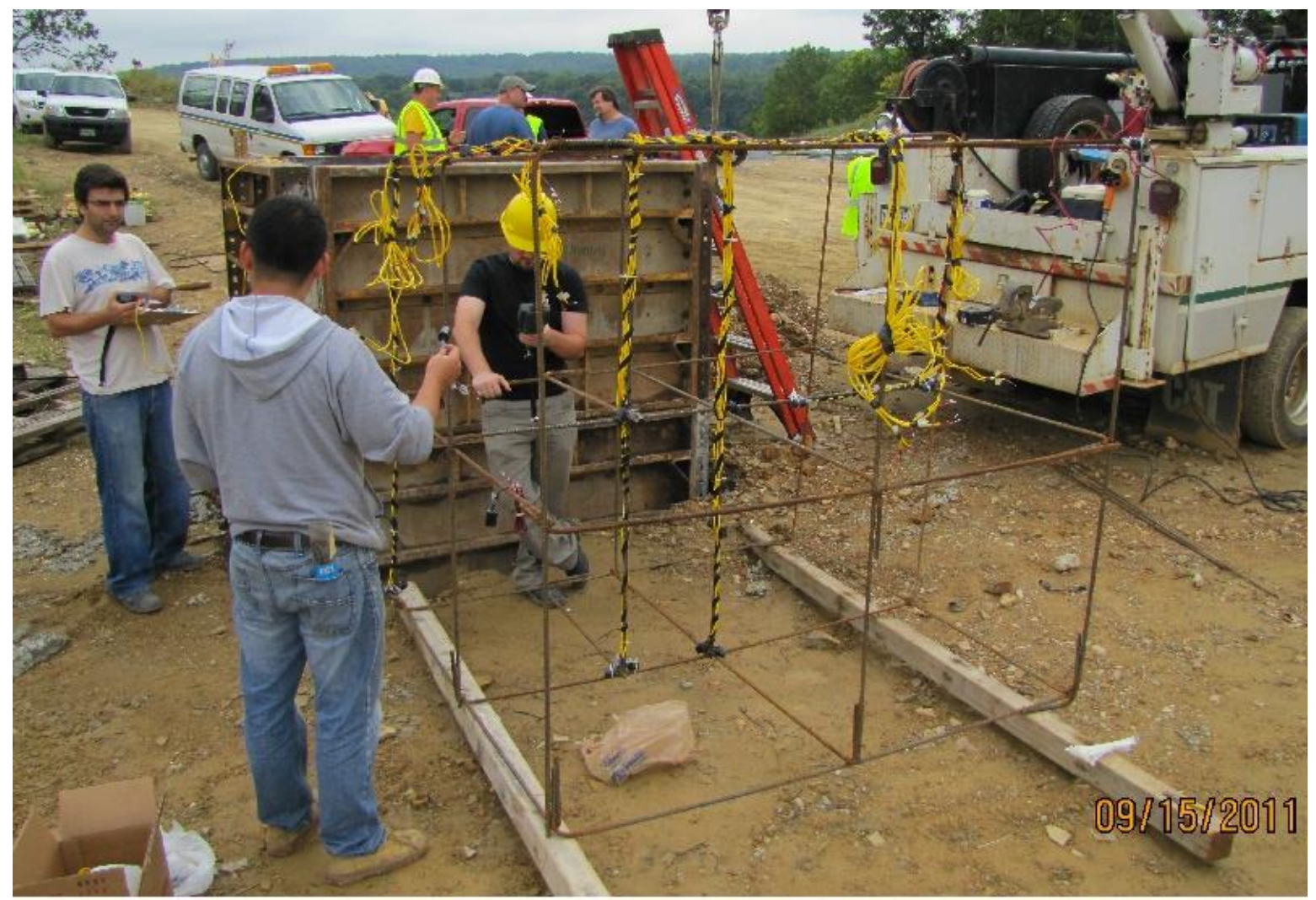

Figure 4-10: Support Grid of District 5 cube 
The maximum temperature observed was $65^{\circ} \mathrm{C}\left(149^{\circ} \mathrm{F}\right)$ at 28 hours after casting in the center (A) location of the District 5 cube. The maximum temperature differential was $23{ }^{\circ} \mathrm{C}$ $\left(41{ }^{\circ} \mathrm{F}\right.$ ) at 41 hours after casting between the center (A) and the side (D) of the cube. The measured maximum center temperature (less than $70^{\circ} \mathrm{C}$ ) was within the $\mathrm{ACI}$ limitation, but the maximum temperature differential (more than $20^{\circ} \mathrm{C}$ ) exceeded the ACI limitation. The use of slag as part of the cementitious material was able to reduce the early age hydration heat, which was able to delay and reduce both maximum center temperature and temperature differential. However, the use of steel formwork instead of wood formwork increased the surface heat loss and reduced the side (D) temperature of concrete. Thus, the maximum temperature differential $\left(23{ }^{\circ} \mathrm{C}\right)$ was still too high to satisfy the ACI limitation of $20^{\circ} \mathrm{C}$.

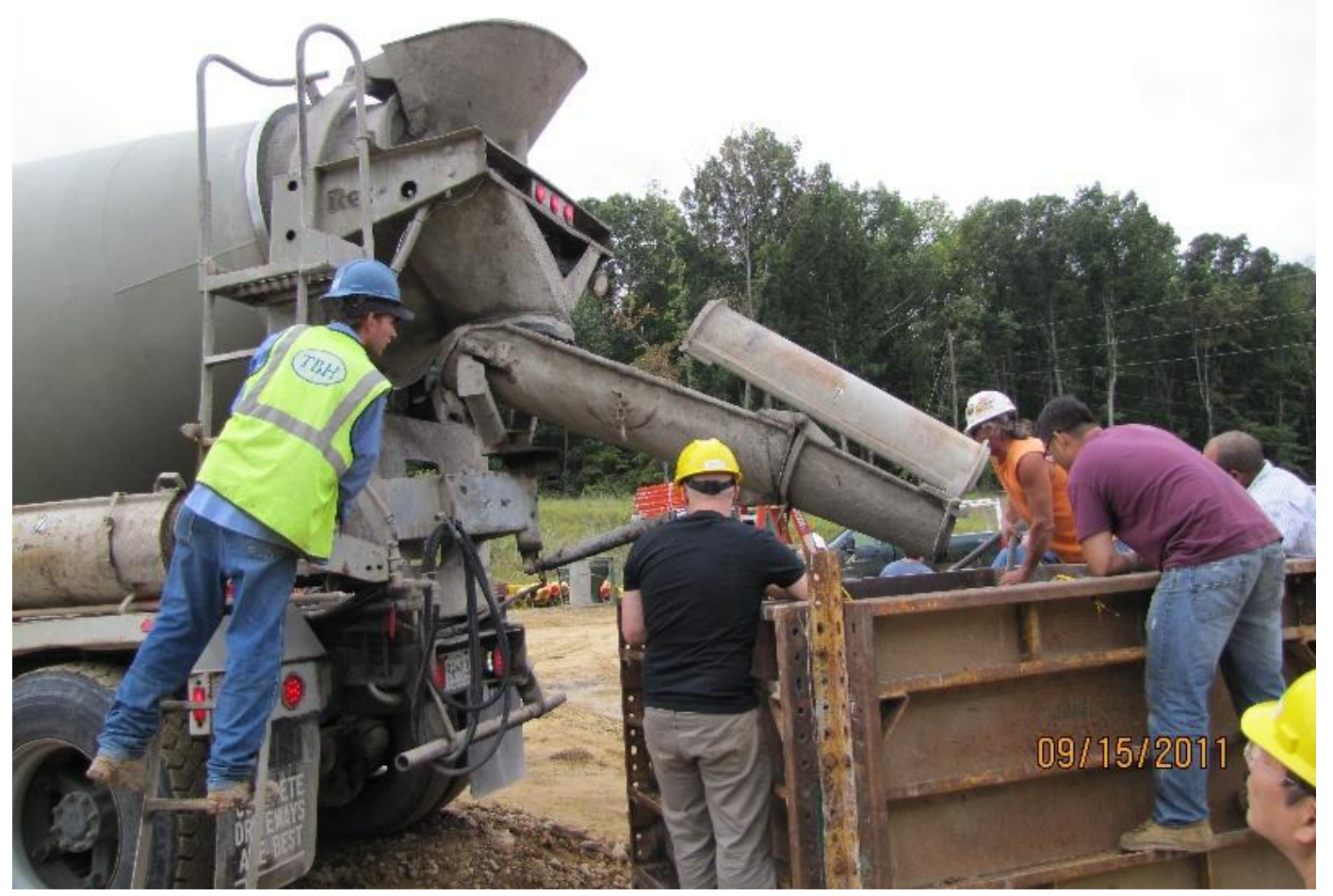

Figure 4-11: Casting of District 5 cube 


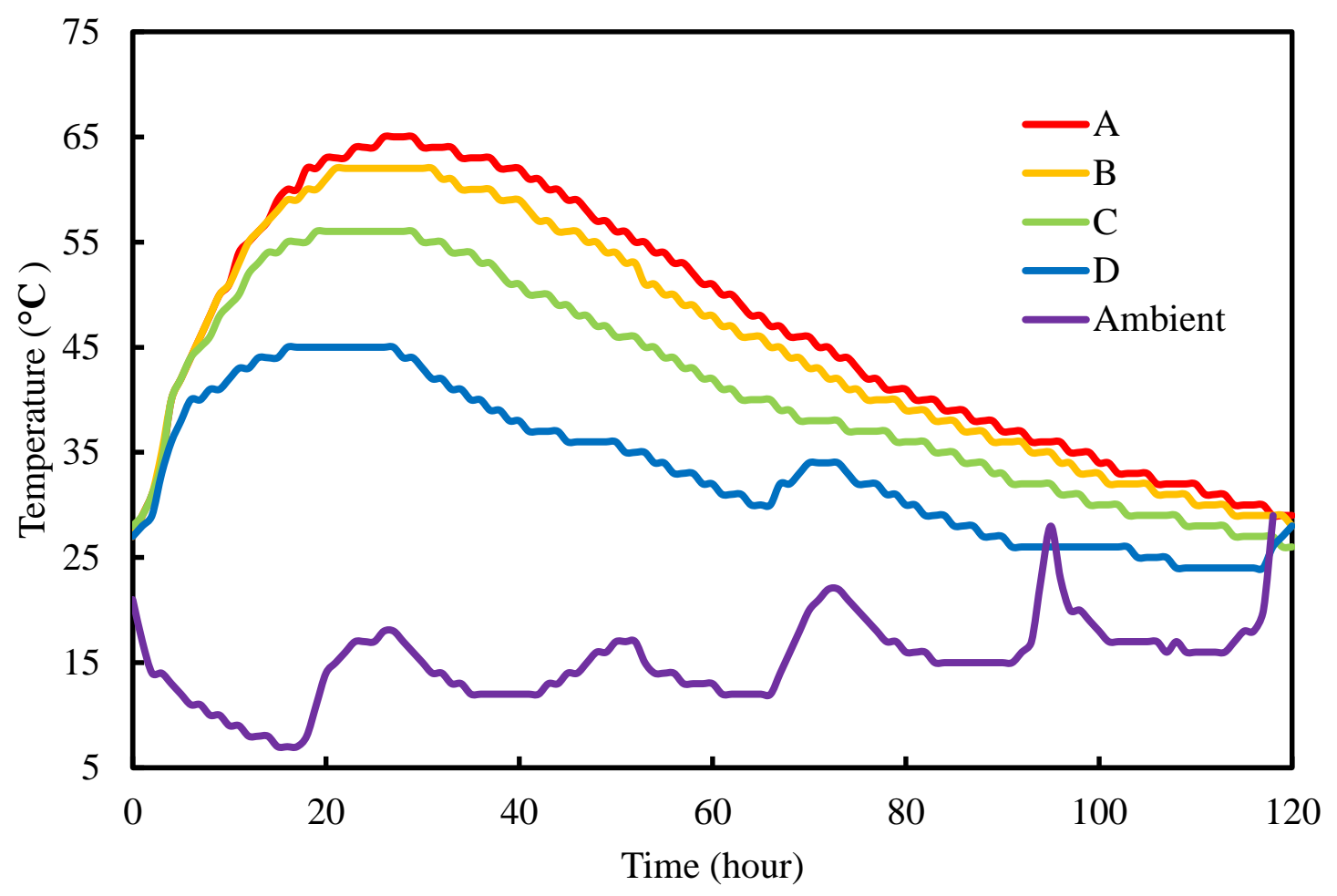

Figure 4-12: Temperature monitoring, District 5 cube

\subsubsection{District 6 Cube (1.8 meter)}

On February 21, 2012, a 1.8-meter cube was constructed in Moundsville (District 6), West Virginia. The concrete used in District 6 cube contains $390 \mathrm{~kg} / \mathrm{m}^{3}$ of OPC. The concrete mixture was measured to have a $4.4 \mathrm{~cm}(1.75 \mathrm{inch})$ slump, $4.8 \%$ air and $24{ }^{\circ} \mathrm{C}\left(75^{\circ} \mathrm{F}\right)$ initial temperature at the job site prior to casting. The concrete casting started 1:00 PM. Figure 4-13 shows the support grid of District 6 cube with mounted temperature loggers. Wood formwork was used for concrete casting on top of a gravel bottom surface. Figure 4-14 shows concrete casting of District 6 cube. Figure 4-15 shows the 120 hour temperature record at A, B, C and D (Figure 4-2) locations and the ambient temperature history for District 6 cube. Two layers of plastic cover were used outside of the wood formwork. 


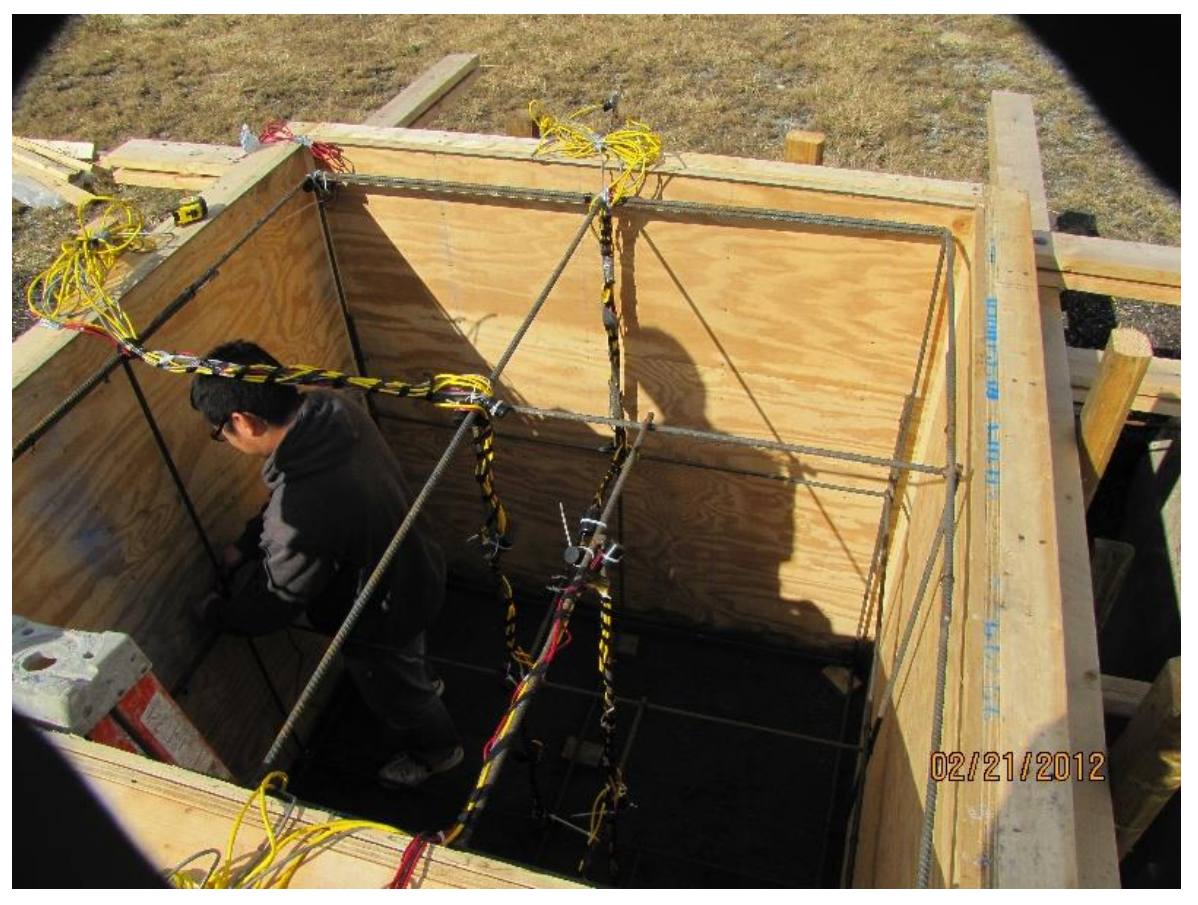

Figure 4-13: Support Grid of District 6 cube

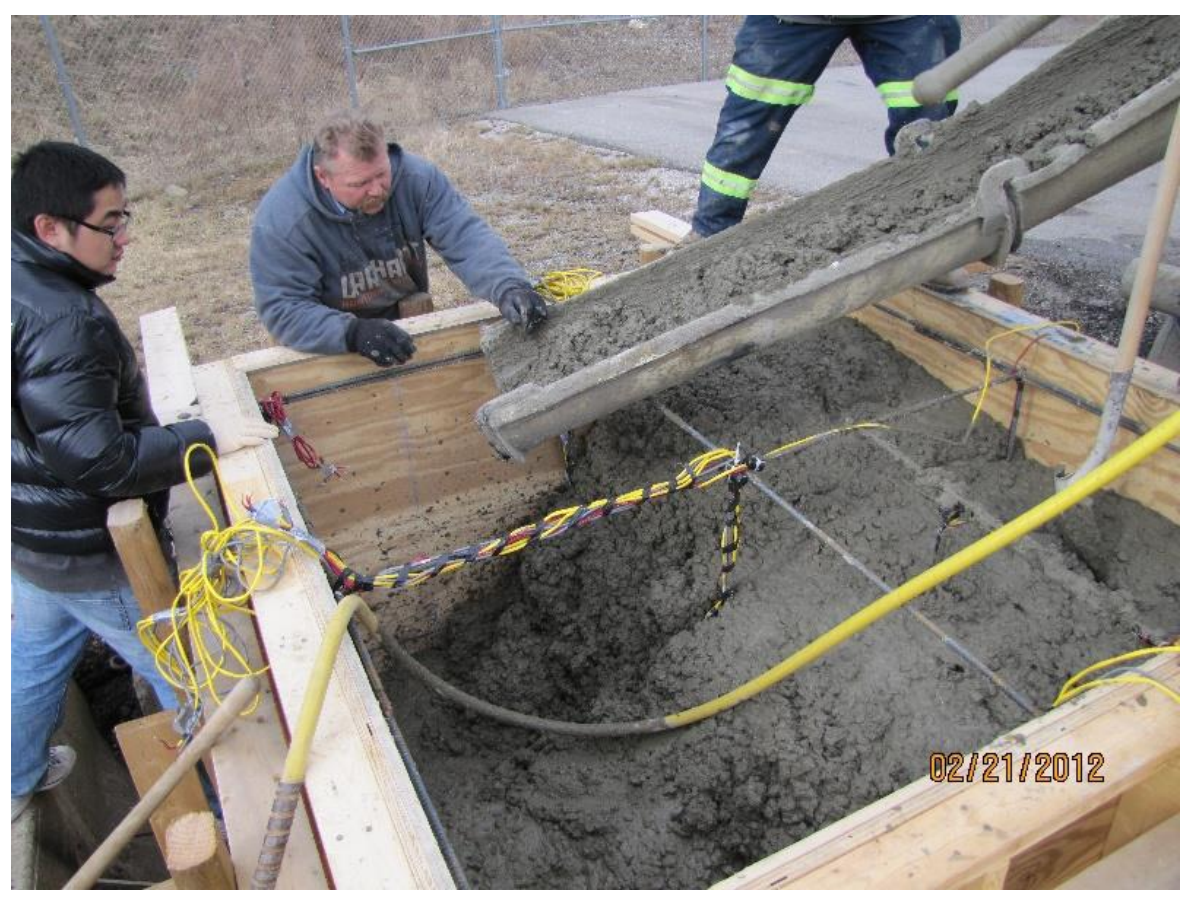

Figure 4-14: Casting of District 6 cube 
The maximum temperature observed was $69^{\circ} \mathrm{C}\left(156^{\circ} \mathrm{F}\right)$ at 25 hours after casting in the center (A) location of the District 9 cube. The maximum temperature differential was $19{ }^{\circ} \mathrm{C}$ $\left(34{ }^{\circ} \mathrm{F}\right)$ at 41 hours after casting between the center (A) and the side (D) of the cube. The measured maximum center temperature (less than $70{ }^{\circ} \mathrm{C}$ ) and maximum temperature differential (equal to $\left.20^{\circ} \mathrm{C}\right)$ were within the ACI limitations. Although a high OPC mix design $\left(390 \mathrm{~kg} / \mathrm{m}^{3}\right)$ was used, the temperature monitoring results still satisfy the ACI limitations. The use of wood formwork and extra plastic covers outside of the formwork was helpful in controlling temperature differentials. In addition, the low initial concrete temperature $\left(24{ }^{\circ} \mathrm{C}\right)$ played an important role in reducing the maximum center temperature.

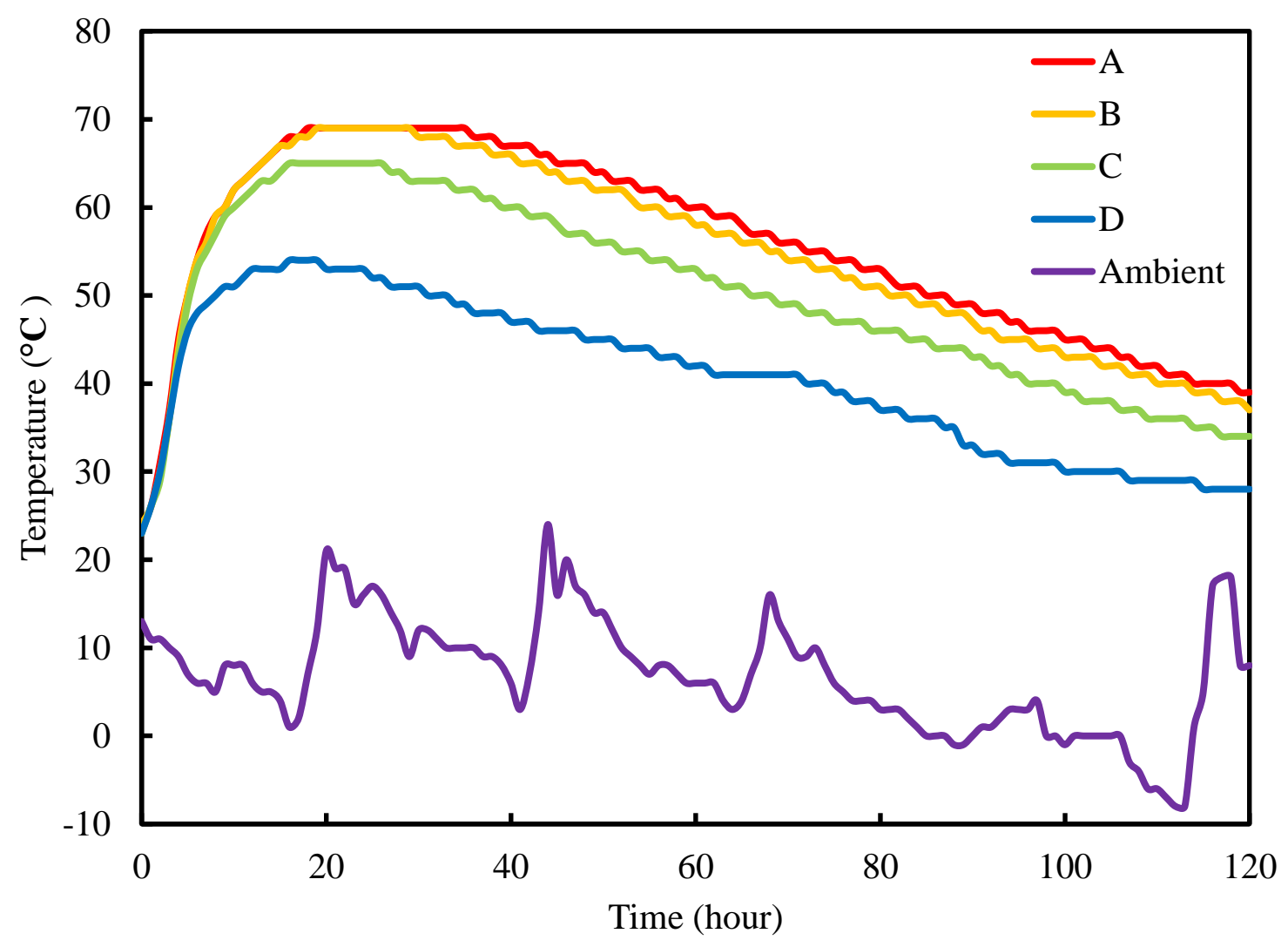

Figure 4-15: Temperature monitoring, District 6 cube 


\subsubsection{WVU Cube \#1 and \#2 (1.2 meter)}

On September 17 and October 15, 2013, two identical 1.2 meter cubes (WVU Cube \#1 and \#2) were constructed in front of the concrete material lab in Morgantown, West Virginia. The concrete mix design contains $335 \mathrm{~kg} / \mathrm{m}^{3}$ of OPC. The concrete mixture for WVU Cube \#1 was measured to have a $10 \mathrm{~cm}(4 \mathrm{in})$ slump, $6.5 \%$ air and $31{ }^{\circ} \mathrm{C}\left(88^{\circ} \mathrm{F}\right)$ initial temperature. For WVU Cube \#2, the concrete mixture was measured to have a $14 \mathrm{~cm}(5.5 \mathrm{in})$ slump, $7.4 \%$ air and $27{ }^{\circ} \mathrm{C}\left(81^{\circ} \mathrm{F}\right)$ initial temperature. The same steel formwork and support grid for temperature loggers were used for both Cube \#1 and \#2 (Figure 4-16). Figure 4-17 shows concrete casting of WVU Cube \#2. Figure 4-18 shows the finished WVU Cube \#1 and \#2. The monitored center, middle, side (Figure 4-16) and ambient temperature histories are shown in Figure 4-19 and Figure 4-20. Both Cube \#1 and 2 were cast on top of wood bases. Plastic covers were used to cover the top surfaces to prevent surface drying for both cubes while no protection was provided at the side surfaces.

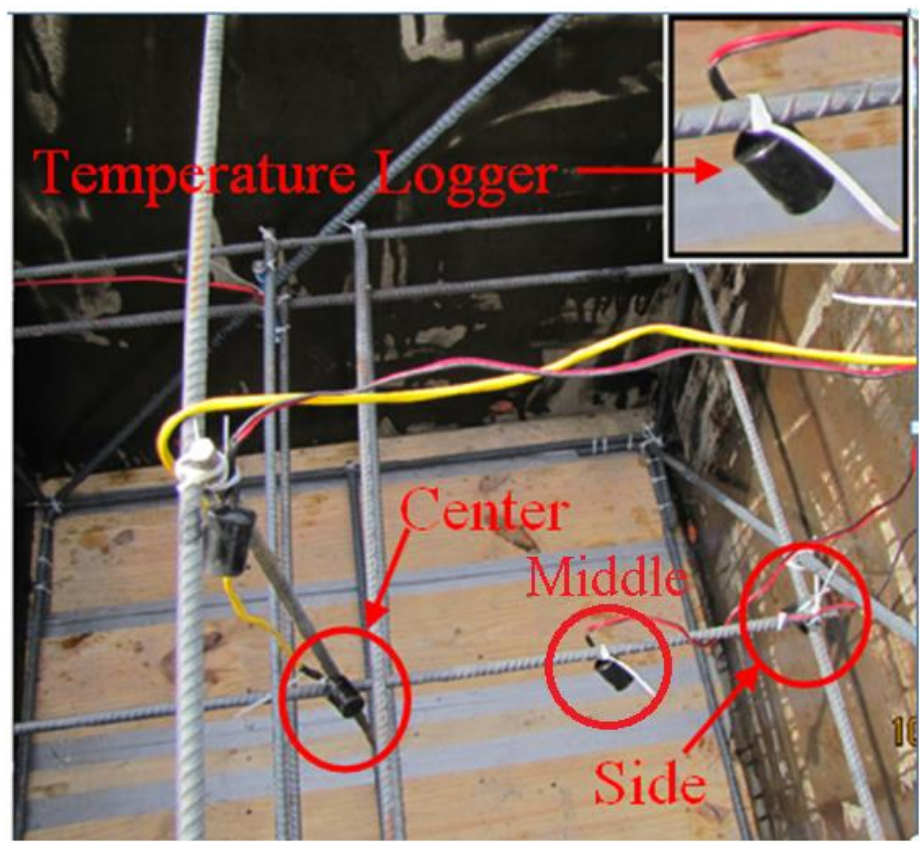

Figure 4-16: Support Grid of 1.2-meter cubes 


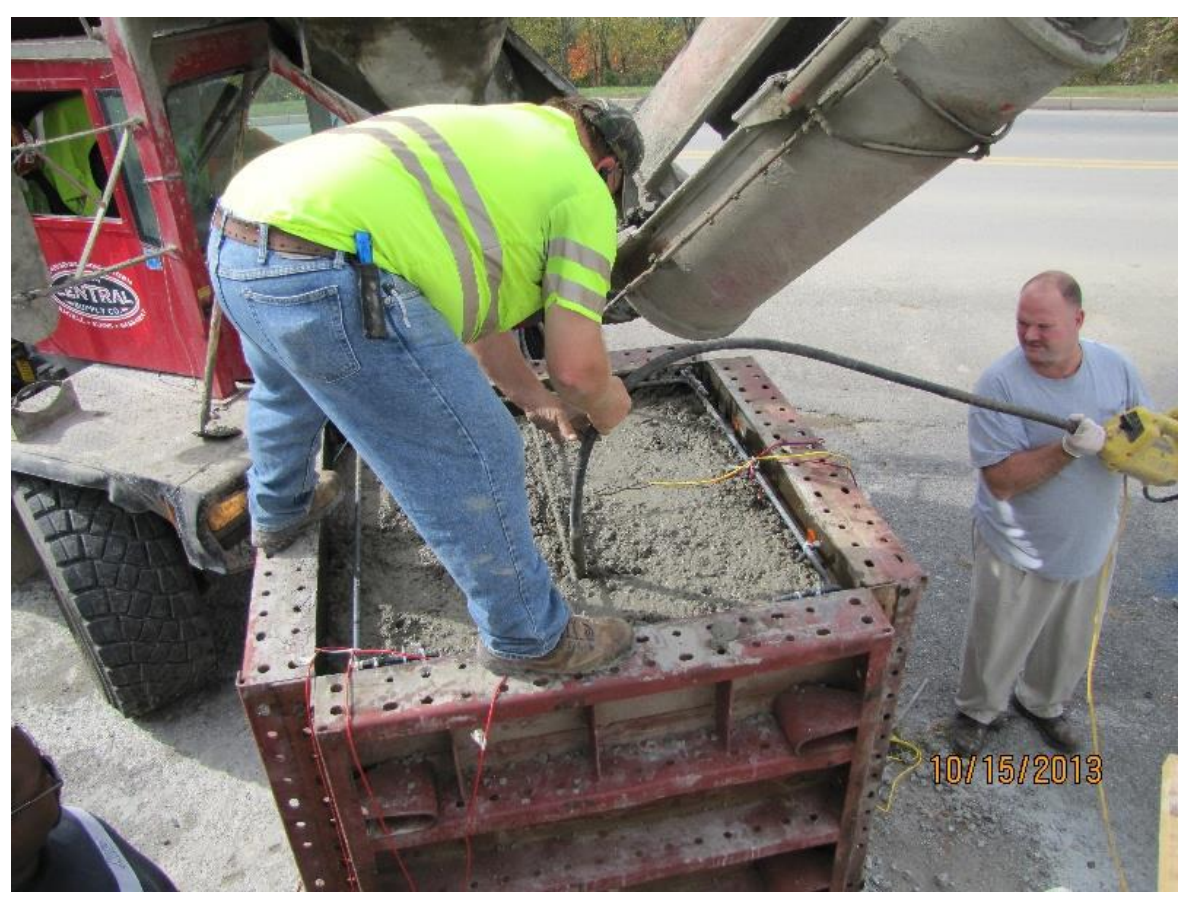

Figure 4-17: Casting of District 1.2-meter cubes

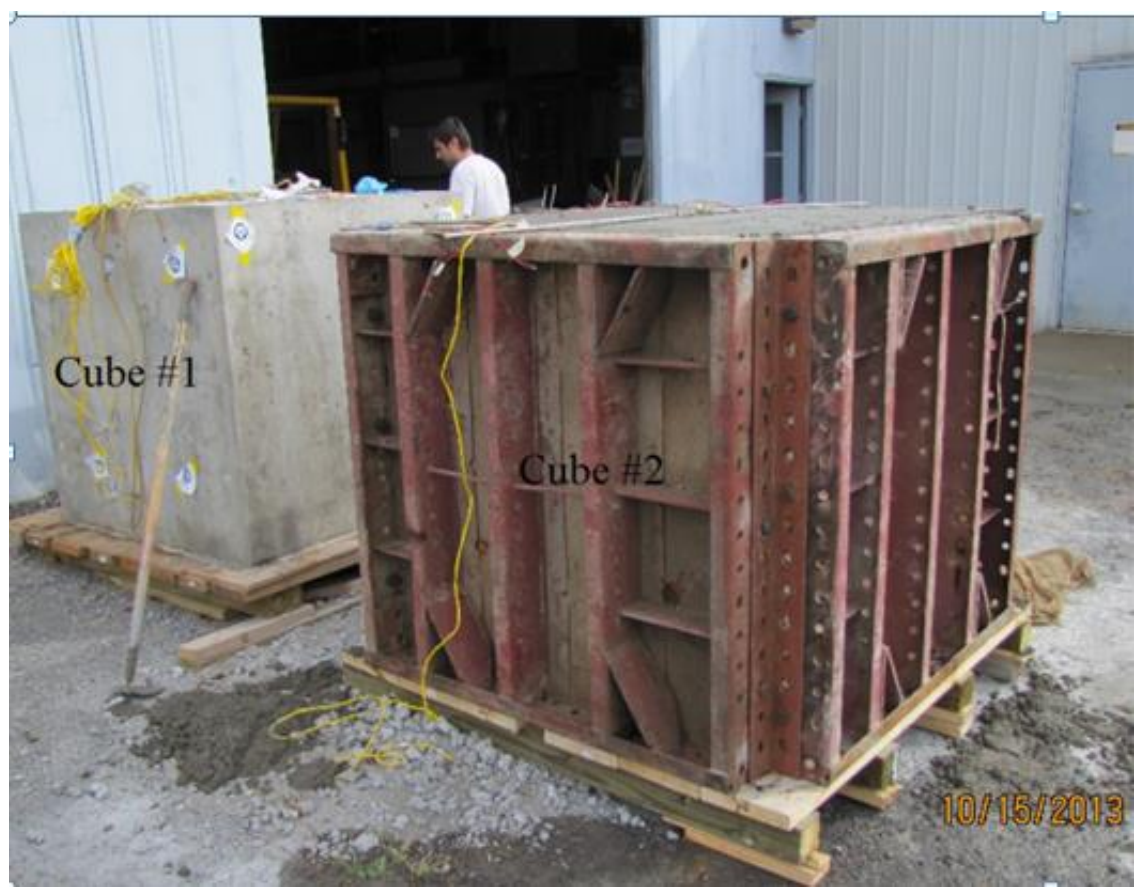

Figure 4-18: Finished WVU Cube \#1 and \#2 


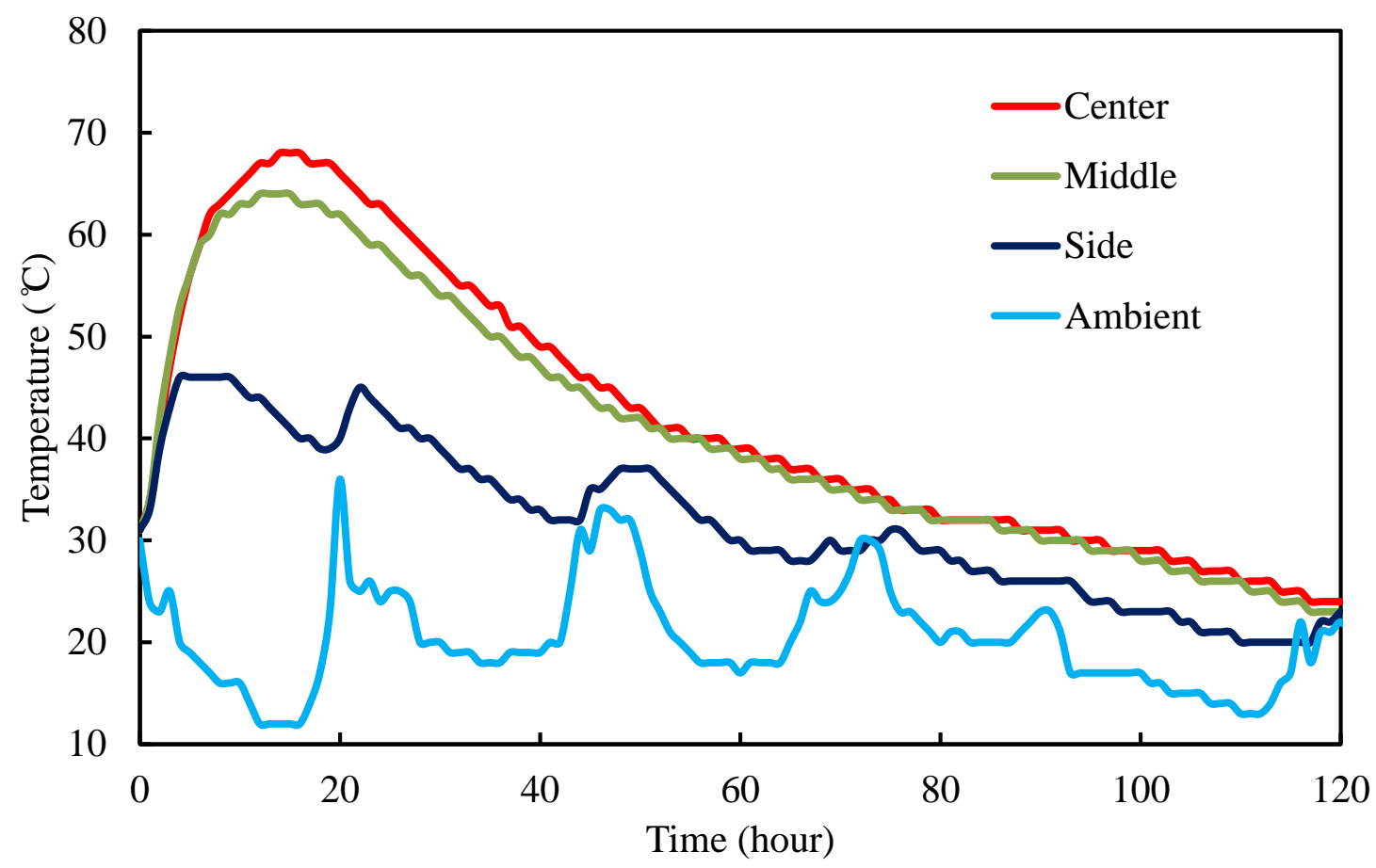

Figure 4-19: Temperature monitoring, WVU Cube\# 1

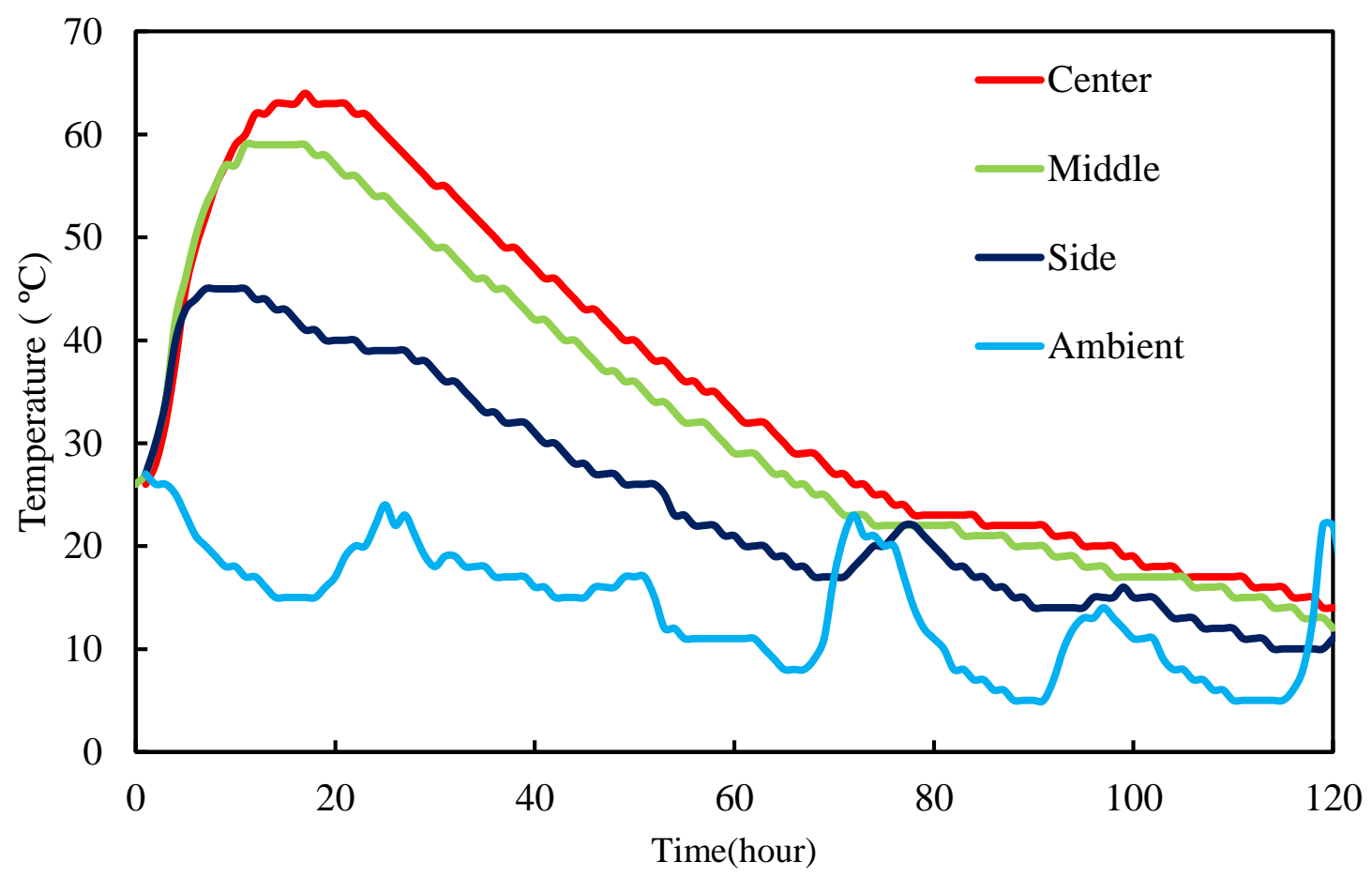

Figure 4-20: Temperature monitoring, WVU Cube\# 2 
The monitored temperature histories for both 1.2-meter cubes were analyzed. The monitored maximum center temperatures were $68^{\circ} \mathrm{C}$ at 15 hours for WVU Cube $\# 1$ and $64{ }^{\circ} \mathrm{C}$ at 16 hours for WVU Cube \#2. In comparison with the 1.8-meter cubes, the center maximum temperature was reached much earlier due to the reduction in size. The maximum temperature differentials were $27^{\circ} \mathrm{C}$ at 18 hours for WVU Cube \#1 and $23^{\circ} \mathrm{C}$ at 19 hours for WVU Cube \#2. Both Cube \#1 and \#2 has high temperature differentials (more than $20^{\circ} \mathrm{C}$ ), due to high cement content and low surface protections (steel formwork). Although WVU Cube \#1 and \#2 were the same, WVU Cube \#1 had a higher temperature differential due to the ambient temperature. The ambient temperature drop for WVU Cube \#1 were much larger during the first night after casting. It caused a lower concrete surface temperature and a higher temperature differential.

\subsubsection{WVU Cube \#3 (0.9 meter)}

A 0.9 -meter cube was constructed in WVU using the mix design from the Ices Ferry Bridge (Section 4.1, Table 4-1) in District 4 in West Virginia. Wooden formwork and based were used. The initial concrete temperature was $23{ }^{\circ} \mathrm{C}\left(73^{\circ} \mathrm{F}\right)$. The slump and air percentage were measured to be $13 \mathrm{~cm}(5 \mathrm{in})$ and $5.3 \%$ air.

Figure 4-21 shows the supporting grid of WVU Cube \#3. Figure 4-22 shows concrete casting of WVU Cube \#3. Figure 4-15 shows the 100 hour temperature records at the center, side locations and the ambient. Due the small size of this cube, the temperatures were well controlled for this 0.9 meter cube. The maximum center temperature was $55^{\circ} \mathrm{C}\left(131{ }^{\circ} \mathrm{F}\right)$ at 17 hours and the maximum temperature differential was $10^{\circ} \mathrm{C}\left(18^{\circ} \mathrm{F}\right)$ at 19 hours. Both maximum center temperature and temperature differential were much lower than the ACI limitations of $70{ }^{\circ} \mathrm{C}$ and $20{ }^{\circ} \mathrm{C}$. 


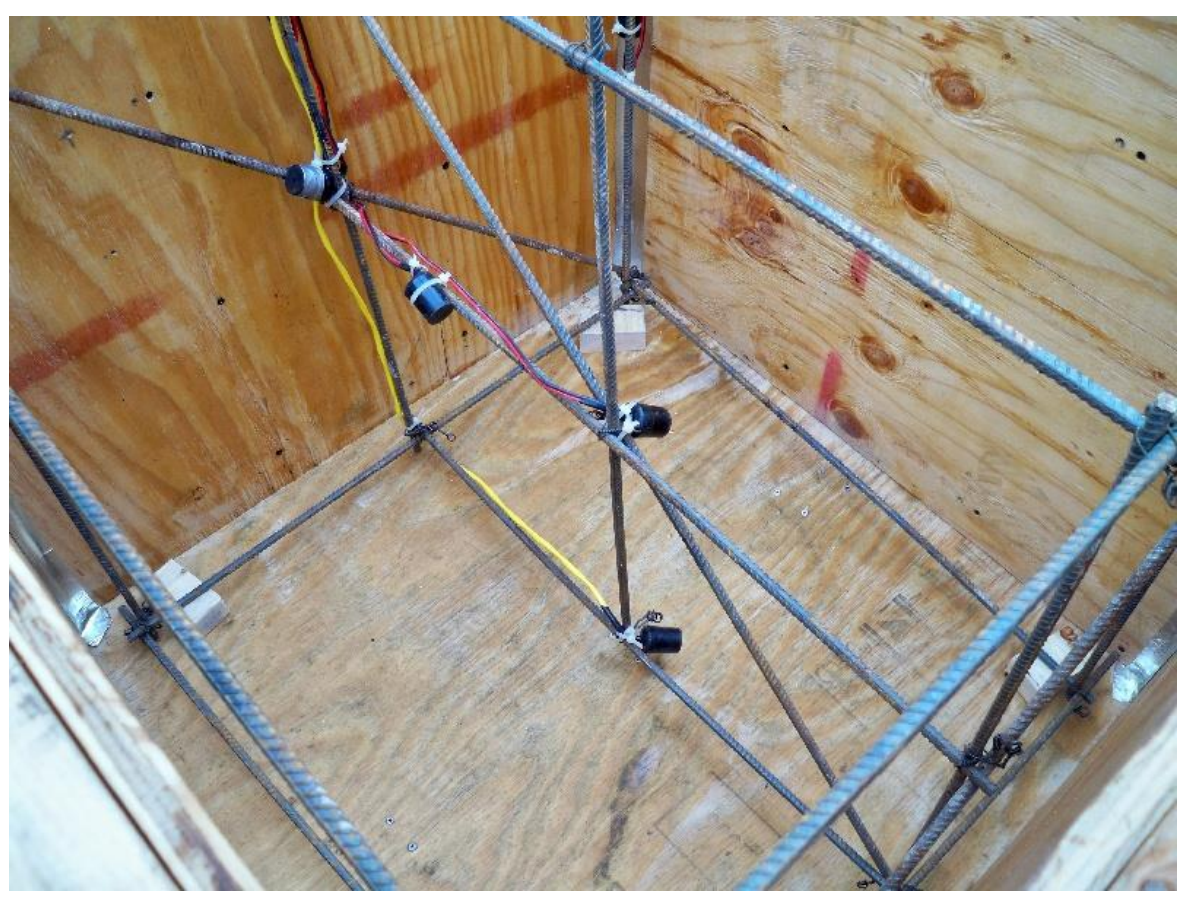

Figure 4-21: Support Grid of WVU Cube \#3 (0.9 meter)

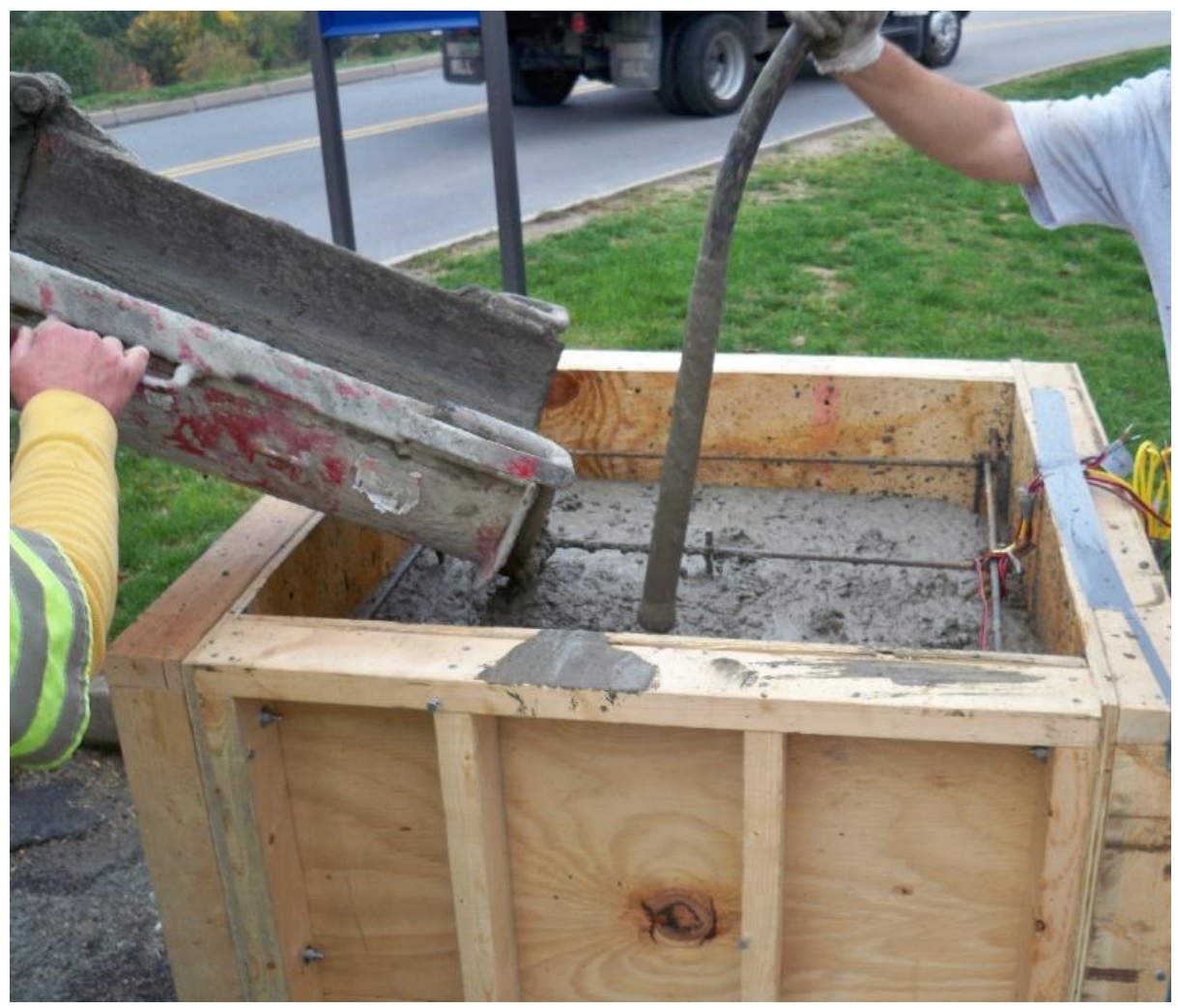

Figure 4-22: Casting of District of WVU Cube \#3 (0.9 meter) 


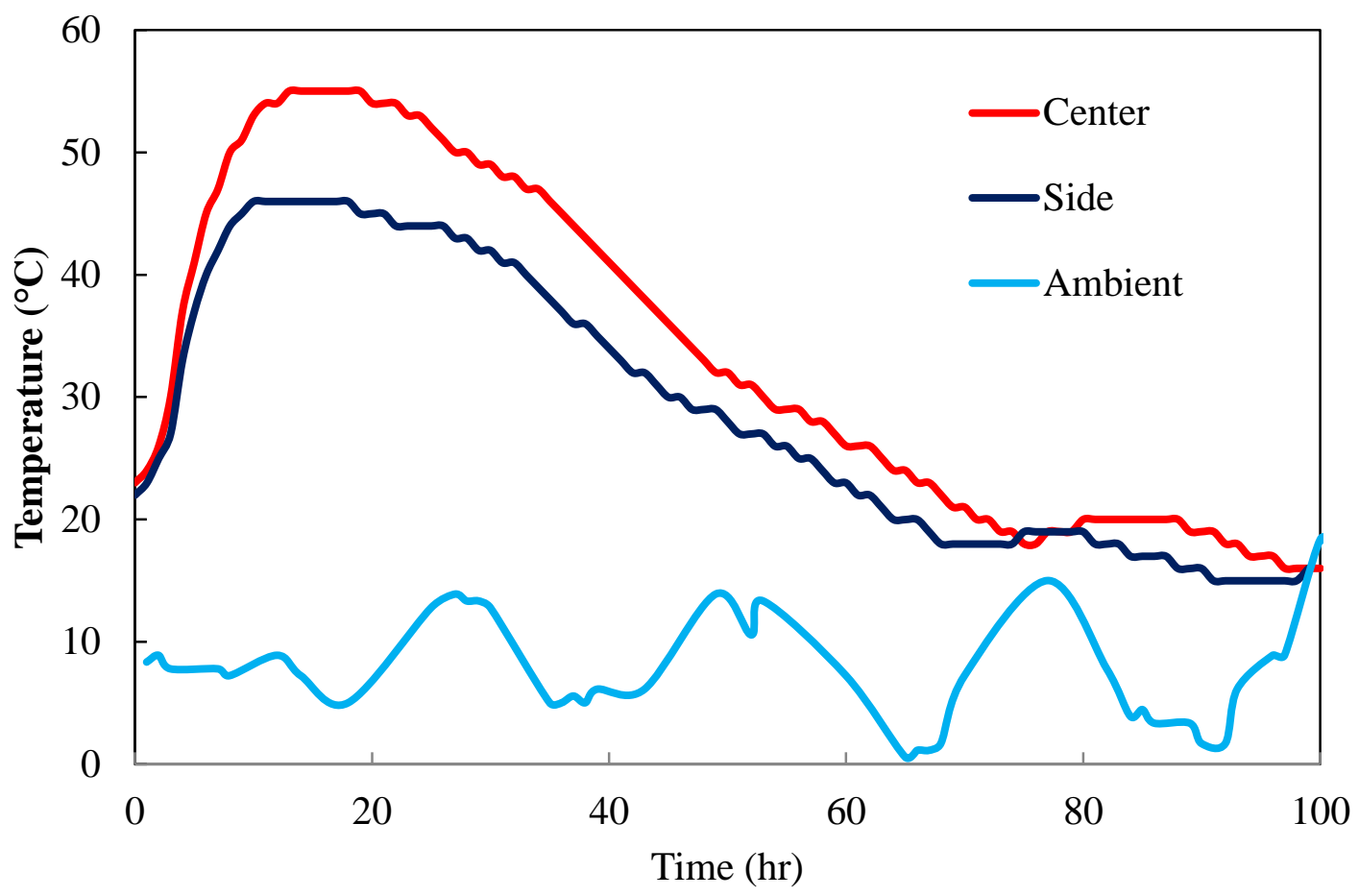

Figure 4-23: Temperature monitoring, WVU Cube \#3

\subsection{Discussions of the Temperature Monitoring Results}

From the temperature monitoring results, eleven out of fourteen real bridge elements violated the $20{ }^{\circ} \mathrm{C}$ maximum temperature differential limitation. It suggests that a very high percentage of concrete structures are in danger of having thermal cracking according to the temperature measurements. The temperature loggers for the fourteen bridge elements were installed by the construction workers without the presence of WVU researchers. Therefore, there may be errors in sensor positions. If the position surface temperature loggers were too deep (> than $5 \mathrm{~cm}$ ), the temperature differential could be under-measured. In the case of Pier-cap \#2 of the Ices Ferry Bridge, the original surface sensor location was found to be $30 \mathrm{~cm}$ in depth and later corrected to $5 \mathrm{~cm}$ by WVU researchers. The temperature loggers for all the concrete cubes were installed by WVU researchers and the locations were ensured to be correct. 
Mass concrete is typically defined by the dimension of the concrete member. However, the results from the seven concrete cubes in terms of temperature (Section 4.2) showed otherwise. The maximum center temperature of an early age concrete member is not only influenced by the size of the member. It is also influenced by initial concrete temperature $\left(\mathrm{T}_{\text {initial }}\right)$ and cementitious content $\left(\mathrm{C}_{\mathrm{C}}\right)$. In fact, despite being smaller in size, the average maximum center temperature of the two 1.2 -meter cubes $\left(66.0^{\circ} \mathrm{C}\right)$ were merely $1.3{ }^{\circ} \mathrm{C}$ lower than the average of the four 1.8 meter cubes $\left(67.3^{\circ} \mathrm{C}\right)$. Table $4-2$ shows the maximum center temperatures of the seven concrete cubes and the influencing factors ( $\mathrm{T}_{\text {initial, }}$, size, $\mathrm{C}_{\mathrm{C}}$ and $\left.\mathrm{T}_{\max }\right)$.

Table 4-2: Maximum center temperature $\left(\mathrm{T}_{\max }\right)$ and the influencing factors

\begin{tabular}{|l|c|c|c|c|c|c|c|}
\hline Cube & District 1 & District 9 & District 5 & District 6 & WVU \#1 & WVU \#2 & WVU \#3 \\
\hline Tinitial $\left({ }^{\circ} \mathrm{C}\right)$ & 29 & 29 & 27 & 24 & 31 & 27 & 23 \\
\hline Size (meter) & $1.8 \mathrm{~m}$ & $1.8 \mathrm{~m}$ & $1.8 \mathrm{~m}$ & $1.8 \mathrm{~m}$ & $1.2 \mathrm{~m}$ & $1.2 \mathrm{~m}$ & $0.9 \mathrm{~m}$ \\
\hline $\mathbf{C C}_{\mathbf{C}}\left(\mathrm{kg} / \mathrm{m}^{3}\right)$ & 323 & 335 & 335 & 390 & 335 & 335 & 379 \\
\hline $\mathbf{T}_{\max }\left({ }^{\circ} \mathrm{C}\right)$ & 63 & 74 & 65 & 69 & 68 & 64 & 55 \\
\hline
\end{tabular}

Maximum center temperature rise $\left(\mathrm{CTR}_{\max }=\mathrm{T}_{\max }-\mathrm{T}_{\text {initial }}\right)$ is the majorly influenced by the concrete hydration heat. Therefore, the cementitious content $\left(\mathrm{C}_{\mathrm{C}}\right)$ certainly has a large influence. Among the four 1.8 meter cubes, District 3 cube has the highest $C_{C}\left(390 \mathrm{~kg} / \mathrm{m}^{3}\right)$ and highest $\mathrm{CTR}_{\max }\left(45^{\circ} \mathrm{C}\right)$ while District 1 cube has the lowest $\mathrm{C}_{\mathrm{C}}\left(323 \mathrm{~kg} / \mathrm{m}^{3}\right)$ and lowest $\mathrm{CTR}_{\max }$ $\left(34{ }^{\circ} \mathrm{C}\right)$. Despite being in different ambient temperatures, the two 1.2-meter cubes have the same $\mathrm{C}_{\mathrm{C}}\left(335 \mathrm{~kg} / \mathrm{m}^{3}\right)$ and $\mathrm{CTR}_{\max }\left(37^{\circ} \mathrm{C}\right)$. 


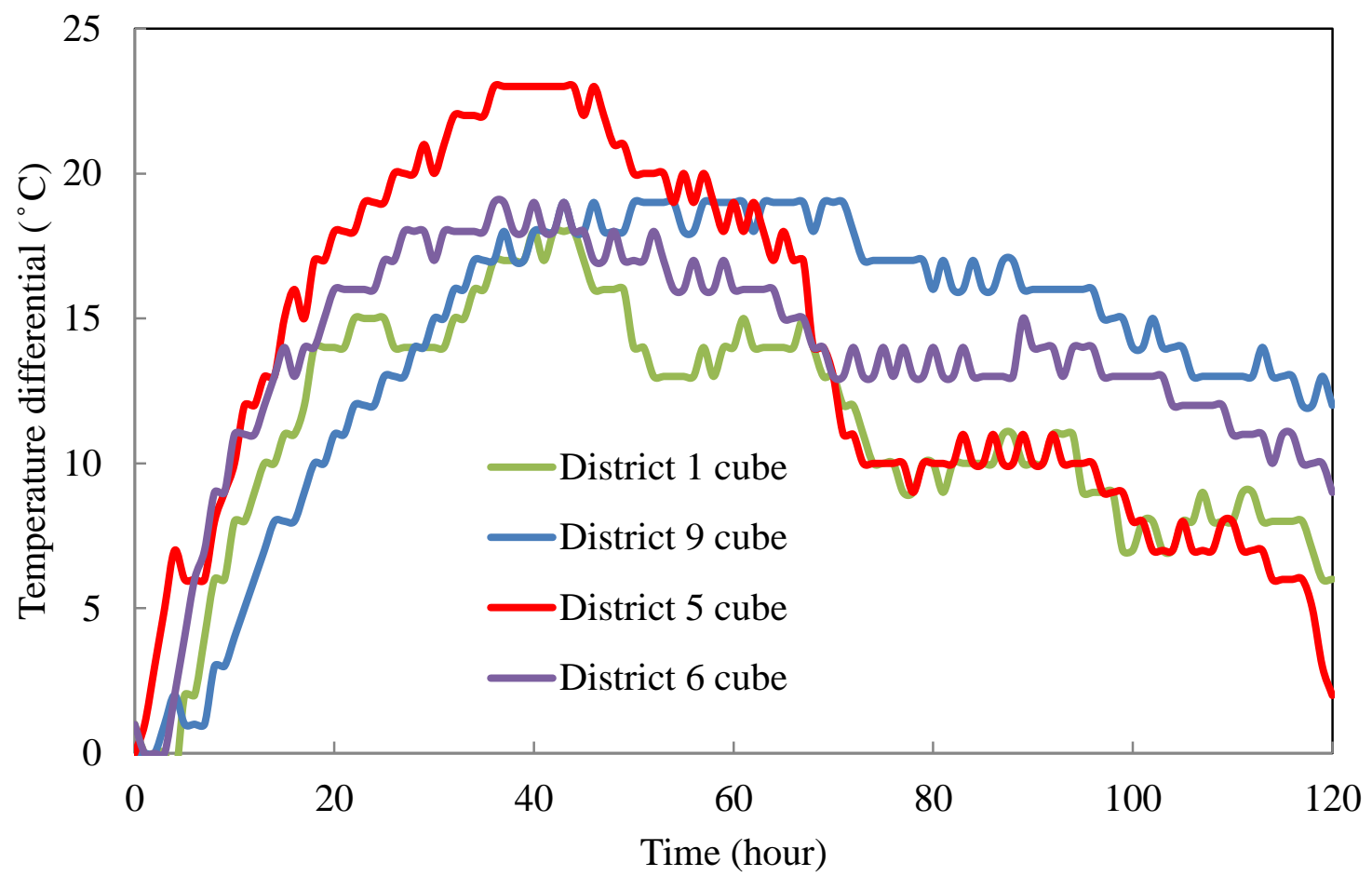

Figure 4-24: Temperature differential of the 1.8-meter cubes

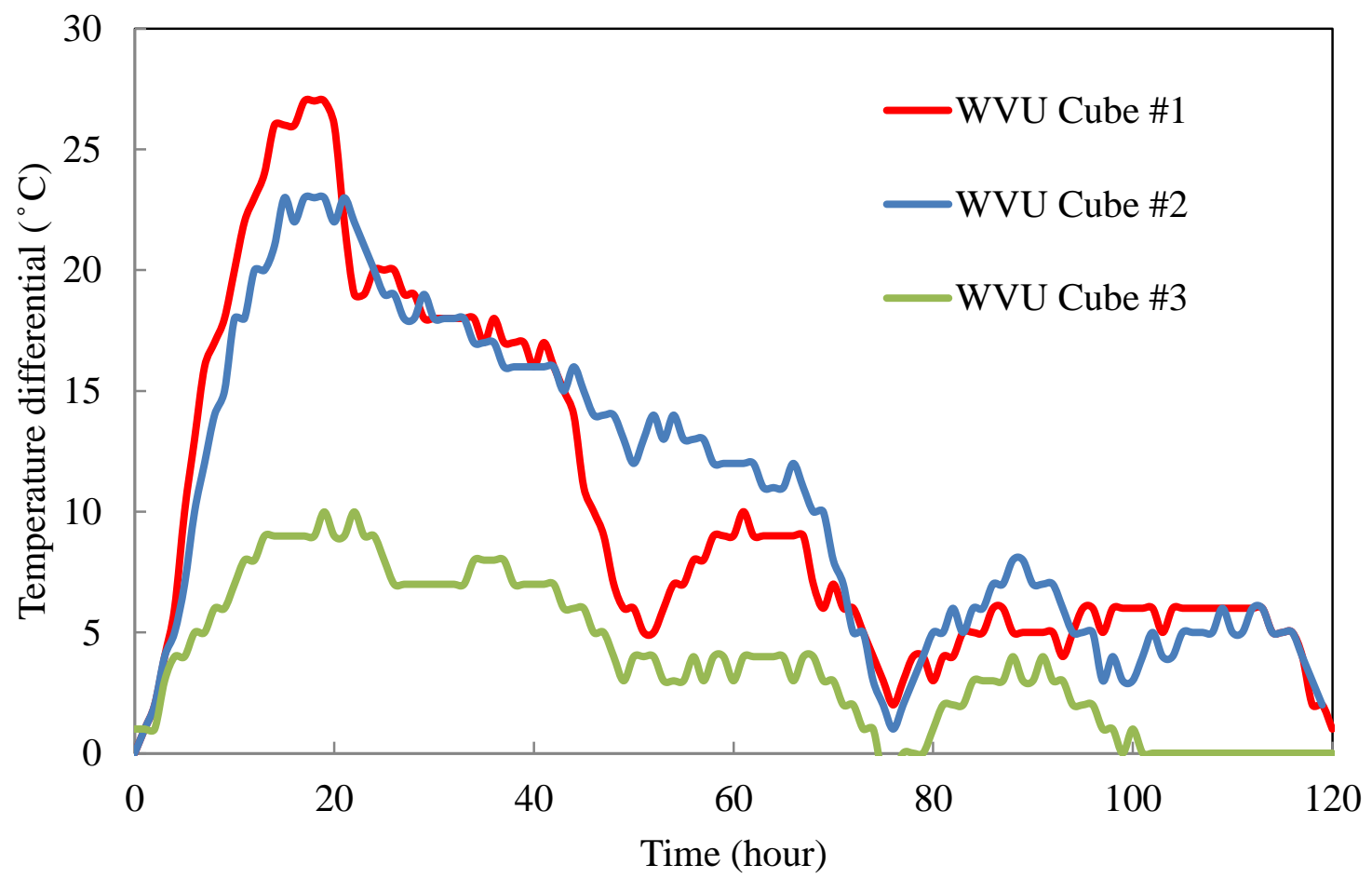

Figure 4-25: Temperature differential of the 1.2-meter and 0.9-meter cubes 
The maximum temperature differential $\left(\Delta \mathrm{T}_{\max }\right)$ of an early age concrete member is not only decided by the internal heat, but also by the thermal conductivity of concrete and the surface insulation. The type of formwork determines the surface insulation has a major influence on the surface insulation. Steel formwork and wood formwork are significantly different in terms of thermal resistance while wood formwork is much more effective. The temperature differentials from the experiments are shown in Figure 4-24 (1.8-meter cubes) and Figure 4-25 (1.2-meter and 0.9-meter cubes).

Among the four 1.8-meter cubes, District 5 cube had the highest $\Delta \mathrm{T}_{\max }$ of $23{ }^{\circ} \mathrm{C}$ using steel formwork. District 1, District 9 and District 6 cubes had lower $\Delta \mathrm{T}_{\max }\left(\leq 20^{\circ} \mathrm{C}\right)$ using wood formwork. Despite having a smaller size for the 1.2-meter cubes, WVU Cube \#1 and WVU Cube \#2 had relatively higher $\Delta \mathrm{T}_{\max }$ of $27{ }^{\circ} \mathrm{C}$ and $23{ }^{\circ} \mathrm{C}$ while both using steel formwork. Therefore, only being smaller in size does not mean to have less chance of having thermal cracking. The ambient temperature can also influence the value of $\Delta \mathrm{T}_{\max }$. The ambient temperature drop of WVU Cube \#1 in the night after the concrete placement was much larger than WVU Cube \#2. It was believed to be the major reason for WVU Cube \#1 to have a much larger $\Delta \mathrm{T}_{\max }$ than WVU Cube \#2. Later, thermal cracking was found on WVU Cube \#1 but not for WVU Cube \#2. More discussion can be found later in Chapter 6.

Therefore, mass concrete cannot be simply defined by size without considering other influencing factors. A more scientific approach is needed to evaluate the risk of thermal cracking. In Chapter 5 and Chapter 6, finite element models were created to predict the temperature and thermal stress for early age concrete members. A mass concrete definition table for the bridge pier-stem was developed using the modeling results (Chapter 7). 


\section{CHAPTER 5 THERMAL ANALYSIS}

\subsection{Introduction}

Quality control of early age concrete is important to ensure a desirable performance and durability throughout the service life. Preventing thermal cracking of an early age concrete structure is crucial to ensure its surface quality and long term durability. An accurate temperature profile history prediction is needed for the thermal stress prediction and to evaluate the cracking risk. Due to the complexity of non-uniform thermal loading from the heat of hydration as well as non-uniform temperature-dependent concrete material properties, it is very difficult to solve for the temperature profile history in a 3-D body using the traditional calculation method.

Numerical approaches such as finite element method (Bombich et al., 1991; Kishi and Maekawa, 1995; Kim et al., 2001; Waller et al., 2004) or finite difference method (Ballim, 2004) have been widely used for thermal analysis of early age concrete. Al-Manaseer and Elias (2008) created a finite element model using ABAQUS to simulate heat transfer process within early age concrete, however, constant concrete thermal properties and uniform thermal loading were assumed during hydration, and the external surface temperature was inaccurately assumed to be the same as the ambient temperature for simplification. On the other hand, Wu et al. (2011) created a heat transfer model for concrete using ANSYS with surface convection that could realistically model the surface heat loss to the surrounding environment. Lawrence et al. (2012) were able to evaluate bridge footings with wooden formwork using TNO Diana software; they considered changes in material properties and thermal loading function based on the degree of hydration of concrete while using a thermal convection model to account for the surface heat loss. 
It is apparent that when assuming temperature equality between the concrete formwork surface and the ambient temperature, a large error in predicting concrete surface temperature can occur, especially when metal formwork with a relatively high thermal conductivity is used. Therefore, a convection model is needed for the surface heat loss. Additionally, the interface between concrete and formwork can provide a significant amount of thermal resistance. To the authors' best knowledge, the thermal resistance of the interface between concrete and steel formwork is significant but is not currently well documented.

In this study, the steel-concrete interface conductance value was experimentally obtained. The combination of using an accurate interface conductance along with the thermal convection model for the formwork surfaces provides a more realistic description of the heat exchange process on the surfaces of the concrete. Also, an experimental procedure used to measure concrete's Adiabatic Temperature Rise (ATR) using an adiabatic calorimeter developed during this study is described. The measured concrete ATR is converted to a thermal loading function for finite element calculations. User-defined subroutine programs were developed to incorporate degree of hydration dependence on both material properties and thermal loading function for the analysis.

The governing equation for heat transfer within a 3-D solid is shown in Eq. (4.1), where $T, t, K_{c}, \rho, C_{p}$ and $q$ are temperature, time, thermal conductivity, density, specific heat and heat flux, respectively. In this chapter, all the related parameters for early age concrete are thoroughly discussed.

$$
\frac{\partial T}{\partial t}=\frac{K_{C}}{\rho c_{p}}\left(\frac{\partial^{2} T}{\partial x^{2}}+\frac{\partial^{2} T}{\partial y^{2}}+\frac{\partial^{2} T}{\partial z^{2}}\right)+\frac{q}{\rho c_{p}}
$$

The temperature history in concrete is difficult to calculate directly by simple heat transfer equations, mainly due to the complications of the combined effect of hydration not being 
homogeneous and the variation of concrete thermal properties. A finite element model using ABQUS is used to calculate the heat transfer process for the first 120 hours after the concrete casting. To account for the effects of both the age and temperature-history dependent material properties and the non-uniform hydration process, user-defined subroutines, "USDFLD" and "DFLUX" were coded and incorporated in the ABAQUS model.

\subsection{Hydration Heat and Thermal Loading Function}

Finite element models were created to predict the temperature profile histories for the concrete three 1.8-meter cubes constructed in District 1, District 5, District 6; two 1.2-meter and one 0.9 meter cubes constructed in WVU (Chapter 4). The heat of hydration is the cause of the internal temperature rise of concrete body. Determine the heat of hydration is the first and important step of the thermal analysis. The shape of the concrete adiabatic temperature rise (ATR) is the same with the cumulative heat generation over time. The magnitude of the total heat generation can be determined is depending on the chemical composition of the cementitious material. The adiabatic calorimeter developed in this study (Chapter 3) was used to determine the ATR for each mix design used in those concrete cubes.

\subsubsection{Mix designs, OPC chemical compositions and ATR results}

Six different mix designs were used in seven different cube constructions (see Section 4.2.1, 4.2.3, 4.2.4, 4.2.5 and 4.2.6). The ATR test for District 9 cube was inaccurate due to equipment failure. Therefore, District 9 cube was not analyzed using finite element method in this study. The mix design number for the rest of six cubes are shown in Table 5-1. The mix designs are shown in Table 5-2. The chemical compositions of the OPC used in each mix design are shown in Table 5-3. The chemical compositions of the cement in Mix 4 were tested by West Virginia Department of Transportation while the rest were from various mill reports provided by 
ready mix companies. The $\mathrm{CaO}$ content in free form (not shown in mill report) was commonly assumed to be $2 \%$. The total hydration energy from the OPC $\left(\mathrm{H}_{\mathrm{cem}}\right)$ can be calculated using the chemical percentages from Table 5-3 using Eq. (2.2). For the mix designs with slag or fly ash (Mix 1, Mix 2 and Mix 5), Eq. 2.7 can be used to calculate the total heat $\left(\mathrm{H}_{\mathrm{u}}\right)$.

Table 5-1:The mix design number for the six concrete cubes

\begin{tabular}{|c|c|c|c|c|c|}
\hline District 1 cube & District 5 cube & District 6 cube & WVU Cube \#1 & WVU Cube \#2 & WVU Cube \#3 \\
\hline Mix 1 & Mix 2 & Mix 3 & Mix 4 & Mix 4 & Mix 5 \\
\hline
\end{tabular}

Table 5-2:Mix designs $\left(\mathrm{kg} / \mathrm{m}^{3}\right)$

\begin{tabular}{|c|c|c|c|c|c|}
\hline Component & Mix 1 & Mix 2 & Mix 3 & Mix 4 & Mix 5 \\
\hline Cement & 279 & 251 & 390 & 335 & 335 \\
\hline Fly ash & 44 & 0 & 0 & 0 & 44 \\
\hline Slag & 0 & 84 & 0 & 0 & 0 \\
\hline Water & 145 & 167 & 153 & 139 & 142 \\
\hline Agg. & 1098 & 1077 & 1038 & 969 & 1032 \\
\hline Sand & 748 & 716 & 659 & 844 & 736 \\
\hline Total & 2314 & 2295 & 2241 & 2287 & 2289 \\
\hline
\end{tabular}

The adiabatic temperature rises of five different mix designs (Table 5-2) were tested using the adiabatic calorimeter developed in this study. The design of the adiabatic calorimeter and sample preparations were discussed in Chapter 3. Figure 5-1 shows the ATR results of all five mix designs. All the starting temperatures were moved to $0{ }^{\circ} \mathrm{C}$ for comparison purposes. The actual initial temperature of the concrete sample for ATR test were between $22{ }^{\circ} \mathrm{C}$ and $25^{\circ} \mathrm{C}$. 
Among the five different concrete mixtures, Mix 3 contained the highest cement content has the highest total ATR of approximately $55^{\circ} \mathrm{C}$. Mix 3 and 4 contained high cement content but no mineral cement replacement exhibited high reaction rate. Mix 5 contained high cement content and $44 \mathrm{~kg} / \mathrm{m}^{3}$ of fly ash also exhibited relatively high reaction rate. Mix 2 exhibited slow reaction rate due to the high percentage of slag.

Table 5-3: Chemical compositions of each mix design

\begin{tabular}{|c|c|c|c|c|c|c|c|}
\hline Cement & Mix design\# & $\mathrm{C}_{3} \mathrm{~S}, \%$ & $\mathrm{C}_{2} \mathrm{~S}, \%$ & $\mathrm{C}_{3} \mathrm{~A}, \%$ & $\mathrm{C}_{4} \mathrm{AF}, \%$ & $\mathrm{MgO}, \%$ & $\mathrm{SO}_{3}, \%$ \\
\hline Mix 1 & Mix 1 & 50.4 & 21.2 & 6.9 & 9.4 & 2.6 & 3.0 \\
\hline Mix 2 & Mix 2 & 51.3 & 16.5 & 7.1 & 10.1 & 3.9 & 3.2 \\
\hline Mix 3 & Mix 3 & 60.0 & 14.0 & 6.0 & 10.4 & 2.6 & 3.2 \\
\hline Mix 4 & Mix 4 & 54.7 & 16.7 & 7.5 & 9.4 & 2.5 & 3.0 \\
\hline Mix 5 & Mix 5 & 60.1 & 13.4 & 6.1 & 10.0 & 2.6 & 3.2 \\
\hline
\end{tabular}

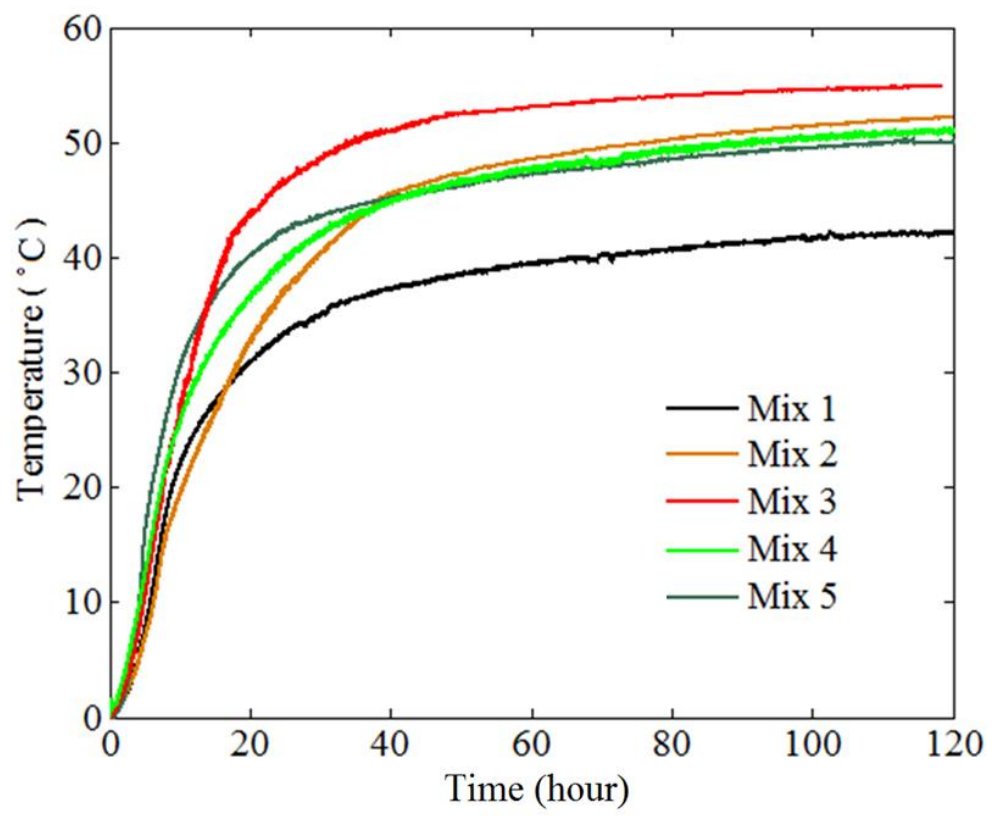

Figure 5-1: ATR results for all five mix designs 


\subsubsection{Thermal loading function}

The heat transfer in concrete starts from the thermal energy released during the cement hydration process. The rate of heat of hydration not only depends on the concrete mixture itself, but also on the concrete temperature histories. The thermal loading can vary between two identical concrete structures cast in two different temperature environments. The heat generation rate can also vary within a concrete member due to non-uniform internal temperature distributions. The degree of hydration and the maturity method were utilized (Section 2.4.3 and 2.4.4). In order to mathematically characterize a non-uniform heat generation, the degree of hydration function in terms of equivalent age (Eq. (2.14)) is used. In Eq. (2.14), the equivalent age $\left(t_{e}\right)$ and the ultimate degree of hydration $\left(\alpha_{\mathrm{u}}\right)$ can be calculated using Eq. (2.16) and Eq. (2.13). A significant increase in the ultimate degree of hydration can be found when fly ash or slag is added to the mix design using Eq. (5.1). Eq. (5.1) is an improved version of Eq. (2.13) when considering the presence of fly ash and slag according to Schindler and Folliard (2005). The hydration parameters $(\tau$ and $\beta$ ) control the shape of the degree of hydration curve, and $\tau, \beta$ can be determined by a curve fitting method using the adiabatic temperature rise curve after converting the time axis to the equivalent age $\left(t_{e}\right)$. The curve fitting and the best-fit $\tau$ and $\beta$ values are shown in Figure 5-2. The activation energy $\left(E_{a}\right)$ of the current concrete mix design was tested by Yikici and Chen (2013) following ASTM C 1074. The total hydration energy per kilogram in Portland cement $\left(\mathrm{H}_{\mathrm{u}}\right)$ can be calculated using Bogue's calculation (ASTM C 150) based on the chemical compostions (Table 5-3) and the percentage of other mineral admixture using Eq. (2.2) and Eq. (2.7). The total hydration energy per unit volume $\left(\mathrm{Q}_{c}\right)$ is the product of $\mathrm{Hu}$ and the mass of cement per unit volume (Table 5-2). Table 5-4 lists the resultofelated to heat of hydration properties for the concrete mixture used in this study. 
Table 5-4:Heat Properties for the five mix designs

\begin{tabular}{|c|c|c|c|c|c|c|}
\hline Mix design & Cube & $\boldsymbol{\tau}$ & $\boldsymbol{\beta}$ & $\mathbf{E}_{\mathbf{a}}(\mathbf{J} / \mathbf{m o l})$ & $\boldsymbol{\alpha}_{\mathbf{u}}(\boldsymbol{\%})$ & $\mathbf{Q}_{\mathbf{c}}\left(\mathbf{J} / \mathbf{m}^{\mathbf{3}}\right)$ \\
\hline Mix 1 & District 1 cube & 15.0 & 0.83 & 44,159 & 0.79 & $1.280 \times 10^{8}$ \\
\hline Mix 2 & District 5 cube & 22.5 & 0.87 & 42,220 & 0.74 & $1.644 \times 10^{8}$ \\
\hline Mix 3 & District 6 cube & 12.0 & 0.92 & 41,841 & 0.69 & $1.905 \times 10^{8}$ \\
\hline Mix 4 & WVU Cube \#1 \& \#2 & 14.0 & 0.94 & 41,841 & 0.70 & $1.672 \times 10^{8}$ \\
\hline Mix 5 & WVU Cube \#3 & 7.8 & 0.95 & 38,317 & 0.74 & $1.613 \times 10^{8}$ \\
\hline
\end{tabular}

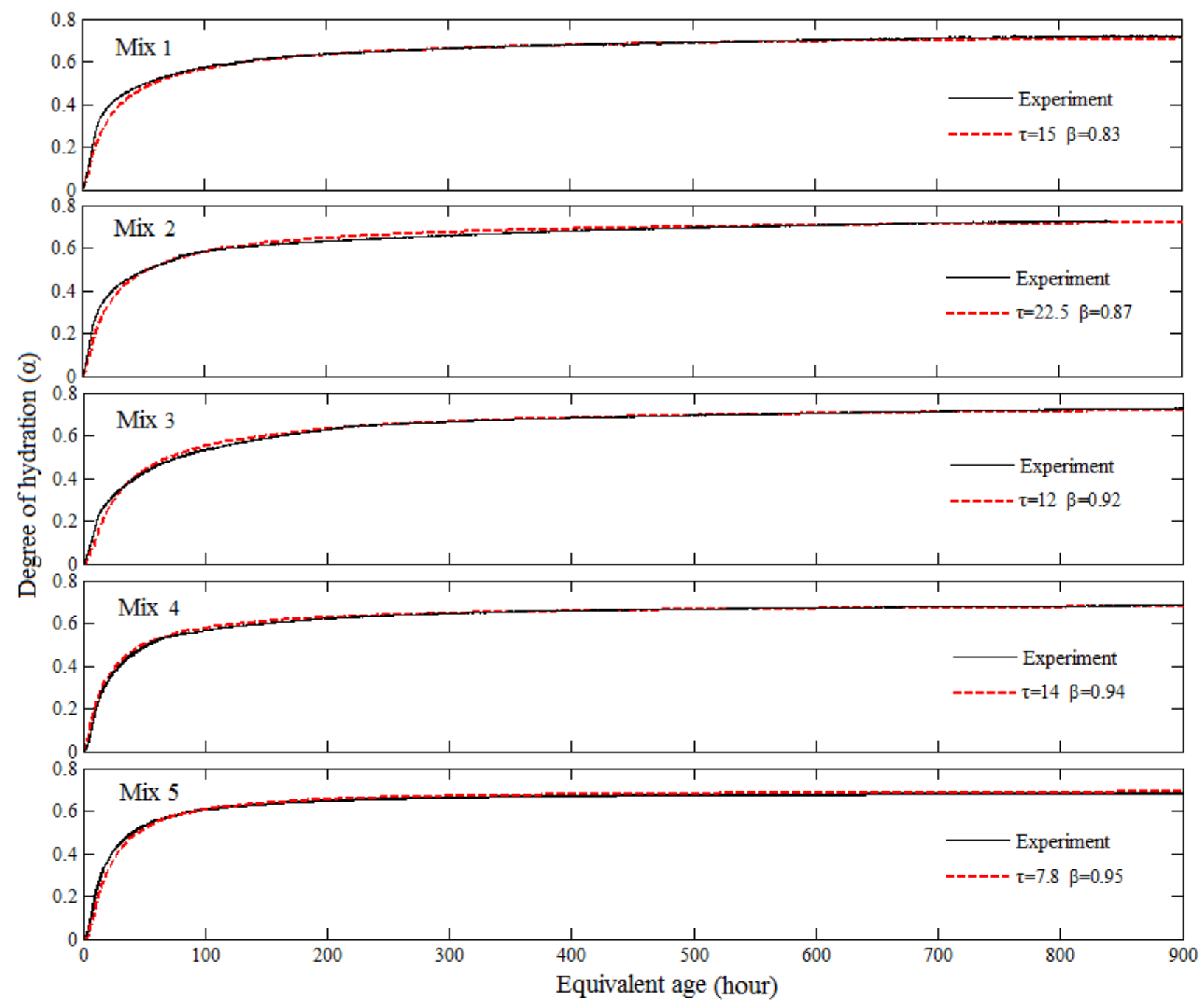

Figure 5-2: Best-fit hydration parameters 
$\alpha_{u}=\frac{1.031 \cdot w / c}{0.194+w / c}+0.5 P_{F A}+0.3 P_{\text {Slag }}$

At any given equivalent age of a unit volume of concrete, the total released heat, $Q\left(t_{e}\right)$ should be equal to the product of the total available heat $\left(Q_{c}\right)$ and the current degree of hydration, $\alpha\left(t_{e}\right)$ (Eq. (5.2)). The heat generation rate per unit volume of concrete, heat flux, $q\left(t_{e}\right)$ is the first derivative of $Q\left(t_{e}\right)$ (Eq. (5.3)). Figure 5-3 shows the cumulative heat curve in Joules per cubic meter of concrete (Eq. (5.2)) in blue line and the heat generation rate per unit volume in terms of Watts per cubic meter of concrete (Eq. (5.3)) in dotted red line for Mix 1 from Table 5-2.

$$
\begin{aligned}
& Q\left(t_{e}\right)=Q_{c} \cdot\left[\alpha\left(t_{e}\right)\right] \\
& q\left(t_{e}\right)=\frac{d Q}{d t_{e}}=Q_{c} \cdot \alpha\left(t_{e}\right) \cdot\left(\frac{\tau}{t_{e}}\right)^{\beta} \cdot \frac{\beta}{t_{e}}
\end{aligned}
$$

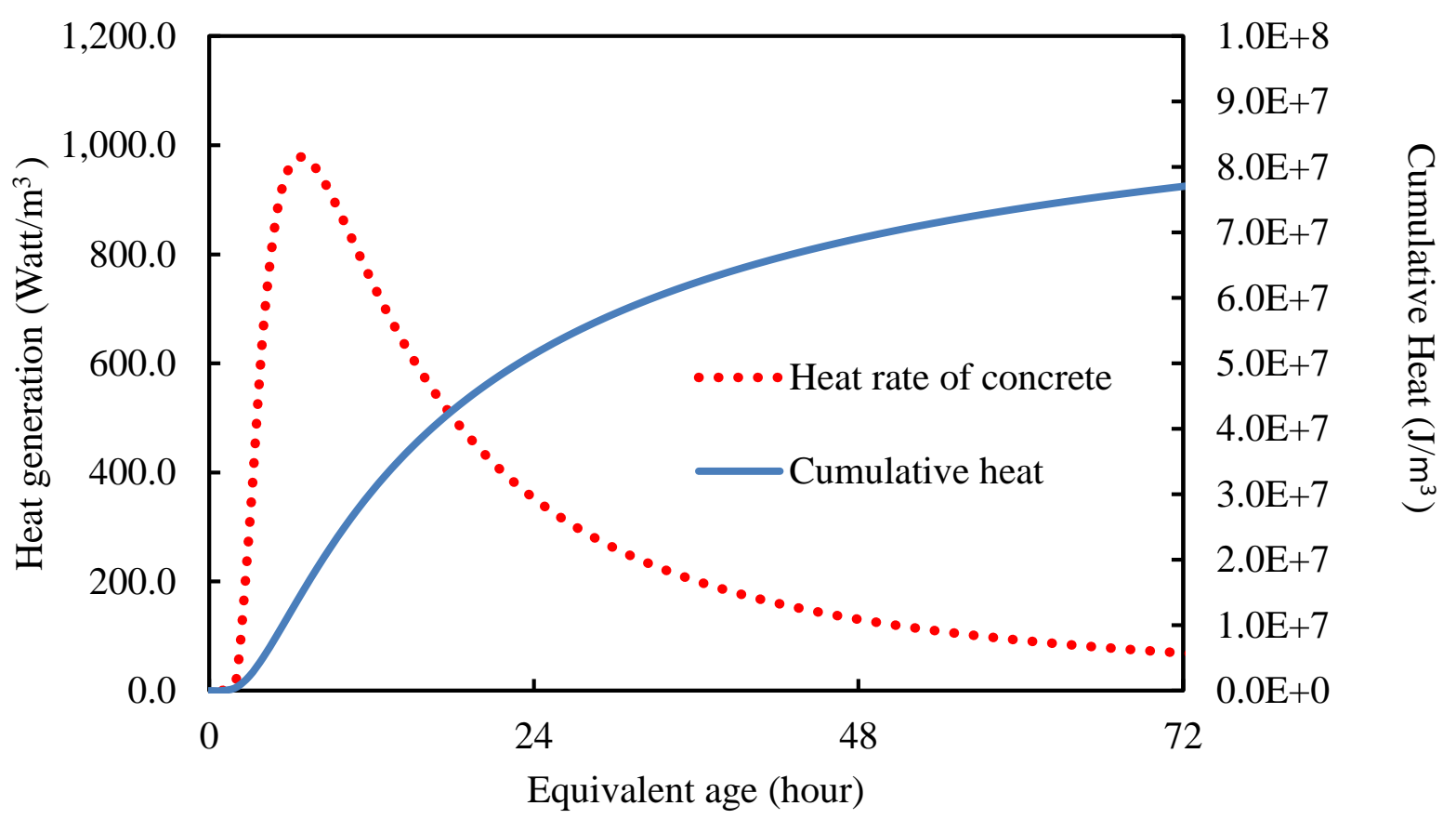

Figure 5-3: Heat generation rate and cumulative heat of Mix 1 concrete 
The $Q\left(t_{e}\right)$ and $q\left(t_{e}\right)$ curves were generated for all five mix designs (Table 5-2). Figure 5-4 shows the comparison of the cumulative heat, $Q\left(t_{e}\right)$. After combining the results from the ATR shape (Figure 5-2) and total available heat $\left(Q_{c}\right.$, Table 5-4) from the cement chemical compositions, the presentation of total cumulative heat curves (Figure 5-4) should be more accurate than obtaining them directly from the ATR results (Figure 5-1). It is because the maximum temperature measured in ATR test might not be as accurate as the calculations in ASTM C 1074. In addition, calculating heat energy from temperature measurements require the specific heat of the concrete sample which is different for each mix design which is difficult to measure. Mix 3 (used in District 6 cube) has the highest cumulative heat because it has the highest cement content while no OPC was substituted with other mineral additives. Mix 1 has the lowest cumulative heat because it has the lowest cement content while $14 \%$ of them was substituted with fly ash.

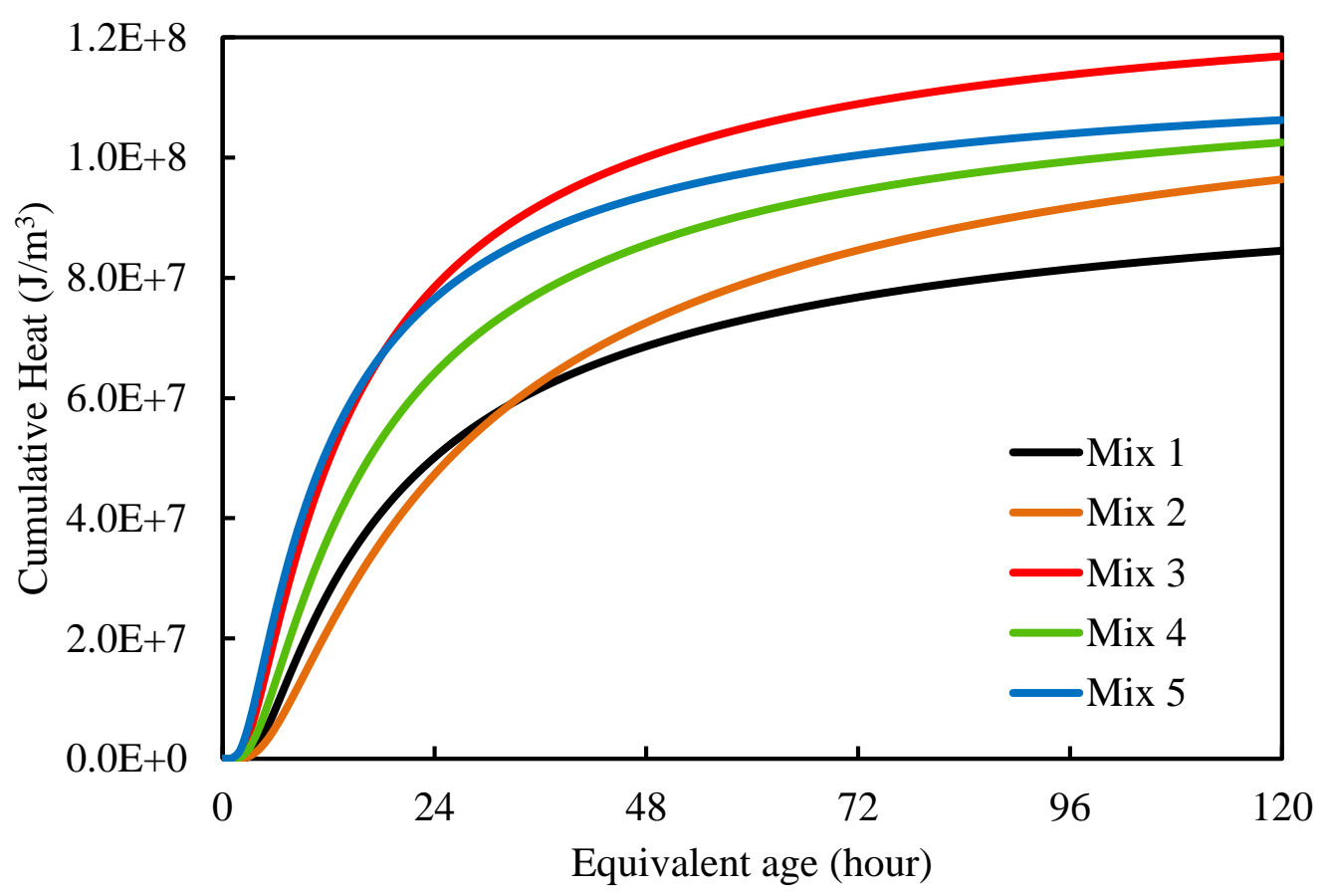

Figure 5-4: Comparison of cumulative heat for all five mix designs 
Figure 5-5 shows the comparison of heat generation rate per unit volume of concrete, $q\left(t_{e}\right)$ for all five mix designs. Mix 3 has the highest maximum heat generation rate due to its highest cement content. Mix 2 (used in District 5 cube) has the lowest maximum heat generation rate, but the rate is longer lasting than other mix designs due to the usage of $25 \%$ slag replacement for OPC.

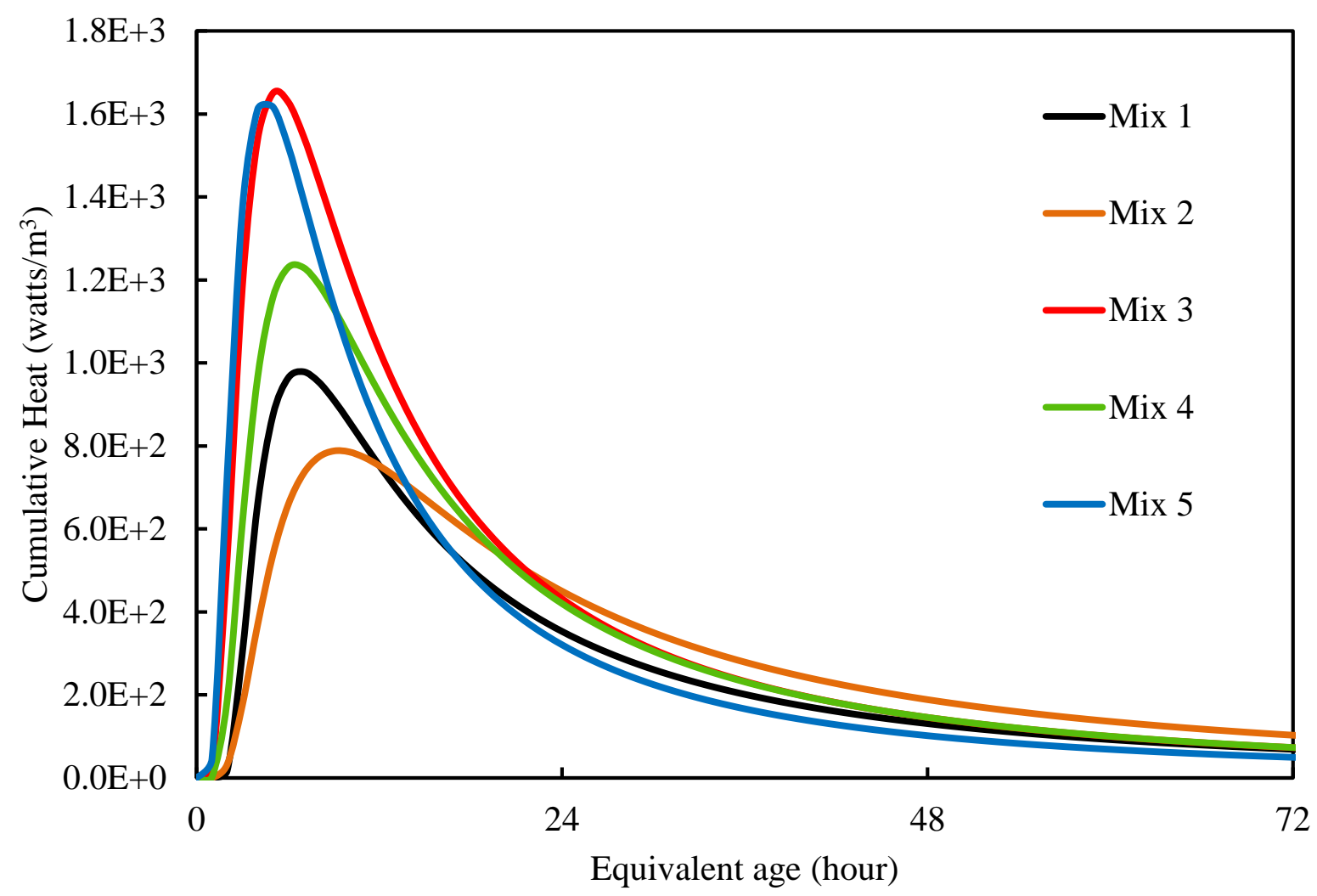

Figure 5-5: Comparison of heat generation rate for all five mix designs

Finite element models typically require a thermal loading function with respect to real time. To change the equivalent age $\left(\mathrm{t}_{\mathrm{e}}\right)$ to the real time $(\mathrm{t})$, $\mathrm{q}(\mathrm{t})$ equation can be derived using Eq. (5.3) and Eq. (5.4). The derived $q(t)$ represents the heat generation rate per unit volume which is often referred as heat flux (Watts $/ \mathrm{m}^{3}$ ). Besides the mix design, the thermal loading function (Eq. 
(5.5) is depending on the temperature histories, while the temperatures are the solutions of the thermal analysis. The thermal loading function needs to be related to the calculated temperature solutions. Therefore, step by step calculations are needed for solution dependent loading function.

$$
\begin{aligned}
& \frac{d Q}{d t}=\frac{d Q}{d t_{e}} \cdot \frac{d t_{e}}{d t}=q(t) \\
& q(t)=Q_{c} \cdot \alpha\left(t_{e}\right) \cdot\left(\frac{\tau}{t_{e}}\right)^{\beta} \cdot \frac{\beta}{t_{e}} \cdot \exp \left(\frac{E_{a}}{R}\left(\frac{1}{T_{r}}-\frac{1}{T_{c}(t)}\right)\right)
\end{aligned}
$$

\subsection{Thermal Properties}

At early ages, concrete material properties and thermal properties are constantly changing during hydration. Van Breugel (1998) proposed a model for the thermal properties for early age concrete shown in Eq. (5.6); Specific heat, $\mathrm{C}_{\mathrm{p}}$ of concrete is dependent on concrete mix proportions, degree of hydration and concrete temperature. Van Breugel (1998) also reported a $30 \%$ decrease of the thermal conductivity, $\mathrm{K}_{\mathrm{c}}$, throughout the entire hydration process; hence, Eq. (5.7) is used to describe the relationship between the concrete thermal conductivity and the degree of hydration. For the current material, the specific heat values for cement, sand, coarse aggregates and water $\left(\mathrm{C}_{\mathrm{cem}}, \mathrm{C}_{\mathrm{s}}, \mathrm{C}_{\mathrm{a}}\right.$ and $\left.\mathrm{C}_{\mathrm{w}}\right)$ are given as $740,710,840$ and 4,184 J/kg/K, respectively. A common thermal conductivity, $\mathrm{K}_{\mathrm{uc}}$, of hardened limestone concrete was assumed for Mix 1, Mix 2, Mix 3 and Mix 5. The assumed $\mathrm{K}_{\mathrm{uc}}$ value was $2.1 \mathrm{~W} / \mathrm{m} / \mathrm{K}$. For Mix 4, a thermal conductivity of $1.87 \mathrm{~W} / \mathrm{m} / \mathrm{K}$ was determined from CRD-C thermal diffusivity test.

$$
C_{p}\left(\alpha_{r}, T(t)\right)=\frac{1}{\rho}\left(W_{c} \alpha_{r} C_{c e f}+W_{c}\left(1-\alpha_{r}\right) C_{c e m}+W_{a} C_{a}+W_{w} C_{w}\right)
$$


$K_{c}\left(\alpha_{r}\right)=K_{u c}\left(1.33-0.33 \alpha_{r}(t)\right)$

where $\alpha_{\mathrm{r}}=\alpha / \alpha_{\mathrm{u}}$

$\rho:$ the concrete mass per unit volume $\left(\mathrm{kg} / \mathrm{m}^{3}\right)$

$\mathrm{W}_{\mathrm{c}}$ : the mass of cement per unit volume $\left(\mathrm{kg} / \mathrm{m}^{3}\right)$

$\mathrm{W}_{\mathrm{a}}$ : the mass of aggregate per unit volume $\left(\mathrm{kg} / \mathrm{m}^{3}\right)$

$\mathrm{W}_{\mathrm{W}}$ : the mass of water per unit volume $\left(\mathrm{kg} / \mathrm{m}^{3}\right)$

$\mathrm{C}_{\text {cem }}$ : the cement specific heat $(\mathrm{J} / \mathrm{kg} / \mathrm{K})$

$\mathrm{C}_{\mathrm{a}}$ : the aggregate specific heat $(\mathrm{J} / \mathrm{kg} / \mathrm{K})$

$\mathrm{C}_{\mathrm{w}}$ : the water specific heat $(\mathrm{J} / \mathrm{kg} / \mathrm{K})$

$\mathrm{C}_{\text {ceff }}$ : a fictitious specific heat of the hydrating cement $(\mathrm{J} / \mathrm{kg} / \mathrm{K})$

$\mathrm{C}_{\text {cef }}=8.4 \mathrm{~T}_{\mathrm{c}}(\mathrm{t})+339$

$\mathrm{T}(\mathrm{t})$ : concrete temperature at time $\mathrm{t}\left({ }^{\circ} \mathrm{C}\right)$

$\mathrm{K}_{\mathrm{uc}}$ : ultimate hardened concrete thermal conductivity $(\mathrm{W} / \mathrm{m} / \mathrm{K})$

\subsubsection{Thermal diffusivity testing}

The thermal diffusivity of Mix 4 concrete was tested according to the CRD-C standard (1973). A $15 \mathrm{~cm} \times 30 \mathrm{~cm}$ meter concrete cylinder was cast with a Type $\mathrm{T}$ thermal couple embedded at the center (Figure 5-6). In accordance to the standard, the cylinder was cured in sealed condition for 28 days prior to testing. The cylinder was heated to boiling temperature, then submerged in running cold water. During the cooling process, the temperature difference between the center of the concrete cylinder and the surrounding water were recorded at 1-min interval. The thermal diffusivity $\left(\mathrm{d}, \mathrm{m}^{2} / \mathrm{hr}\right)$ of the concrete can be calculated using Eq. (5.8) where $\left(t_{1}-t_{2}\right)$ is the time elapsed (in minutes) between temperature differences of $44{ }^{\circ} \mathrm{C}\left(80{ }^{\circ} \mathrm{F}\right)$ and $11^{\circ} \mathrm{C}\left(20^{\circ} \mathrm{F}\right)$. 


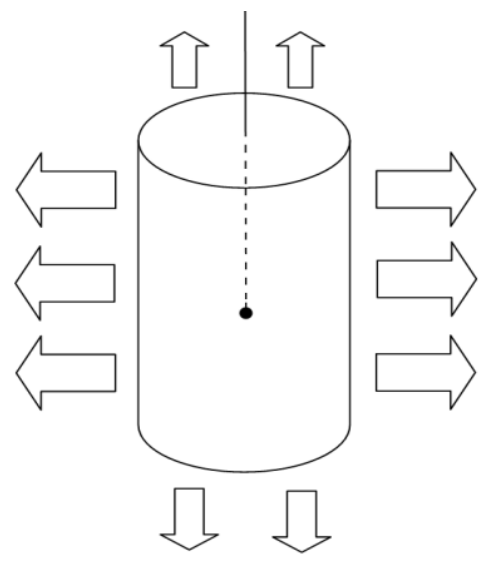

Figure 5-6: Thermal diffusivity test

As required in CRD-C standard (1974), the test was performed two times and the difference should be within $0.000186 \mathrm{~m}^{2} / \mathrm{hr}\left(0.002 \mathrm{ft}^{2} / \mathrm{hr}\right)$ the results should have an accuracy of . Those two testing results are correlated very closely and the thermal diffusivity values were determined to be $0.00339 \mathrm{~m}^{2} / \mathrm{hr}\left(0.0365 \mathrm{ft}^{2} / \mathrm{hr}\right)$ and $0.00340 \mathrm{~m}^{2} / \mathrm{hr}\left(0.0367 \mathrm{ft}^{2} / \mathrm{hr}\right)$, respectively. Figure 5-7 shows the measured temperature differences history between the center of the cylinder and the surrounding water.

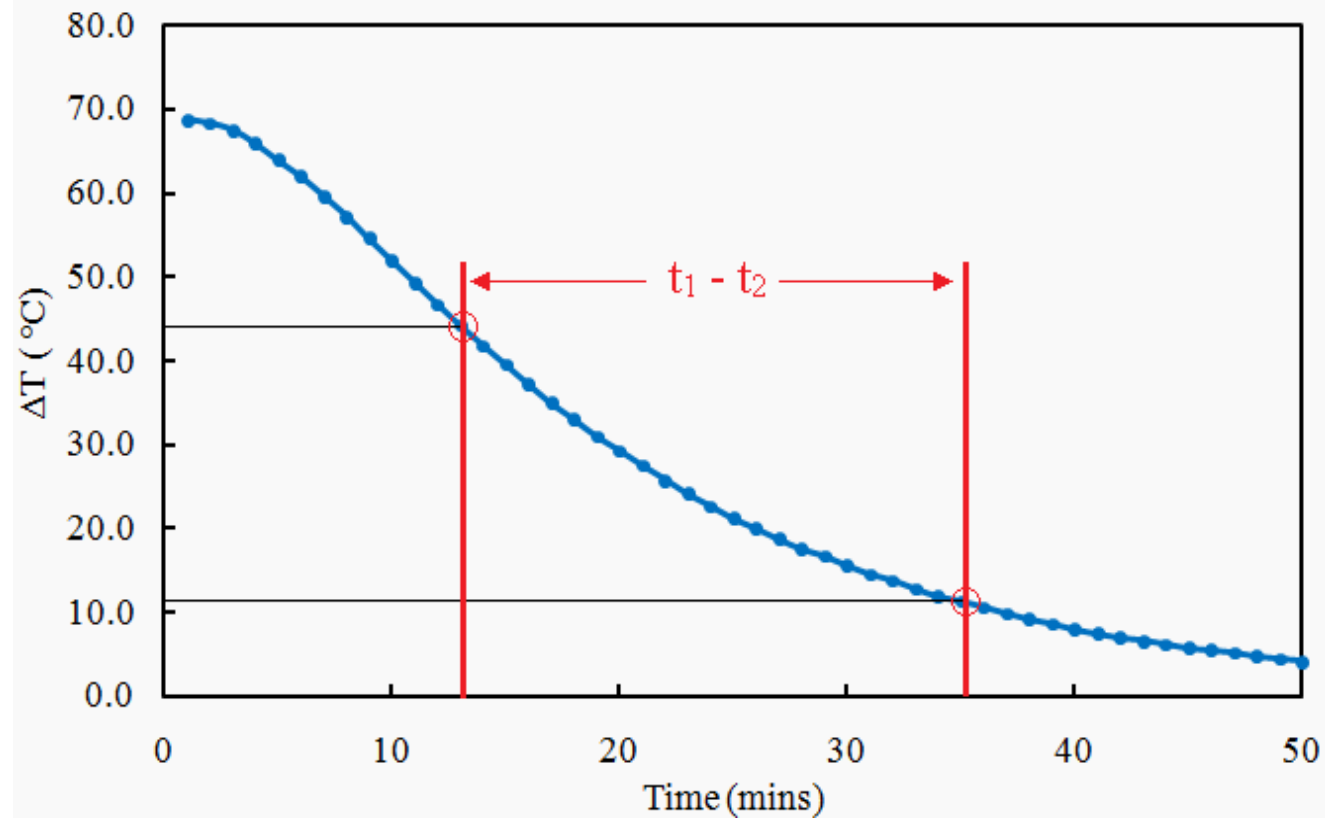

Figure 5-7: The measured temperature differences between concrete and water 


\subsection{Contact Interface Conductance}

One phenomenon that was often ignored is the thermal resistance effect provided by the interface between the formwork and concrete. An interface of two materials in contact acts like a very thin layer of insulation. As demonstrated in Figure 5-8, a thin air layer is embedded in between two materials, $\mathrm{A}$ and $\mathrm{B}$, due to an imperfect interface connection. As a heat flow $(Q)$ travel through the interface, a temperature drop $\left(\Delta T_{c}\right)$ is created because of the interface thermal resistance (Figure 5-9). The thermal conductance $\left(h_{c}\right)$, which is the inverse of thermal resistance, can be calculated using Eq. (5.9). The insulation effect of the concrete/formwork interface can be particularly significant when using metal formwork due to metal's relatively low thermal resistance. However, the interface conductance effect can be neglected when wood formwork is used because wood formwork is much higher in thermal resistance. In this study, the interface conductance for concrete-steel interface is experimentally obtained.

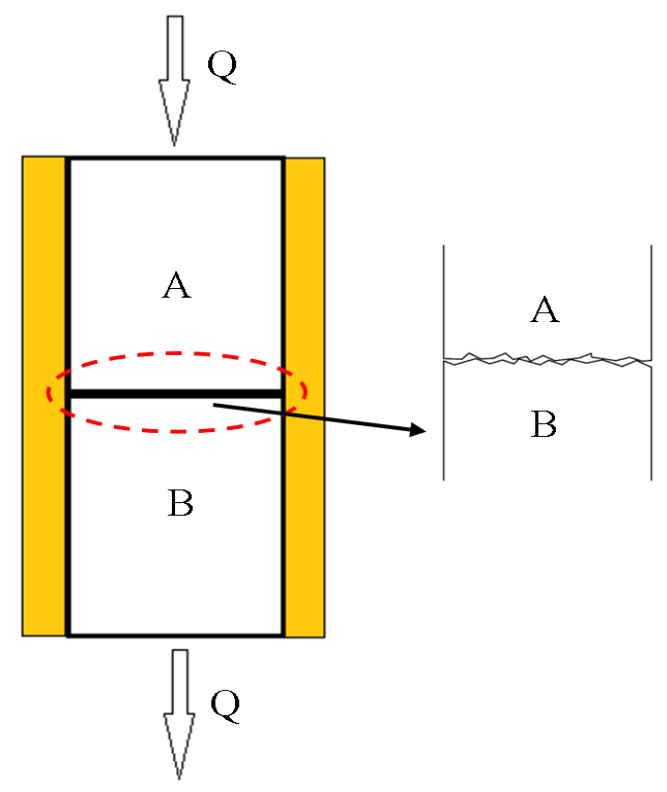

Figure 5-8: Contact Interface and its effect of thermal resistance 


$$
h_{c}=\frac{Q / \text { Area }}{\Delta T_{c}}
$$

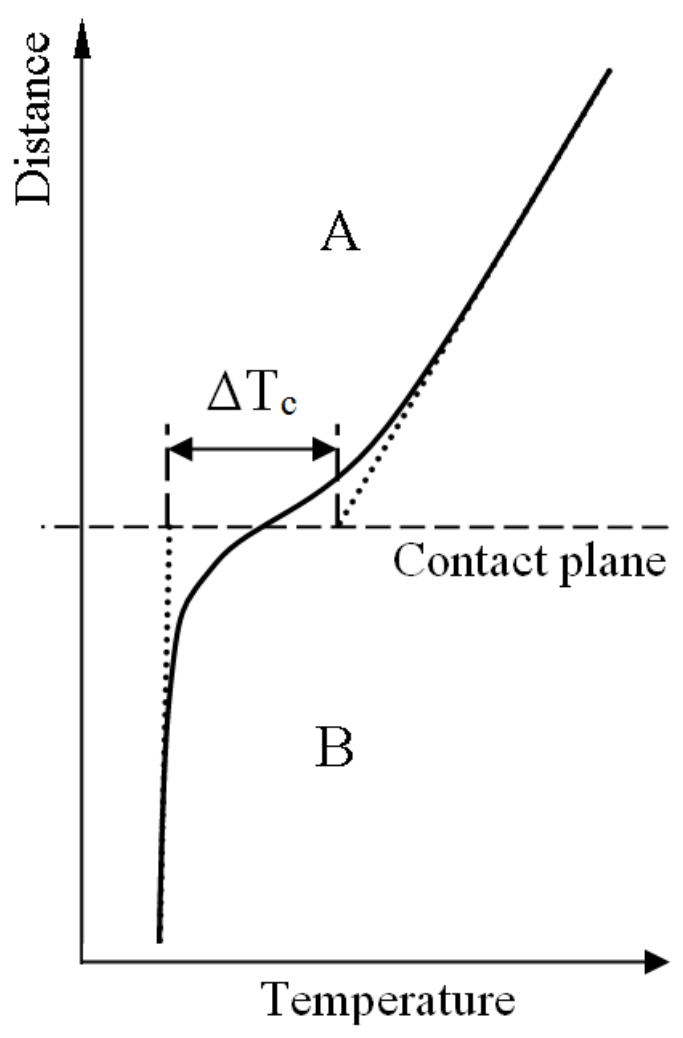

Figure 5-9: Temperature distribution accross the contact plane

Although the interface conductance was scarcely discussed in mass concrete topics, it is often studied for the fire resistance of the concrete-filled steel tubes (CFST). However, results with large deviations can be observed between various researchers. Hong and Varma (2009) assumed that the steel and concrete temperatures at the steel-concrete interface are equal. This indicates that $h_{c}$ was an infinitely large value, which is the case when the "TIE" constraint was used in ABAQUS. Espinos et al. (2010) suggested that $h_{c}$ could be taken as a constant value of $200 \mathrm{~W} / \mathrm{m}^{2} / \mathrm{K}$, while a constant value of $100 \mathrm{~W} / \mathrm{m}^{2} / \mathrm{K}$ was suggested by Lu et al. (2010). 


\subsubsection{Concrete/steel interface conductance testing}

A test set up was created to simulate the condition of the contact between concrete and steel formwork. Figure 5-10 shows the schematic diagram, while Figure 5-11 shows the pictures of the test set up. A concrete cylinder of $12.7 \mathrm{~cm}$ diameter was directly cast on top of a steel cylinder to simulate the concrete-formwork contact condition. A 5-cm thick foam insulation layer was added around the entire length surrounding the concrete and steel cylinder sample to simulate one-dimensional thermal conduction through the center path of the sample. The concrete was cured inside of the testing set up with a sealed top surface for 28 days. During the experiment, the top surface of the concrete is uniformly heated with a heating pad at approximately $150{ }^{\circ} \mathrm{C}$. A heat sink was installed at the bottom of the sample and submerged in $20{ }^{\circ} \mathrm{C}$ water to increase the heat flow. A series of Type $\mathrm{K}$ thermal couples were embedded in concrete along the center path during casting. In the steel cylinder, thermal couples were inserted horizontally to reach the center path through pre-drilled slots ( $3 \mathrm{~mm}$ in diameter). After sensors were inserted, the slots were filled with oil and sealed from outside. The seven black dots along the center path of Figure 5-10 were the sensor locations. Heat flow (Q) traveled from the top concrete though the interface to the heat sink at the bottom. The heat transfer reached the steady state after 5 to 6 hours.

The temperature distribution along the center path was recorded to determine the temperature difference between the two sides of the concrete-steel interface $\left(\Delta T_{c}\right)$ in Eq. (5.9). The recorded temperature histories of all seven temperature sensors along the center path are shown in Figure 5-12. The top, middle and bottom sensor locations in the concrete sample showed large differences in temperature evolution due to the thermal resistance of concrete. However, the temperatures of the four sensor locations in steel cylinder were almost the same 
throughout the testing period due to steel's high thermal conductivity. The final temperature readings at all seven locations were taken at the end of the test. Figure 5-13 shows the final temperature distribution at the end of the test. The test was repeated three times with almost identical results. The results of these experiments show that $\Delta \mathrm{T}_{\mathrm{c}}$ was $2.2{ }^{\circ} \mathrm{C}$ and $\mathrm{h}_{\mathrm{c}}$ was calculated to be $358 \mathrm{~W} / \mathrm{m}^{2} / \mathrm{K}$ using Eq. (5.9). In this equation, heat flow $\mathrm{Q}$ was calculated based on the thermal gradient within the concrete and its thermal conductivity $(1.87 \mathrm{~W} / \mathrm{m} / \mathrm{K})$ is identical to $\mathrm{K}_{\mathrm{uc}}$ (Section 5.3). The change in concrete Internal moisture level can affect the thermal conductivity value. The concrete sample for the interface conductance test and thermal diffusivity test (Section 5.3.1) both was sealed for 28 days prior to testing. Xu et al. (2009) showed the internal moisture to be $98 \%$ to $100 \%$ for sealed concrete. Therefore, the concrete internal moisture content was assumed to be $100 \%$ constantly and the change of moisture level during curing was neglected.

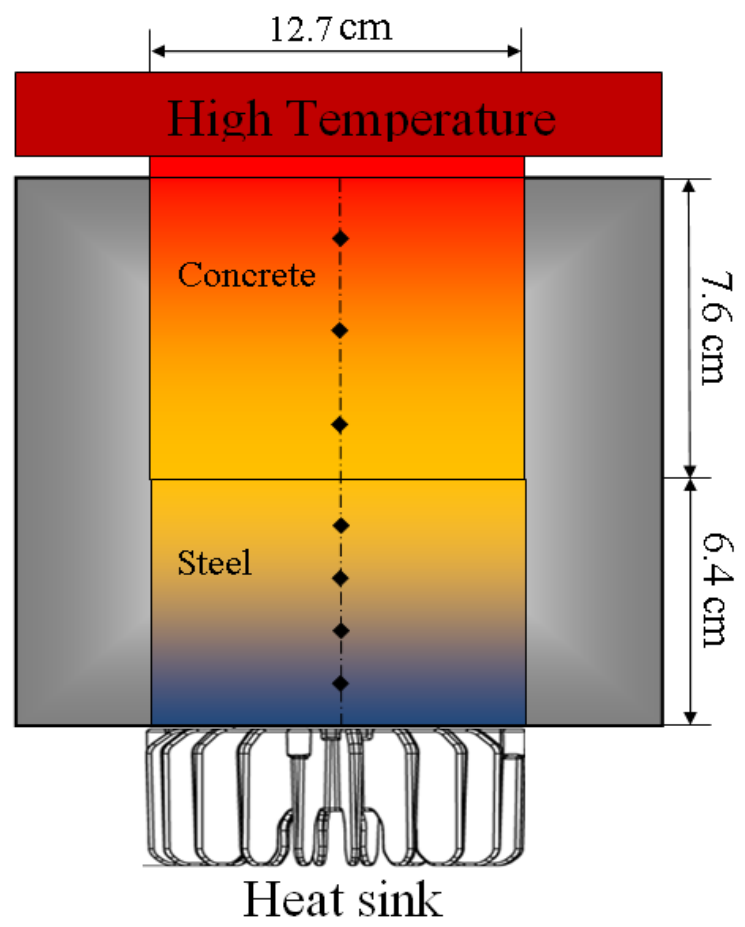

Figure 5-10: Schematic diagram of the interface conductance test set up 

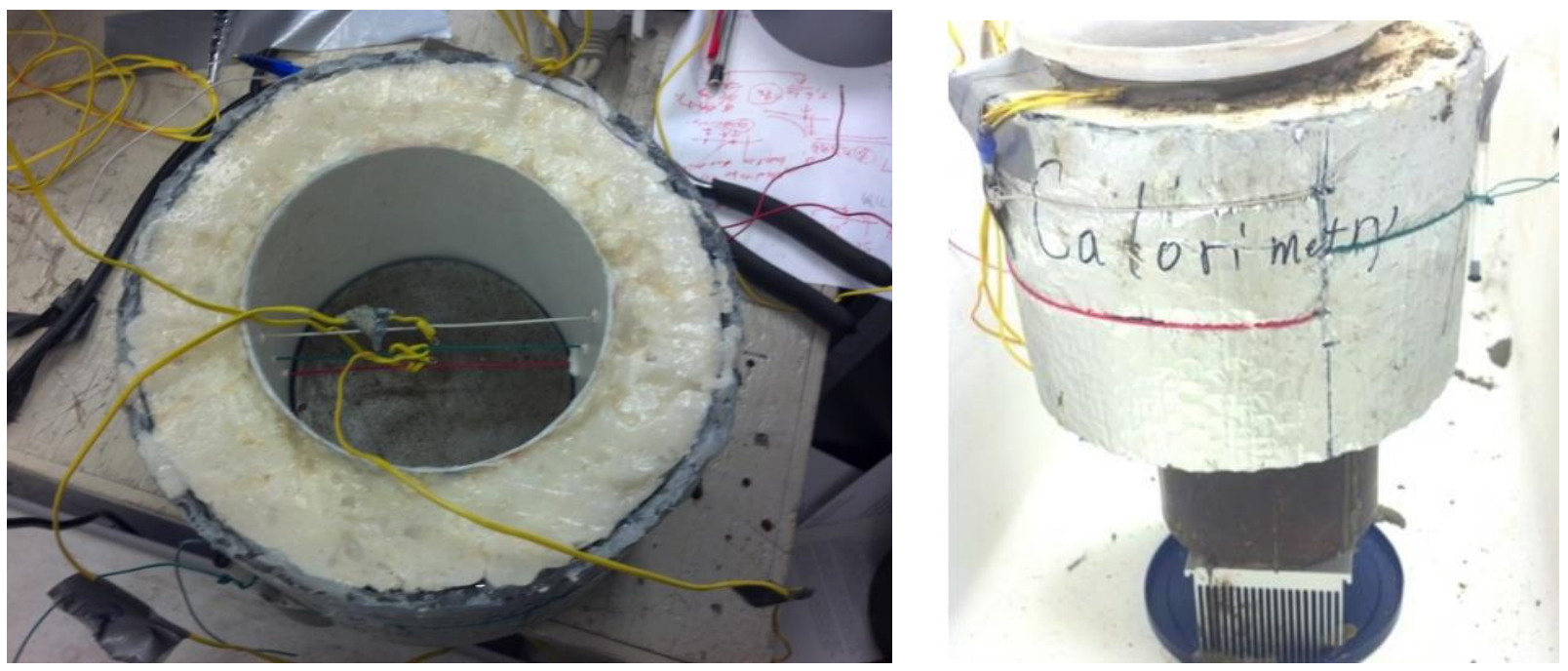

Figure 5-11: Pictures of the interface conductance test setup

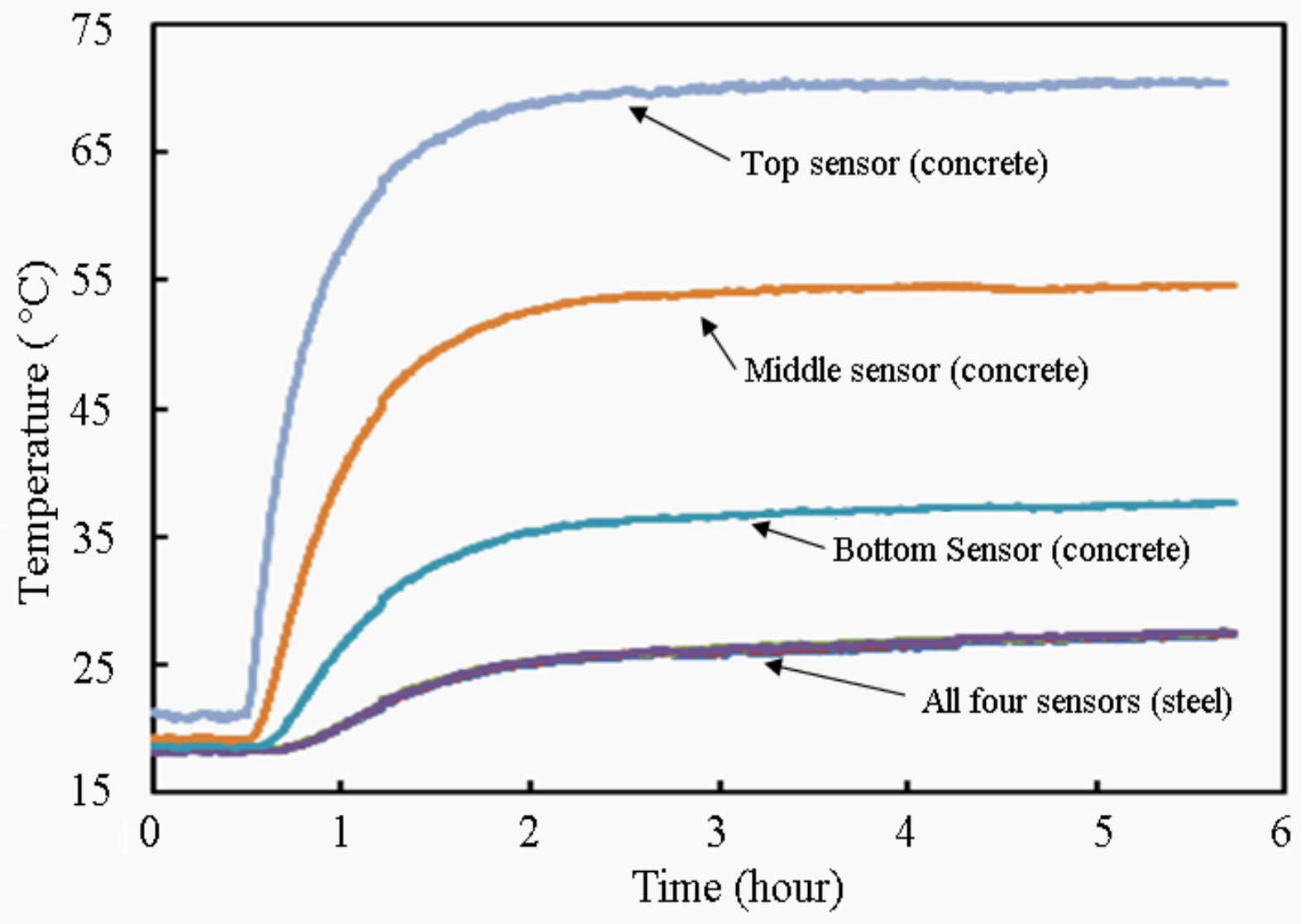

Figure 5-12: Temperature histories from all sensors in thermal conductance test 


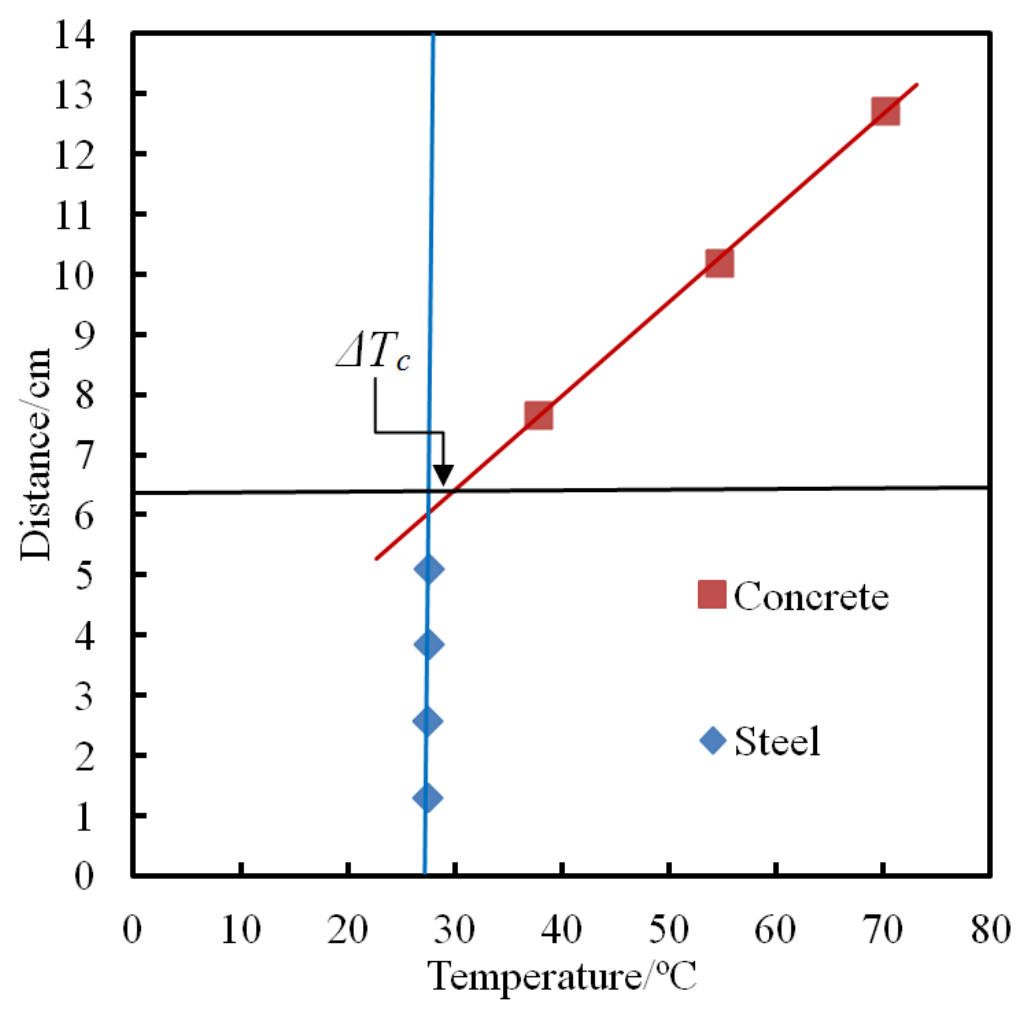

Figure 5-13: Measured temperature distribution of interface conductance test

\subsection{Surface Convection}

Surface convection is used to describe heat transfer between solid and fluid. The governing equation (Eq. (5.10)) for thermal convection is Newton's law of cooling (Thomas, 1980; Burmeister, 1993). The schematic diagram of thermal convection of a solid plane to the fluid in contact is shown in Figure 5-14. In Eq. (5.10), $\mathrm{q}_{\mathrm{cv}}$ is the convection heat flux in $\mathrm{W} / \mathrm{m}^{2}$, $\mathrm{h}_{\mathrm{cv}}$ is the convection coefficient in $\mathrm{W} / \mathrm{m}^{2} / \mathrm{K}, \mathrm{T}_{\mathrm{s}}$ is the solid surface temperature in Kelvin, and $\mathrm{T}_{\mathrm{F}}$ is the fluid temperature or ambient temperature in Kelvin. The ambient temperature records for the 1.8-meter concrete cubes are shown in Figure 5-15. The ambient temperature records for the 1.2-meter and 0.9-meter cubes are shown in Figure 5-16.

$q_{c v}=h_{c v} A_{s}\left(T_{S}-T_{F}\right)$ 
The convection heat transfer can be categorized to free convection and forced convection. Free convection is defined when fluid motion is simply caused by buoyancy forces due to the differences in density and forced convection is when external forces control fluid motion. In this study, the concrete structures were constructed where minimal wind was observed. Therefore, free convection was assumed in this case and a typical value $\left(7.9 \mathrm{~W} / \mathrm{m}^{2} / \mathrm{K}\right)$ was used as the free convection coefficient for the interface between the surface of the steel formwork and the air.

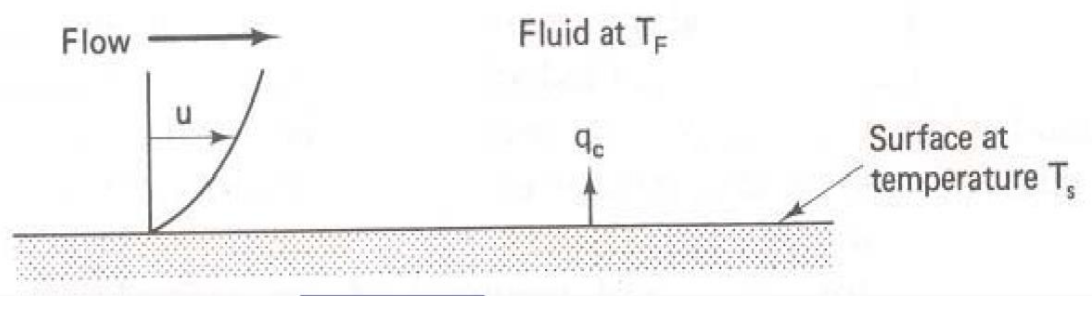

Figure 5-14: Convection heat transfer (Thomas, 1908)

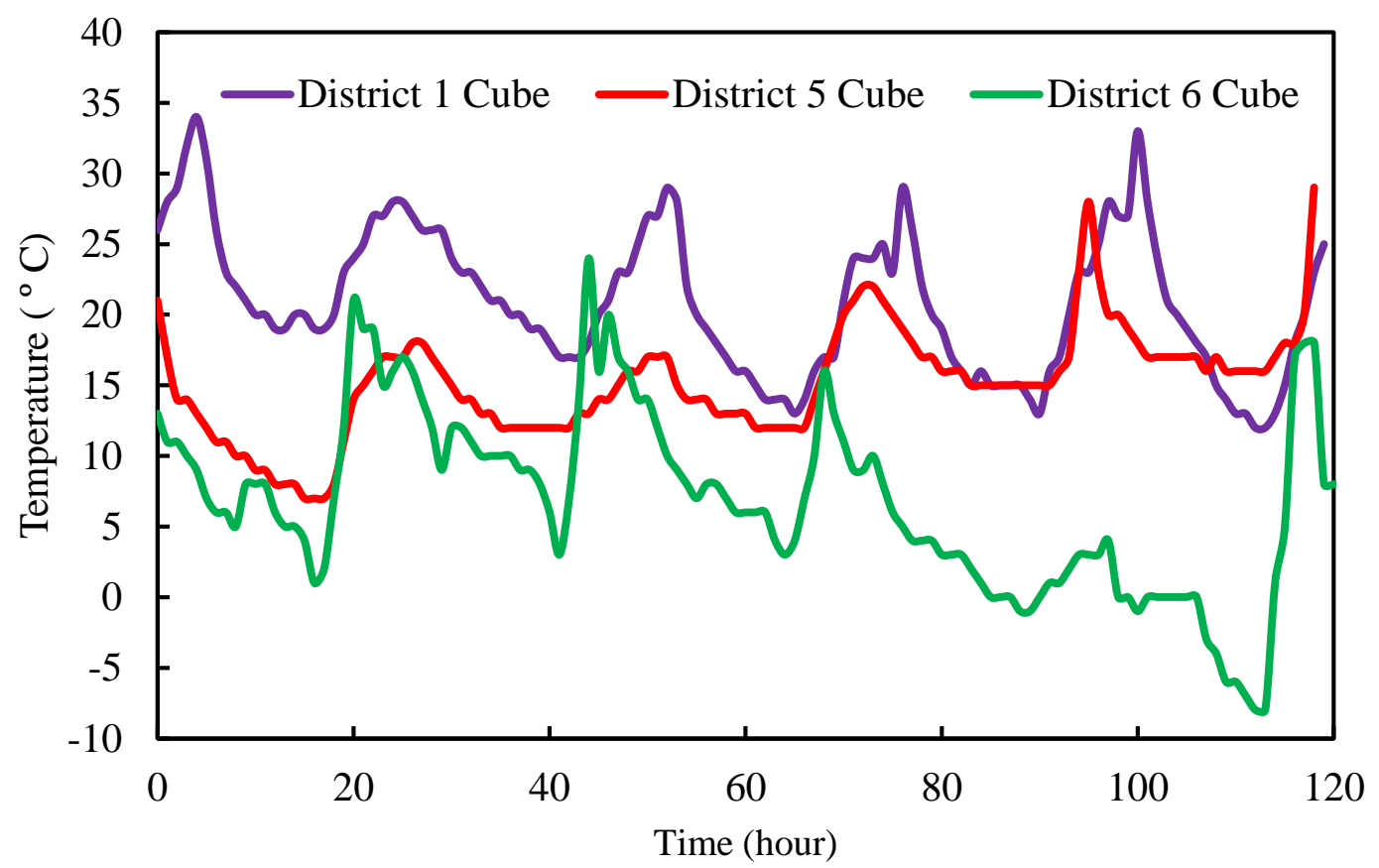

Figure 5-15: Ambient temperature record for 1.8-meter cubes located in District1, 5 and 6 


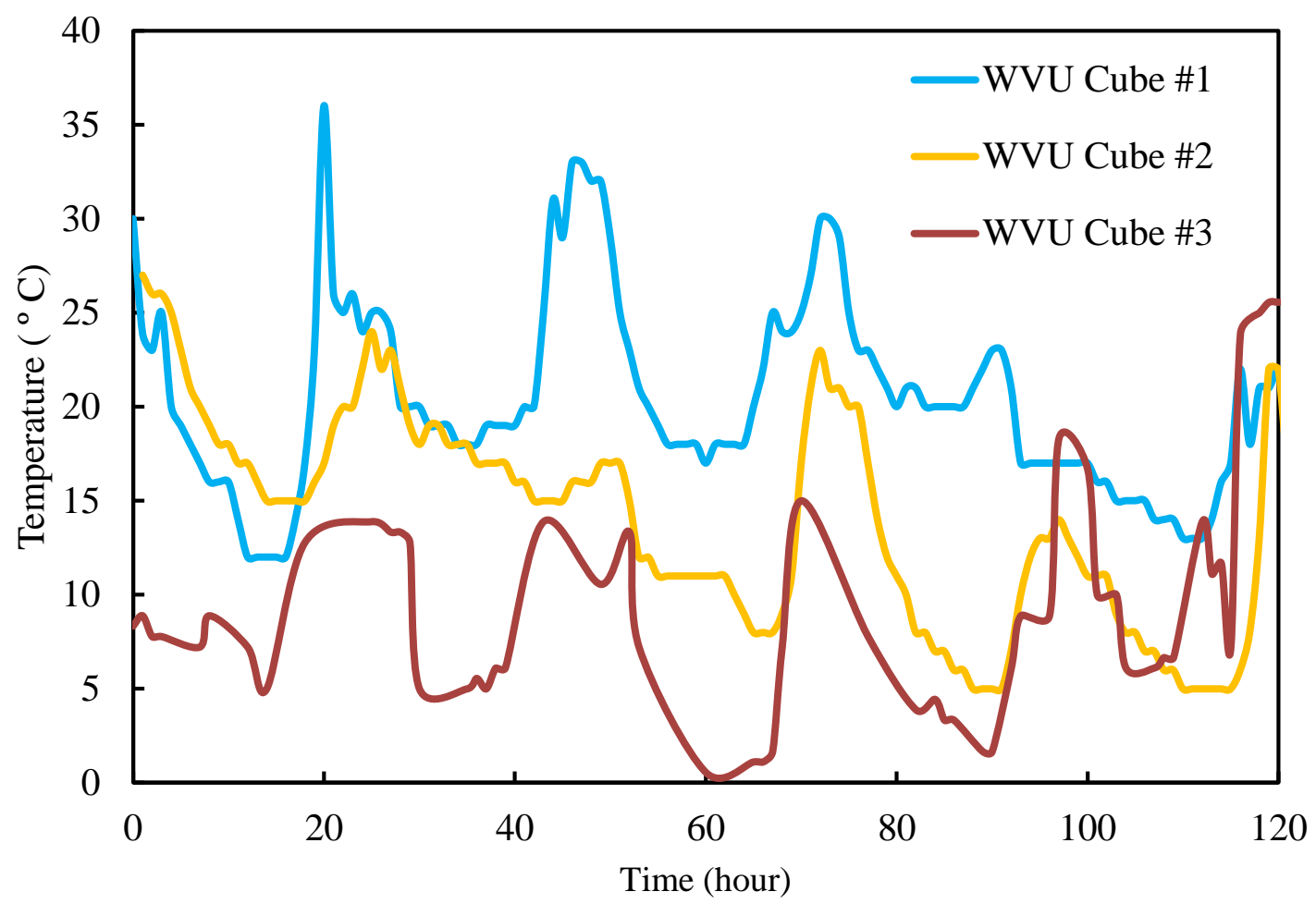

Figure 5-16: Ambient temperature record for 1.2-meter and 0.9-meter cubes located in WVU

\subsection{3-D Finite Element Model Geometry}

Finite element (FE) models were created using ABAQUS software according to the cube experiment stated in Section 4.2. The cube models have four parts: a concrete block, a side insulation layer, a top cover and a base. Figure 5-17 shows the dissembled parts of the cube model. The parts information for all six modeled concrete cubes is shown in Table 5-5. Eightnode linear heat transfer brick element (DC3D8, Figure 5-18) was used in all the models. 5-cm element size was used for the thermal analysis, which is determined based on the results of element size sensitivity analysis. The FE results using 5 -cm element size had less than $1 \%$ difference in comparison with $2.5-\mathrm{cm}$ element. The 1.8-meter cubes had a total of 50,223 elements and 56,561 nodes. 


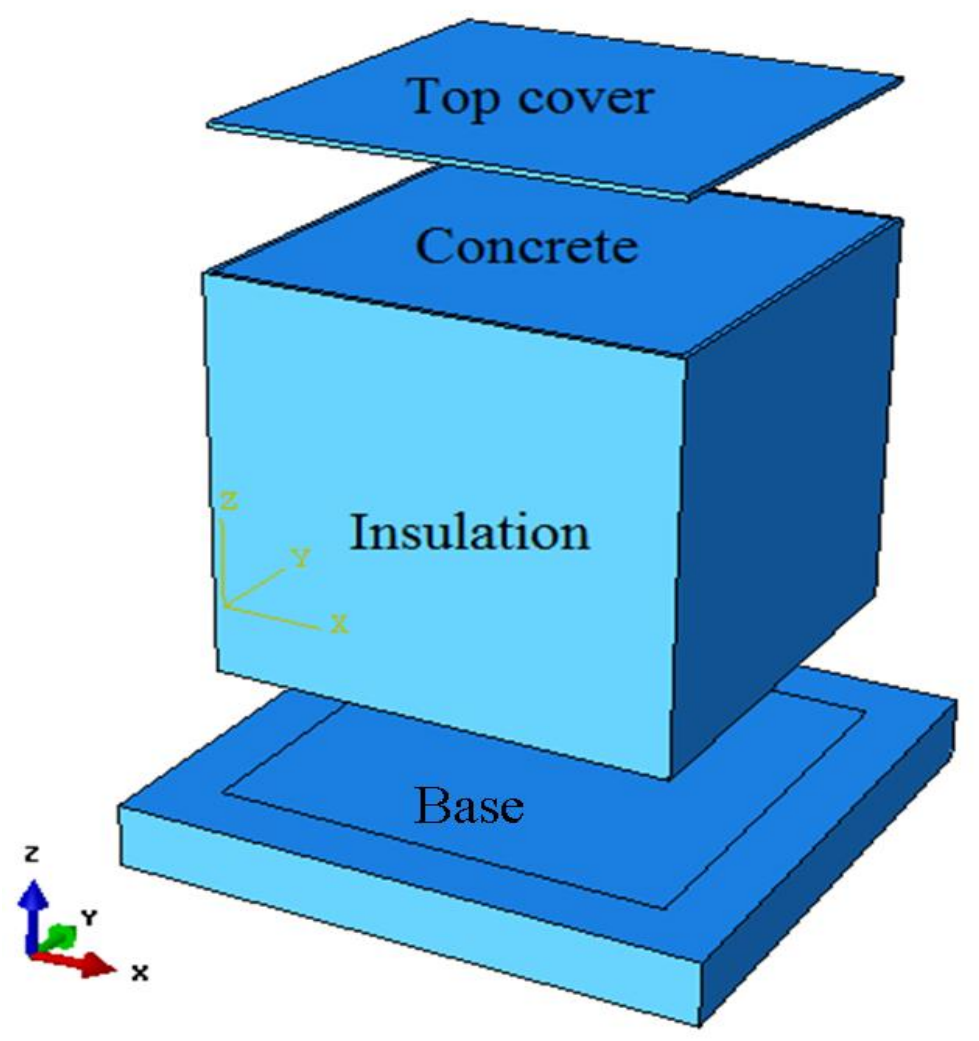

Figure 5-17: Dissembled parts of the concrete cube model

Table 5-5:Details of the parts from each modeled cube

\begin{tabular}{|l|c|c|c|c|c|}
\hline & Dimension & $\begin{array}{c}\text { Formwork } \\
\text { material }\end{array}$ & $\begin{array}{c}\text { Formwork } \\
\text { Thickness }\end{array}$ & $\begin{array}{c}\text { Base } \\
\text { material }\end{array}$ & $\begin{array}{c}\text { Base } \\
\text { thickness }\end{array}$ \\
\hline District 1 & $1.83 \mathrm{~m}$ & Wood & $2.5 \mathrm{~cm}$ & Soil & $0.3 \mathrm{~m}$ \\
\hline District 5 & $1.83 \mathrm{~m}$ & Steel & $2.5 \mathrm{~cm}$ & Gravel & $0.3 \mathrm{~m}$ \\
\hline District 6 & $1.83 \mathrm{~m}$ & Wood & $2.5 \mathrm{~cm}$ & Gravel & $0.3 \mathrm{~m}$ \\
\hline WVU \#1 & $1.22 \mathrm{~m}$ & Steel & $2.5 \mathrm{~cm}$ & Wood & $0.3 \mathrm{~m}$ \\
\hline WVU \#2 & $1.22 \mathrm{~m}$ & Steel & $2.5 \mathrm{~cm}$ & Wood & $0.3 \mathrm{~m}$ \\
\hline WVU \#3 & $0.91 \mathrm{~m}$ & Wood & $2.5 \mathrm{~cm}$ & Wood & $0.3 \mathrm{~m}$ \\
\hline
\end{tabular}




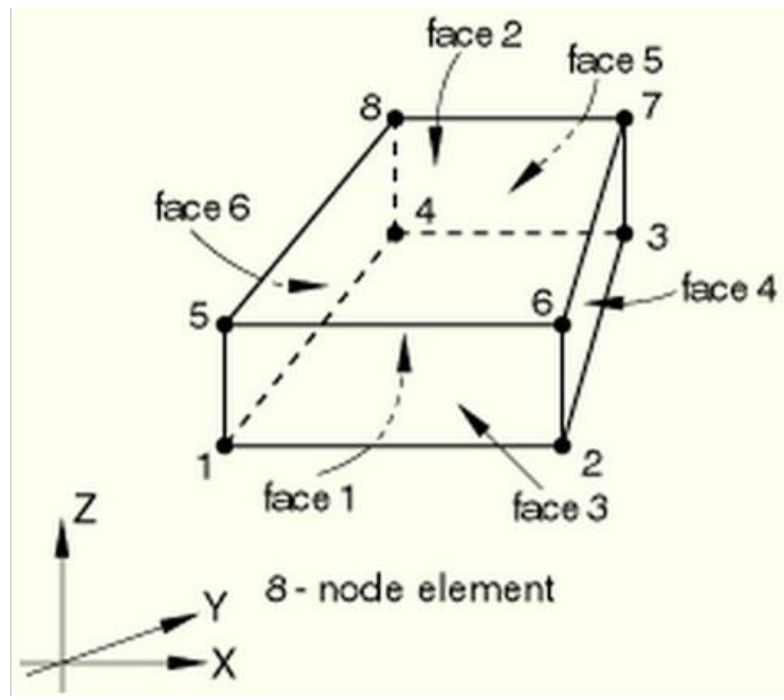

Figure 5-18: DC3D8 element (ABAQUS 6.12 manual)

\subsection{Modeling Algorithm}

The thermal analysis model was designed to calculate the heat transfer for the first 120 hours after the concrete casting. With a fix time increment of 1 hour, 120 time steps were assigned to the model. To account for the effects of age and temperature-history dependent material properties and the non-uniform hydration process, two FORRTRAN subroutines, "USDFLD" and "DFLUX", were created and incorporated. For each time step, both subroutines were called for each individual element. When each of the two subroutines was called, the equivalent age ( $t_{e}$, Eq. 2.16) and the degree of hydration ( $\alpha$, Eq. 2.14) were calculated based on the temperature history (calculated temperature solutions in previous time steps) of the current element. For each element at any time step, USDFLD calculate and update the thermal conductivity (Eq. 5.7) and specific heat (Eq. 5.6) while DFLUX calculate the thermal loading (Eq. 5.5). As a result, each element in different locations can realistically have its own unique histories of thermal properties and heat generation. 
During each time step, a new set of temperature solutions for the current time step was computed using the geometry, material properties, temperature profile from the previous time step and the current thermal loading and boundary conditions. At the end of each time step, a new temperature solution would be collected to update the degree of hydration in each concrete element. With the updated degree of hydration, thermal conductivity, specific heat, and thermal loading can be updated for the following time step. The algorithm flowchart of the thermal analysis model is shown in Figure 5-19.

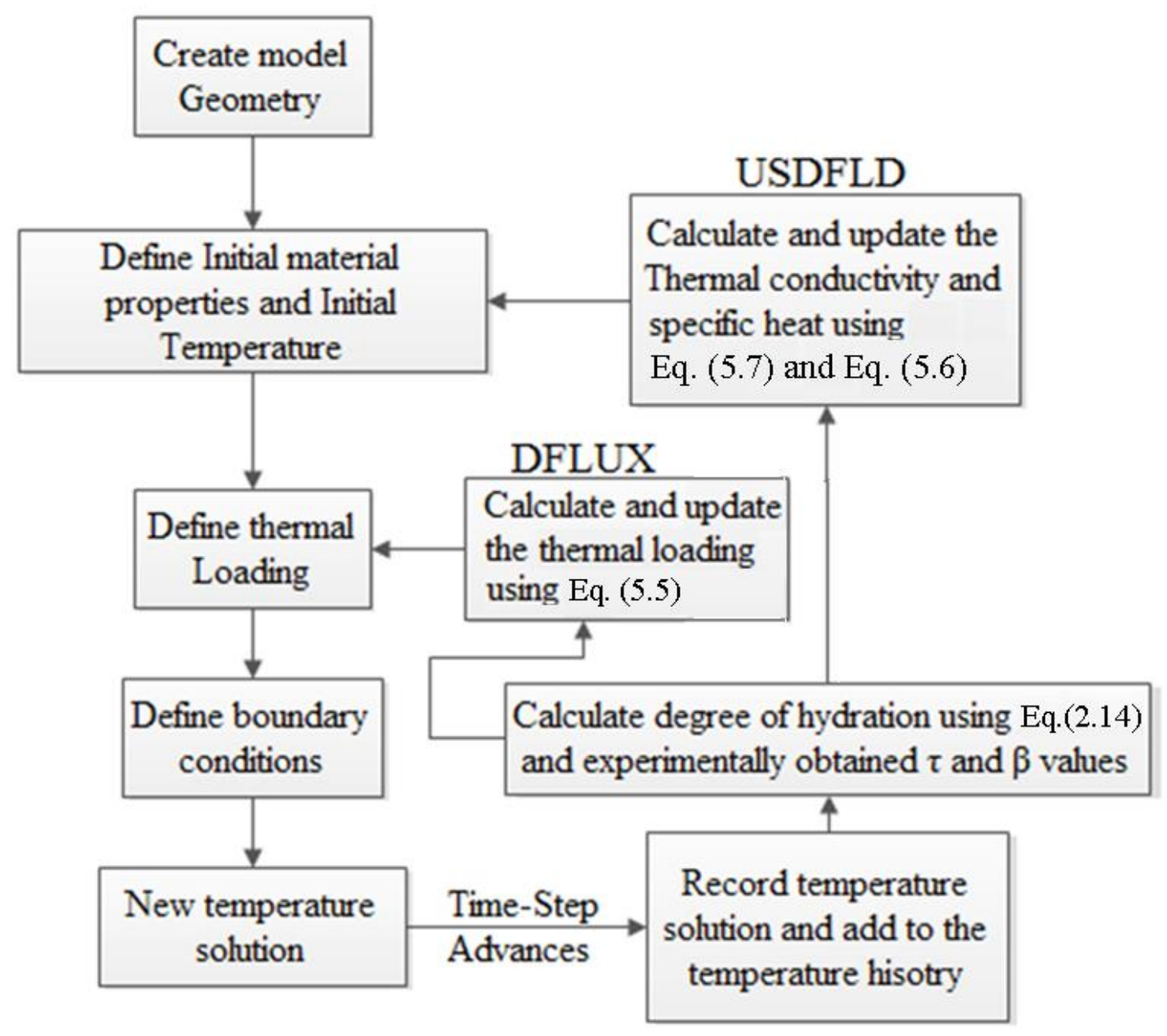

Figure 5-19: The algorithm of the thermal analysis model 
The concrete-steel interface conductance and steel-air thermal convection model discussed earlier were implemented in the analysis. More specifically, temperature differences between the concrete surface and inner steel formwork surface as well as the outer steel formwork surface and the external air were included. Figure 5-20 shows a sketch of the temperature distribution from the center to the external air (ambient temperature) at an early age after casting. The values of interface conductance of steel-concrete and the surface convection coefficient of steel-air were discussed in Section 5.4 and Section 5.5. When wood formwork was used, the interface conductance of wood-concrete and the surface convection coefficient of wood-air were not sensitive to the temperature results due to the low thermal conductivity of wood. Therefore, the same values of the interface conductance and surface convection coefficient were used for the cubes with wood formwork.

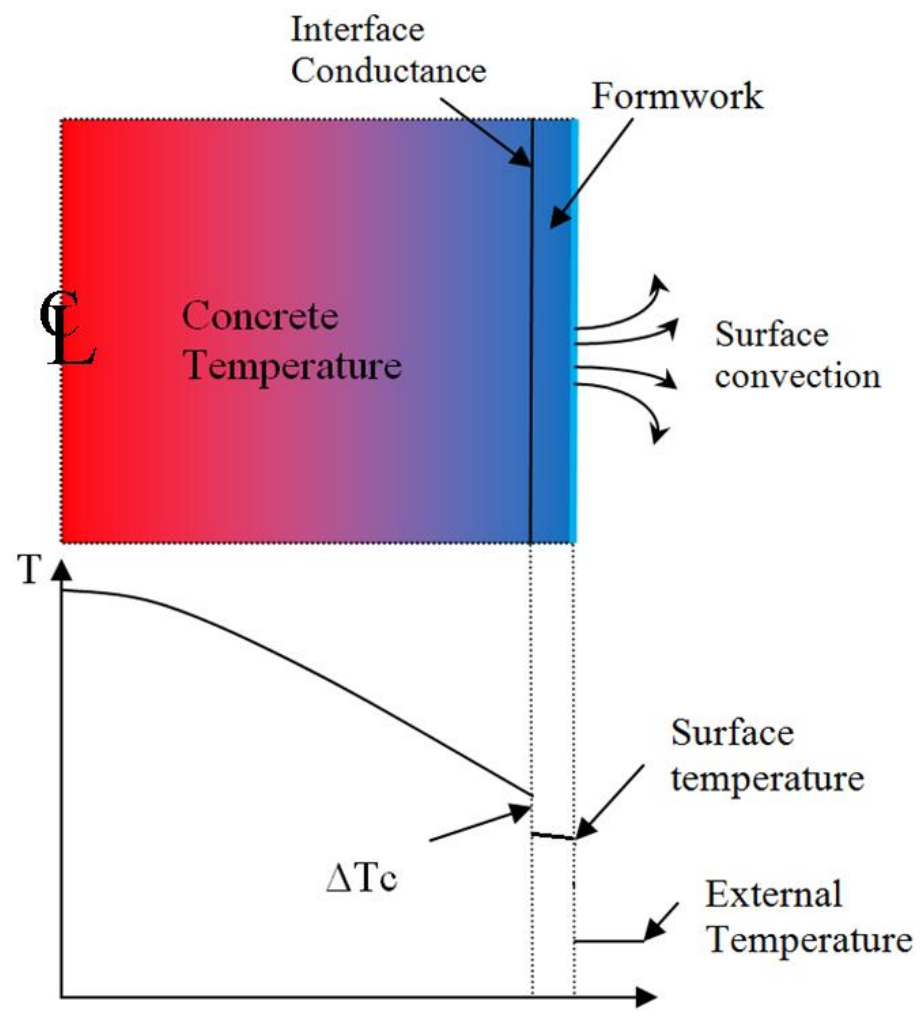

Figure 5-20: Temperature distribution from the cube center to the external air at early age 


\subsection{Thermal Analysis Results}

The temperature profile histories of three 1.8-meter cubes (District 1, District 5 and District 6), two 1.2-meter cubes (WVU \# Cube\#1 and \#2) and one 0.9-meter cube (WVU \#3) were calculated using the created ABAQUS finite element models with the attendances of two subroutines as described in Figure 5-19. The temperature profile history of the entire concrete cube can be extracted from the ABAQUS ODB file after the analysis is finished. ABAQUS program can display the temperature distribution on any cut plane at any time step. As an example, Figure 5-21 shows the calculated temperature contour field of the middle cross-section of District 5 cube as an example. At the time step of 29 (29 hours after the concrete placement) the center (in the grey area) temperature reached the maximum temperature of $65^{\circ} \mathrm{C}\left(149^{\circ} \mathrm{F}\right)$. The temperature at the side location $(5 \mathrm{~cm}$ from the surface) in the green area has a lower temperature of $41^{\circ} \mathrm{C}\left(106^{\circ} \mathrm{F}\right)$.

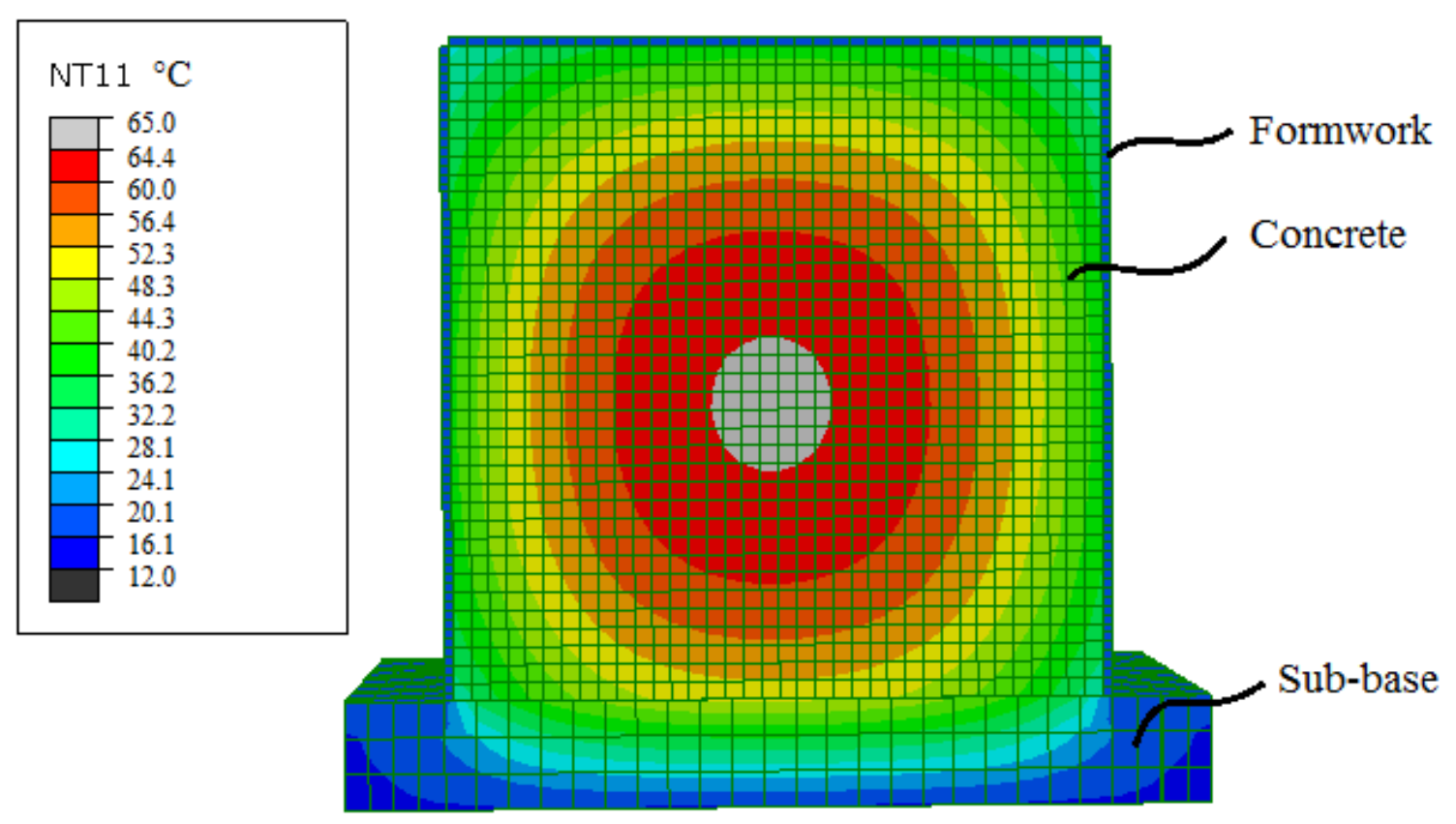

Figure 5-21: Temperature distribution of the center cross-sectional cut of Cube \#2 at 29 hours 
The accuracy of temperature calculations at center and side (the length of one mesh element) locations (see Section 4.2 for temperature logger locations) are the most important in order to predict the maximum center temperature and maximum temperature differential. Hence, the results can be used to check with the limitations. ACI 301-10 states that the maximum center temperature cannot exceed $70{ }^{\circ} \mathrm{C}\left(158^{\circ} \mathrm{F}\right)$ while the maximum temperature differential between the center and side locations cannot exceed $20^{\circ} \mathrm{C}\left(35^{\circ} \mathrm{F}\right)$. Figure 5-22 to Figure 5-27 shows the comparisons of FEM predictions (lines and dotted lines in red) and experimental measurements (" $x "$ and " $+"$ in blue) of the center and side temperature histories for six concrete cubes (District 1 cube, District 5 cube, District 6 cube, WVU Cube \#1, WVU Cube \#2 and WVU Cube \#3). The correlations between FEM results and experimental measurements were evaluated by statistical analysis (correlation test) shown in Section 5.10.

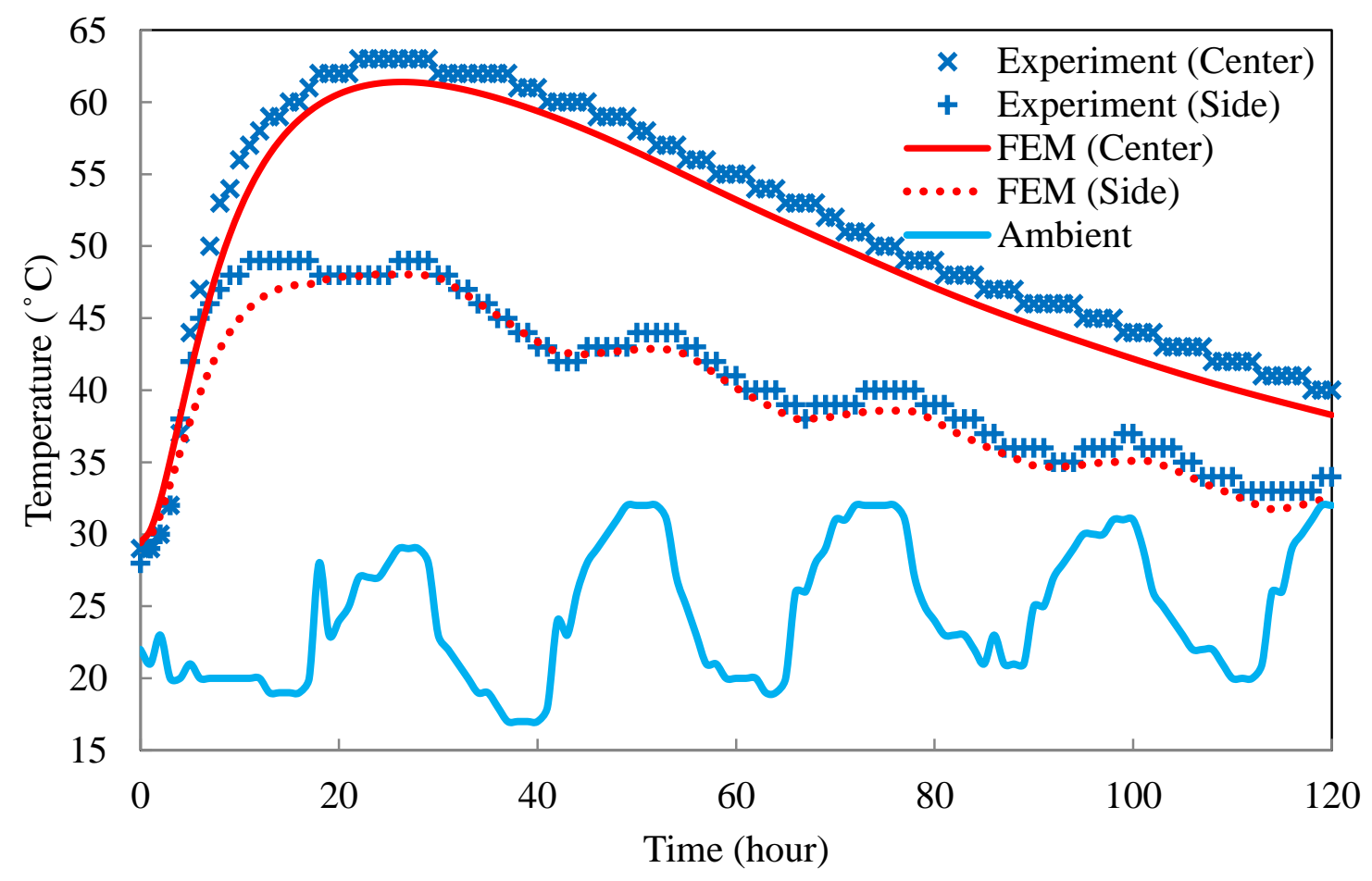

Figure 5-22: Experimental and FEM results of center and side temperatures (District 1 cube) 


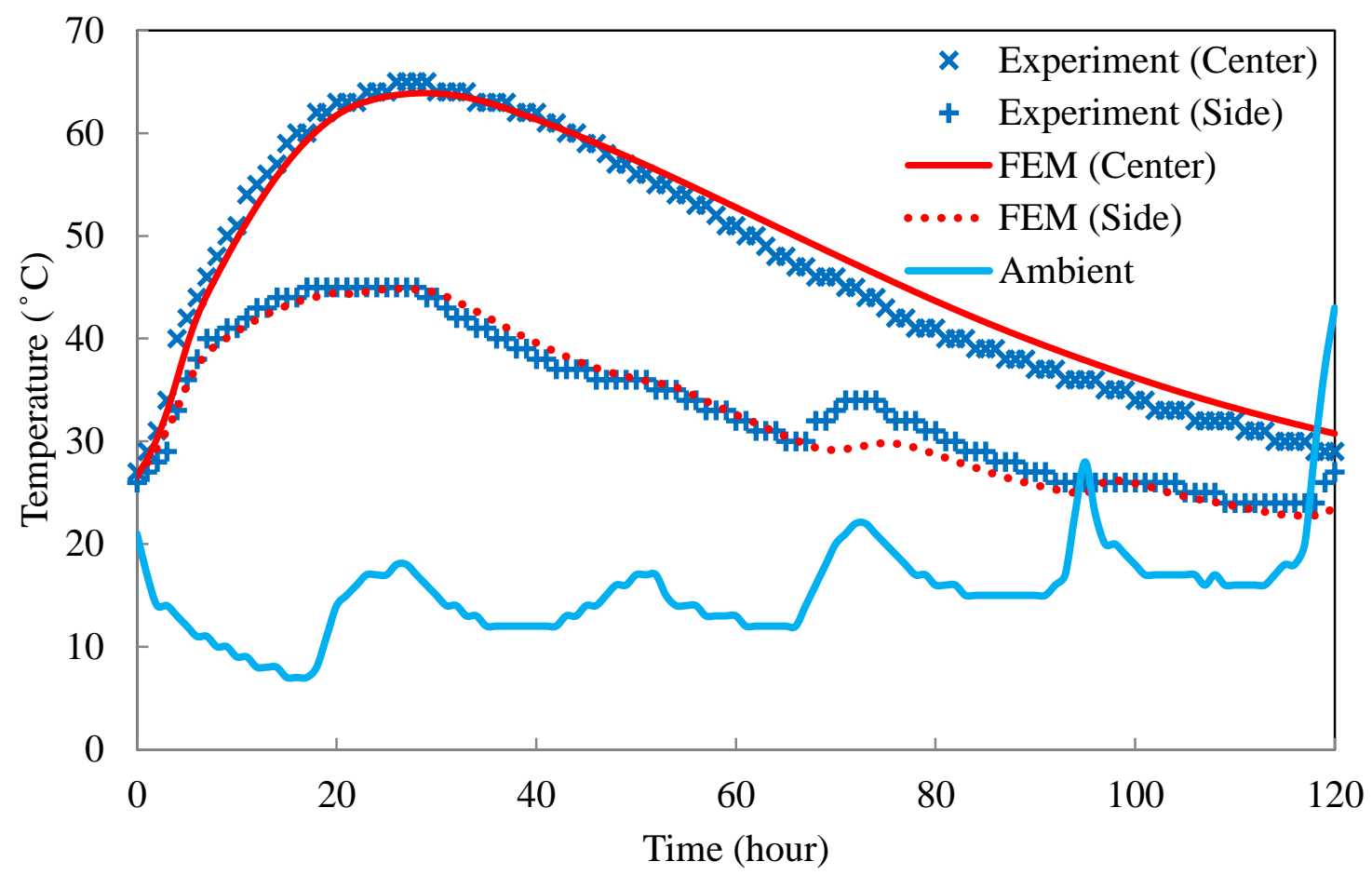

Figure 5-23: Experimental and FEM results of center and side temperatures (District 5 cube)

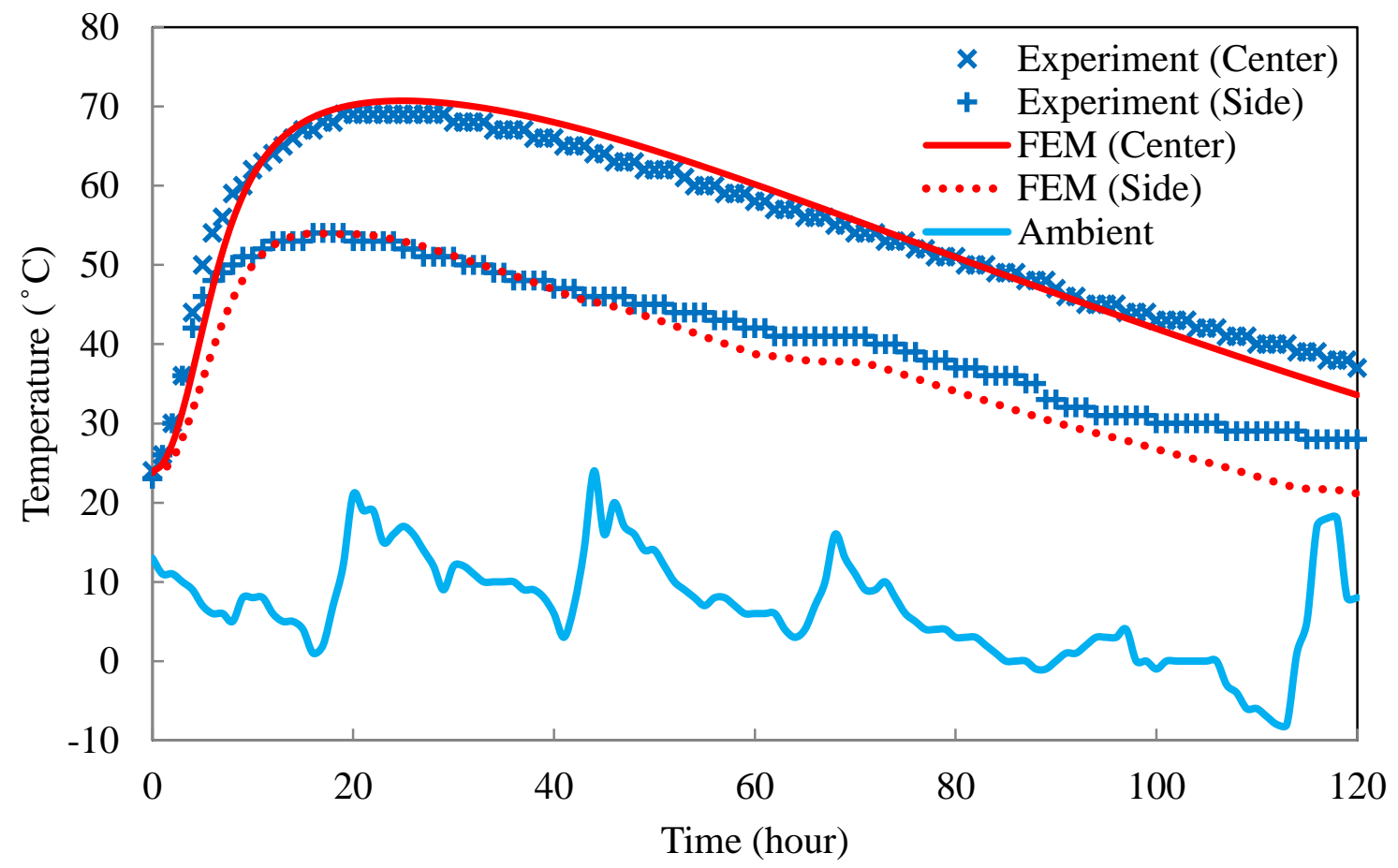

Figure 5-24: Experimental and FEM results of center and side temperatures (District 6 cube) 


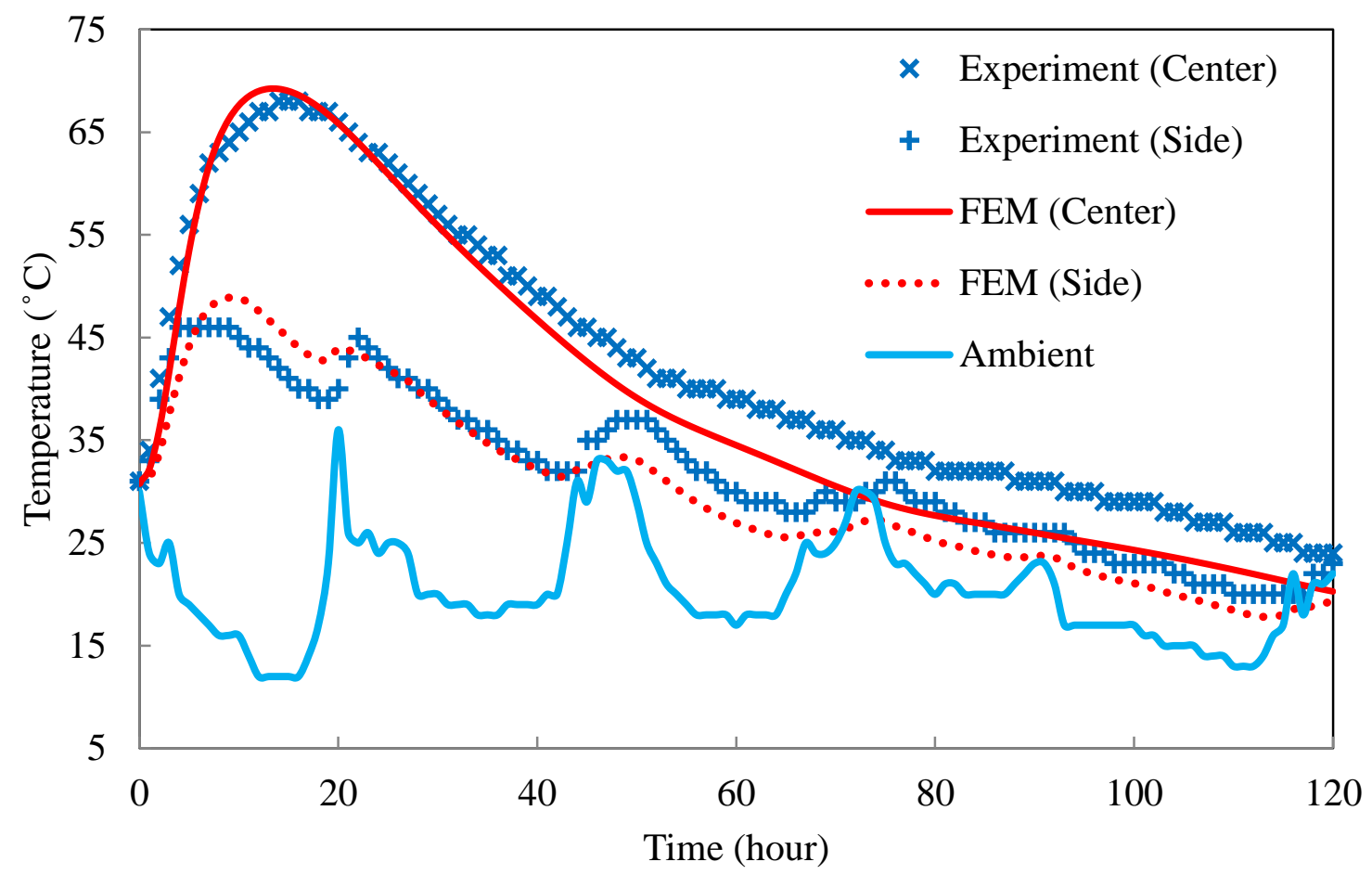

Figure 5-25: Experimental and FEM results of center and side temperatures (WVU Cube \#1)

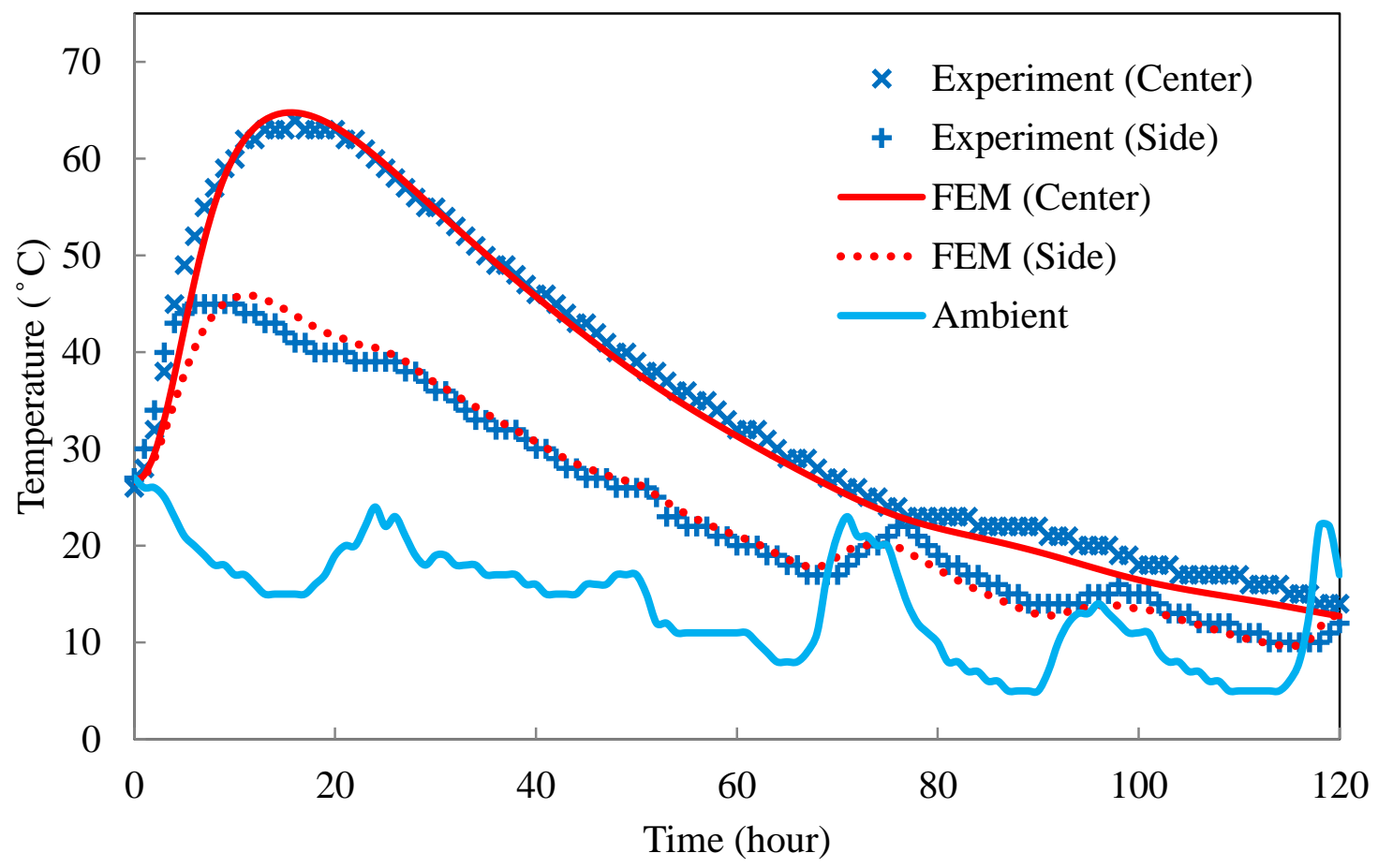

Figure 5-26: Experimental and FEM results of center and side temperatures (WVU Cube \#2) 


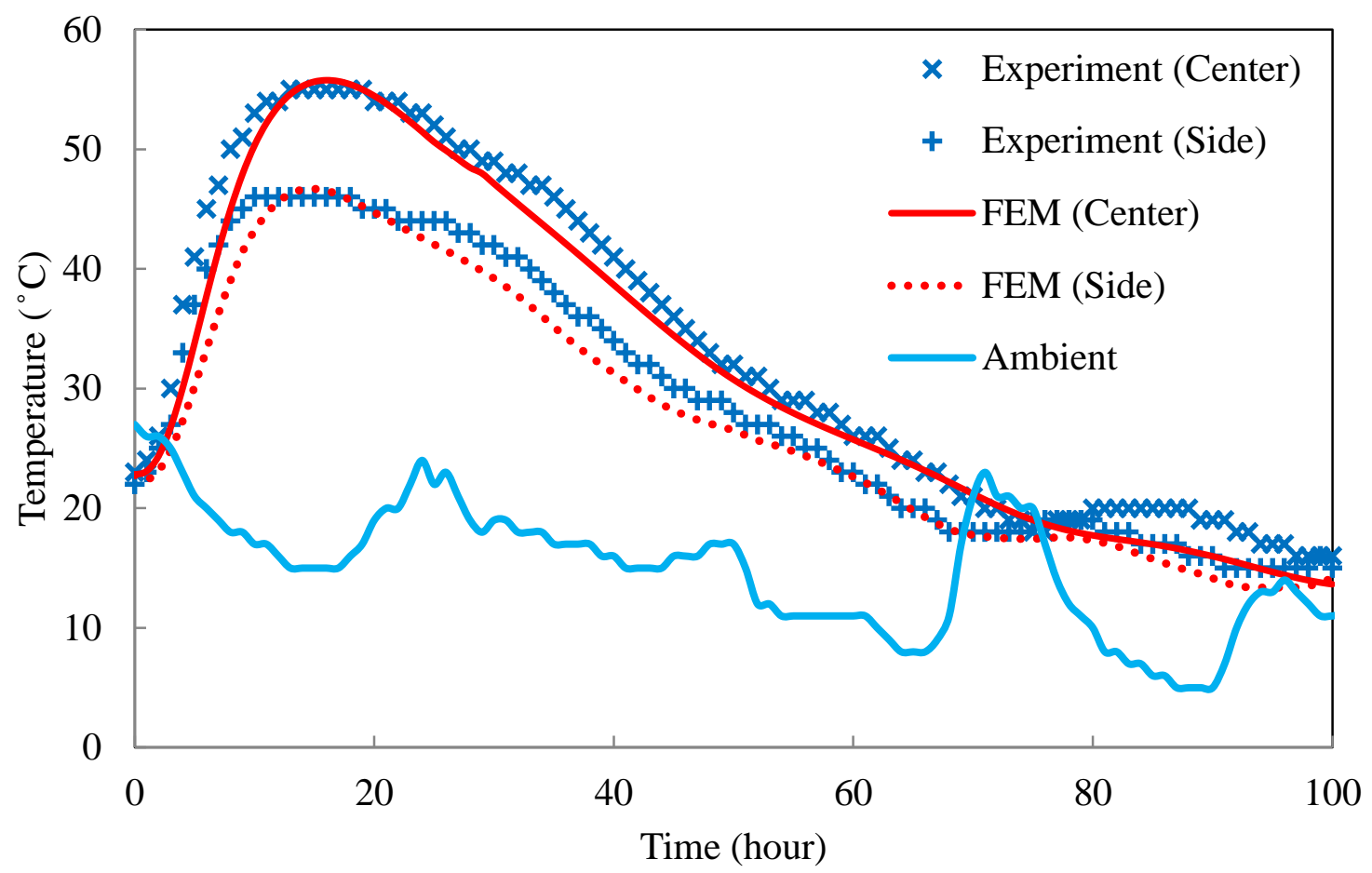

Figure 5-27: Experimental and FEM results of center and side temperatures (WVU Cube \#3)

The temperature differential $(\Delta \mathrm{T})$ between the center and side is one of the key factors which is influencing the thermal stress development. The histories of $\Delta \mathrm{T}$ were obtained and compared between the experimental measurements and FEM calculations. The comparisons of $\Delta \mathrm{T}$ for the concrete cubes are shown in Figure 5-28 to Figure 5-33. The statistical analysis of the prediction accuracy is shown in Section 5.10. The influences of the cube size can be seen in the experimental measurements and FEM results. The times of maximum center temperatures were between 25 hours to 28 hours for the 1.8-meter cube and 15 to 16 hours for the 1.2 meter cubes. The times of maximum temperature differentials were between 41 hours to 43 hours for the 1.8meter cubes and 18 to 19 hours for the 1.2 meter cubes. The FEM results were also able to predict the time of those occurrences for cubes with different sizes. 


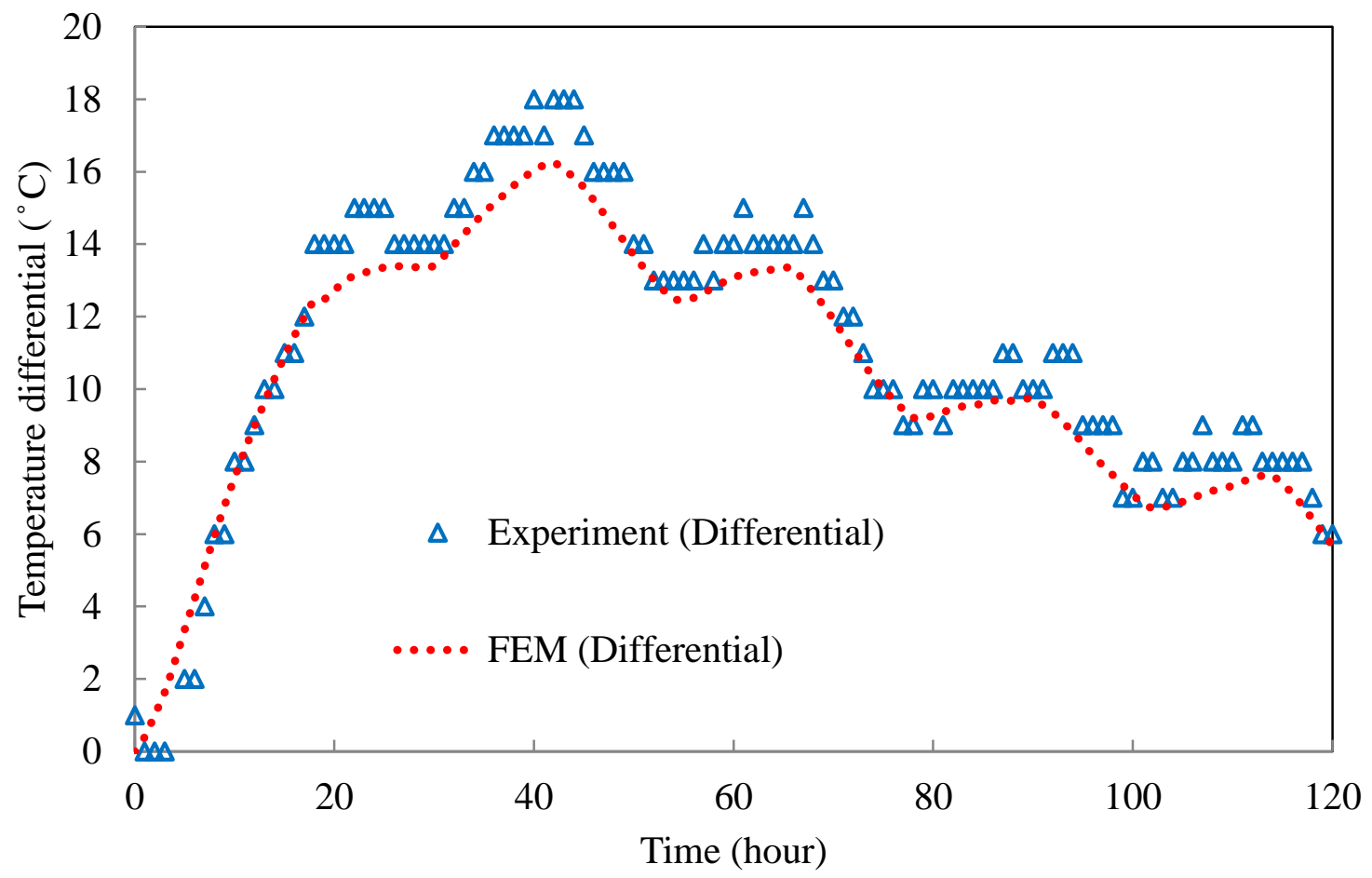

Figure 5-28: Experimental and FEM results of temperature differentials (District 1 cube)

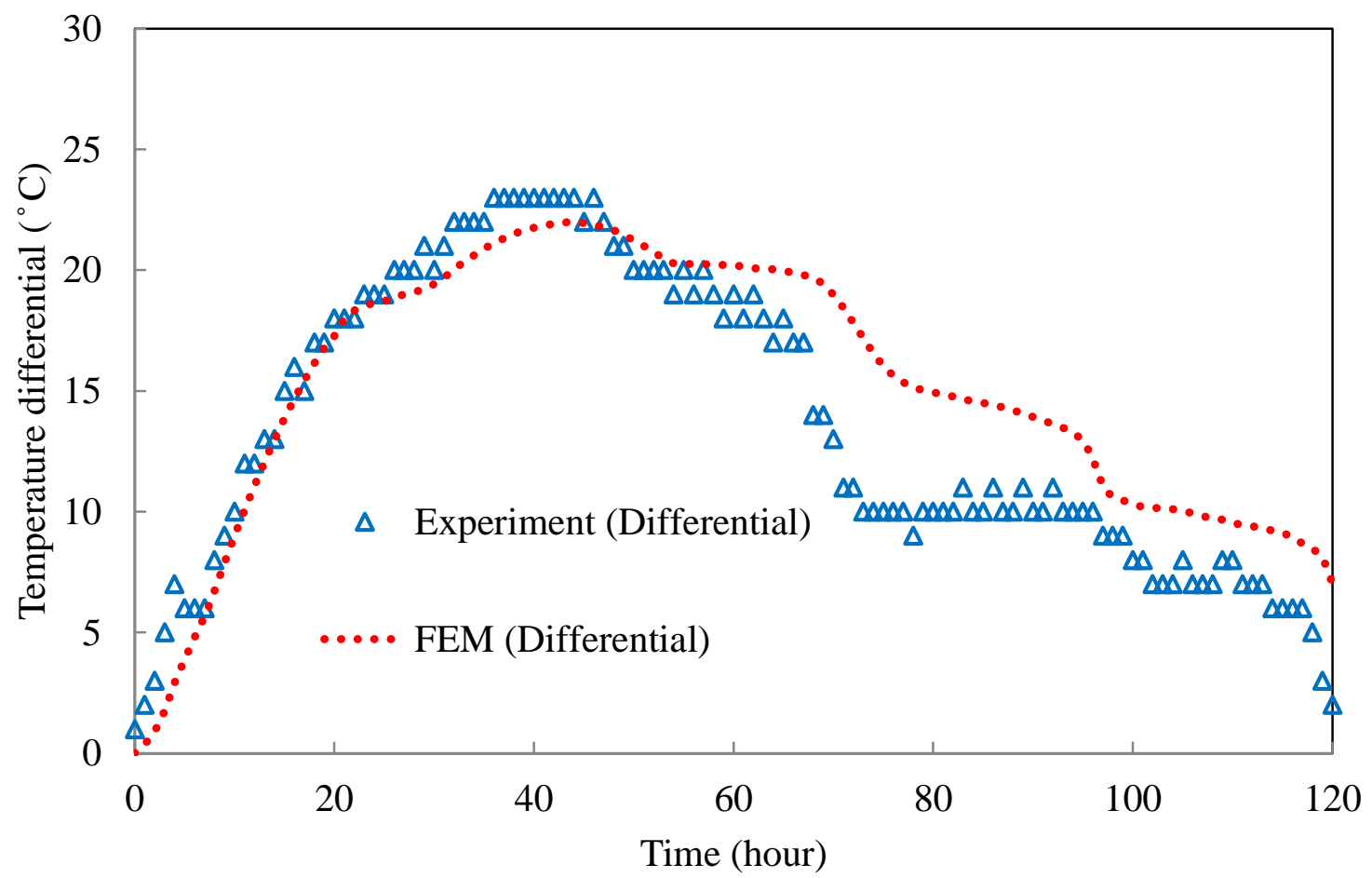

Figure 5-29: Experimental and FEM results of temperature differentials (District 5 cube) 


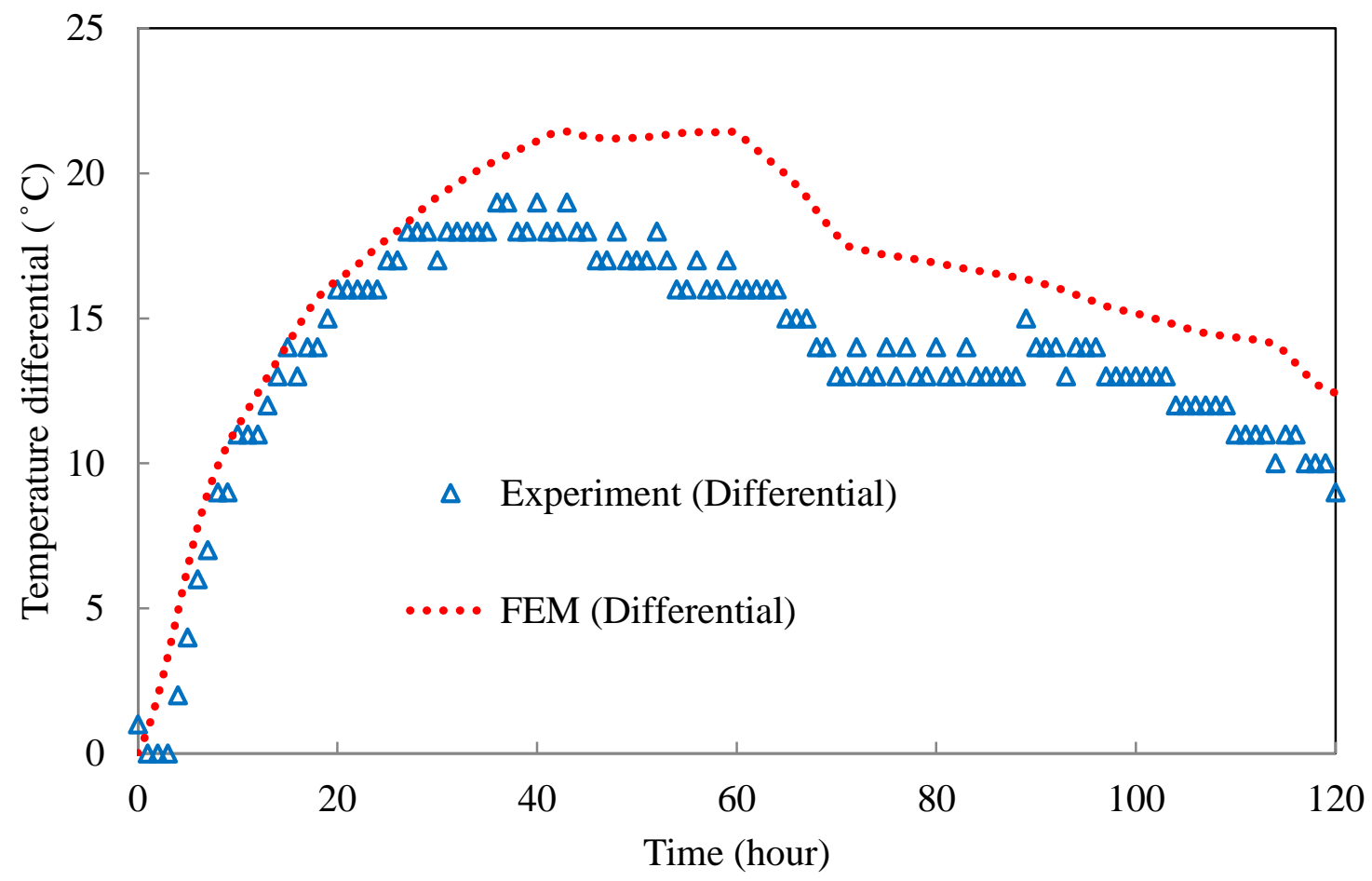

Figure 5-30: Experimental and FEM results of temperature differentials (District 6 cube)

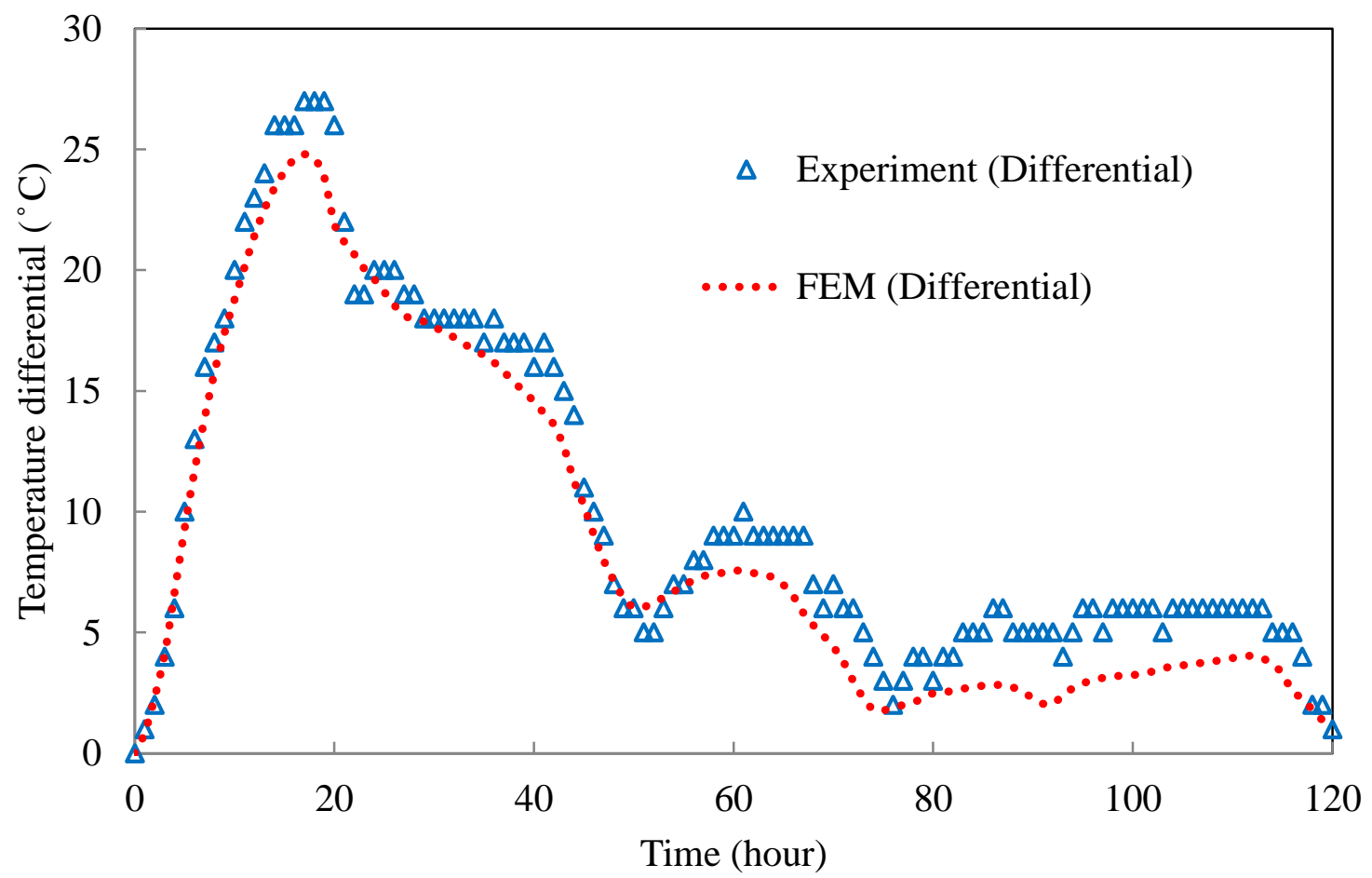

Figure 5-31: Experimental and FEM results of temperature differentials (WVU Cube \#1) 


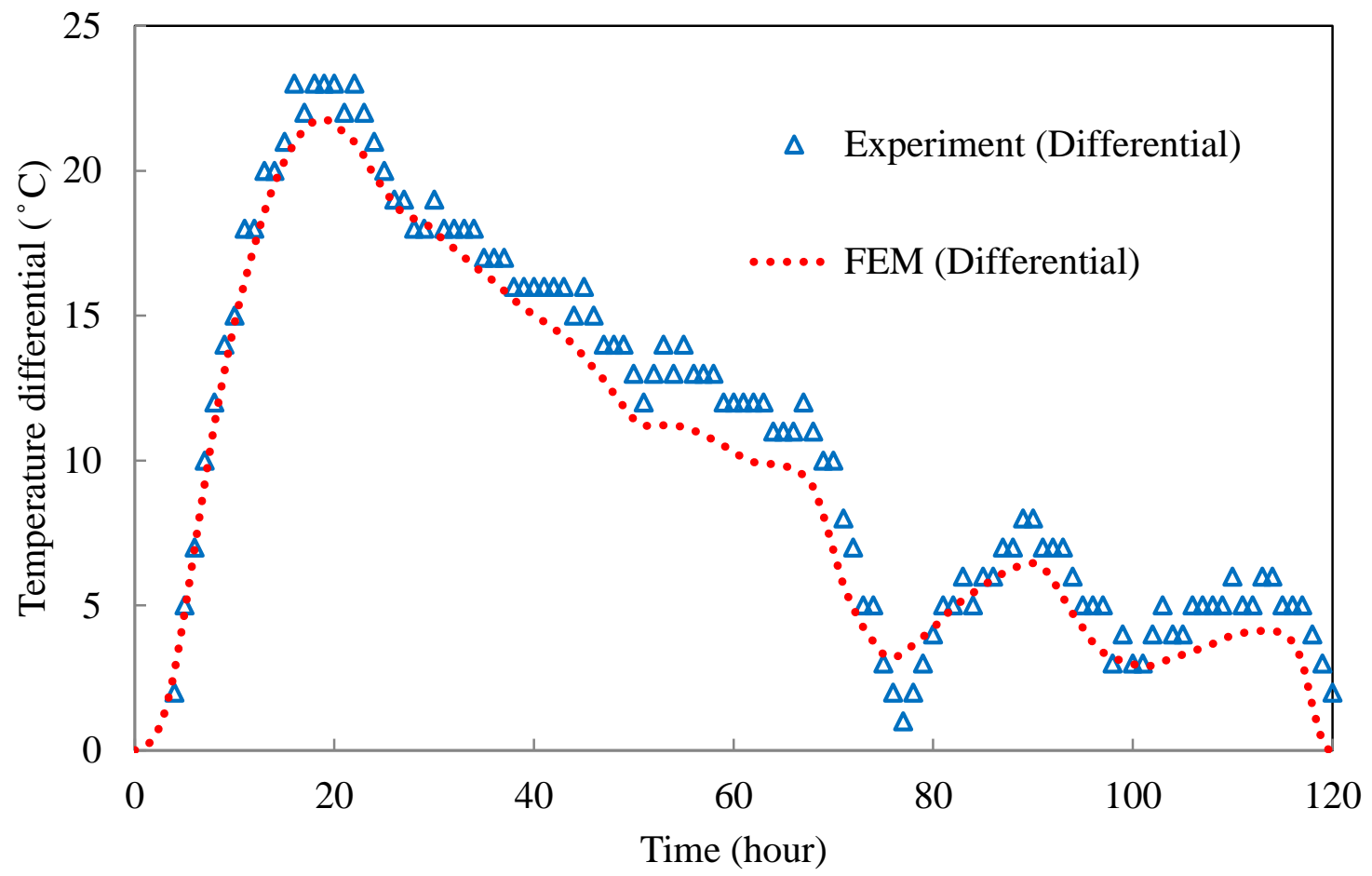

Figure 5-32: Experimental and FEM results of temperature differentials (WVU Cube \#2)

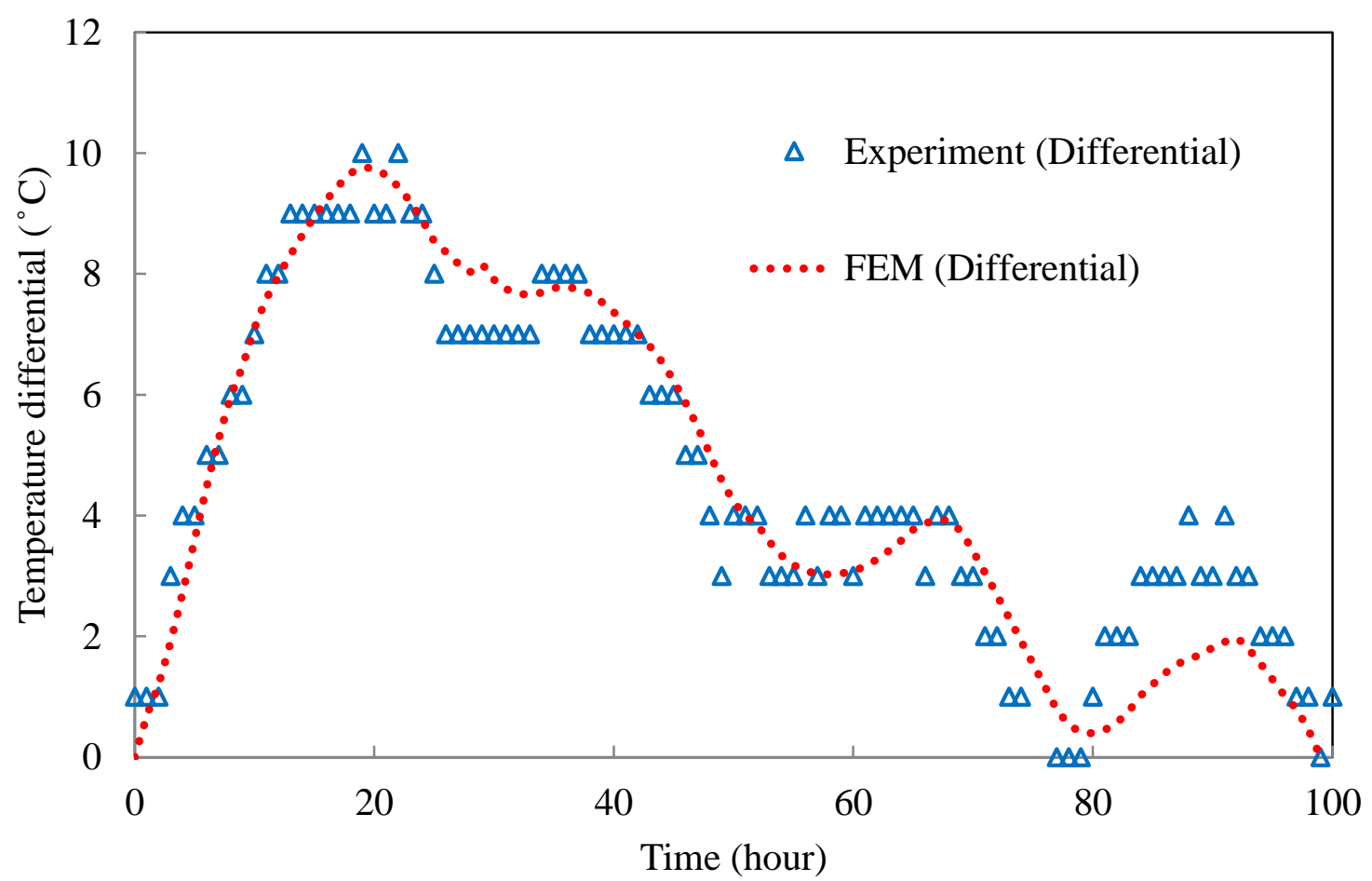

Figure 5-33: Experimental and FEM results of temperature differentials (WVU Cube \#3) 
The temperature distributions from center to surface of the concrete cubes can show how well the concrete is insulated. Temperature loggers were installed along the center-surface path as described in Section 4.2. The center-surface temperature distributions were compared with the FEM results different times $(30,50,70$ hours for 1.8-meter cubes and 15, 30, 45 hours for 1.2-meter cubes). The comparisons of the temperature distributions are shown in Figure 5-34 to Figure 5-38. Among the three 1.8-meter cubes (Figure 5-34, Figure 5-35 and Figure 5-36), District 5 cube has the largest temperature gradient (temperature change per unit distance) because it was the only one using steel formwork. Both the two 1.2-meter cubes used steel formwork. However, the temperature gradient of WVU Cube \#1 was much larger than WVU Cube \#2 only at 15 hours while similar temperature gradients were found at 30 hours and 45 hours (Figure 5-37 and Figure 5-38). The reason was the ambient temperature drop in the first night after casting was much larger in the case of WVU Cube \#1. It caused a higher rate of heat loss and temperature gradient during that night.

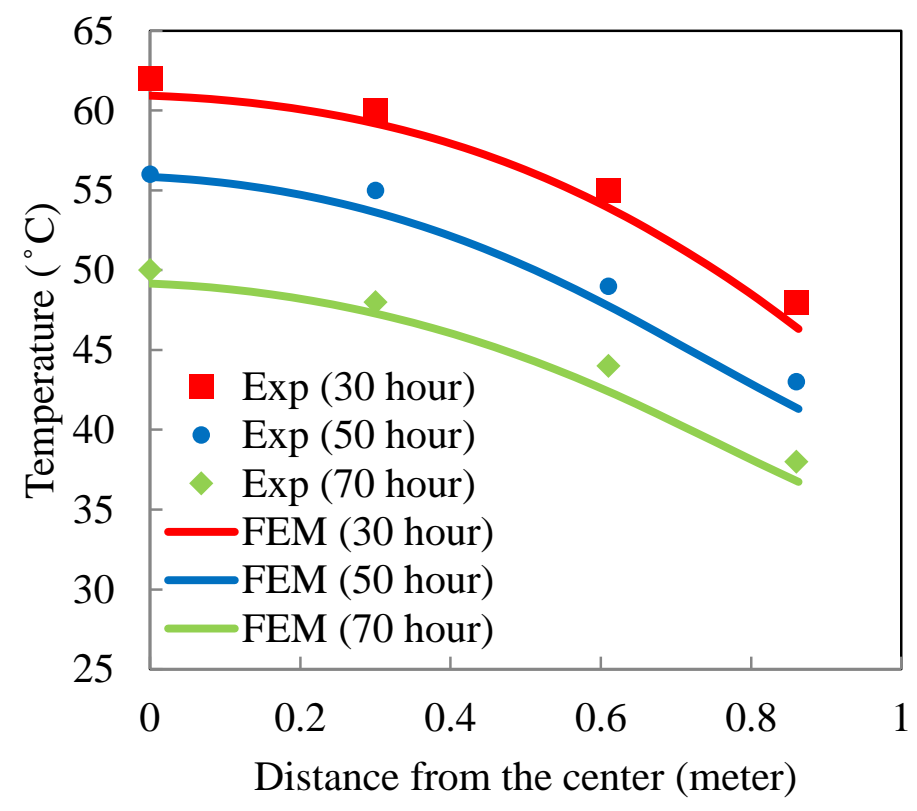

Figure 5-34: Center to surface temperature distribution (District 1 cube) 


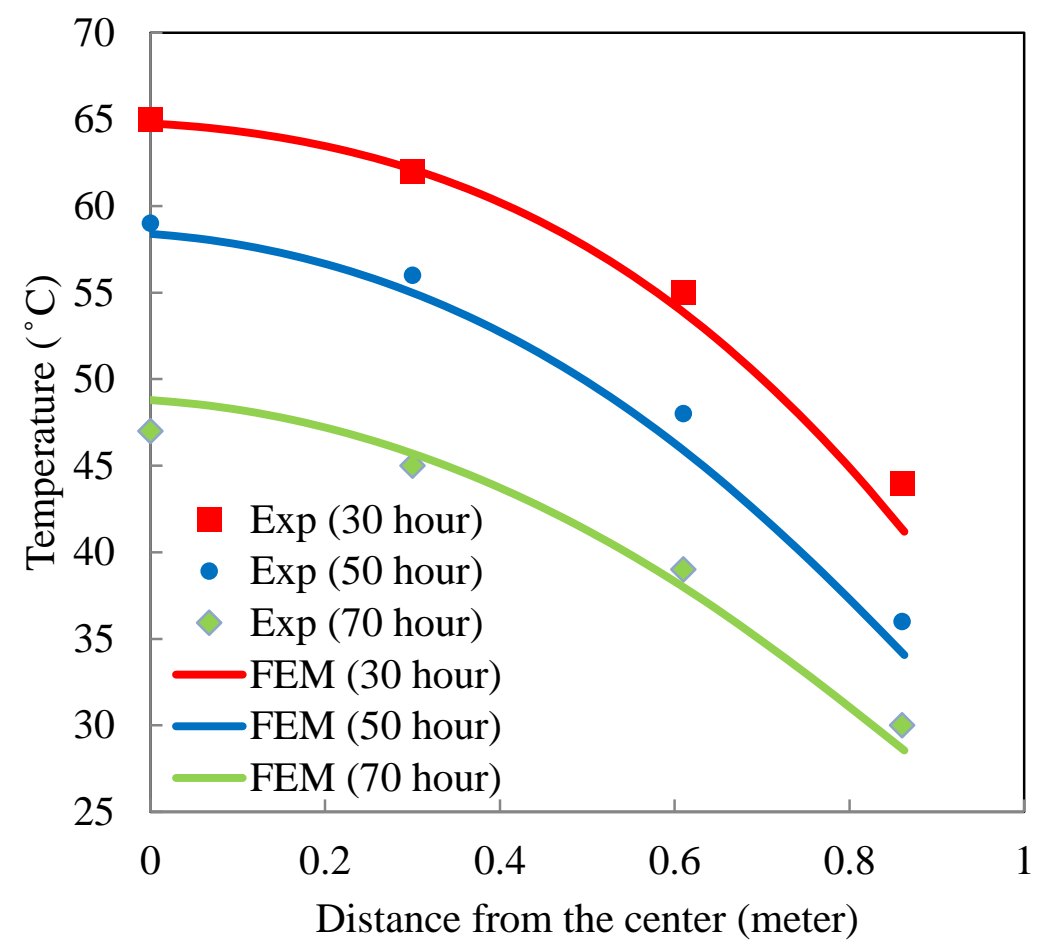

Figure 5-35: Center to surface temperature distribution (District 5 cube)

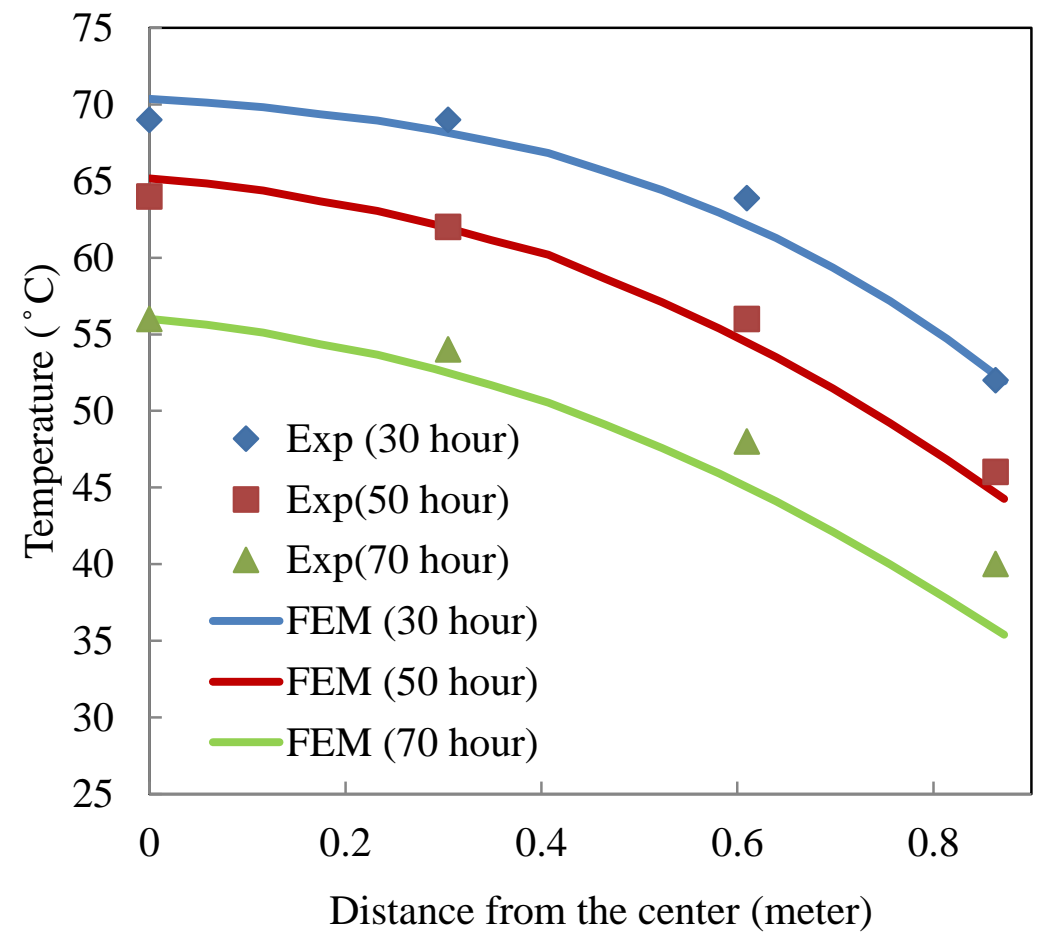

Figure 5-36: Center to surface temperature distribution (District 6 cube) 


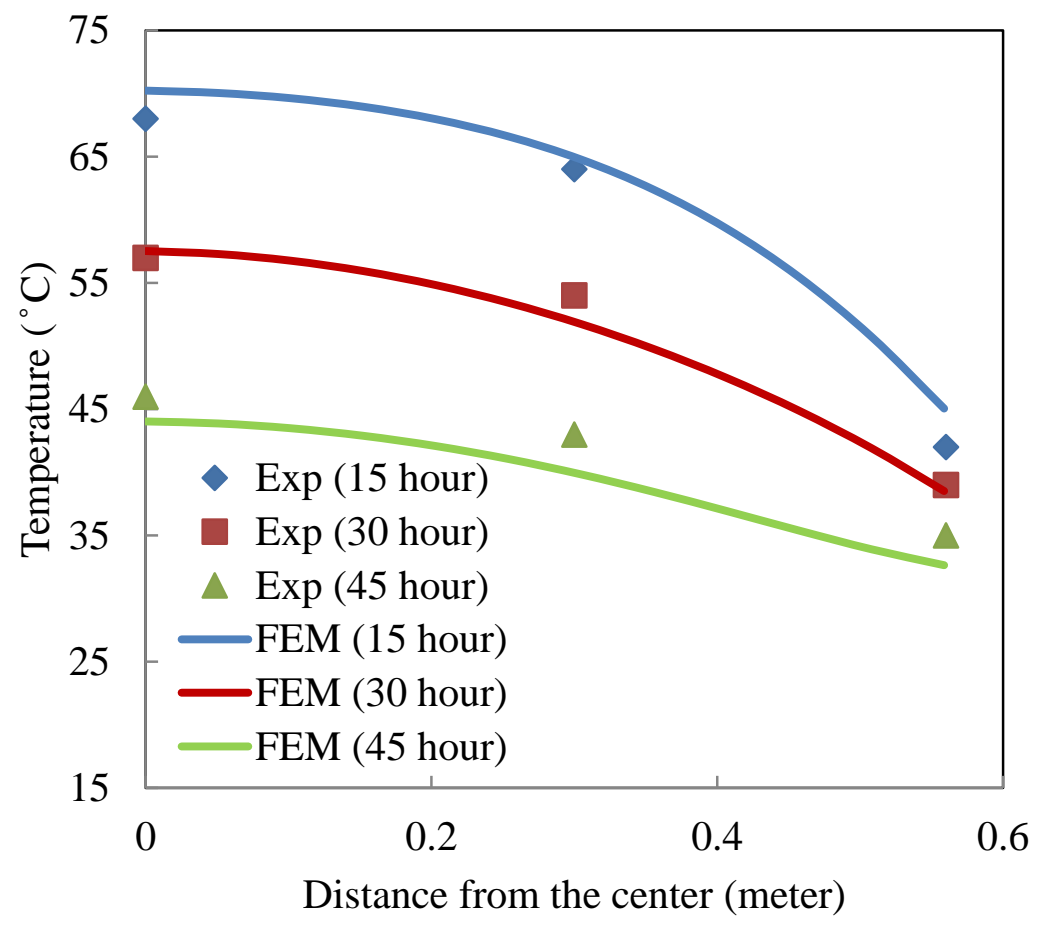

Figure 5-37: Center to surface temperature distribution (WVU Cube \#1)

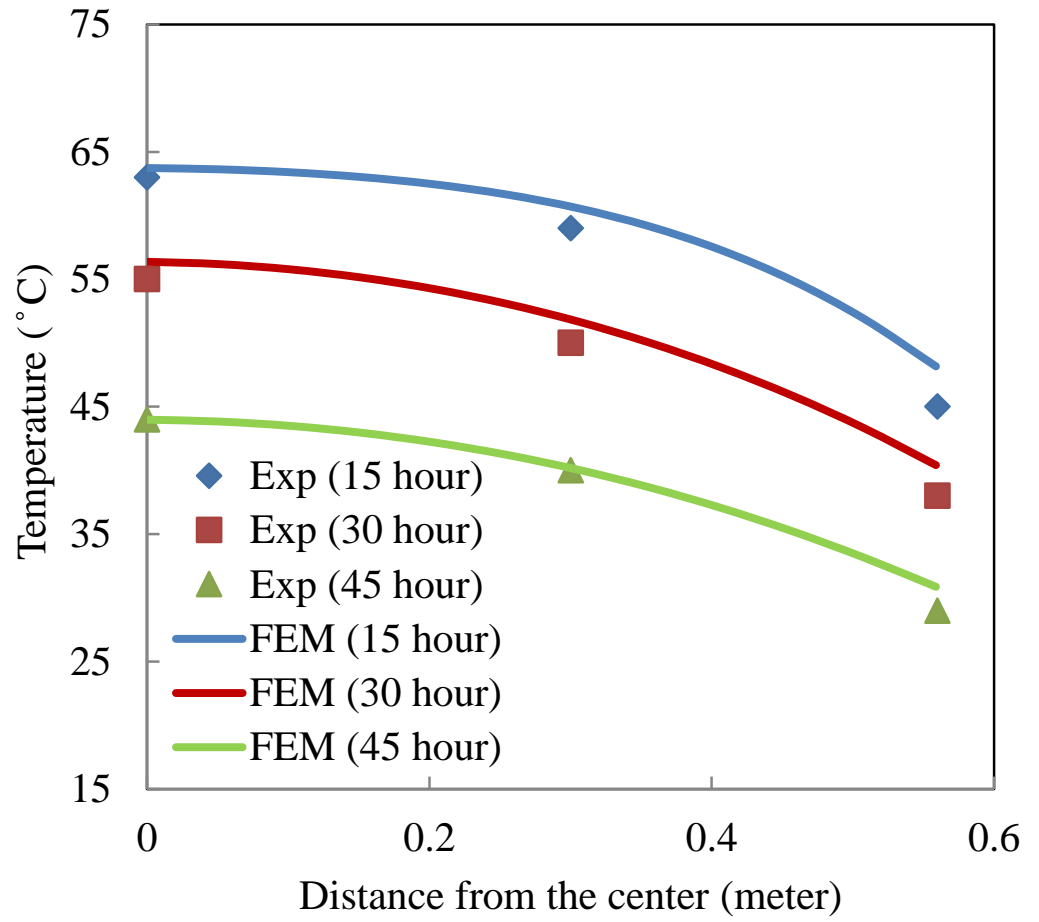

Figure 5-38: Center to surface temperature distribution (WVU Cube \#2) 
The experimentally measured maximum center temperatures $\left(\mathrm{T}_{\max }\right)$ and the maximum temperature differentials $\left(\Delta \mathrm{T}_{\max }\right)$ of each cube were described with the associated influencing factors (Section 4.3). The center and side temperature histories from FEM results can be used to calculate the values of $\mathrm{T}_{\max }$ and $\Delta \mathrm{T}_{\max }$ for the concrete cubes. From FEM results, the values $\mathrm{T}_{\max }$ and $\Delta \mathrm{T}_{\max }$ and the time when it occurred for each cube are compared between the experiments (Section 4.2) and the FEM results as shown in Table 5-6. Small errors (difference between the experiment and FEM) in temperature and time of occurrence are shown in Table 5-7.

Table 5-6: The comparison of $\mathrm{T}_{\max }$ and $\Delta \mathrm{T}_{\max }$ between the experiment and FEM analysis results

\begin{tabular}{|c|c|c|c|c|c|c|c|c|c|}
\hline \multirow{2}{*}{ Cube } & \multirow{2}{*}{ Formwork } & \multicolumn{2}{|c|}{ Experiment } & \multicolumn{2}{c|}{ FEM } & \multicolumn{2}{c|}{ Experiment } & \multicolumn{2}{c|}{ FEM } \\
\cline { 3 - 10 } & & $\begin{array}{c}\mathbf{T}_{\max } \\
\left({ }^{\circ} \mathrm{C}\right)\end{array}$ & $\begin{array}{c}\text { Time } \\
(\text { hour})\end{array}$ & $\begin{array}{c}\mathbf{T}_{\max } \\
\left({ }^{\circ} \mathrm{C}\right)\end{array}$ & $\begin{array}{c}\text { Time } \\
(\text { hour })\end{array}$ & $\begin{array}{c}\Delta \mathbf{T}_{\max } \\
\left({ }^{\circ} \mathbf{C}\right)\end{array}$ & $\begin{array}{c}\text { Time } \\
(\text { hour })\end{array}$ & $\begin{array}{c}\Delta \mathbf{T}_{\max } \\
\left({ }^{\circ} \mathrm{C}\right)\end{array}$ & $\begin{array}{c}\text { Time } \\
(\text { hour })\end{array}$ \\
\hline District 1 & Wood & 63 & 25 & 61.4 & 26 & 18 & 43 & 16.3 & 42 \\
\hline District 5 & Steel & 65 & 28 & 63.9 & 29 & 23 & 41 & 22.0 & 43 \\
\hline District 6 & Wood & 69 & 25 & 70.7 & 25 & 19 & 41 & 21.1 & 42 \\
\hline WVU \#1 & Steel & 68 & 15 & 69.2 & 14 & 27 & 18 & 24.8 & 17 \\
\hline WVU \#2 & Steel & 64 & 16 & 64.8 & 16 & 23 & 19 & 21.8 & 19 \\
\hline WVU \#3 & Wood & 55 & 17 & 55.8 & 16 & 10 & 19 & 9.8 & 19 \\
\hline
\end{tabular}

Table 5-7: Errors in temperature prediction

\begin{tabular}{|c|c|c|c|c|}
\hline \multirow{2}{*}{ Cube } & \multicolumn{4}{|c|}{ Error } \\
\cline { 2 - 5 } & $\begin{array}{c}\text { Tmax } \\
\left({ }^{\circ} \mathrm{C}\right)\end{array}$ & $\begin{array}{c}\text { Time_T } \\
\text { (hour) }\end{array}$ & $\begin{array}{c}\Delta \mathbf{T}_{\max } \\
\left({ }^{\circ} \mathbf{C}\right)\end{array}$ & $\begin{array}{c}\text { Time_} \Delta \mathbf{T}_{\max } \\
\text { (hour) }\end{array}$ \\
\hline District 1 & 1.6 & 1 & 1.7 & 1 \\
\hline District 5 & 1.1 & 1 & 1 & 2 \\
\hline District 6 & 1.7 & 0 & 2.1 & 1 \\
\hline WVU \#1 & 1.2 & 1 & 2.2 & 1 \\
\hline WVU \#2 & 0.8 & 0 & 1.2 & 0 \\
\hline WVU \#3 & 0.8 & 1 & 0.2 & 0 \\
\hline Average & 1.2 & 0.7 & 1.4 & 0.8 \\
\hline St. Dev. & 0.38 & 0.52 & 0.76 & 0.75 \\
\hline
\end{tabular}




\subsection{A Case Study of a Real World Concrete Element}

One of the pier-caps of the Ices Ferry Bridge was used as a case study to test the thermal analysis model. A picture of the studied pier-cap is shown in Figure 5-39, which has a maximum and minimum dimensions of 11.25 meters and 1.83 meters. Same with WVU Cube \#3, Mix 5 in Table 5-2 was used as the mix design. Steel formwork was used for the construction. The piercap was constructed on top of the pier-stem made of hardened concrete with an initial concrete temperature of $15{ }^{\circ} \mathrm{C}$. The ABAQUS model of this pier-cap is shown in Figure 5-40 with marked dimensions. Using the modeling method described in this chapter, the temperature profile histories were calculated. The temperature distribution in the center cross-sectional cut at 33 hours (when maximum center temperature occurred) after construction is shown in Figure 5-41. The center and side temperature history along with the FEM calculation results are presented in Figure 5-42.

The predicted center temperature seems to be decreasing slower than the measured temperature. Unlike the concrete cubes, the pier-cap structure was embedded with heavy steel reinforcement inside of the concrete body. The thermal conductivity of the steel is much higher than plain concrete. Therefore, the heat flow from the center to surface of the reinforced concrete should be faster than plain concrete. In the finite element model, a thermal conductivity of plain limestone concrete $\left(2.1 \mathrm{~W} / \mathrm{m} / \mathrm{K}\right.$ or $\left.1.2 \mathrm{BTU} / \mathrm{ft} / \mathrm{hr} /{ }^{\circ} \mathrm{F}\right)$ was used for the entire pier-cap body. Therefore, the modeled heat transfer was slower than the actual results. The influence of the steel reinforcement is depending on the size, amount and locations of the steel bars. Further studies are recommended on the influence of the steel reinforcement. 


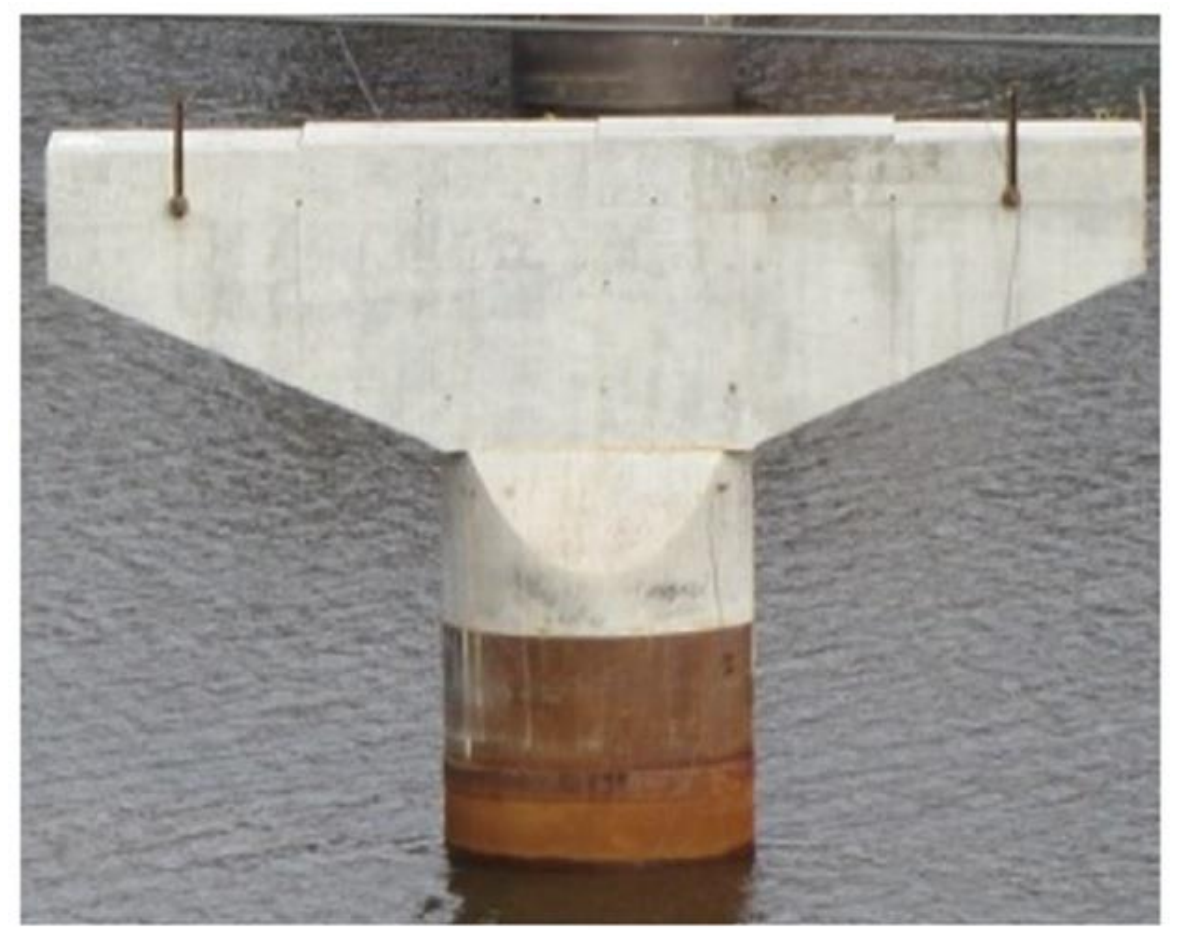

Figure 5-39: A picture of constructed Ices Ferry Bridge Pier-cap

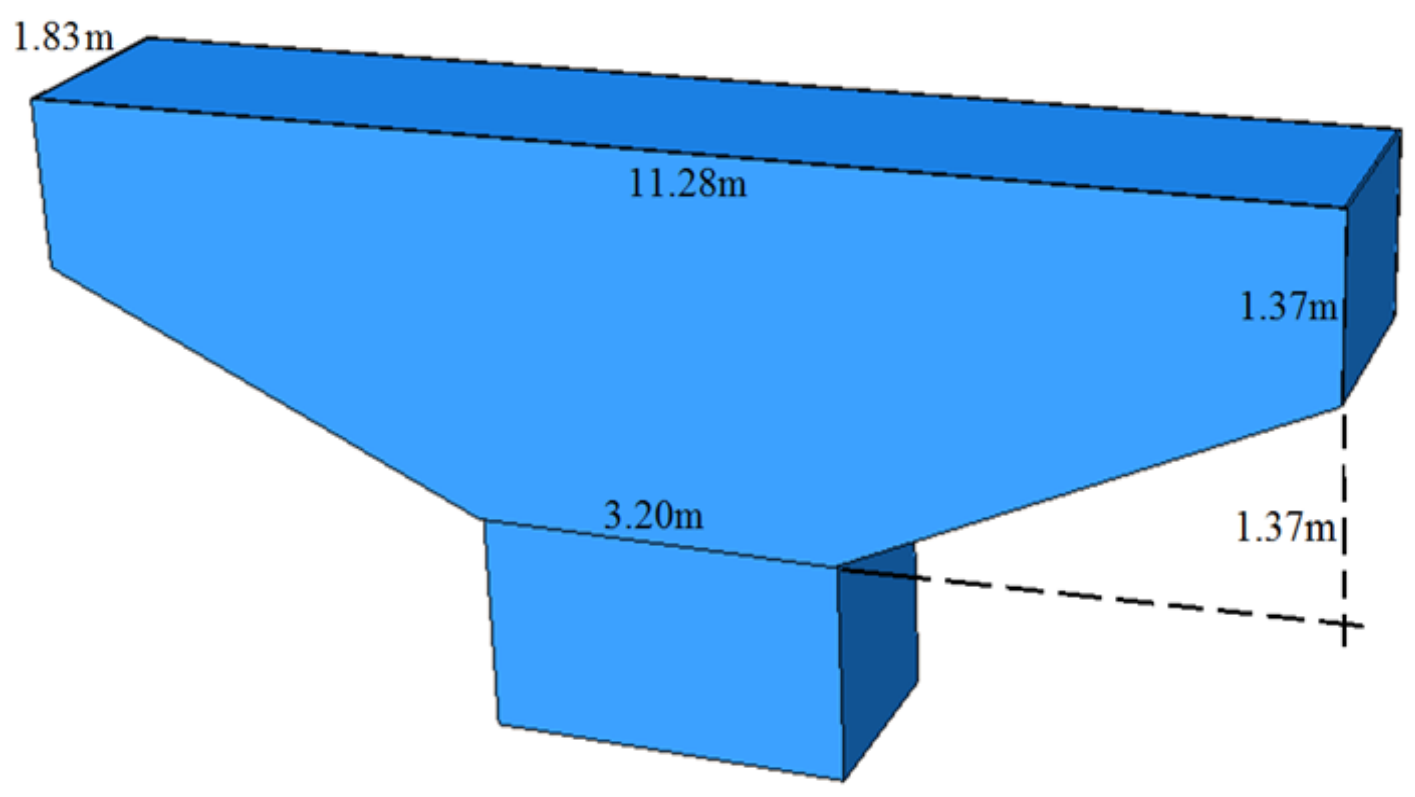

Figure 5-40: Geometry of the Ices Ferry Bridge Pier-cap 

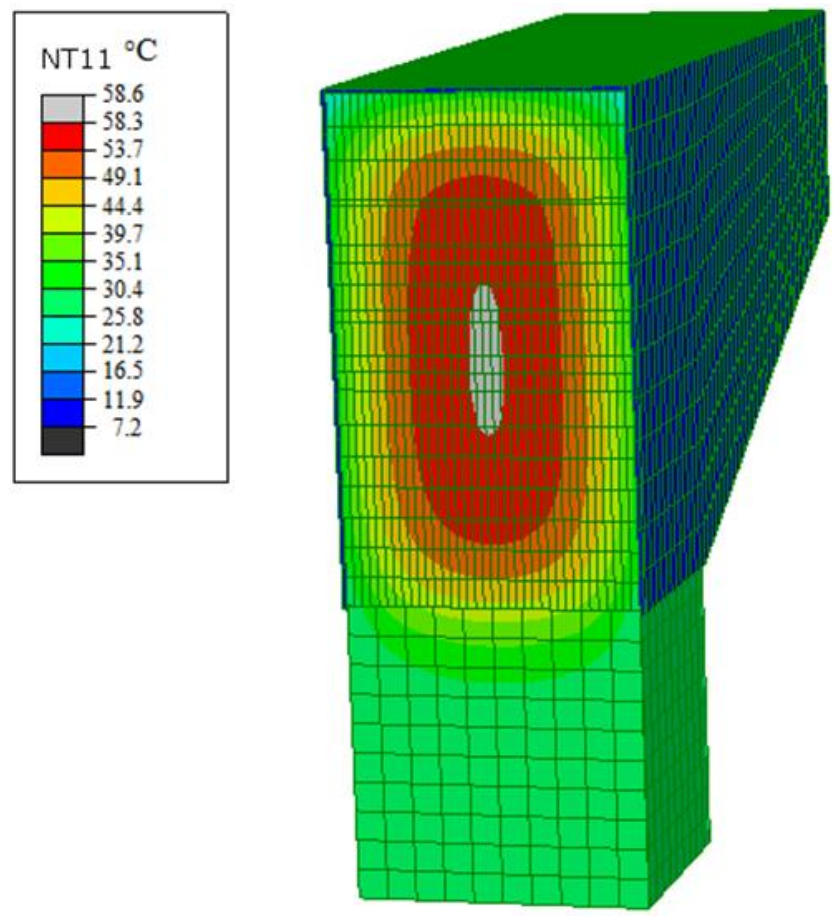

Figure 5-41: Temperature distribution of the center cross-sectional cut at 33 hours

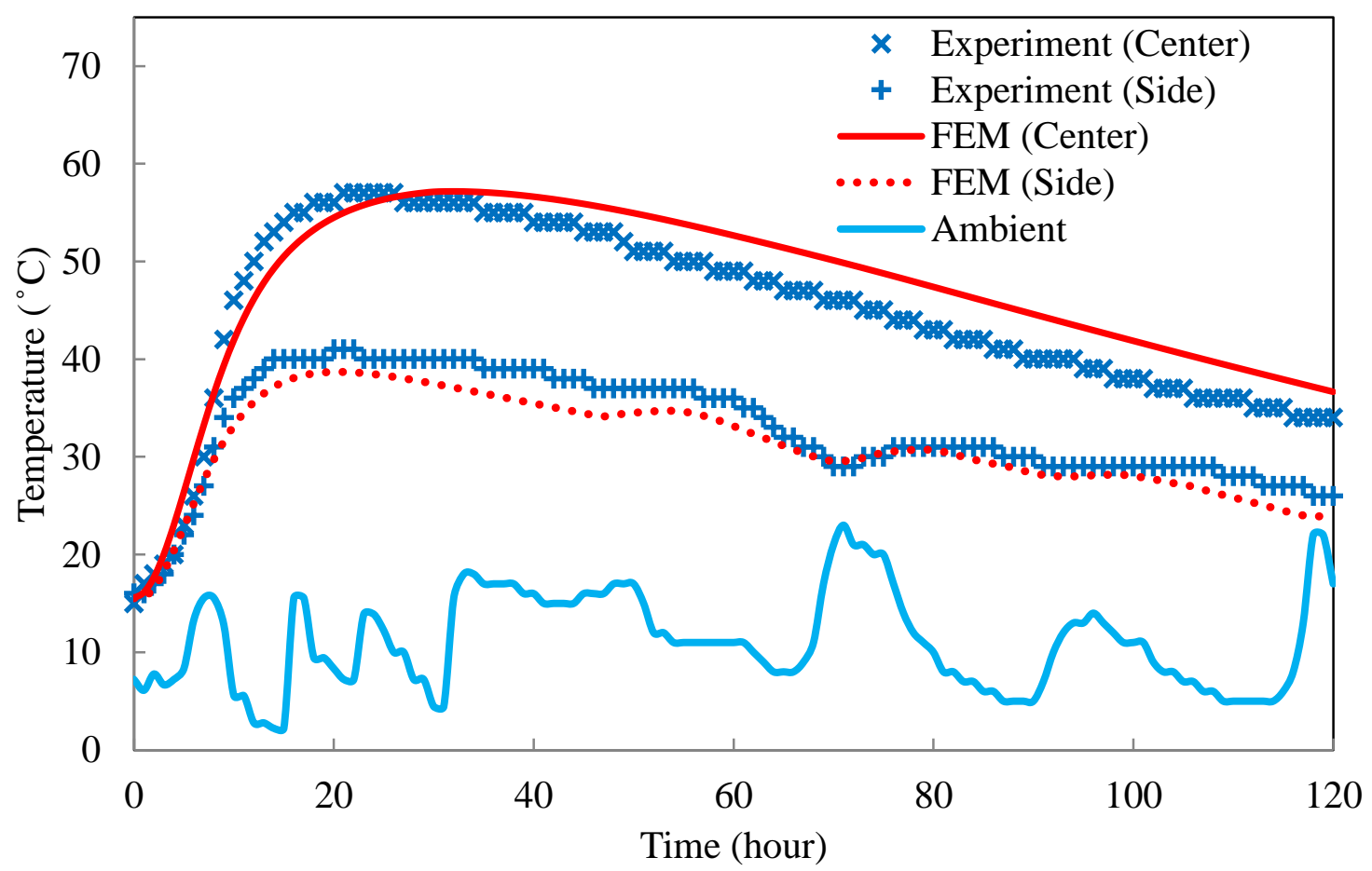

Figure 5-42: Experimental and FEM results of center and side temperatures (pier-cap) 


\subsection{Statistical Analysis of the Thermal Analysis Results}

The correlation coefficient (a value between -1 and +1 ) shows how strongly two variables are related to each other. A correlation coefficient of " $+1 "$ indicates a perfect positive correlation, "-1" indicates a perfect negative correlation and "0" indicates no correlation. The correlation coefficient can be calculated using Eq. (5.11). Correlation test was performed on temperatures between experimental measurements and FEM results (120 hours) for each cube as well as the pier-cap. The comparison of temperature between experiment and FEM is shown in Figure 5-22 to Figure 5-27 and Figure 5-42. The calculated correlation coefficients are summarized in Table 5-8. The correlation coefficients between the experiment and FEM temperatures for all cubes (both side and center) are very high (above 0.95) which indicate very strong correlations. The average correlation coefficients for center and side locations among all concrete structures are 0.9866 and 0.9944 , respectively.

$\operatorname{Correl}(x, y)=\frac{\sum\left(x-x^{\prime}\right)\left(y-y^{\prime}\right)}{\sqrt{\sum\left(x-x^{\prime}\right)^{2}\left(y-y^{\prime}\right)^{2}}}$

$\mathrm{x}$ : Temperature data from experimental measurements

X': Average temperature data from experimental measurements

y: Temperature data from FEM results

$y^{\prime}:$ Average temperature data from FEM results 
Table 5-8: Correlation test results

\begin{tabular}{|l|l|c|}
\hline \multicolumn{2}{|c|}{ Concrete cube } & Hourly data for 120 hours \\
\cline { 3 - 3 } District 1 cube & Center & 0.9946 \\
\cline { 2 - 3 } & Side & 0.9811 \\
\hline \multirow{2}{*}{ District 5 cube } & Center & 0.9920 \\
\cline { 2 - 3 } & Side & 0.9833 \\
\hline \multirow{2}{*}{ District 6 cube } & Center & 0.9920 \\
\cline { 2 - 3 } & Side & 0.9833 \\
\hline \multirow{2}{*}{ WVU Cube \#1 } & Center & 0.9973 \\
\cline { 2 - 3 } & Side & 0.9763 \\
\hline \multirow{2}{*}{ WVU Cube \#2 } & Center & 0.9975 \\
\cline { 2 - 3 } & Side & 0.9873 \\
\hline \multirow{2}{*}{ WVU Cube \#3 } & Center & 0.9930 \\
\cline { 2 - 3 } & Side & 0.9918 \\
\hline \multirow{2}{*}{ Pier-cap } & Center & 0.9698 \\
\cline { 2 - 3 } & Side & 0.9866 \\
\hline \multirow{2}{*}{ Average } & Center & 0.9944 \\
\cline { 2 - 3 } & Side & 0.9839 \\
\hline
\end{tabular}

\subsection{Conclusions}

In this chapter, a procedure to predict temperature profile histories of early age concrete members using finite element calculation was described. To maximize the modeling accuracy, all the material related parameters are addressed in details. The adiabatic temperature rise of the concrete was determined experimentally using an adiabatic calorimeter and converted into a mathematical formulation for finite element modeling. Thermal properties including specific heat and thermal conductivity were considered to be degree of hydration dependent and determined individually for each element in the model. The interface conductance between concrete and steel formwork was determined experimentally and implemented to account for the thermal resistance provided by the interface. External surface convection for a steel-air interface 
was used on the formwork surface. Based on the results from the seven concrete cubes, the modeling method and experimental procedures developed have been validated to exhibit reasonable accuracy and can be used to predict temperature profile histories for early age concrete members. 


\section{CHAPTER 6 STRESS ANALYSIS}

\subsection{Introduction}

Currently, the most common thermal control practice is to limit the temperature differential between the center and the surface of the concrete structures (see Section 2.5.1). However, only temperature differential is not conclusive enough to determine cracking risks due to thermal stresses. Nagy and Thelandersson (1994) pointed out that the development of concrete Young's modulus is very important in thermal-stress modeling. Gutsch and Rosatasy (1995) suggested the importance of tensile strength development and the tensile creep behavior in terms of cracking potentials. Lawrence et al. (2012) reported that temperature differential alone was not sufficient to determine thermal stresses. Instead, a thermal stress analysis considering the changes of concrete material properties, such as thermal expansion coefficient, elastic modulus and viscoelastisity should be used.

During the early age, the non-uniform temperature profile distribution causes disproportionate thermal expansions within the concrete body. The surface concrete in lower temperatures can be under high tensile stresses caused by restricting the relative thermal expansions from internal concrete. Whether the high surface tensile stresses can cause cracking is depending on the stress to strength ratio at the critical locations. During the hydration process of the early age concrete, both the thermally-induced stresses and the concrete strength are developing but at different rates. Cracks are most likely to occur at the critical locations where tensile stress exceeds the tensile strength. Figure 6-1 originally presented by Tia et. al. (2010) described an example of thermal stress and concrete tensile strength development. The cracking zone in the figure refers to the time when the tensile stress exceeds tensile strength. In practice, 
this cracking time zone is most likely to occur between 0.5 to 2 days after concrete placement, depending on the member geometry, size, boundary restraint and the ambient temperature variations.

The development of thermally-induced stresses is a complicated phenomenon which includes the variability of temperature distribution, concrete thermal and mechanical properties, and the viscoelastic behavior of early age concrete. In recent years, finite element models have been used to predict the thermally-induced stresses of early age concrete members. Waller et al. (2004) presented a model using CESAR-LCPC which included two modules, TEXO and MEXO, to perform the thermal analysis and stress analysis of concrete structures. Wu et al. (2011) described the procedures calculating thermally-induced stresses for a wall element using ANSYS. Tia et al. (2013) evaluated bridge footing elements with wooden formwork using TNO Diana software. Their research findings are very helpful to this topic, however, the modeling procedure of the viscoelastic behaviors due to tensile or compressive stresses were not detailed enough for replication purposes.

Researchers have emphasized the importance of concrete's viscoelasticity, which is crucial in calculating thermal stresses. Bažant's B3 model (Bažant, 1988), which was designed for long-term creep behaviors, has been widely adopted recently to describe creep behaviors of early age concrete. Østergaard et. al. (2001) improved the B3 model on the early age creep behavior by adjusting the "aging" term, while Wei and Hansen (2013) made an adjustment on the later ages by modifying the "flow" term of B3 model. However, the temperature, although often ignored in the creep calculation, has a significant effect on early age concrete creep behavior. Using the equivalent age to consider the temperature effect in creep was suggested by Bažant and Baweja (2000). Atrushi (2003) also showed the usage of equivalent age on the modified 
double power law (DPL) with some experimental proof. Luzio and Cusatis (2012) validated the solidification-microprestress-microplane (SMM) model considering moisture variation and moisture diffusion associated with environmental exposure and internal water consumption.

This chapter describes the thermal-stress calculation of early age concrete using a modified B3 model considering the aging and temperature effect in a variable loading and temperature environment. A thermal stress calculation algorithm with experimental testing and validations are presented. The only mix design discussed in this chapter is a 6-bag (43 $\mathrm{kg}$ per bag of cement) straight Class B which is Mix 4 (Table 5-2). A lot of research effort was spent in this particular mix design because it will be later used as the base-line mixture for the mass concrete definition. In Section 5.3.1, the CRD-C thermal diffusivity test was conducted for Mix 4. In this chapter, different mechanical properties were also tested and used in the FEM stress analysis.

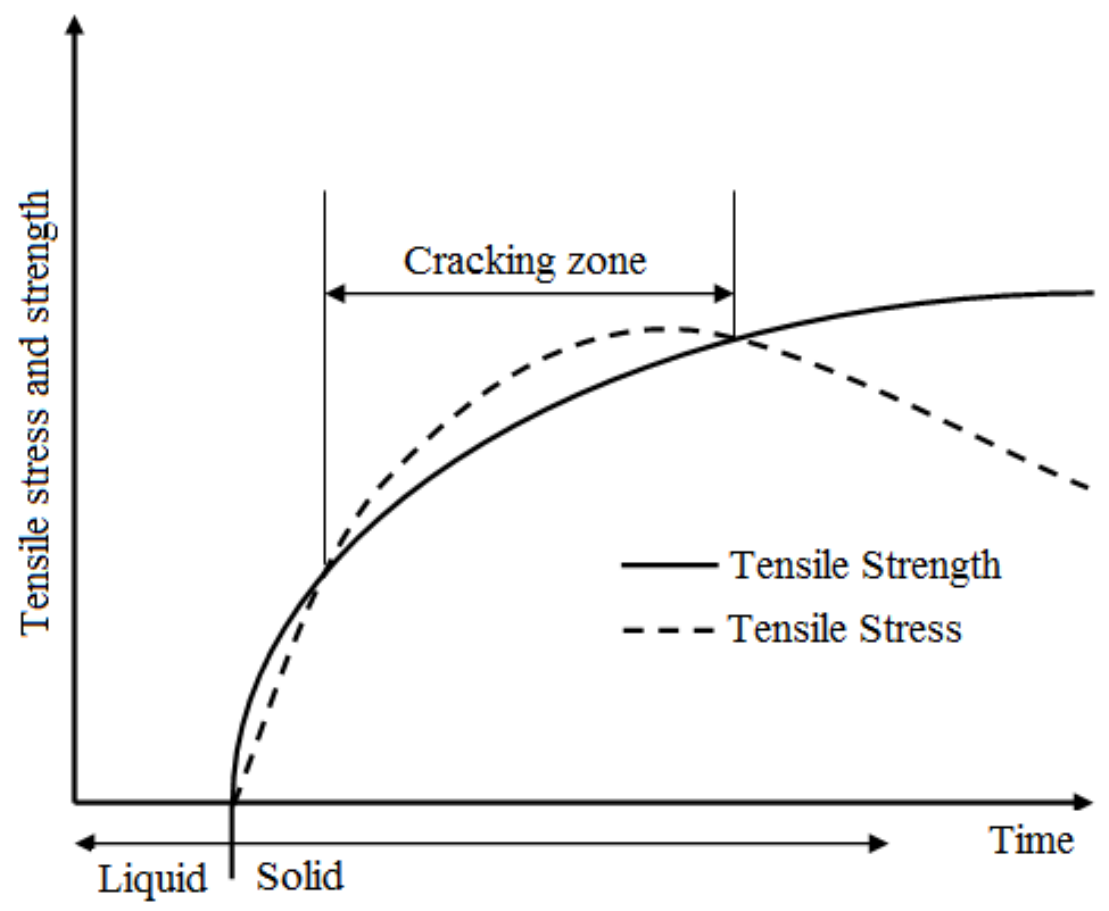

Figure 6-1: Thermal stress and tensile strength development (Tia et. al., 2010) 


\subsection{Sensor Installation in WVU Cube \#1 and \#2}

In addition to the temperature loggers (see Section 4.2.5), WVU Cube \#1 and \#2 were installed with Geokon vibrating wire strain gages (Model 4200, gage length $15.25 \mathrm{~cm}$, Figure 6-2) in order to study the development of thermal stresses. The internal structure of Geokon gage is shown in Figure 6-3. The stain is able to continuously measure the strain changes between the two circular end blocks (O-ring end block as in Figure 6-3) based on the vibrating frequency measurements of the internal metal wire connecting the two end blocks. It also has an internal thermistor measuring temperature at the middle of the strain gage. Therefore, the temperature variation induced stain changes to the vibrating wire itself can be eliminated from the concrete strain readings.

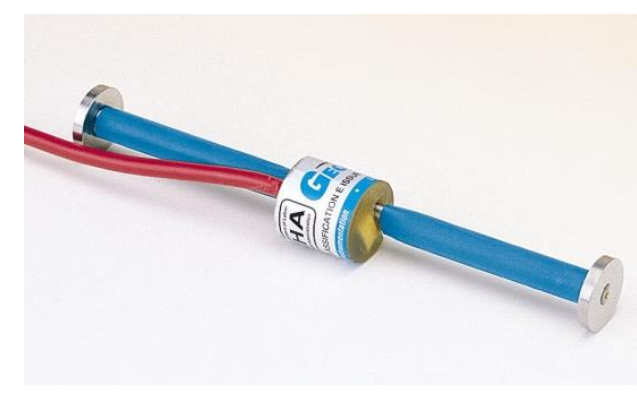

Figure 6-2: Geokon embedment strain gage Model 4200

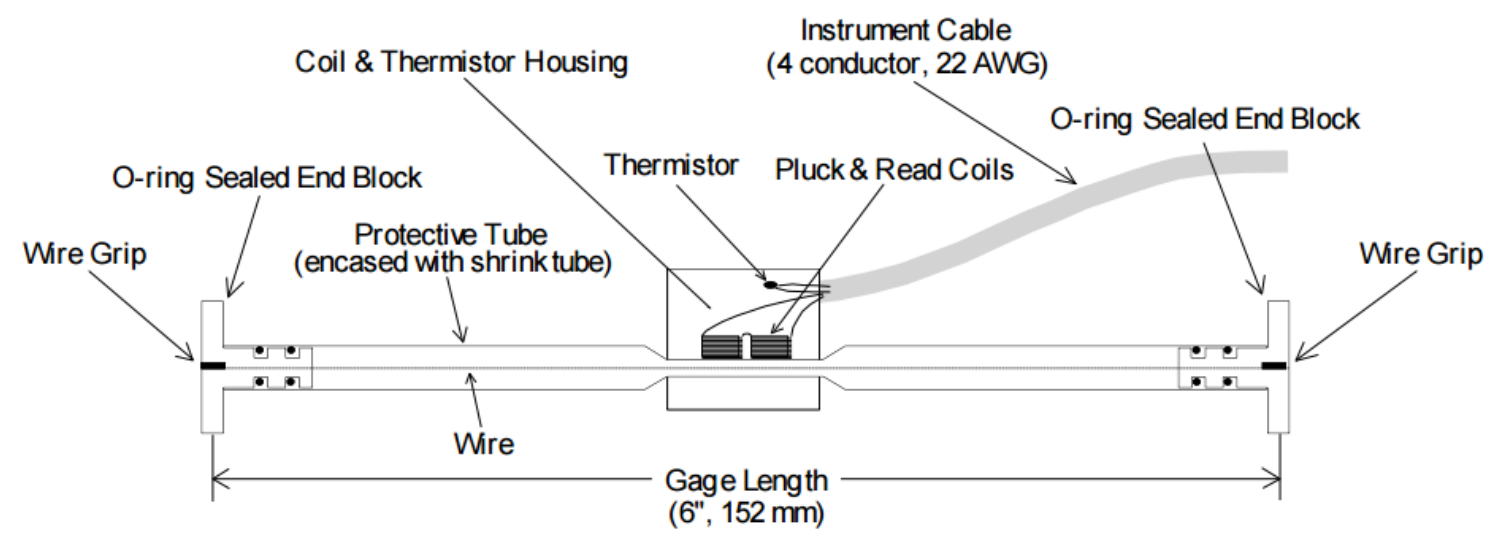

Figure 6-3: The internal structure of the strain gage 
Figure 6-4 shows the supporting grid made of \#5 steel bar and the installed sensors. The Geokon strain gages were installed at Location A for Cube 1 and Location A, B, and C for Cube 2. The locations of the strain gage are illustrated in Figure 6-4; Location A and B are $10 \mathrm{~cm}$ and $5 \mathrm{~cm}$ from the center of the side surface, while Location $\mathrm{C}$ is $2.5 \mathrm{~cm}$ from the center of the top surface. Figure 6-5 shows two pictures of the cube casting (WVU Cube \#1 and \#2).
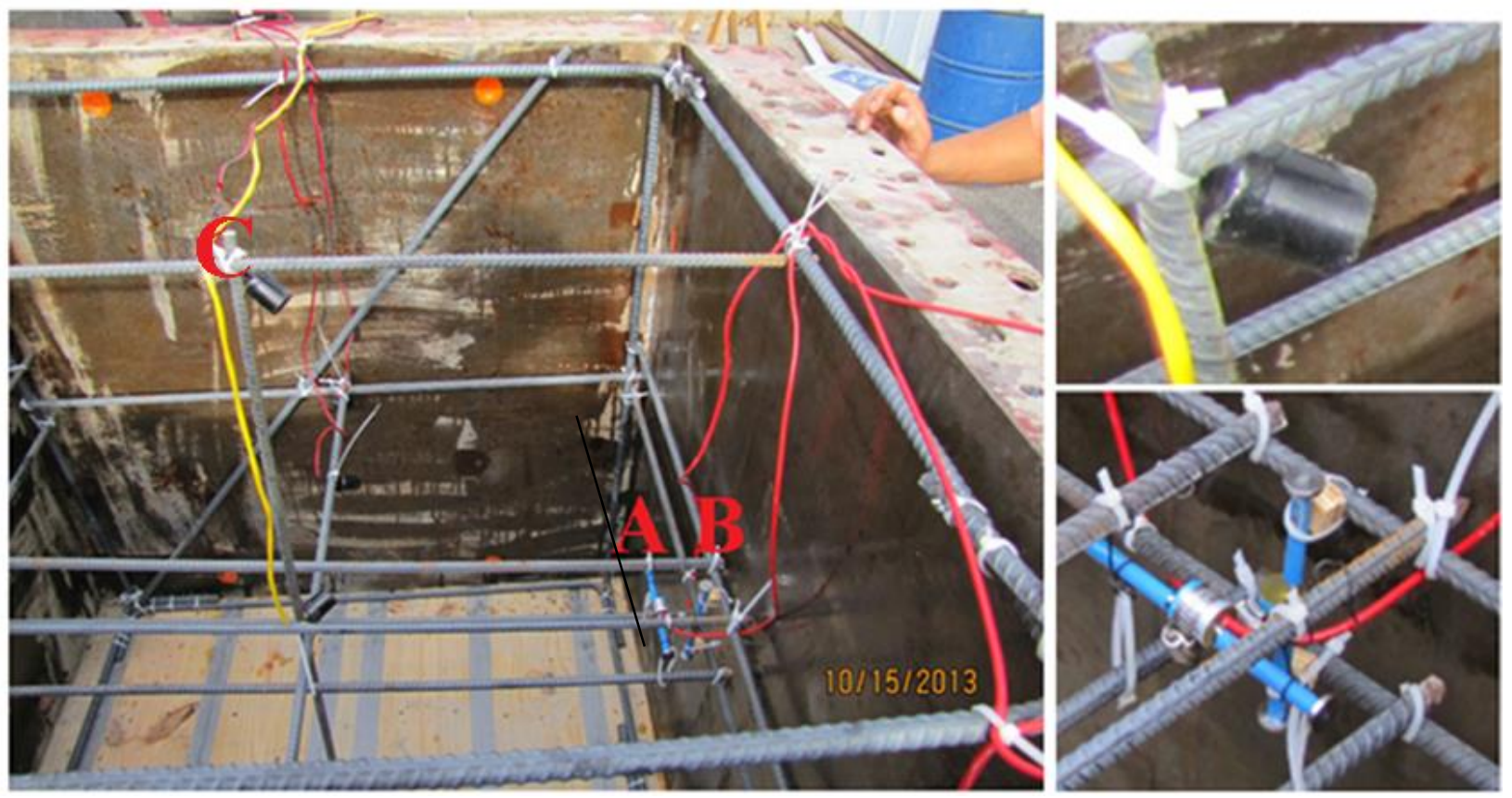

Figure 6-4: A pictures of the support grid and sensors before casting
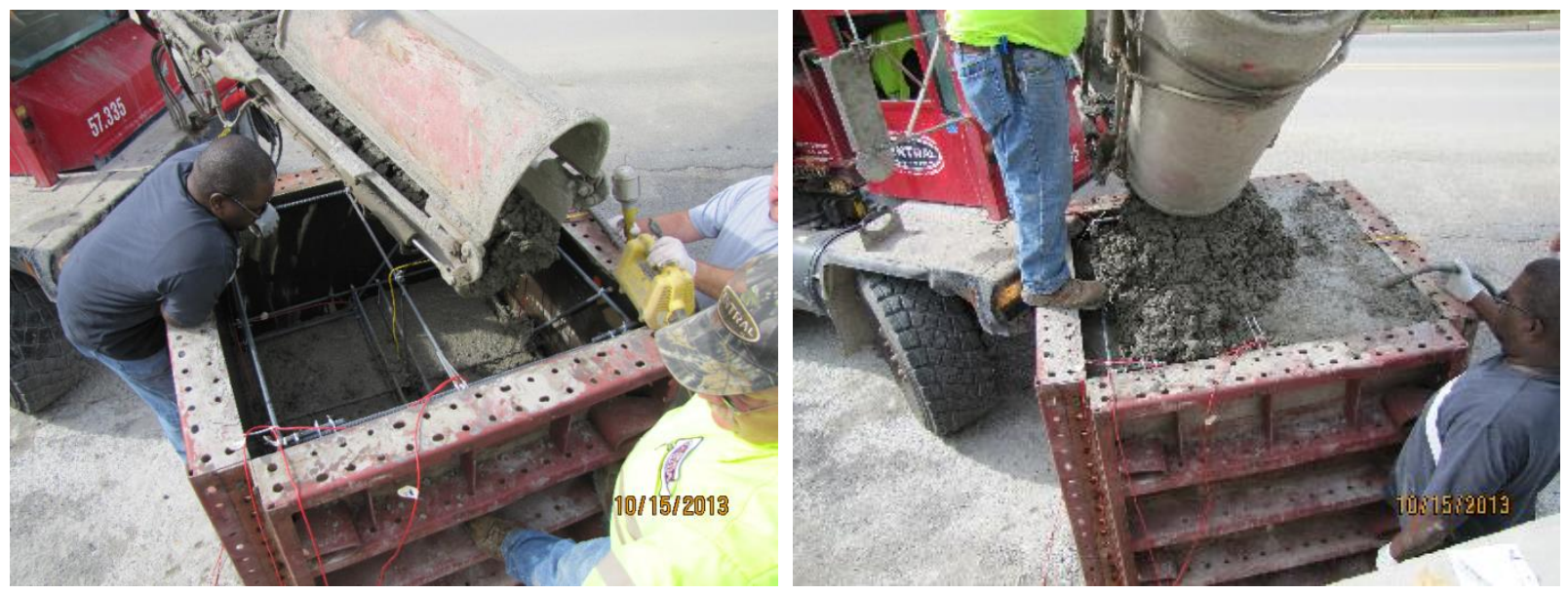

Figure 6-5: Cube casting pictures 


\subsection{Mechanical Properties of Early age Concrete}

In order to calculate the thermal stresses, accurate estimations of the concrete tensile strength and the modulus of elasticity development are crucial. The degree of hydration $(\alpha)$ calculated using Eq. (2.14) was used to estimate the concrete strength and modulus at any given time, which is a function of the equivalent age, $t_{e}$. The equivalent age can be calculated using the Arrhenius equation, Eq. (2.16) (Freiesleben-Hansen \& Pedersen, 1985), which is depending on the concrete temperature history and the activation energy, $E_{a}$. The activation energy of Mix 4 from Table 5-2 was determined to be $41,800 \mathrm{~J} \mathrm{~mol}^{-1}$ by Yikici and Chen (2013) following ASTM C 1074-10 procedures. The ultimate degree of hydration, $\alpha_{u}$, can be calculated using Eq. (2.13) (Mills, 1966). The hydration parameters, $\tau$ and $\beta$, were two constants depending on the mix design. $\tau=14.0$ and $\beta=0.94$ were determined from the adiabatic temperature rise tests and curve fitting method as described in Section 5.2.2 and a published research paper by Lin and Chen (2015).
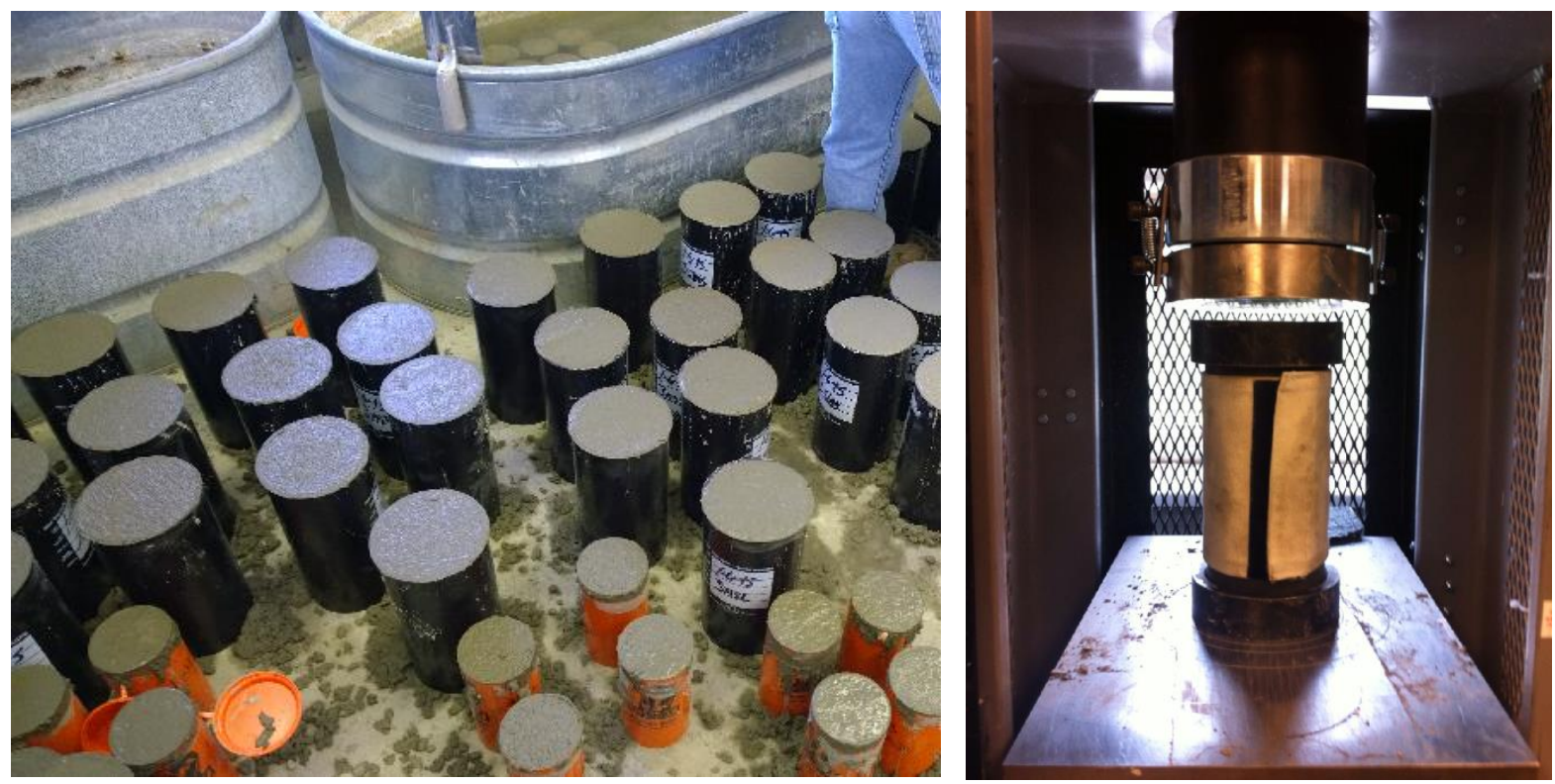

Figure 6-6: Compressive strength testing 


\subsubsection{Concrete strength testing}

The compressive strength in development curves of Mix 4 (6-bag straight Class B, WV) were tested using the $15 \mathrm{~cm} \times 30 \mathrm{~cm}(6$ in $\times 12$ in $)$ cylinders and $10 \mathrm{~cm} \times 20 \mathrm{~cm}(4$ in $\times 8$ in $)$ cylinders (Figure 6-6). The concrete samples were cured at a constant temperature of $23{ }^{\circ} \mathrm{C}$ $\left(73{ }^{\circ} \mathrm{F}\right)$. No significant differences in compressive strength were spotted due to the sample size. The test was repeated at least four times. A typical early age $(0.5,1,2,3$ and 7 days $)$ compress strength development curve is shown in Figure 6-7.

In the past, many researchers have shown a linear relationship between concrete compressive strength and degree of hydration (Byfors, 1980; Ulm and Coussy, 1996; Lokhorst 1998; Schutter 2002). In this case, the compressive strength and degree of hydration $(\alpha)$ exhibited a high linear correlation as shown in Figure 6-8. The concrete ages were converted to the degree of hydration using Eq. (2.14). This linear relationship, Eq. (6.1) will be used to describe the concrete strength at any given degree of hydration.

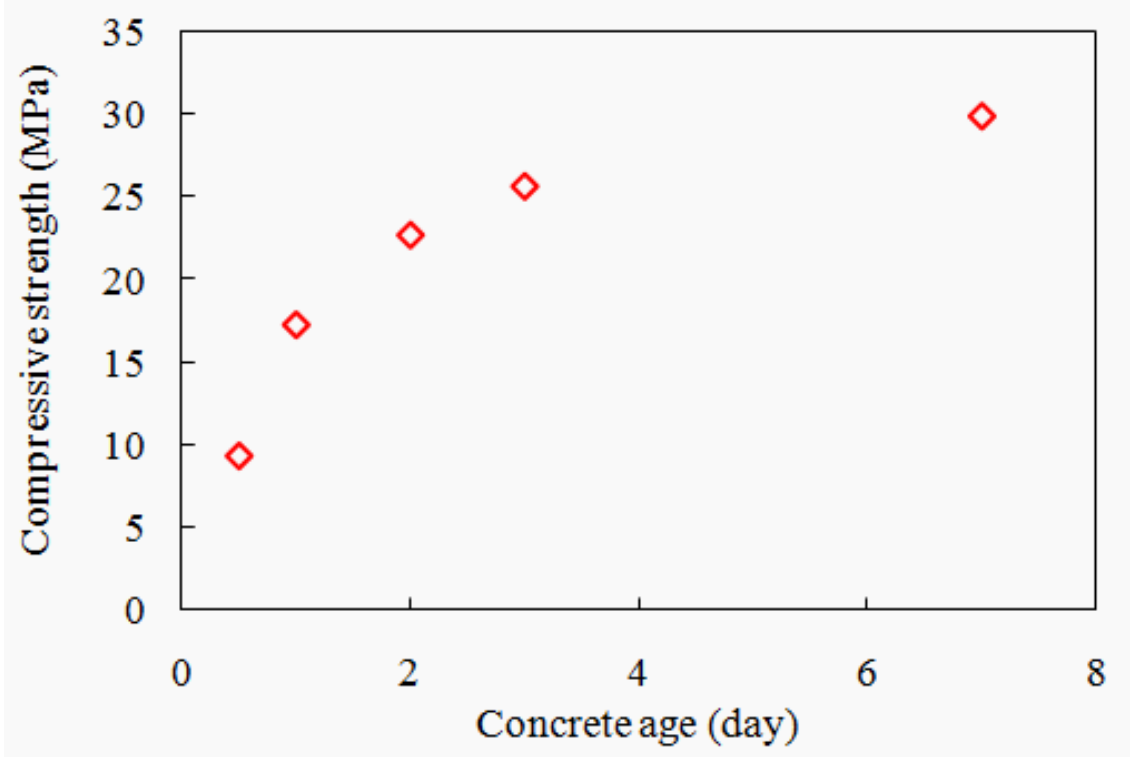

Figure 6-7: Compressive strength curve of Mix 4 


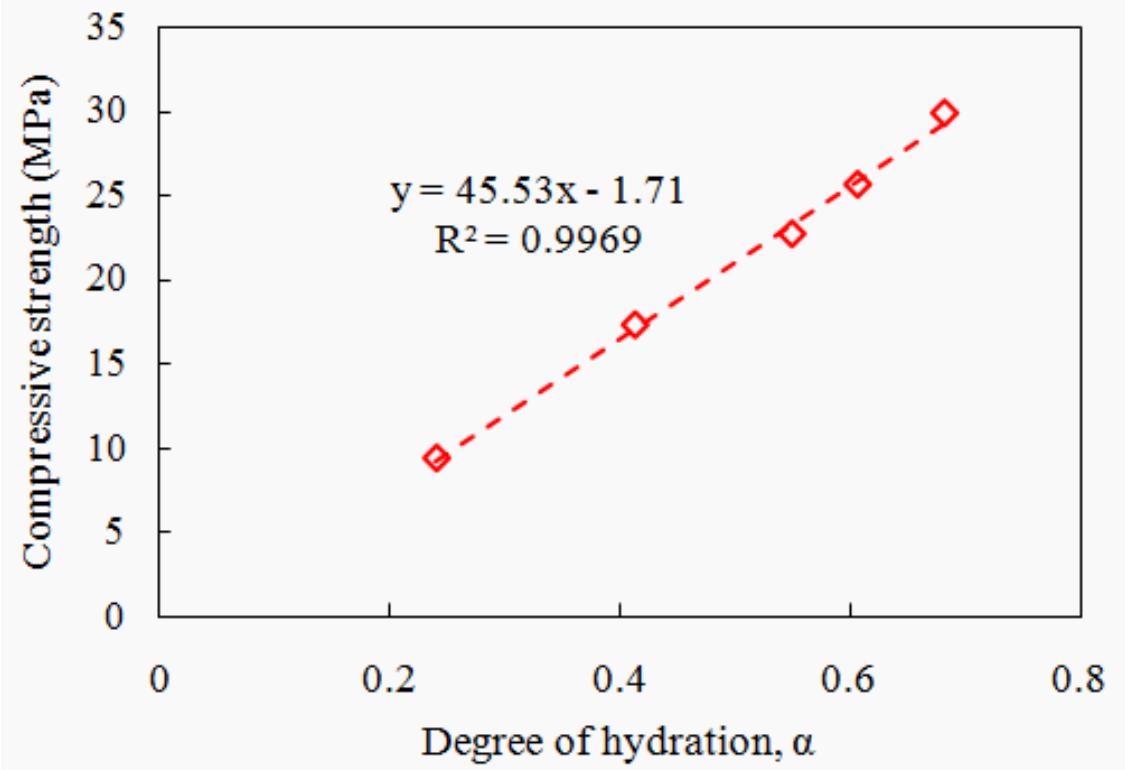

Figure 6-8: Relationship between compressive strength and degree of hydration

$$
f_{c}^{\prime}=45.53 \alpha-1.71 \quad\left(f_{c}^{\prime} \geq 0\right)
$$
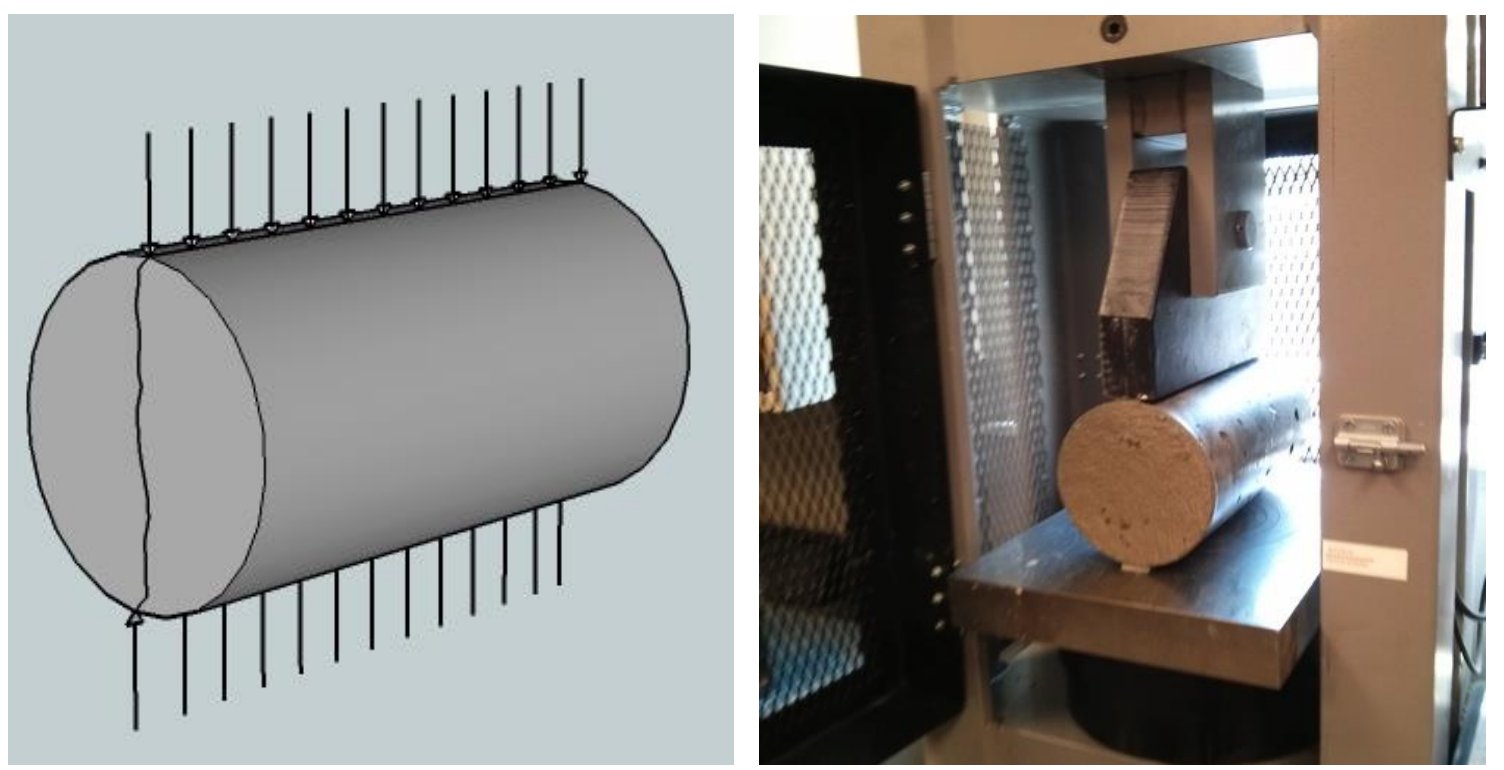

Figure 6-9: Splitting tensile strength testing

Splitting tensile strength development (Figure 6-9) was determined according to ASTM C 496 using $15 \mathrm{~cm}$ by $3 \mathrm{~cm}$ cylinders with the same curing temperature of $23{ }^{\circ} \mathrm{C}\left(73{ }^{\circ} \mathrm{F}\right)$. Wight and MacGregor (2009) presented Eq. (6.2) obtained from the mean split cylinder strength $\left(f_{c t}\right)$ 
from a massive database. The curve described by Eq. (6.2) has a high correlation with the current splitting tensile experiment results; the comparison of the test results and the predicted values using Eq. (6.2) are shown in Figure 6-10. For modeling purposes, the splitting tensile strength development can also be expressed in terms of the degree of hydration shown in Eq. (3.1.3) which is derived from Eq. (3.1.1) and Eq. (3.1.2).

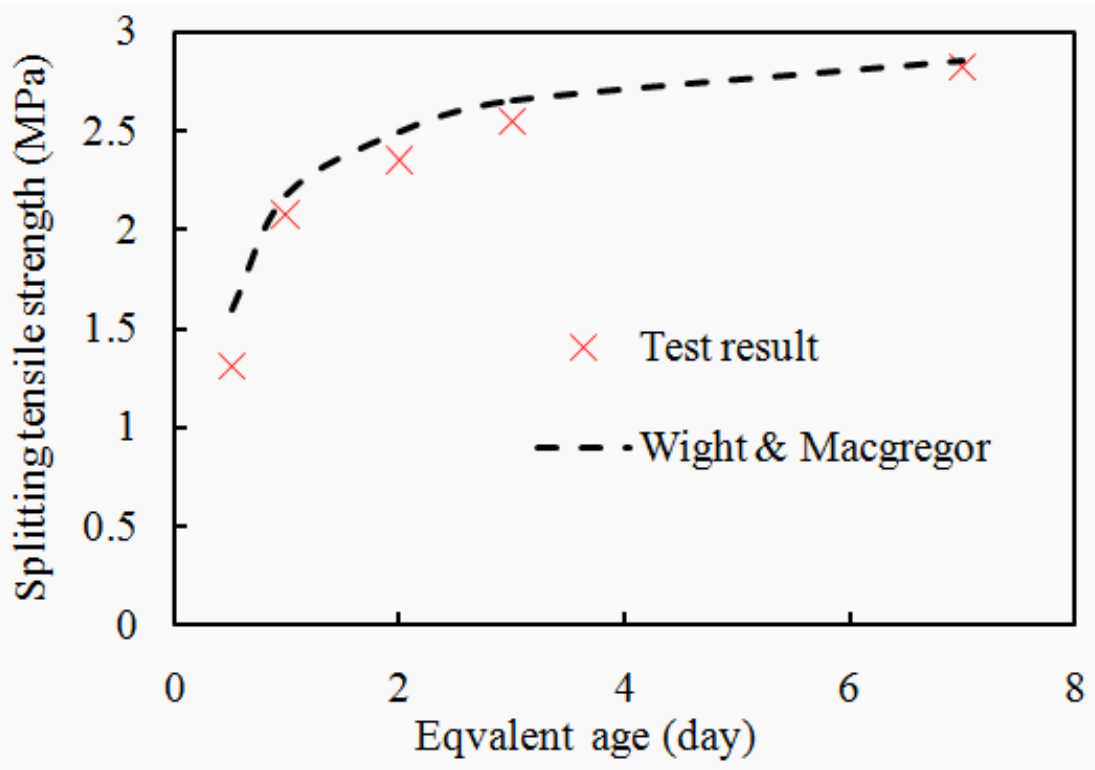

Figure 6-10: Splitting tensile strength test results in comparison with Wight \& Macgregor (2009)

$f_{c t}=0.53 \sqrt{f_{c}^{\prime}(\text { in } M P a)}$

$f_{c t}=0.53 \sqrt{45.53 \alpha-1.71} \quad\left(f_{c}^{\prime} \geq 0\right)$

\subsubsection{Elastic modulus testing}

In the stress analysis, accurately assigning elastic modulus for the concrete under tension is essential for thermal stress calculations. The tensile modulus development curve was experimentally obtained. The samples used in the tensile modulus test were 0.9-meter long dogbone samples, each with a $10 \mathrm{~cm} \times 10 \mathrm{~cm}$ mid-cross-section (Figure 6-11). One Geokon 
vibrating wire strain gage was embedded in the middle of the concrete sample. A steel hook was placed at each end in order to apply tension. The sample was loaded in direct tension nondestructively (Figure 6-12) using a force between 600 to 2400 Newtons (approximately $10 \%$ stress to strength ratio) depending on the concrete maturity. The strain due to external tensile stress was measured by the vibrating-wire strain gage. The sample was loaded four times for each data point to ensure the accuracy. Each loading lasted approximately 10 seconds to minimize any creep effect. The tensile modulus values shown in Figure 6-13 were obtained based on the measured stress to strain ratios. The relationship between compressive strength and Young's modulus for this particular mix design can be determined using the curve fitting method. A best- fit exponential function as shown in Eq. (6.4) is used to describe the development of the Young's modulus. In Eq. (6.4), the compressive strength, $f_{c}^{\prime}$ can be expressed with degree of hydration (Eq. (6.1)). The elastic modulus can also be expressed in terms of the degree of hydration as in Eq. (6.5). The Young's modulus is assumed identical in both tensile and compressive directions.
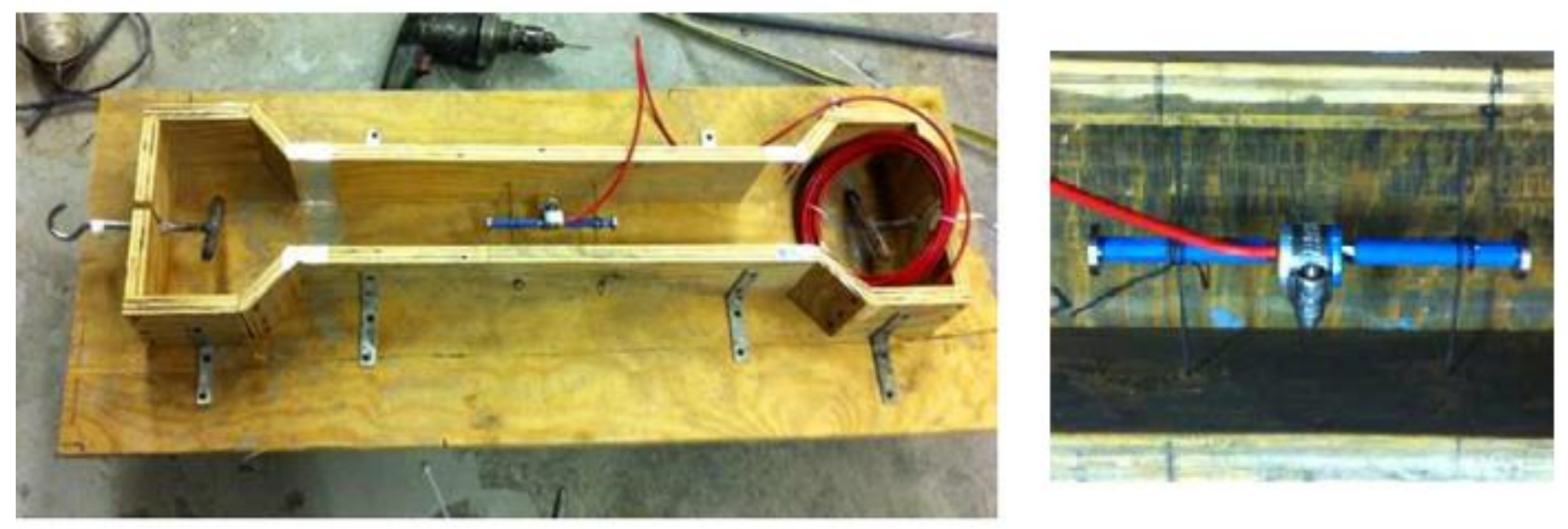

Figure 6-11: Dog-bone sample for tensile modulus testing 


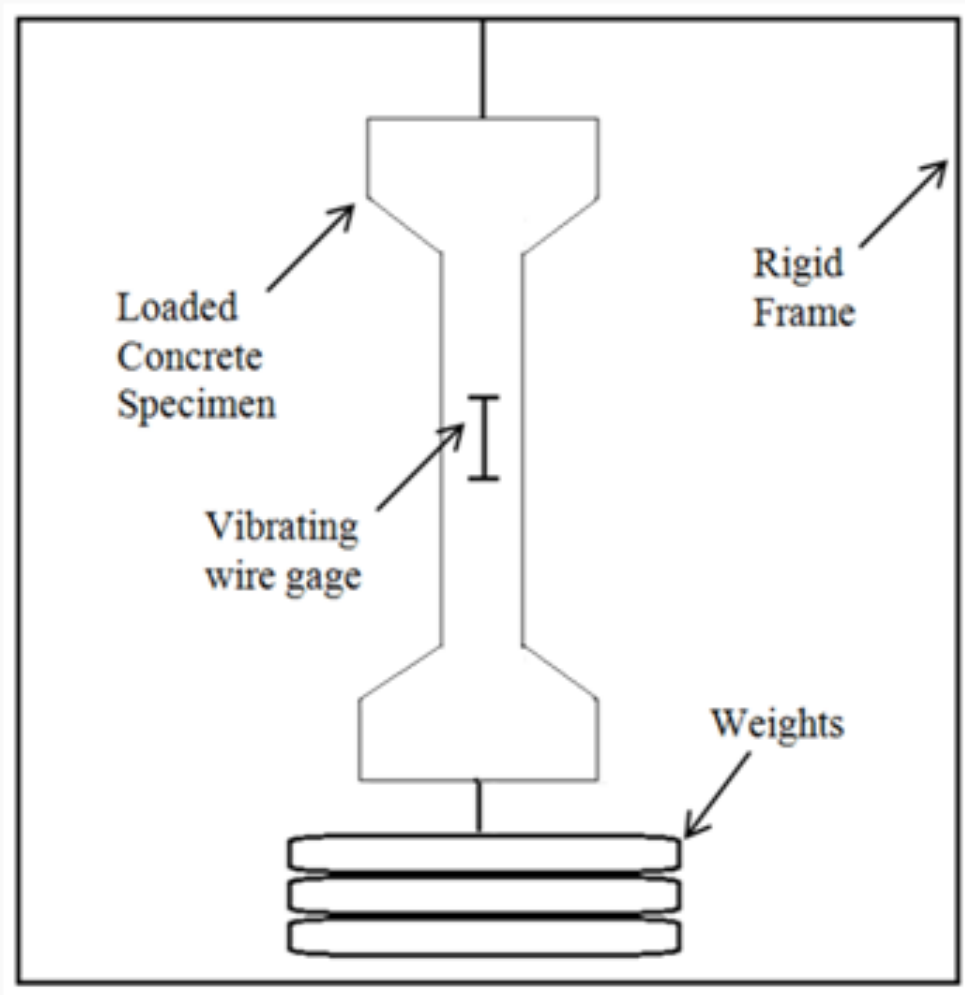

Figure 6-12: Elastic tensile modulus testing

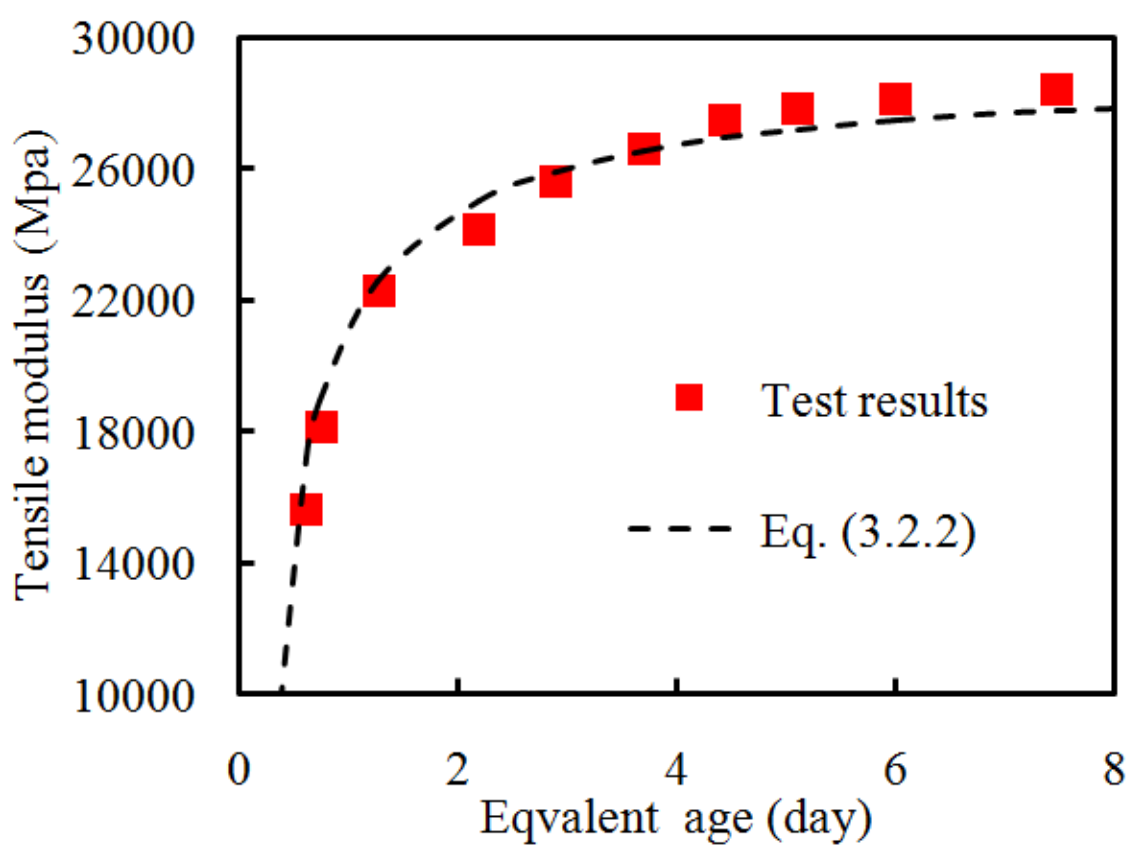

Figure 6-13: Tensile modulus development of Mix 4 
$E_{c}=5,407 f_{c}^{\prime 0.492}$

$E_{c}=5,407(45.53 \alpha-1.71)^{0.492} \quad\left(f_{c}^{\prime} \geq 0\right)$

\subsubsection{Coefficient of thermal expansion (CTE) testing}

After performing the tensile modulus testing, the dog-bone sample with embedded vibrating-wire strain gage was reused to test the coefficient of thermal expansion (CTE). The dog-bone sample was submerged into a temperature controlled water tank and placed on frictionless base provided by ball bearings (Figure 6-14). The sample was able to freely expand and contract due to temperature changes. The strain data of the dog-bone sample was recorded while the water temperature was controlled to slowly rise and drop. The CTE test was repeated three times and the test results correlated closely with an average thermal expansion coefficient of 8.53 micro-strains per ${ }^{\circ} \mathrm{C}$ at 28 days of age. Figure 6-15 shows the plot of the measured strain vs. temperature. An almost perfect straight fitted line in red $\left(\mathrm{R}^{2}=0.999\right)$ was displaced which means a constant value of CTE was obtained within the displaced temperature range of $24^{\circ} \mathrm{C}$ to $40{ }^{\circ} \mathrm{C}$.

The thermal expansion coefficient is assumed to be a constant for simplicity. The variation of CTE of concrete is difficult to measure because of the temperature influence of the concrete maturity, especially at an early age; it was shown by McCullough and Rasmussen (1998) that concrete CTE variation after 24 hours of age could be assumed negligible where the CTE before 24 hours decreased noticeably. It is noted that CTE is also depending on the moisture level inside concrete, and it is assumed that the moisture level in the current concrete cube is close to $100 \%$ (Lin and Chen, 2015). 


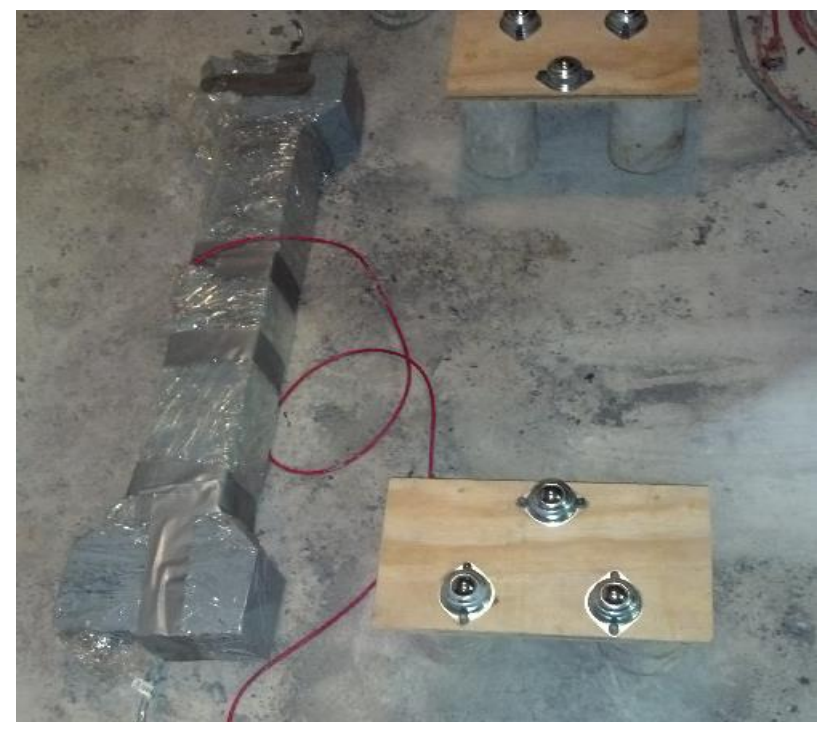

Figure 6-14: CTE test sample

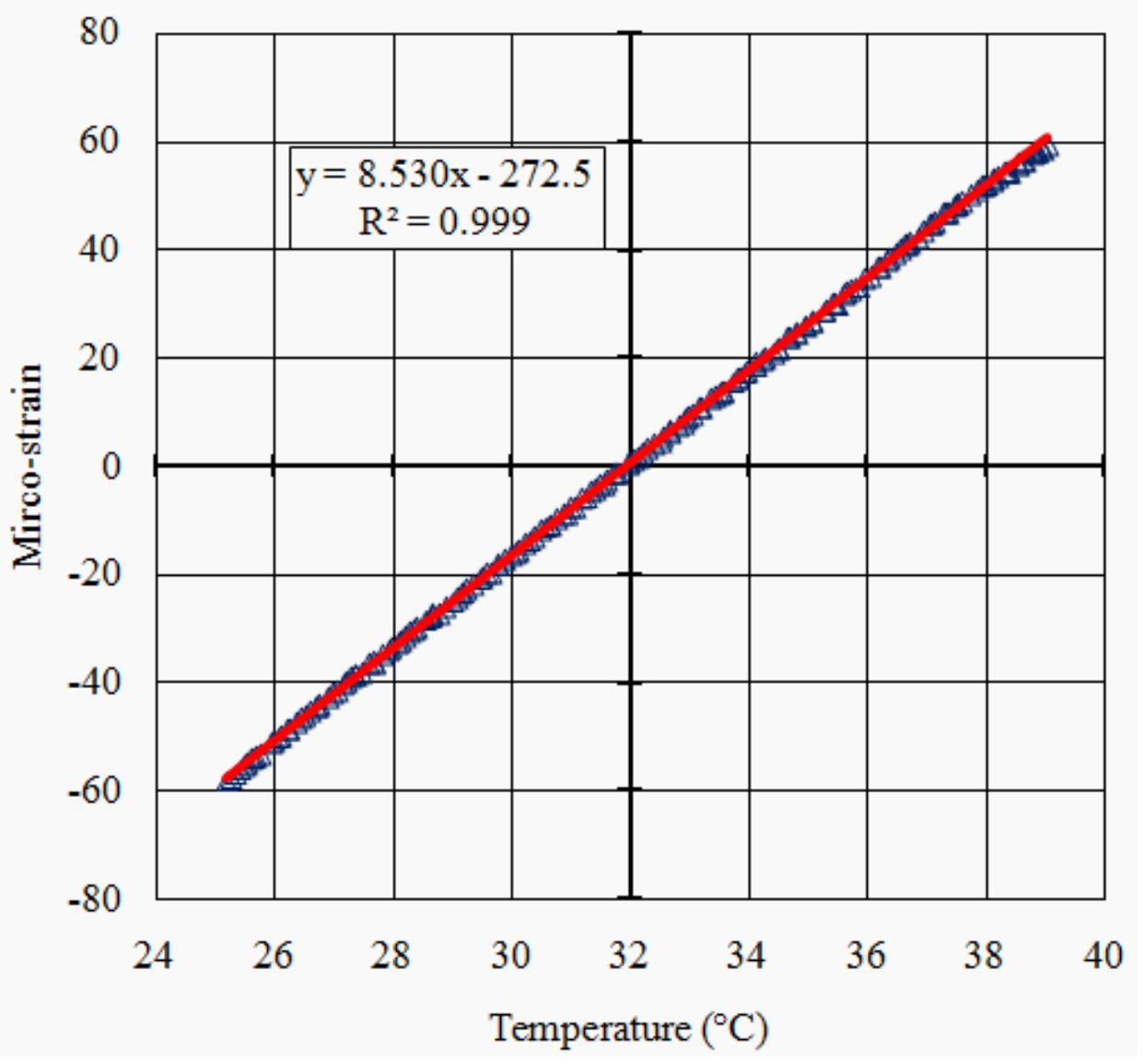

Figure 6-15: Strain vs. temperature 


\subsection{Viscoelasticity of Early Age Concrete Viscoelasticity}

The viscoelastic behavior of early age concrete plays an important role in calculating thermal stresses. The tensile creep behavior of early age concrete is complicated. Tensile creep tests performed by Gutch and Rostasy (1995) showed pronounced viscoelasticity when load was applied at an early age. Umehara and Uehara (1995) and Atrushi (2003) demonstrated the influence of temperature on early age tensile creep. Østergaard et al. (2001) and Atrushi (2003) showed the strong loading age dependency in the early ages. Bažant and Baweja (2000) presented a mathematical expression of structural creep law (B3 model) shown in Eq. (6.6). With experimentally determined empirical constants (q1 to q4), B3 model was often found accurate in terms of correlating with the experimental data.

$J\left(t, t^{\prime}\right)=\frac{\varepsilon(t)}{\sigma}=q_{1}+q_{2} Q\left(t, t^{\prime}\right)+q_{3} \ln \left[1+\left(t-t^{\prime}\right)^{0.1}\right]+q_{4} \ln \frac{t}{t^{\prime}}$

where,

$Q\left(t, t^{\prime}\right)=Q_{f}\left(t^{\prime}\right)\left[1+\left(\frac{Q_{f}}{Z\left(t, t^{\prime}\right)}\right)^{r}\right]^{-1 / r}$

$Q_{f}\left(t^{\prime}\right)=\left[0.086\left(t^{\prime}\right)^{\frac{2}{9}}+1.21\left(t^{\prime}\right)^{\frac{4}{9}}\right]^{-1}$

$Z\left(t, t^{\prime}\right)=\left(t^{\prime}\right)^{-1 / 2} \ln \left[1-\left(t-t^{\prime}\right)^{0.1}\right]$

$r=1.7\left(t^{\prime}\right)^{0.12}+8.0$

$\mathrm{t}$ : current age in days ( $\mathrm{t}=0$ is when water is added to the mixture.)

$t^{\prime}$ : loading age in days

$q_{1}, q_{2}, q_{3}$ and $q_{4}:$ empirical constants

Østergaard et al. (2001) found that for early age tensile creep, B3 model may underestimate the specific creep. The early age concrete exhibits much greater viscoelasticity. They modified the $q_{2}$ constant using Eq. (6.7) to amplify the age dependency for early age 
concrete, where $q_{5}$ is always less than the physical loading age $\left(t^{\prime}\right)$. In their research, with a very early loading age of 0.67 days ( 16 hours), the best-fit value of $q_{5}$ was found to be 0.58 days (14 hours).

$q_{2}^{\prime}=q_{2} \frac{t^{\prime}}{t^{\prime}-q_{5}}$

Temperature is also an important factor, which has two different effects on the creep behavior of early age concrete. From the maturity concept, higher curing temperature will accelerate the hydration process and increase the concrete maturity at the time of loading and therefore decrease the specific creep. However, the creep deformation at an early age increases significantly as the temperature increases. Atrushi (2003) stated that the increasing effect is much greater than the decreasing effect. In Atrushi's experimental results, a significant increase in tensile creep was found due to the effect of temperature increase. In order to consider the effect of the temperature, the equivalent age concept was used by Bažant and Baweja (2000) and Atrushi (2003); the equivalent age was used to replace the regular age in the places of the loading age and the loading duration, where they found better agreements between the theoretical and experimental results. Hence, the modified B3 model can be expressed as shown in Eq. (6.8).

$$
J\left(t_{e}, t_{e}^{\prime}\right)=\frac{\varepsilon\left(t_{e}\right)}{\sigma}=q_{1}+q_{2} \frac{t_{e}^{\prime}}{t_{e}^{\prime}-q_{5}} Q\left(t_{e}, t_{e}^{\prime}\right)+q_{3} \ln \left[1+\left(t_{e}-t_{e}^{\prime}\right)^{0.1}\right]+q_{4} \ln \frac{t_{e}}{t_{e}^{\prime}}
$$

\subsubsection{Basic tensile creep testing}

To measure the basic tensile creep of early age concrete, surface sealing is important because tensile loading can significantly accelerate the drying effect and lead to more load induced drying shrinkage. In this study, during each creep testing, two identical 0.9-meter dog- 
bone samples with a $0.1 \mathrm{~m} \times 0.1 \mathrm{~m}$ cross-section at the mid-span region were used. The concrete molds and sensor installation were the same as shown in Figure 6-11. Both samples were sealed with epoxy paint plus four layers of plastic wraps immediately after unmolding (one hour prior to the loading). Epoxy paint creates an adhesion between the plastic wrap and the concrete surfaces to further prevent surface drying. Both samples were kept in the same room with a controlled temperature of $23{ }^{\circ} \mathrm{C}$ and $50 \%$ humidity level. One of the samples was loaded with a tensile stress of $0.13 \mathrm{MPa}$ (approximately $10 \%$ stress to strength ratio) while the other was kept free to deform. Although the loading magnitude is small with respect to its tensile strength, the specific creep was assumed to be un-affected. Hauggaard et. al. (1997) reported that the specific creep response of early age concrete was found to be unchanged when a stress to strength ratio is below 60\%. A similar conclusion was found by Atrushi (2003) in his tests up to $80 \%$ stress to strength ratio.

The strain measurements for both samples (loaded and free) were recorded using Geokon vibrating wire strain gages. The difference in the monitored strain between the two samples divided by the loading magnitude is calculated to show creep compliance. The tensile creep test for Mix 4 was performed three times at three different loading ages $(0.75,1$ and 10 days $)$ and the results are shown in Figure 6-16. As shown in Figure 6-16, all of the three test results can be described by the modified B3 model (Eq. (6.8)). The best-fit empirical constants are shown in Table 6-1.

Table 6-1: Best fit empirical constants for Eq. (6.8)

\begin{tabular}{cccccc}
\hline Constant & $\mathrm{q}_{1}$ & $\mathrm{q}_{2}$ & $\mathrm{q}_{3}$ & $\mathrm{q}_{4}$ & $\mathrm{q}_{5}$ \\
\hline Value & 0.3 & 24.0 & 65.0 & 0.5 & 0.2 \\
\hline
\end{tabular}




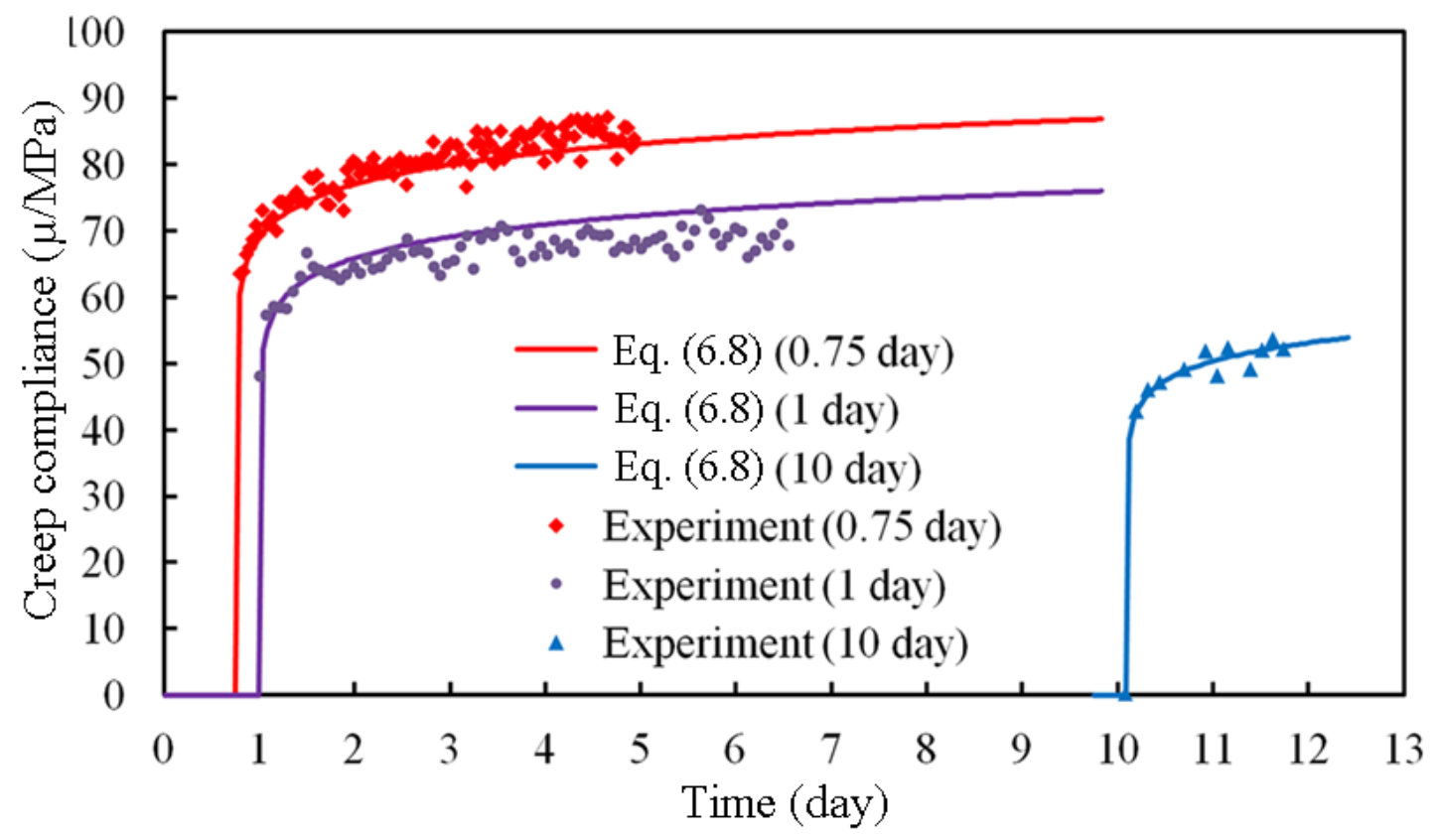

Figure 6-16: Comparison of creep compliance between experimental results and Eq. (6.8)

\subsubsection{Basic compressive creep}

Although tensile and compressive creep models were often assumed to be the same for simplicity, different tensile and compressive creep behaviors were discovered by numerous researchers (Atrushi, 2003; Kanstad et al., 2012; Hilaire et al., 2011). The compressive creep model of the current mix design was obtained from an existing model by Atrushi (2003) showing in Eq. (6.9). The Double Power Law (DPL) developed by Bažant and Osman (1976) has been widely used to model compressive creep behavior of hardened concrete. Atrushi (2003) modified the DPL for early age concrete by incorporating the temperature effect observed in early age. The equation includes equivalent age at loading $\left(t_{e}^{\prime}\right)$, the current equivalent age $\left(t_{e}\right)$, the Young's modulus at loading $\left(E\left(t_{e}^{\prime}\right)\right)$ and three additional creep parameters $(\phi, \mathrm{d}$ and $\mathrm{p})$. This modified double power law (M-DPL) is shown in Eq. (6.9). Since the Mix 4 was similar to the "Base-0 mix" from Atrushi (2003), same creep parameter values were used in the current calculation. The 
values of $\phi, \mathrm{d}$ and $\mathrm{p}$ were $0.75,0.2$ and 0.21 , respectively obtained from Atrushi (2003). The MDPL with these pre-determined creep parameters were used to account for compressive creep of concrete in the FEM calculations.

$J\left(t_{e}, t_{e}^{\prime}\right)=\frac{1}{E\left(t_{e}^{\prime}\right)}\left[1+\phi t_{e}^{\prime-d}\left(t_{e}-t_{e}^{\prime}\right)^{p}\right]$

\subsubsection{Modeling of viscoelastic behavior}

Before cracking, the concrete material is usually assumed linear elastic as in Eq. (6.10) for one-dimensional stress; the elastic modulus is the ratio of the stress and the instantaneous strain $\left(\varepsilon_{\text {ins }}\right)$. However, the early age concrete exhibits high viscoelastic behavior which causes a change in effective modulus. The analytical response is illustrated in Figure 6-17. To simplify the creep calculation, an effective modulus ( $\left.E_{\text {eff }}\right)$ is used in the FEM modeling. The effective modulus (Eq. (6.11)) represents the ratio of the stress and the total deformation. Figure 6-18 demonstrates a typical creep compliance, $\mathrm{J}\left(\mathrm{t}, \mathrm{t}^{\mathrm{t}}\right)$ of a concrete sample under constant loading. $\mathrm{J}\left(\mathrm{t}, \mathrm{t}^{\prime}\right)$ is defined as the ratio of the total strain $\left.\left(\varepsilon(\mathrm{t})=\varepsilon_{\mathrm{total}}=\varepsilon_{\mathrm{cr}}+\varepsilon_{\text {ins }}\right)\right)$ and the stress $\left(\mathrm{J}\left(\mathrm{t}, \mathrm{t}^{\prime}\right)=\right.$ $\varepsilon(\mathrm{t}) / \sigma)$. The creep coefficient $\left(\mathrm{C}_{\mathrm{cr}}\right)$ is defined as the ratio of the creep strain $\left(\varepsilon_{\mathrm{cr}}\right)$ and the instantaneous strain ( $\left.\varepsilon_{\text {ins }}\right)$ due to the loading (Eq. (6.12)). Eq. (6.13) can be derived according to Figure 6-18. The growth of Young's modulus is considered in this model for early age concrete as shown in Figure 6-18.

$$
\begin{aligned}
& E=\frac{\sigma}{\varepsilon_{\text {ins }}} \\
& E_{\text {eff }}=\frac{\sigma}{\varepsilon_{\text {total }}}=\frac{\sigma}{\varepsilon_{\text {ins }}\left(1+C_{c r}\right)}=\frac{E}{1+C_{c r}}
\end{aligned}
$$




$$
\begin{aligned}
& C_{c r}\left(t, t^{\prime}\right)=\frac{\varepsilon_{c r}(t)}{\varepsilon_{\text {ins }}(t)}=\frac{\varepsilon_{\text {total }}(t)-\varepsilon_{\text {ins }}(t)}{\varepsilon_{\text {ins }}(t)} \\
& C_{c r}\left(t, t^{\prime}\right)=\frac{J\left(t, t^{\prime}\right) \sigma-\varepsilon_{\text {ins }}(t)}{\varepsilon_{\text {ins }}(t)}=\frac{J\left(t, t^{\prime}\right)-\frac{1}{E(t)}}{\frac{1}{E(t)}}=E(t) J\left(t, t^{\prime}\right)-1
\end{aligned}
$$

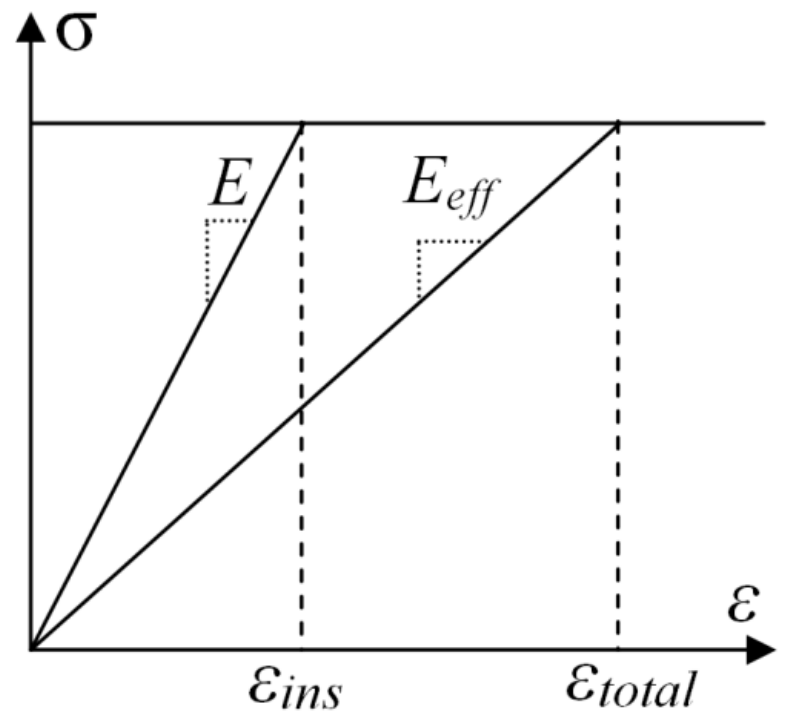

Figure 6-17: Concept of effective modulus, $\mathrm{E}_{\mathrm{eff}}$

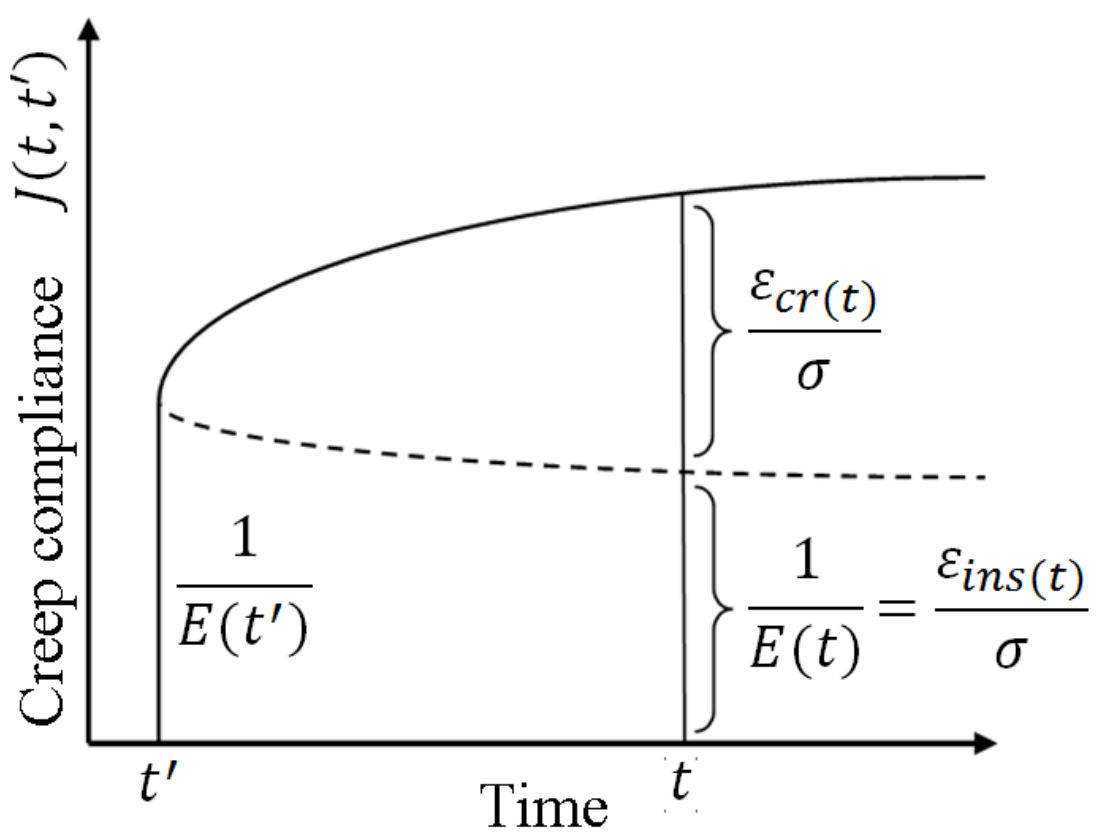

Figure 6-18: Creep behavior of early age concrete 


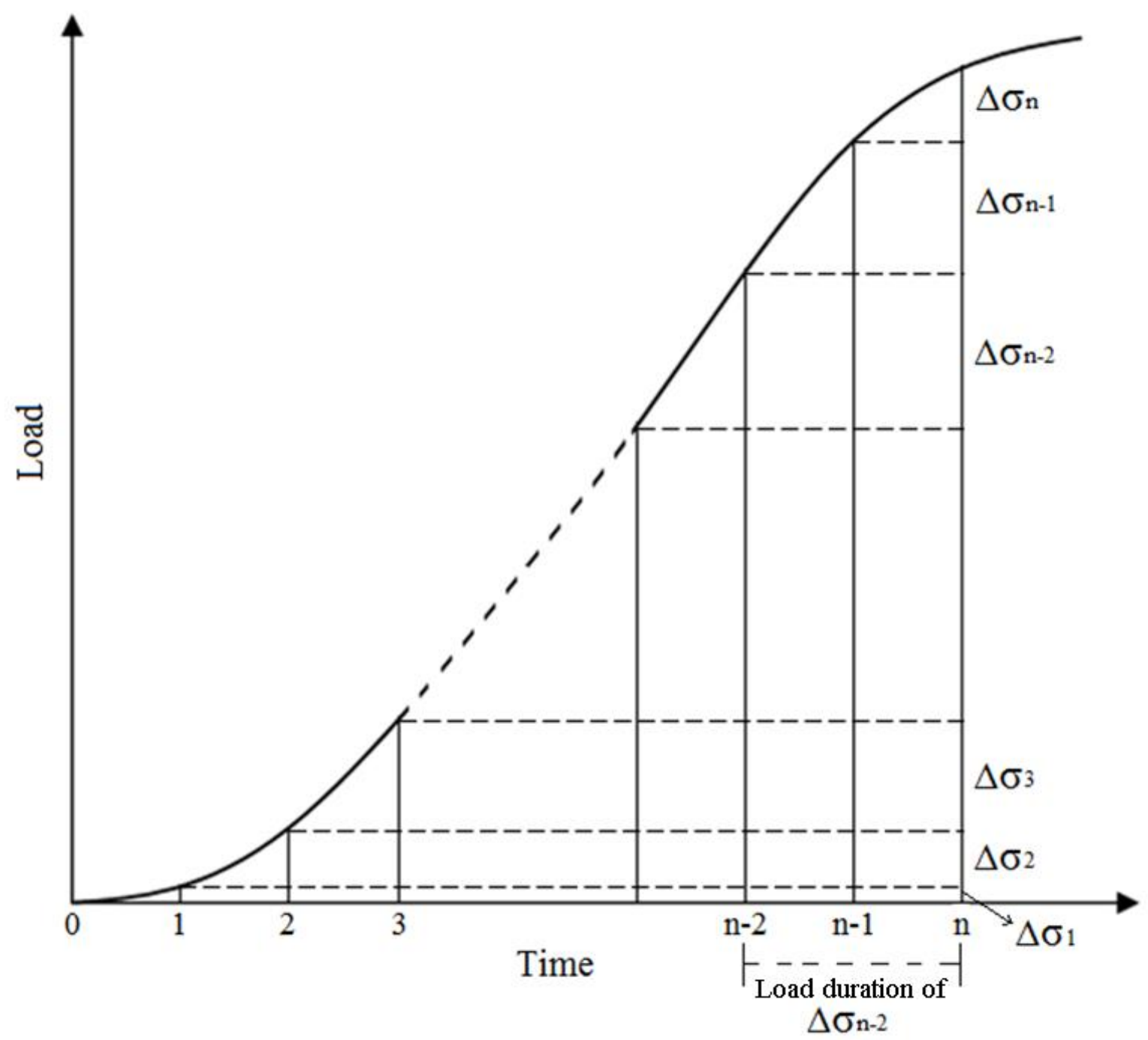

Figure 6-19: Variable load decomposition

The creep behavior becomes more complicated when the concrete member is under variable loading such as thermally-induced stresses which would change due to the variations of the temperature gradient and the mechanical properties. The variable loading problem can be solved using the superposition principle. At time $\mathrm{n}$, the total load can be decomposed to $\mathrm{n}$ small increments $\left(\Delta \sigma_{t}\right)$. Each loading increment has its individual loading time $\left(t^{\prime}=i\right)$ and loading duration $\left(n-t^{\prime}=n-i\right)$ (Figure 6-19). Without considering creep, the total stress at $\mathrm{t}=\mathrm{n}, \sigma_{\text {total }}(n)$ can be expressed as the summation of the load increments (Eq. 6.14). When creep is considered, 
each loading increment $\left(\Delta \sigma_{t_{-}} r\right)$ can be derived as in Eq. (6.15) and the total load can be expressed as shown in Eq. (6.16) or Eq. (6.17). The actual overall stress release percentage due to all of the load increments can be expressed as the ratio of $\sigma_{\text {total_cr }}(n)$ and $\sigma_{\text {total }}(n)$. Thus, the overall creep coefficient and effective modulus can be derived as in Eq. (6.18) and Eq. (6.19), respectively. In the FEM analysis, only basic creep was considered. Basic creep refers to the strain observed on sealed samples due to sustained loading (Bažant and $\mathrm{Xi}, 1995)$. In reality, all the surfaces of the two 1.2-meter cubes were covered for the entire 5 days after casting. The influences from drying effect are assumed negligible.

$\sigma_{\text {total }}(n)=\Delta \sigma_{1}+\Delta \sigma_{2}+\Delta \sigma_{3}+\cdots+\Delta \sigma_{n-2}+\Delta \sigma_{n-1}+\Delta \sigma_{n}$

$\sigma_{\text {total }}(n)=\sum_{i=1}^{n} \Delta \sigma_{i}$

$\Delta \sigma_{t_{-} c r}=\frac{\Delta \sigma_{t}}{1+C_{c r}\left(n, t^{\prime}\right)}=\frac{\Delta \sigma_{t}}{E(n) J\left(n, t^{\prime}\right)}$

$\sigma_{\text {total }_{c r}}(n)=\frac{\Delta \sigma_{1}}{E(n) J(n, 1)}+\frac{\Delta \sigma_{2}}{E(n) J(n, 2)}+\frac{\Delta \sigma_{3}}{E(n) J(n, 3)}+\cdots+\frac{\Delta \sigma_{n-2}}{E(n) J(n, n-2)}+$

$\frac{\Delta \sigma_{n-1}}{E(n) J(n, n-1)}+\frac{\Delta \sigma_{n}}{E(n) J(n, n)}$

$\sigma_{\text {total_cr }}(n)=\sum_{i=1}^{n} \frac{\Delta \sigma_{i}}{E(n) J\left(t=n, t^{\prime}=i\right)}$

$C_{c r_{-} \text {overall }}(n)=\frac{\sigma_{\text {total }}(n)}{\sigma_{\text {total_cr }}(n)}-1=\frac{\sum_{i=1}^{n} \Delta \sigma_{i}}{\sum_{i=1}^{n} \frac{\Delta \sigma_{i}}{E(n) J(n, i)}}-1$

$E_{\text {eff }}(n)=\frac{E(n)}{1+C_{\text {cr_overall }}(n)}$ 
It is also noted that the relationship between the creep compliances and loading could become non-linear if the loading stress and strength ratio becomes very high (Bažant and $\mathrm{Xi}$, 1995); the creep deformation would be further increased due to nonlinear creep behavior at high stress to strength ratio (Atrushi, 2003). In this study, since only linear creep behavior is considered, when stress to strength ratio is beyond $80 \%$, the current creep model would slightly overestimate the thermal stresses.

\subsection{Discussion of Maturity Method on this Application}

As discussed in Section 2.4.4, the maturity method has been usedthe late 1940ste in-situ concrete strength since late 1940s. Many researchers have discovered that high temperature curing may have a negative effect on the long-term concrete strength gain and maturity method might not accurately estimate the strength values. Carino and Lew (2001) described the "crossover" effect due to high temperature curing. They suggested that maturity method is more reliable in predicting the relative strength rather than absolute strength. Tepke et al. (2004) concluded that high temperature curing affect the strength-maturity relationship. Kim and Rens (2008) experimented on three sets of concrete cylinders in three different curing temperatures of $40{ }^{\circ} \mathrm{C}, 50{ }^{\circ} \mathrm{C}$ and $60^{\circ} \mathrm{C}$. Their results showed higher temperature cured samples exhibited lower ultimate strength at the equivalent age of 28 days.

In this study, three sets of concrete cylinders of Mix 4 were cured at $23^{\circ} \mathrm{C}, 40^{\circ} \mathrm{C}$ and 50 ${ }^{\circ} \mathrm{C}$. The strength development curves converted into equivalent age are shown in Figure 6-20. Concrete cylinders cured at $23{ }^{\circ} \mathrm{C}$ and $40{ }^{\circ} \mathrm{C}$ showed very similar strength-maturity relationship while the cylinders cured at $50{ }^{\circ} \mathrm{C}$ showed lower strength. It suggests that maturity method works for concrete with curing temperature between $23^{\circ} \mathrm{C}$ and $40{ }^{\circ} \mathrm{C}$ but may not work for $50{ }^{\circ} \mathrm{C}$ or higher temperature. For validation purposes, another batch of concrete with the same mix 
design was cast and cured at $23^{\circ} \mathrm{C}, 30^{\circ} \mathrm{C}$ and $40{ }^{\circ} \mathrm{C}$. As shown in Figure 6-21, maturity method worked quite well up to 7 days of equivalent age. In mass concrete applications, the concrete temperatures are normally higher due to the relatively larger member sizes. At the center of a mass concrete member, the temperature can be kept higher than $50{ }^{\circ} \mathrm{C}$ for an extended period. However, since only the surface tensile stresses are critical, the temperature near the surface is of particular concern and the temperature is usually much lower due to external heat loss.

For both 1.2-meter concrete cubes constructed, the surface maximum temperatures were about $45^{\circ} \mathrm{C}$ to $46^{\circ} \mathrm{C}$ and quickly decreased after the maximum temperatures were reached. To validate if the concrete surface strength of these two cubes can be predicted using the maturity method, another compressive strength test was performed using a set of concrete cylinders $(0.1$ $\mathrm{m} \times 0.2 \mathrm{~m}$ ) cured in a temperature history similar to the surface temperatures experienced by the surfaces of the cubes (Figure 6-22). Similar to Figure 6-22, the strength development curve from cylinders of identical concrete cured at $23{ }^{\circ} \mathrm{C}$ was also obtained. Figure 6-23 shows that the compressive strength of the cylinders with this variable temperature curing can be predicted by the strength-maturity relationship. These results indicate that the maturity method may not accurately predict the strength for long duration high temperature curing at a constant $50{ }^{\circ} \mathrm{C}$ or above, but it is applicable for the strength prediction of the concrete experiencing short-duration high temperature curing, such as those experienced on the surface of the 1.2-meter cubes. 


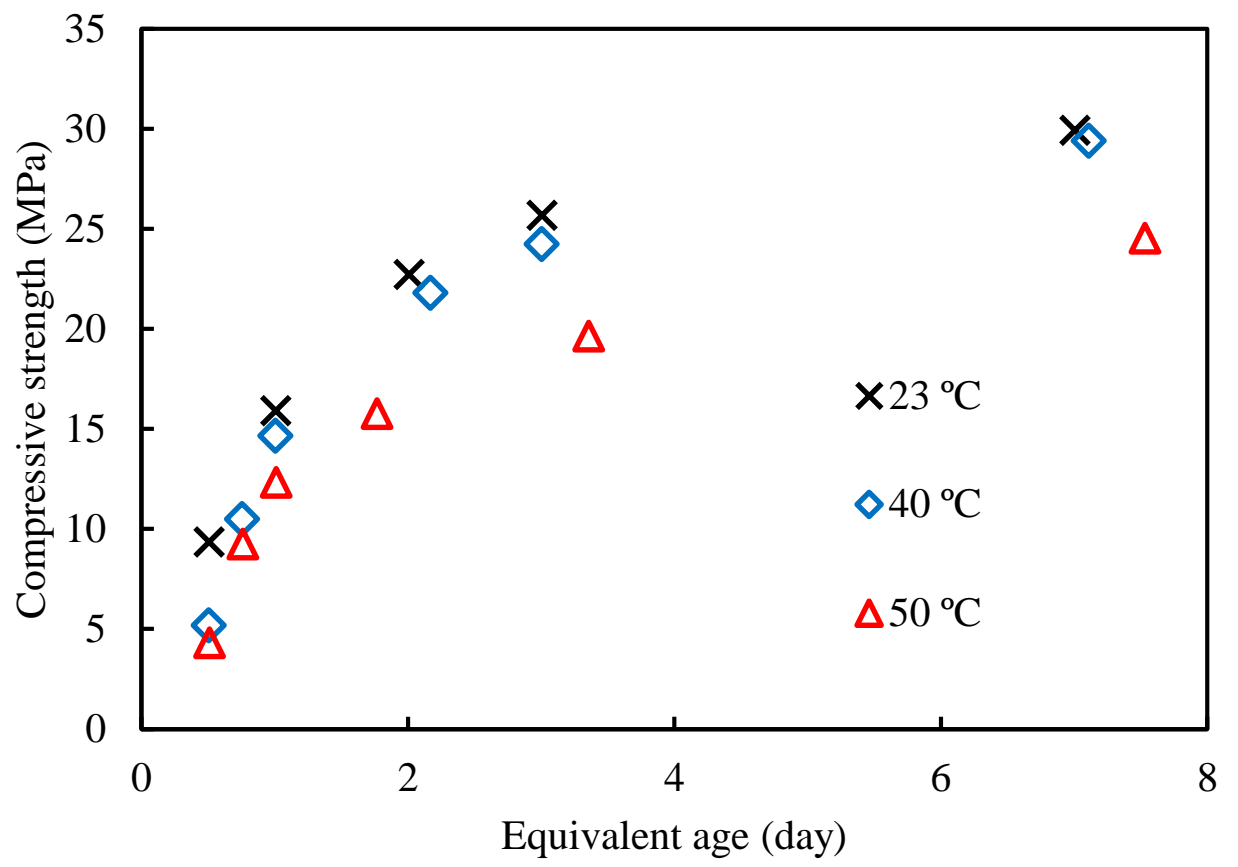

Figure 6-20: Strength vs. Equivalent age in $23{ }^{\circ} \mathrm{C}, 40{ }^{\circ} \mathrm{C}$ and $50{ }^{\circ} \mathrm{C}$

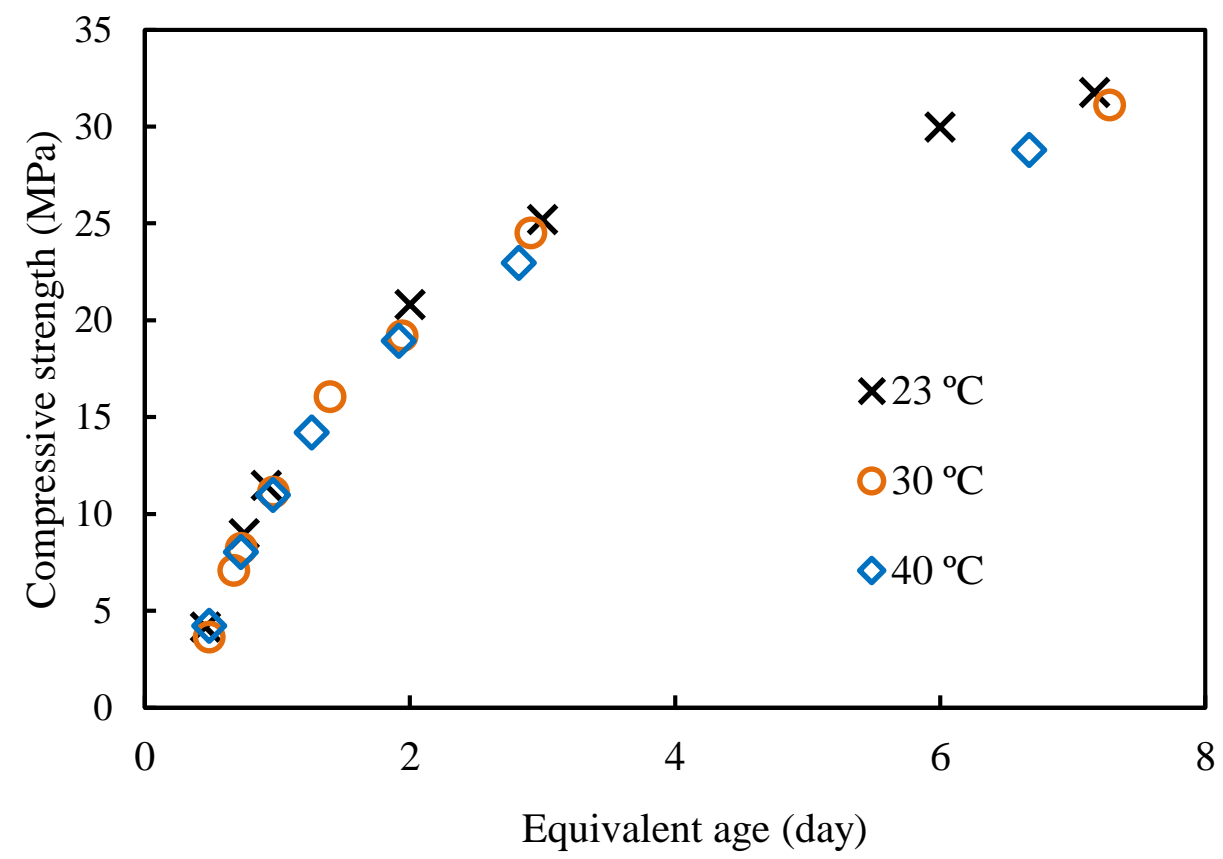

Figure 6-21: Strength vs. Equivalent age in $23{ }^{\circ} \mathrm{C}, 30^{\circ} \mathrm{C}$ and $40{ }^{\circ} \mathrm{C}$ 


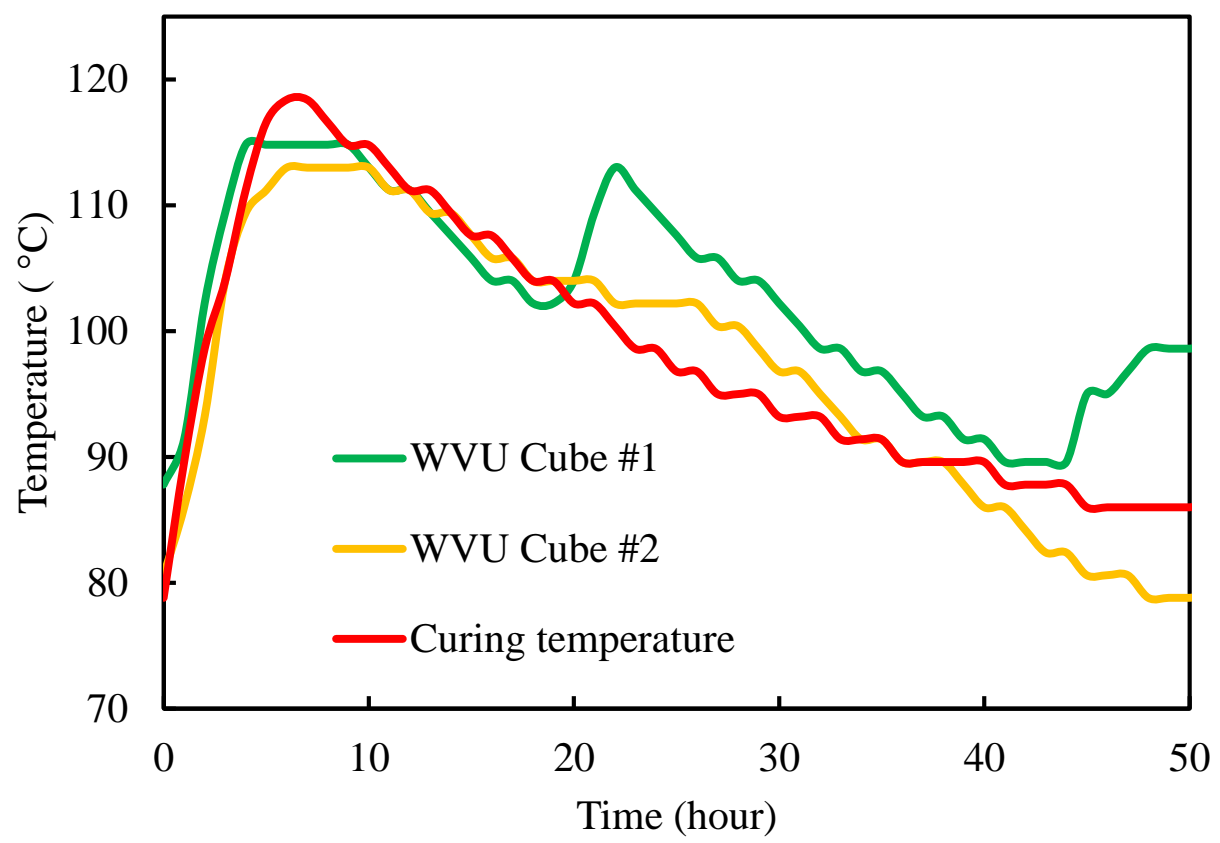

Figure 6-22: Concrete surface temperature of Cube \#1 and \#2 and curing temperature

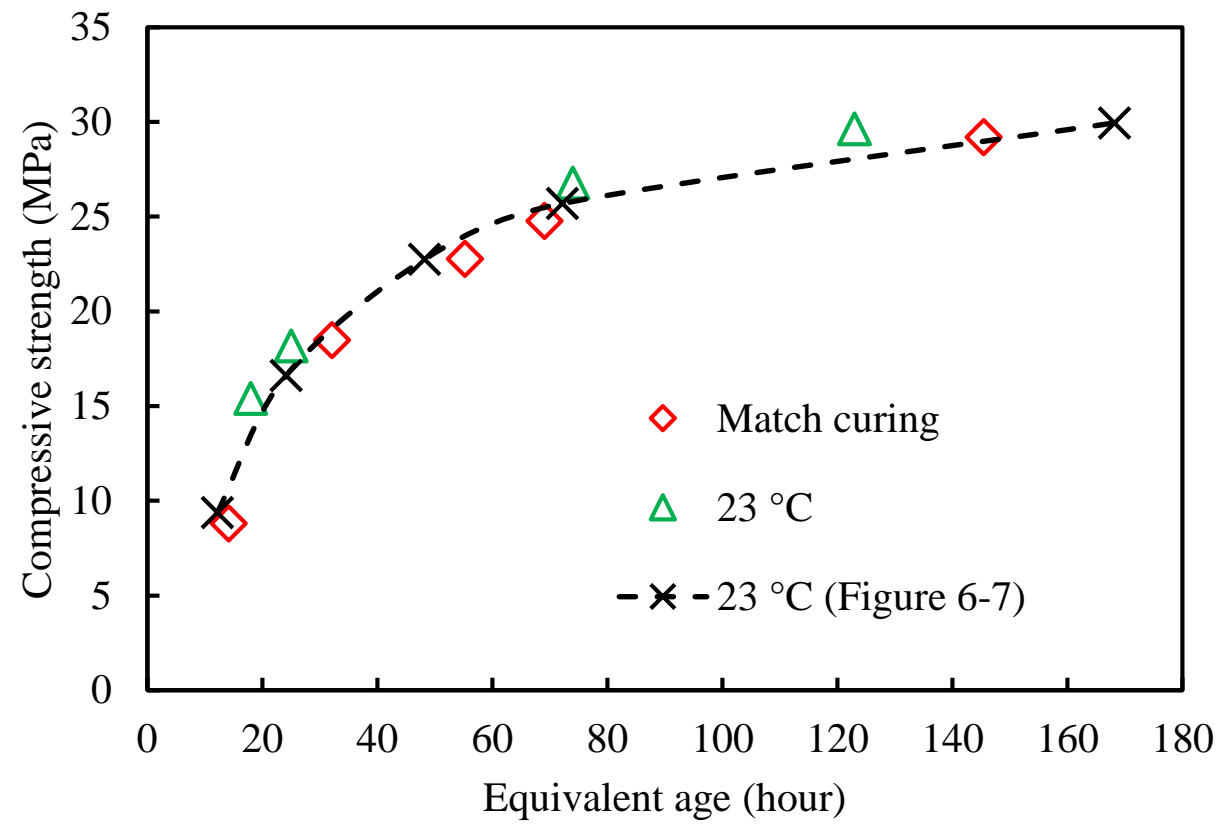

Figure 6-23: Measured compressive strength of the samples cured differently 


\subsection{Stress Analysis and Results}

The computation of thermally-induced stresses for early age concrete contains two parts: thermal analysis and stress analysis. Thermal analysis was first conducted using 3-dimensional finite element method (FEM) and the calculated temperature compared quite well with the experimental measurements (Chapter 5). The calculated temperature profile histories for WVU Cube \#1 and \#2 were used as temperature input. For thermal stress analysis, the complexity of variation in material properties and viscoelastic behavior required us to develop a subroutine "USDFLD" to account for the change of material properties and viscoelastic behavior at every time increment. For each individual element, the program first calculates the equivalent age $\left(t_{e}\right)$ and degree of hydration $(\alpha)$ based on the calculated temperature history. The compressive elements and tensile elements are treated independently. The difference in creep behavior between elements in tension and compression is considered (Section 6.4). The modified-B3 model is used to describe the tensile creep, and the modified Double Power Law (M-DPL) is used to describe the compressive creep behavior. To simplify the analysis, it was programmed to check the maximum principal stress in each element at every time step to identify tensile and compressive elements.

The creep stress loading magnitude changes because of temperature variation. Load decomposition and superposition rules were used to calculate the overall creep coefficient. The effective modulus was then used to incorporate both elastic deformation and viscoelastic deformation due to the creep behavior (Section 6.4). At each time-step, the thermal stress was computed for each element based on the calculated thermal gradient, current elastic modulus and overall creep coefficient. Finally, the equivalent age, degree of hydration and stresses in principle directions for each element were stored for the next time-step. Figure 6-24 shows the 
programming algorithm of the stress analysis. The analysis used a fix time increment of one hour. The entire algorithm was executed for each individual element at every time-step. For simplicity, the Poisson's ratio and coefficient of thermal expansion (CTE) were assumed constants. The Poisson's ratio was assumed to be 0.2 . CTE was experimentally obtained to be 8.53 micro-strains per ${ }^{\circ} \mathrm{C}$ (Section 6.4). The frictional interaction between the bottom of the concrete cube and the wood base was neglected for simplicity.

Stress analysis was performed for both 1.2-meter concrete cubes using the ABAQUS program and the above FORTRAN subroutine. The model had 15,625 nodes and 13,824 elements using 3-D 8-node linear element (C3D8R) with $5 \mathrm{~cm}$ element size. Results showed that due to the temperature evolution and the thermal expansion, the inner elements were expanding which caused the surface element to be in tension. The calculated surface tensile stress contour patterns for the two cubes are similar. As shown in Figure 6-25 (WVU Cube \#1), the tensile strength of the concrete was exceeded by maximum thermal stress at the center locations of the edges (shown as grey color) at 16 hours after concrete placement. The predicted tensile stresses and the estimated tensile strength at the critical locations for both cubes were compared in Figure 6-26 and Figure 6-27. The estimated tensile strength history was calculated using Eq. (6.3) for the concrete at that location; concrete strength was temperature history dependent, and hence, location dependent. The FEM result showed that Cube \#1 was likely to crack at these locations because the maximum thermal stress exceeded the tensile strength. From the experimental observation, four large cracks with an approximate cracking length of 0.6 meters were found at the center of the top edges ( 0.3 meters on the top surface and 0.3 meters downward to the side surfaces). Figure 6-25 shows the calculated stress distribution and the actual crack locations for Cube \#1. No other crack was found at the sides or bottom edges of Cube \#1. The reason can be 
the non-uniform strength distribution due to vibration compaction; the top surface is typically found to be the weakest part of the concrete cube (Yikici and Chen, 2013). For Cube \#2, the predicted maximum stress was shown meeting the estimated tensile strength at the critical locations (Figure 6-27), however, no thermal crack could be visually identified on any surface of Cube \#2. The reason for Cube \#1 to have larger stress magnitudes in comparison with Cube \#2 was because of a larger ambient temperature drop at the night right after the Cube \#1 was constructed (see Figure 6-25); an $18{ }^{\circ} \mathrm{C}$ (Figure 5-16) drop in ambient temperature at the first night after Cube \#1 construction caused a significant increase in thermal stresses.

It is noted that the current FEM model assumes a creep model that is linear to the applied stresses. The nonlinear creep behavior due to high stress to strength ratio is not considered in the current model. It was observed by Atrushi (2003) that when applied tensile stress to strength ratio was about $80 \%$, the creep coefficient became nonlinear with respect to the applied stress; more creep strain was observed at higher stress to strength ratio. Therefore, it is assumed that the current creep model is only able to estimate the allowable thermal stress up to $80 \%$ of the tensile strength. Because of the linear assumption, the estimation of the stress at the level higher than $80 \%$ is considered to be conservative (the estimation is higher than the actual stress value) using the current model. Although the grey region of Figure 6-25 shows thermal stress exceeded the tensile strength, it can only be used as a qualitative indication of high cracking probability. The current modified-B3 model is assumed to be only valid to obtain the thermal stress up to $80 \%$ of the tensile strength. The nonlinear creep behavior due to high stress to strength ratio needs further investigation. 


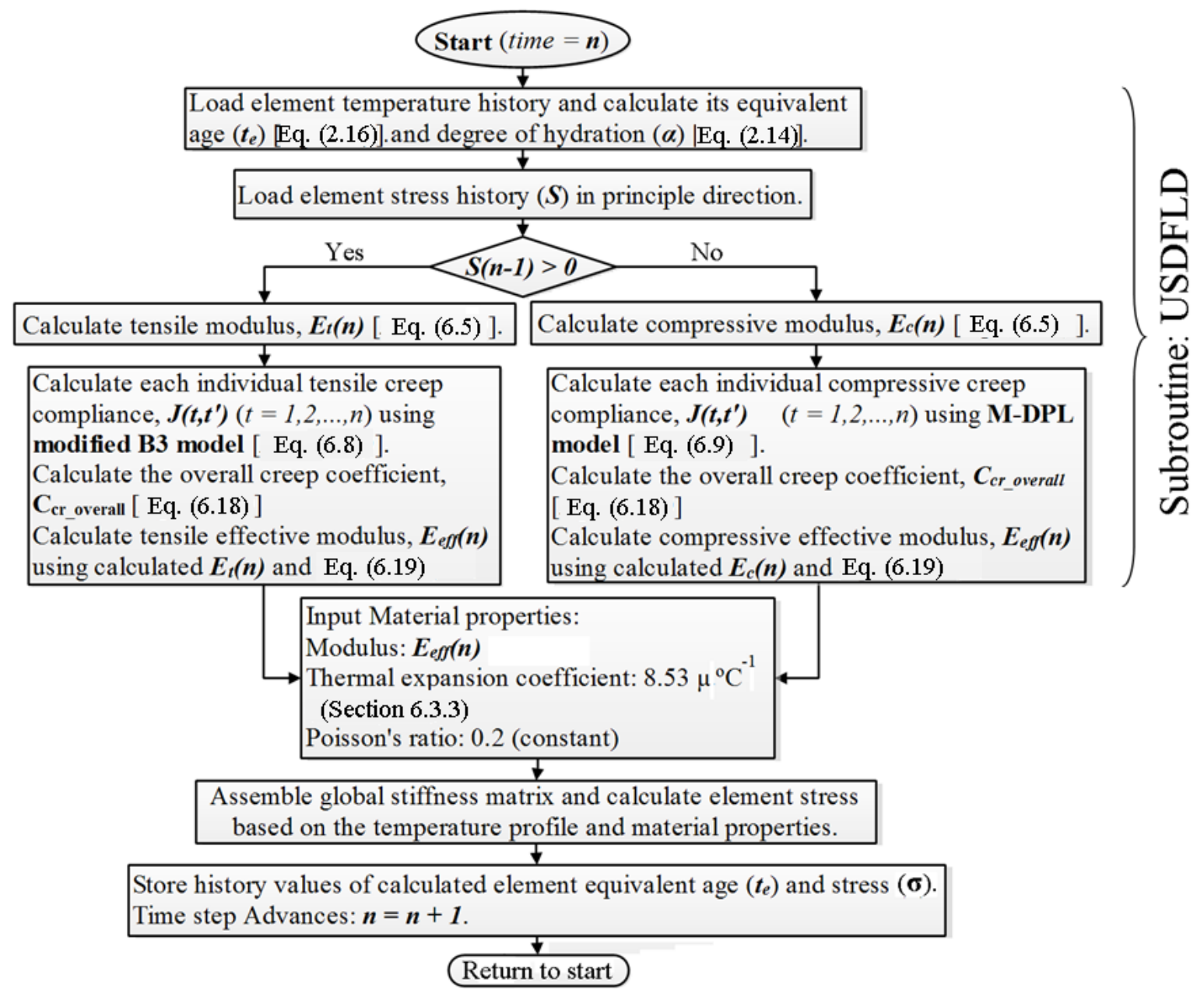

Figure 6-24: The algorithm of the stress analysis
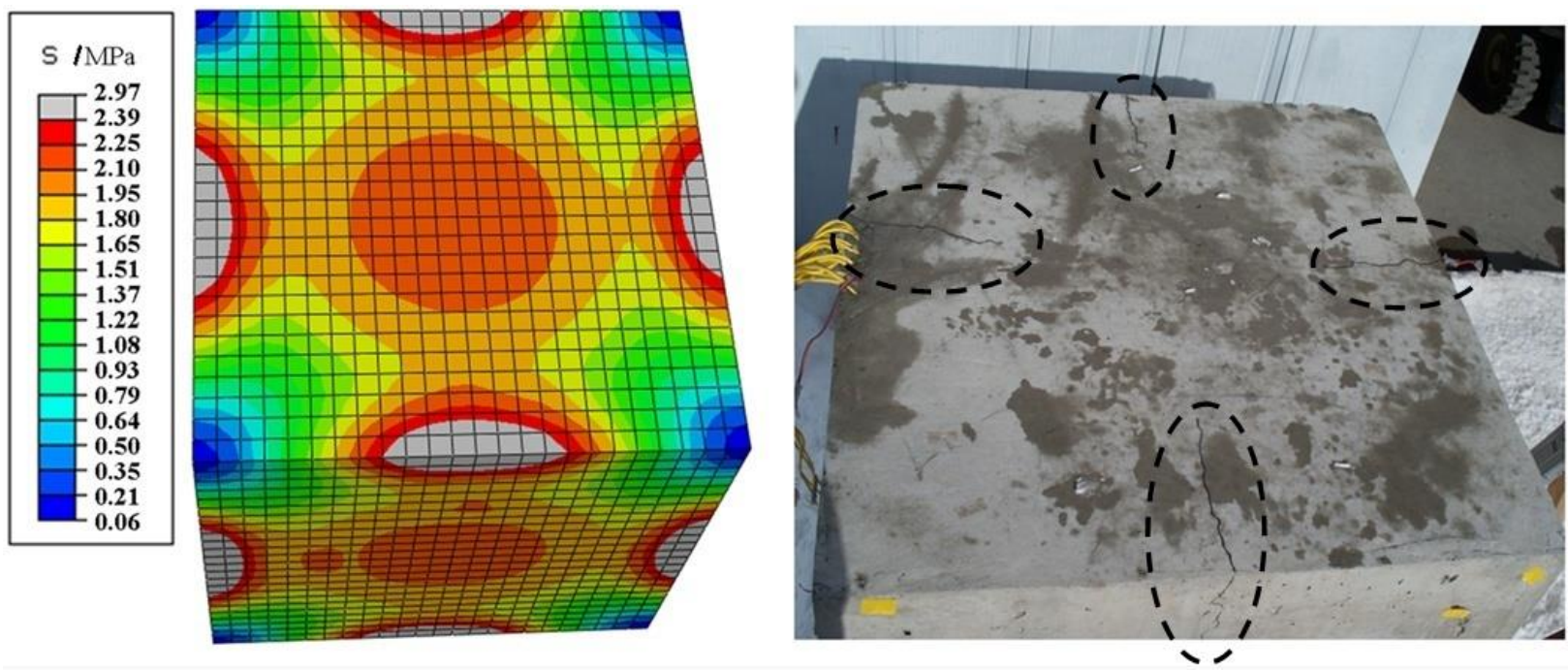

Figure 6-25: Predicted surface stress field and crack locations for WVU Cube \#1 


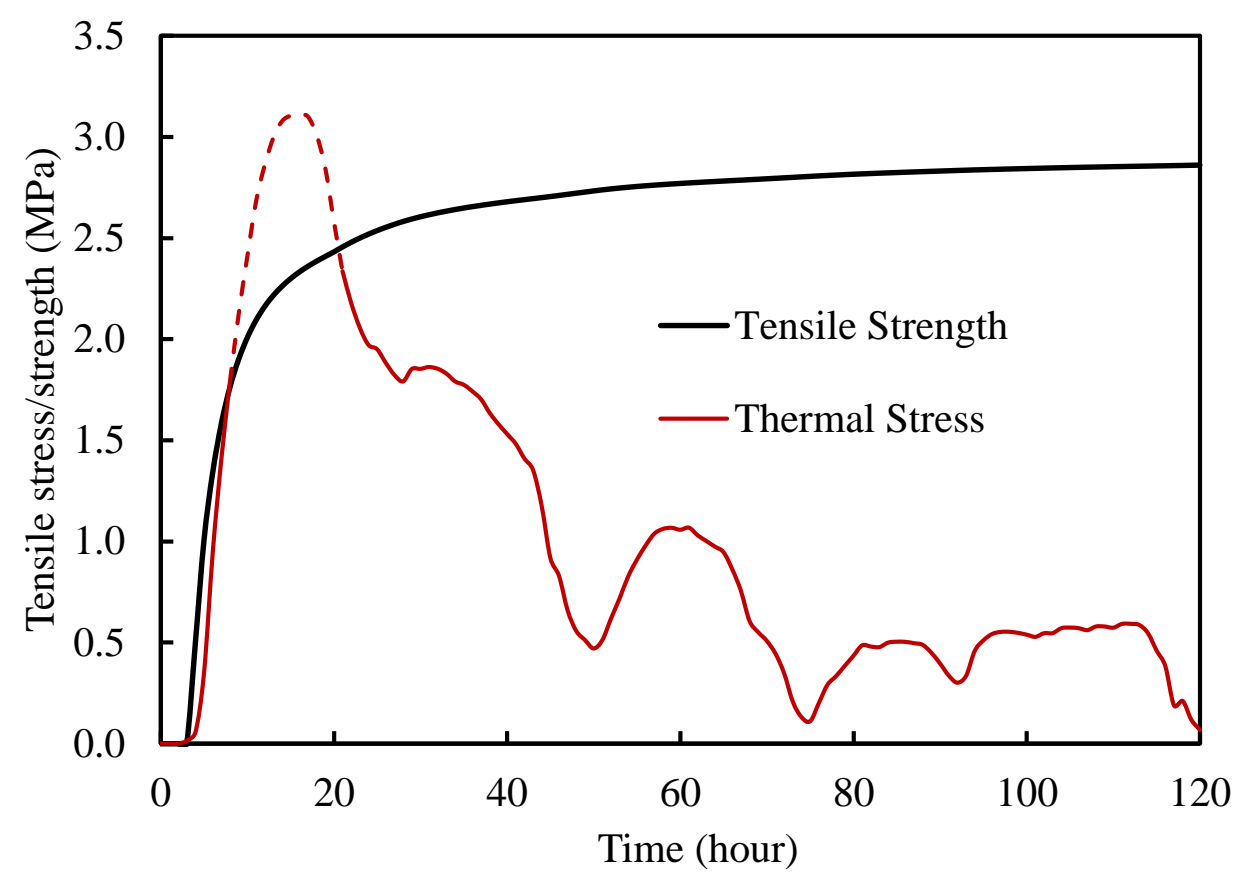

Figure 6-26: Comparison of calculated thermal stress and estimated tensile strength for Cube \#1

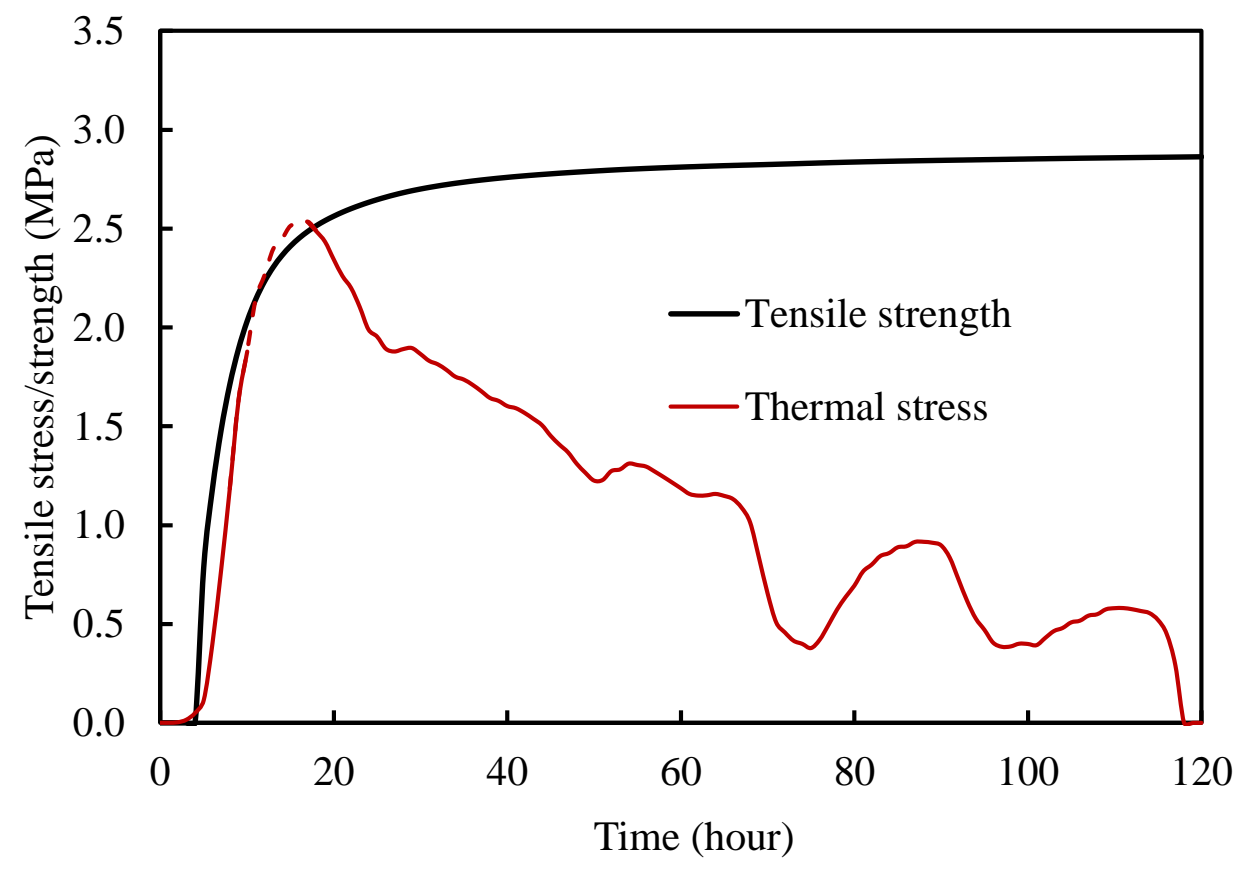

Figure 6-27: Comparison of calculated thermal stress and estimated tensile strength for Cube \#2 
The current calculations can only predict the thermal stresses up to the peakstress thermal stress value; the unloading curve was calculated by assuming a constant creep coefficeient obtained at the peak stress level. The effect of unloading was not included in the current creep model, and hence, the stress values at the unloading portion of the curve were likely underestimated. The effect of unloading on the creep behavior needs further investigation.

The finite element calculated strains were validated with the measurements. As mentioned in Section 6.2, concrete strain histories were measured at several locations using vibrating-wire gages. For Cube \#1, the strain history was measured at Location A. For Cube \#2, strain values were measured at Location A, B and C. The locations are marked in Figure 6-4. The FEM calculated strain histories at these locations were found to be reasonably close to the measurements as shown in Figure 6-28. The best match was shown at location $\mathrm{C}$ of Cube \#2 (2.5 $\mathrm{cm}$ in depth at the center of the top surface) which was far from any steel reinforcement (shown in Figure 6-28(d)). The calculated strain histories (Figure 6-28(a)) showed some deviations from the experimental measurements, which were possibly due to the restrains of concrete movement provided by the parallel steel grid close to the sensor during Cube \#1 testing. On the other hand, during the Cube \#2 testing (shown in Figure 6-28(b), identical location), there was no parallel steel grid attached to the sensor. Autogenous shrinkage of concrete causes a uniform shrinkage behavior which does not influence the thermal stress caused by disproportionate temperature distribution. It may influence the thermal stress due to external restraint. It is noted that the current FEM calculation neglected the effects of autogenous shrinkage and external restraint; therefore, it was not included in the predicted strains in Figure 6-28. The autogenous shrinkage of this particular concrete mixture was measured to be approximately 10 micro-strains in sealed condition after the first 7 days. 

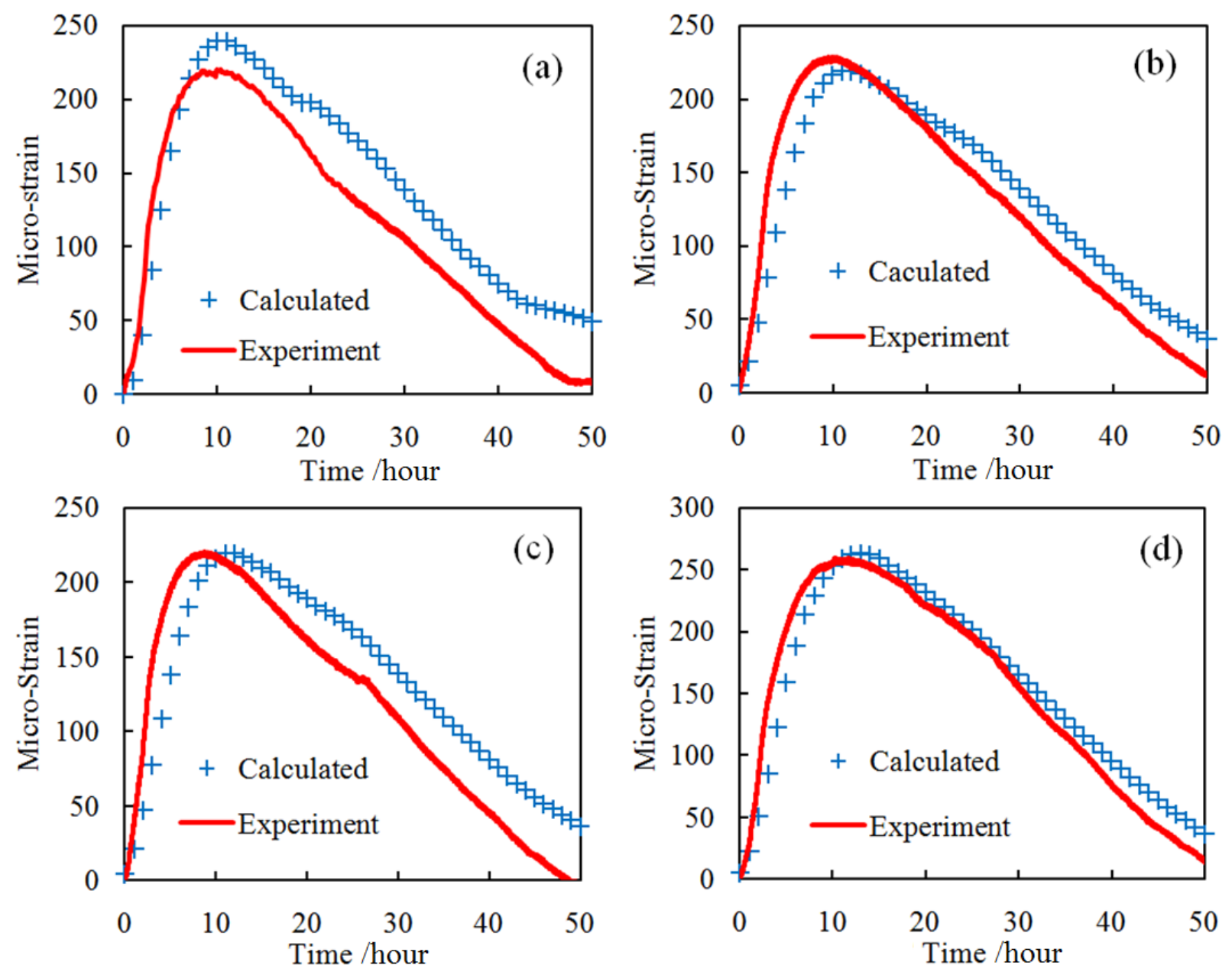

Figure 6-28: Comparison of calculated and measured strain changes at the locations near the concrete surfaces (a) Cube \#1 - Location A, (b) Cube \#2 - Location A, (c) Cube \#2 - Location B and (d) Cube \#2 - Location C

\subsection{Conclusions}

This paper describes a method to perform thermal stress analysis using ABAQUS program with the aid of user subroutines. The developed subroutine program uses the degree of hydration to estimate the variable elastic modulus and strength developments. Concrete tensile creep and compressive creep behavior were included using a step-by-step incremental 
calculation algorithm. The influences from loading age and temperature effects were considered in each time increment of the creep models. It was assumed that the current creep model is able to calculate the thermal stress up to $80 \%$ of the concrete strength. The finite element simulations were validated by the experimental data from two 1.2-meter concrete cubes testing. Strain deformations at the locations near the concrete cube surfaces were measured and correlated reasonably well with the calculated results.

The concrete cubes have high tensile stresses at the surfaces, especially at the center of the edges. The tensile strength development of the concrete at surface locations can be estimated using the maturity method, and the cracking risk could be assessed using the stress to strength ratio obtained at the critical locations. Four visible cracks were found perpendicular to the top four edges on WVU Cube \#1 as predicted, due to a relatively high ambient temperature drop at the first night after construction. The method developed can be used to estimate the thermallyinduced stress of concrete members so that precautions can be implemented prior to concrete cast in order to prevent unexpected cracking. The FEM stress analysis procedures were published in Lin and Chen (2015). 


\section{CHAPTER 7 MASS CONCRETE DEFINITION}

In this study, a good understanding of the behaviors of early age concrete was developed. The important parameters influencing the temperature evolution and stress development were studied. The created FEM models were able to predict the temperature and the thermal stress histories for early age concrete members (Chapter 5 and Chapter 6). The experimental procedures and the FEM modeling techniques described in this study can be used to estimate the cracking risk of any up-coming concrete members. A mass concrete definition table was developed using the modeling results described in Chapter 5 and Chapter 6.

\subsection{Mix Design}

It was understood that the size definition of mass concrete is highly depending on the concrete mix design. WVDOT proposed that the Mix 4 (Table 5-2) should be used to produced the mass concrete definition table as the thermally worst case scenario. Mix 4 (Central Supply \#13196891) is a very commonly used mix design in West Virginia, which has a total of 335 $\mathrm{kg} / \mathrm{m}^{3}\left(564 \mathrm{lb} / \mathrm{yd}^{3}\right.$ ) of Portland Cement with no mineral additive (6-bag straight Class B, WV). The early age properties of Mix 4 were studied in Chapter 5 and Chapter 6 including the temperature and thermal stress calculations of the two 1.2-meter cubes (WVU Cube \#1 and \#2). Instead of performing actual experiments to cover all the different sizes and geometries, the finite element models developed in this study were used to evaluate different cases. A mass concrete definition table is described in this chapter to define the minimum sizes of mass concrete for three most common pier-stem geometries 


\subsection{Ambient Temperature and Minimum Surface Cover}

With no future record or predictions of the ambient temperature, a proper 5-day ambient temperature history is needed for the FEM analysis. The most important characteristic of the ambient temperature on thermal stress development is not the magnitude of the temperature but the daily temperature variations. Large ambient temperature drop when the concrete temperature is still high can induce a higher rate of surface heat loss and higher thermal stress. The 20122013 temperature record in Morgantown, WV was checked from wunderground.com. Approximately $92 \%$ of the days had a max-min temperature variation less than $17^{\circ} \mathrm{C}\left(30{ }^{\circ} \mathrm{F}\right)$. Therefore, a $17{ }^{\circ} \mathrm{C}$ daily ambient temperature variation was assumed, varying linearly between $16{ }^{\circ} \mathrm{C}\left(60^{\circ} \mathrm{F}\right)$ at $6 \mathrm{AM}$ (the lowest point) and $32{ }^{\circ} \mathrm{C}\left(90^{\circ} \mathrm{F}\right)$ at $3 \mathrm{PM}$ (the highest point). The assumed daily ambient temperature is shown in Figure 7-1. The concrete cast was assumed to be finished at 10:00 AM with ambient temperature of $23{ }^{\circ} \mathrm{C}\left(73{ }^{\circ} \mathrm{F}\right)$. The initial concrete temperature was assumed to be $24{ }^{\circ} \mathrm{C}\left(75^{\circ} \mathrm{F}\right)$ which is $1.1^{\circ} \mathrm{C}\left(2^{\circ} \mathrm{F}\right)$ higher than the assumed current ambient temperature.

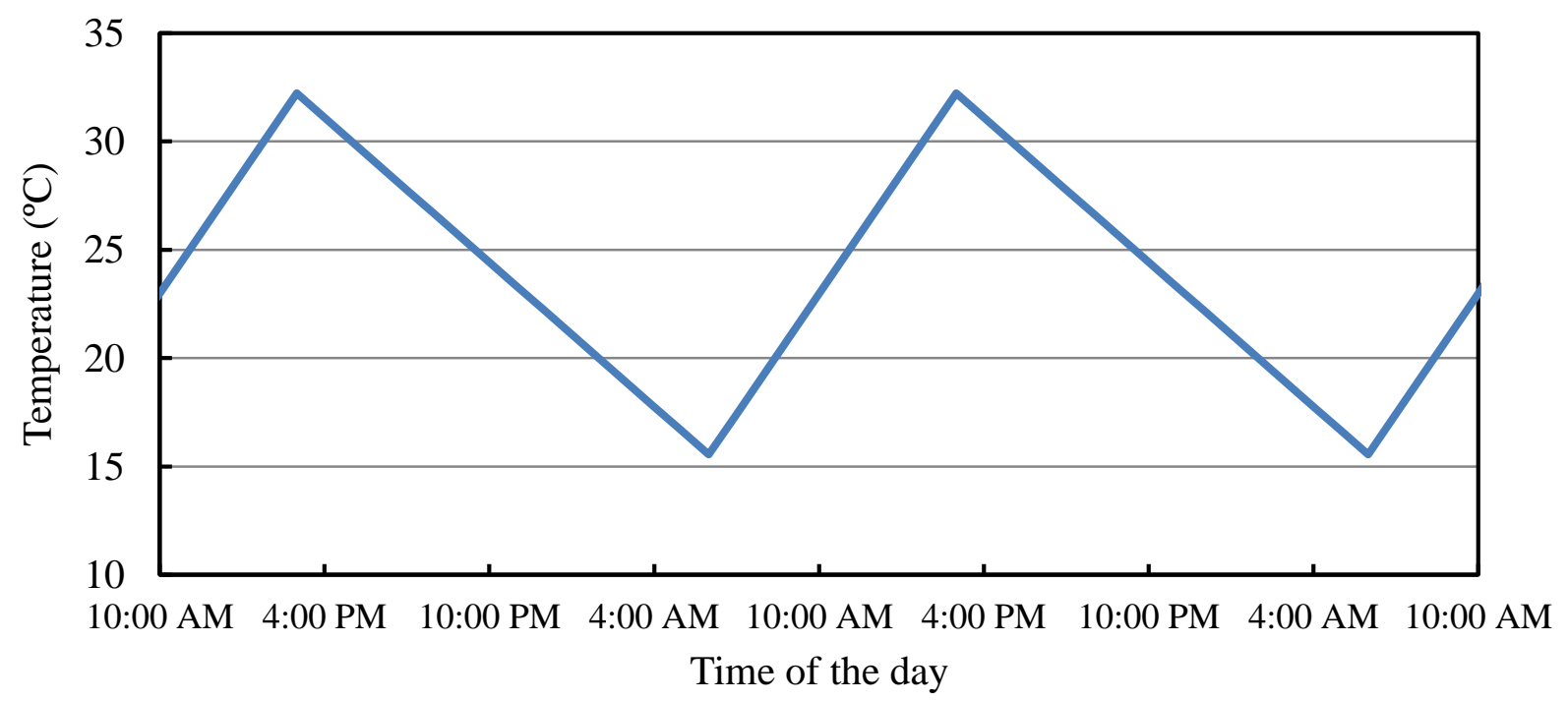

Figure 7-1: Assumed ambient temperature 
Steel formwork was chosen due to its low thermal resistance. Wind speed is known to have significant impact on the surface heat loss rate due to the change of convection coefficient mentioned in the thermal analysis in Section 5.5. A higher wind speed can significantly increase the thermal stress and the possibility of thermal cracking. The variations of wind speed from day to day can be very large which makes the assumption of wind speed very difficult for the mass concrete definition analysis. Either any unconservative or overly conservative assumptions of wind speed cannot provide the proper solution. As a feasible solution, a wind speed of zero was assumed with the requirement a minimum surface cover outside the steel formwork. It means that the steel formwork needs to be completely covered to prevent any direct contact from external wind blowing. For example, a thin plastic sheet can be used to cover the formwork.

\subsection{FEM Analysis}

The thermal-stress analysis developed in this study was used to evaluate the thermal stresses for concrete members in three common pier-stem geometries using Mix 4 (Table 5-2) as the mix design. The experimental results and the modeling techniques for Mix 4 was discussed in details in Chapter 5 and Chapter 6. A summary of Mix 4 experiments and modeling are presented in the following bullet points.

Experimental results used in the thermal analysis model:

- Adiabatic temperature rise $(4$ tests $)=47.3{ }^{\circ} \mathrm{C} \sim 50.2^{\circ} \mathrm{C}\left(85.1^{\circ} \mathrm{F} \sim 90.3^{\circ} \mathrm{F}\right)$

- Thermal conductivity of concrete (hardened concrete) $=1.87 \mathrm{~W} / \mathrm{m} / \mathrm{K}\left(1.07 \mathrm{Btu} / \mathrm{hr} / \mathrm{ft} /{ }^{\circ} \mathrm{F}\right)$

- Specific heat of the initial concrete mixture is based on the amount of each ingredient Assumed specific heat of individual ingredients:

Limestone: $840 \mathrm{~W} / \mathrm{kg} / \mathrm{K}\left(0.20 \mathrm{Btu} / \mathrm{lb} /{ }^{\circ} \mathrm{F}\right)$

Fine Aggregate: $710 \mathrm{~W} / \mathrm{kg} / \mathrm{K}\left(0.17 \mathrm{Btu} / \mathrm{lb} /{ }^{\circ} \mathrm{F}\right)$

Cementitious material: $740 \mathrm{~W} / \mathrm{kg} / \mathrm{K}\left(0.18 \mathrm{Btu} / \mathrm{lb} /{ }^{\circ} \mathrm{F}\right)$

Water: $4184 \mathrm{~W} / \mathrm{kg} / \mathrm{K}\left(1.0 \mathrm{Btu} / \mathrm{lb} /{ }^{\circ} \mathrm{F}\right)$

The initial specific heat of concrete: $\sim 963 \mathrm{~W} / \mathrm{kg} / \mathrm{K}\left(\sim 0.23 \mathrm{Btu} / \mathrm{lb} /{ }^{\circ} \mathrm{F}\right)$

- Activation Energy $=41,800(\mathrm{~J} / \mathrm{mol})$ 
Experimental results used in the stress analysis model:

- Tensile modulus curve

- Compressive modulus curve

- Compressive strength curve

- Thermal expansion coefficient $\left(8.5 \times 10^{-6} /{ }^{\circ} \mathrm{C}\right)$

- Tensile creep test result

- Activation Energy $=41,800(\mathrm{~J} / \mathrm{mol})$

Thermal analysis modeling

- Temperature history dependent degree of hydration

- Degree of hydration dependent thermal conductivity

- Degree of hydration dependent specific heat

- Degree of hydration dependent thermal loading based on ATR results

- Assumed ambient temperatures with a $30^{\circ} \mathrm{F}$ daily variation

- Steel formwork with no extra insulation protection

- Thermal convection model with zero wind speed

- Class B Straight 6-bag limestone concrete mix (Mix 4, or Central Supply \#1396891)

$\underline{\text { Stress analysis modeling }}$

- Temperature history dependent degree-of-hydration

- Degree-of-hydration dependent Young's modulus

- Difference in concrete tensile modulus and compressive modulus

- Experimentally confirmed thermal expansion coefficient

- Incremental creep behavior using Bazant's creep models considering:

1. Different loading age for each load increment

2. Different loading duration for each load increment

3. Temperature effect on creep

4. Consider tensile creep and compressive creep separately

\subsection{Mass Concrete Definition Table}

Bridge pier-stem with three common column geometries (circular, rectangular and square) (Figure 7-2) were evaluated from $0.6 \mathrm{~m}(2 \mathrm{ft})$ to $1.5 \mathrm{~m}(5 \mathrm{ft})$ with a size increment of $0.15 \mathrm{~m}(0.5$ $\mathrm{ft})$. The predicted tensile stress histories were compared with estimated surface concrete tensile strength development curve. A certain concrete member will be defined as "mass concrete" if the predicted stress exceeds $80 \%$ of the tensile strength at any time step. The "80\%" was 
included as a safety factor for various unpredictable conditions. The procedures to determine whether a certain concrete member is mass concrete are listed in the following bullet points.

- Perform thermal analysis and obtain temperature profile history.

- Load temperature profile history, perform stress analysis and obtain stress profile history.

- Locate the maximum stress location and plot its tensile stress history in principle direction.

- Calculate the estimated tensile strength history at the maximum stress location using its temperature history and experimentally obtained strength curve.

- Compare the stress and $80 \%$ strength to see if the stress is higher at any time to decide whether the structure is "mass concrete" or "non-mass concrete".

A typical representation of tensile strength versus tensile stress comparison is shown in Figure 7-3, which describes the strength and stress time history comparison for a $1.07 \mathrm{~m}(3.5 \mathrm{ft})$ square column. As seen in Figure 7-3, the calculated thermal stress exceeded 80\% of the tensile strength but did not exceed $100 \%$ of the tensile strength. Therefore, this case is defined as mass concrete, which is shown in "red" in the definition table (Table 7-1). As shown in Figure 7-4,

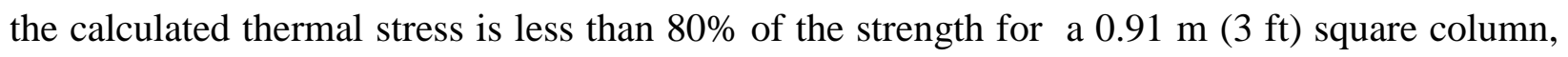
and it is referred as non-mass concrete and shown in "green" in Table 7-1. In Table 7-1, the results of all three geometries are presented in terms of mass ("red") and non-mass ("green") using a size increment of $0.15 \mathrm{~m}(0.5 \mathrm{ft})$. The minimum size (D) of mass concrete for circular, square and rectangular shapes are $1.22 \mathrm{~m}(4 \mathrm{ft}), 0.91 \mathrm{~m} \mathrm{(3ft)}$ and $0.61 \mathrm{~m} \mathrm{(2ft),} \mathrm{respectively.} \mathrm{It}$ can be very useful on pier-stem design in terms of different geometries, because different geometries affect the thermal stress distribution and cracking potentials. As a reference, Table 7-2 presented the mass concrete definition table with $100 \%$ strength limit. 
1. Circular pier stem: $\mathrm{D}$ (diameter) $\mathrm{x} 3 \mathrm{D}$ (height)

2. Square pier stem: $D \times D \times 3 D$

3. Rectangular pier stem: $\mathrm{D} \times 3 \mathrm{D} \times 3 \mathrm{D}$

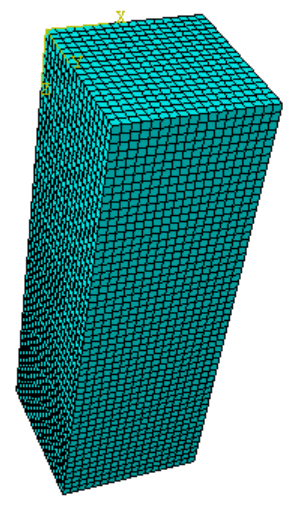

Square cross-section

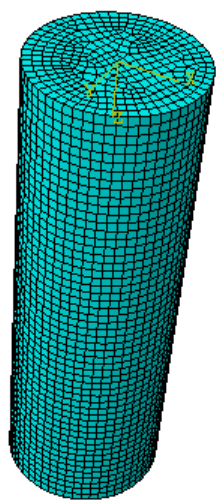

Circular cross-section

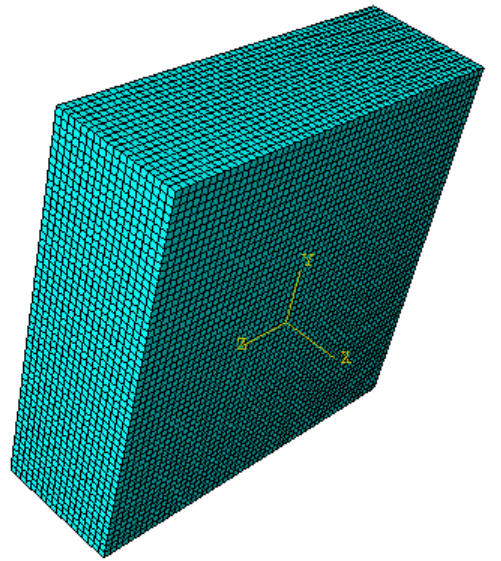

Rectangular cross-section

Figure 7-2: Three common geometries

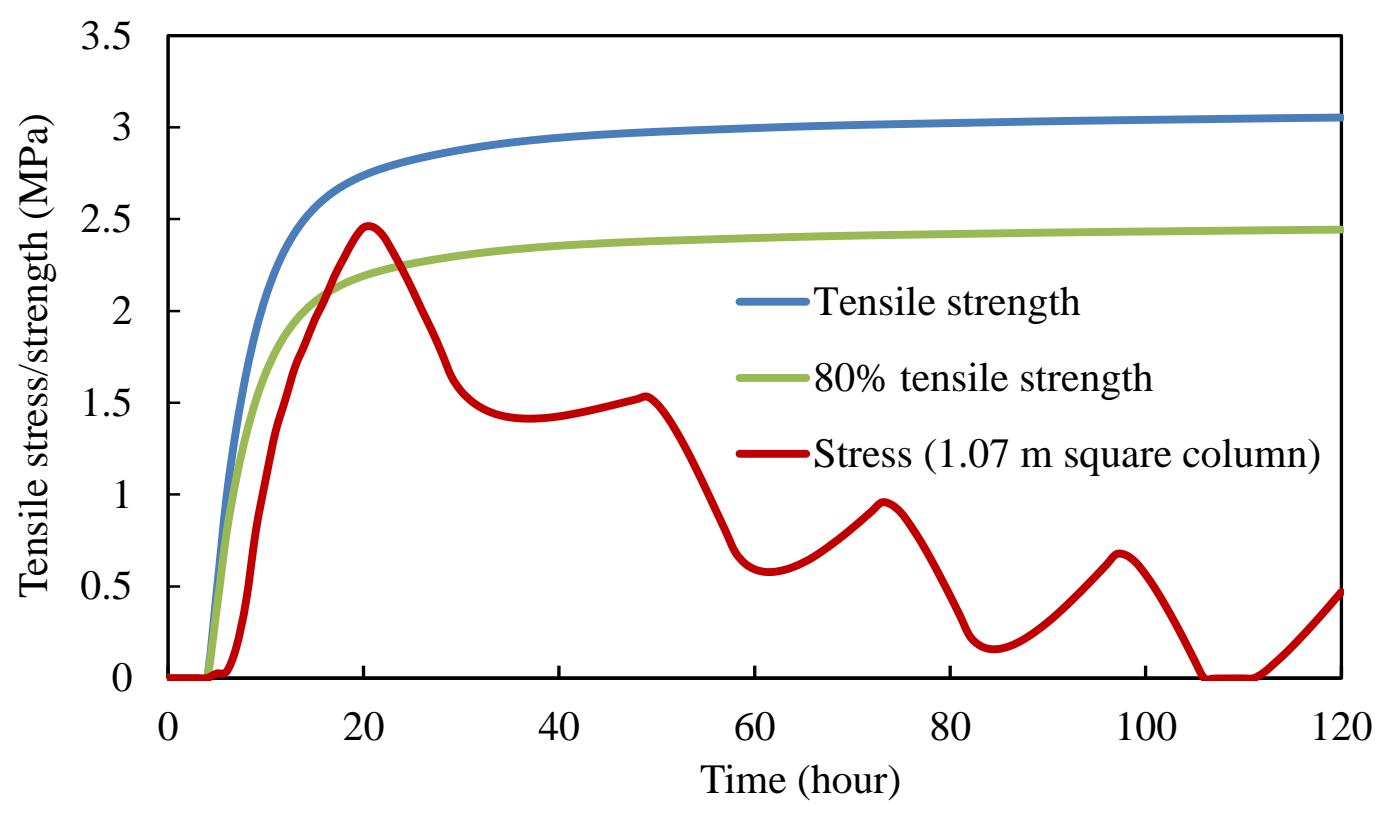

Figure 7-3: Stress and strength comparison from FEM results of the $1.07 \mathrm{~m}$ square column 


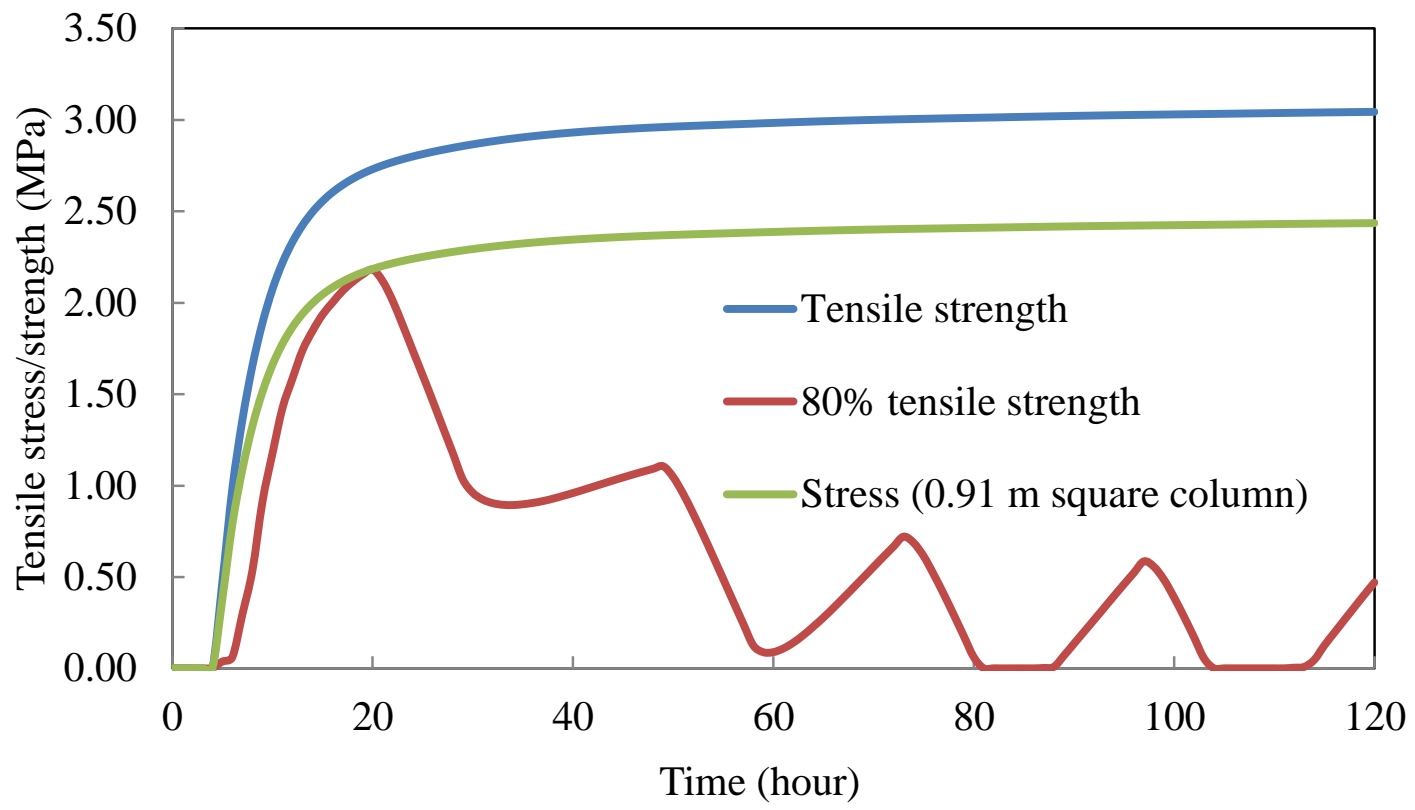

Figure 7-4: Stress and strength comparison from FEM results of the $0.91 \mathrm{~m}$ square column

Table 7-1: Mass Concrete Member Definition Table (80\% Strength Limit)

\begin{tabular}{|c|c|c|c|c|c|c|c|}
\hline & $1 \mathrm{ft}$ & $1.5 \mathrm{ft} \quad 2 \mathrm{ft}$ & $2.5 \mathrm{ft}$ & $3 \mathrm{ft}$ & $3.5 \mathrm{ft}$ & $4 \mathrm{ft}$ & $4.5 \mathrm{ft}$ \\
\hline Circular & & & & & & & \\
\hline Square & & & & & & & \\
\hline Rectangular & & & & & & & \\
\hline
\end{tabular}

Table 7-2: Reference Table (100\% Strength Limit)

\begin{tabular}{|c|c|c|c|c|c|c|c|c|}
\hline & $1 \mathrm{ft}$ & $1.5 \mathrm{ft}$ & $2 \mathrm{ft}$ & $2.5 \mathrm{ft}$ & $3 \mathrm{ft}$ & $3.5 \mathrm{ft}$ & $4 \mathrm{ft}$ & $4.5 \mathrm{ft} \quad 5 \mathrm{ft}$ \\
\hline Circular & & & & & & & & \\
\hline Square & & & & & & & & \\
\hline Rectangular & & & & & & & & \\
\hline
\end{tabular}




\subsection{Important Terms of Use}

The mass concrete definition table developed in this study should not be used unless the following terms are satisfied.

1. The total cementitious material should be less than $335 \mathrm{~kg} / \mathrm{m}^{3}\left(564 \mathrm{lb} / \mathrm{yd}^{3}\right)$. The use of Type III cement (high early age) are prohibited. Exceptions can be made if the proposed mix design has less early age hydration heat than Mix 4 (Table 5-2) measured by WVU lab or a third party certified by WVDOT.

2. Coarse aggregates with a higher coefficient of thermal expansion should not be used especially natural river aggregates.

3. Formwork and minimum surface cover must be in place for a minimum of 5 days.

4. Watering or applying wet burlap directly to the concrete surfaces are prohibited within 5 days after casting.

\subsection{Preliminary Analysis Results with Additional Insulation}

The mass concrete definition table using the Mix 4 (6-bag straight Class B) was presented above using a conservative approach. The allowable sizes are relatively small due to the high hydration heat and lack of thermal protections. There are different methods that can be applied to mass concrete structures to reduce thermal stresses and increase the allowable size. Using surface insulation is one of the most cost-effective solutions. Surface insulation can effectively slow down the rate of surface heat loss and reduce the thermal stress. A preliminary analysis was performed on the three types of pier-stems. Insulation $\mathrm{R}$ values were added to the surface protection of the existing mass concrete elements (R5 $=2.5 \mathrm{~cm}$ or 1 in of Styrofoam). The effect can be seen that allowable sizes for all geometries are increased in Table 7-3. With R5 insulation 
added, the allowable size for rectangular, square and circular elements is increased to $0.76 \mathrm{~m}$ ( 2.5 $\mathrm{ft}), 1.22 \mathrm{~m}(4 \mathrm{ft})$, and $1.52 \mathrm{~m}(5 \mathrm{ft})$, respectively. More insulation can be added to further increase the size of the rectangular element. The allowable size can be up to $1.22 \mathrm{~m} \mathrm{(4ft)} \mathrm{if} \mathrm{R15} \mathrm{(5} \mathrm{cm} \mathrm{or}$ 2 in of Styrofoam) are added. The results are still preliminary without any experimental confirmation. Further analysis and experimental validation are needed.

Table 7-3: Reference Table (additional $\mathrm{R}$ values and $80 \%$ Strength Limit)

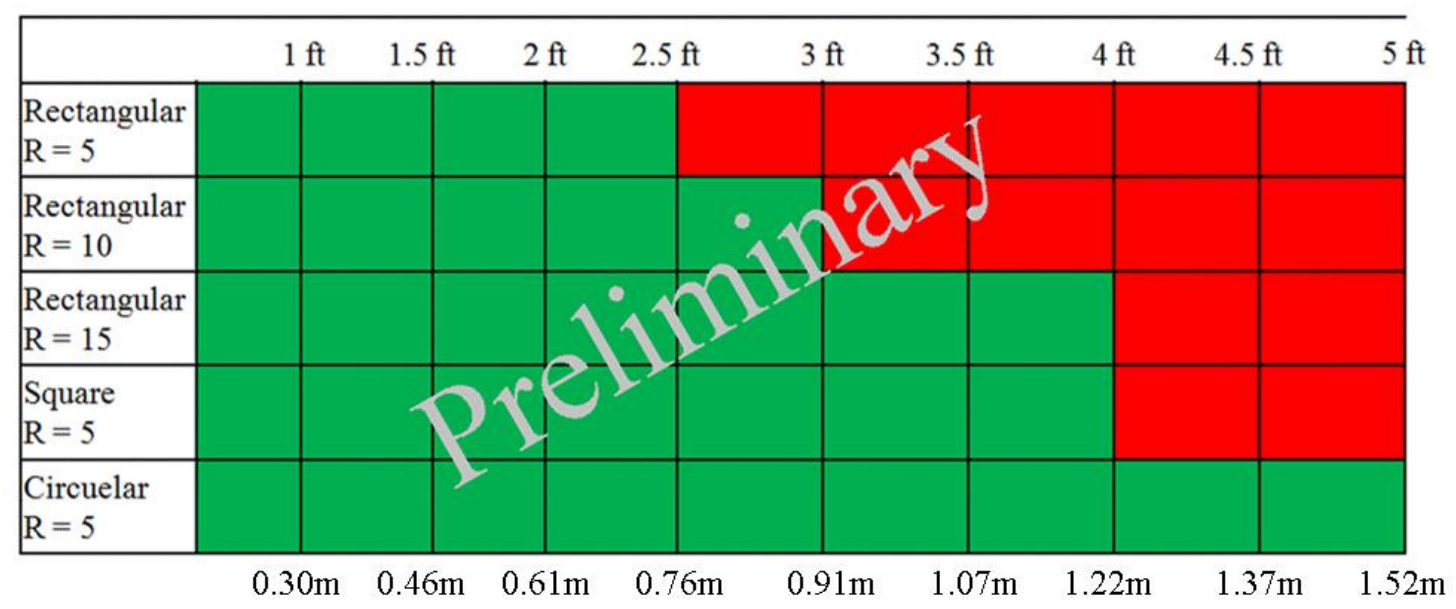




\section{CHAPTER 8 GROUND GRANULATED BLAST-FURNACE SLAG}

\subsection{Production of GGBFs}

Blast furnace slag is produced when iron ore is reduced at about 1,350 to $1,550{ }^{\circ} \mathrm{C}$ in a blast furnace. The main product of a blast furnace is the molten iron. The other components turn to a liquid slag form at such high temperature and flow to the bottom of the furnace. The liquid slag has a lower density than the molten iron, and thus forms a liquid slag layer above. After being cooled down in the air, the solid slag is collected for further use (Siddiqui 2008). Typically, about 220 to 370 kilograms of blast furnace slag are produced per metric ton of pig iron (Kalyoncu, 1998).

The liquid slag crystallizes if cooled slowly or becomes a form of glass if cooled rapidly. There are three ways of cooling to form three different types of blast furnace slag. The palletized slag is produced by partially cooling the slag with water, and then flinging it into the air. The pellets contain much less glass content if compared to the granulates, as low as $50 \%$. Part of the palletized slag is used as concrete aggregate and is much used in cement production as raw material as well. The air-cooled slag is formed by allowing the slag to solidify slowly in the air, and sometimes followed by accelerated cooling with a water spray. The air-cooled slag is hard and dense, being normally used for road bases, railway ballast, asphalt paving and concrete aggregate. The granulated slag is produced by quenching the liquid slag with large amount of water to produce sand-like granulates. Later, they are ground to fine powder, called Ground Granulated Blast Furnace slag (GGBFs). 
Among the three different types of slag, GGBFs is the most valuable one because it can be used as cementitious material when mixed with Portland cement, lime or other types of Alkalis. Figure 8-1 shows the raw and final product of GGBFs (Anderson, 2009). When flowing to the bottom of the furnace, the liquid slag forms a layer above the molten iron due to the smaller density of slag. After being separated from the molten iron, the liquid slag is cooled down in the air or water and prepared for further use. Lower grade ore results in more slagsometimes as much as 1.0 to 1.2 tons of slag per ton of pig iron (Kalyoncu, 1998).
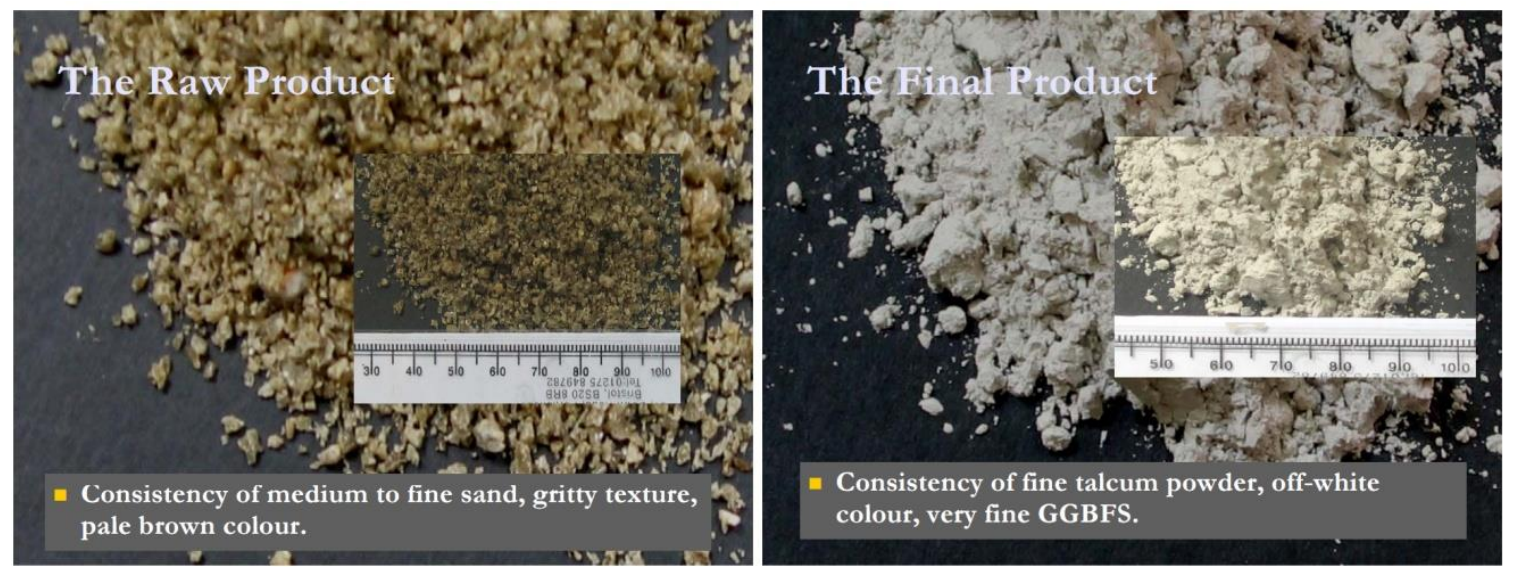

Figure 8-1 The raw and final product of GGBFs (Gordon Anderson, 2009)

\subsection{Properties of GGBFs Power}

Ground granulated blast-furnace slag (GGBFs) is an off-white powder as described in Tasong et al. (1999). Figure 8-2 shows the color difference of GGBFs and OPC. Concrete containing GGBFs often appears brighter in color in comparison with traditional Portland cement concrete due to its fineness. A smoother surface can often be achieved with concrete containing GGBFs due to its finer particle size. GGBFs has a bulk density of $1200 \mathrm{~kg} / \mathrm{m}^{3}$, a specific gravity of 2.8 and a specific surface of 425 to $470 \mathrm{~m}^{2} / \mathrm{kg}$ (Tasong et al., 1999). GGBFs powder is found 
to be a finer than Ordinary Portland Cement (OPC) powder as in the SEM image (Metla et al. (2014) (Figure 8-3).

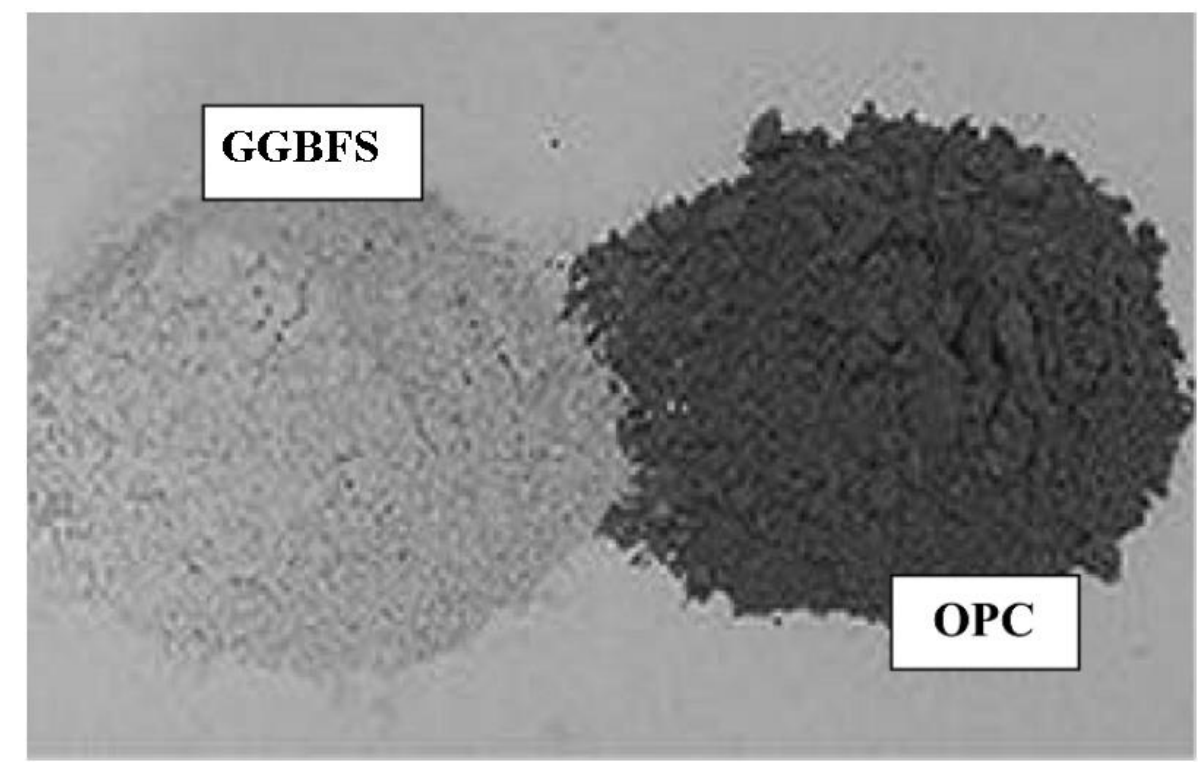

Figure 8-2: Physical appearances of GGBFs and OPC (Siddiqui 2008)

The chemical compositions of a slag significantly vary depending on the production process. One key factor is the composition of the raw materials in the iron production process. In the case of GGBFs, it floats to the top layer due to smaller density. Another key factor is the cooling process (Chen, 2007). To obtain good cementitious property and reactivity, the slag melt needs to be rapidly cooled or quenched below $800{ }^{\circ} \mathrm{C}$ in order to prevent any crystallization from happening. To cool and fragment the slag a granulation process can be applied in which molten slag is subjected to jet streams of water or air under pressure. In order to achieve a suitable reactivity, the obtained fragments are grounded to reach the same or better fineness than Portland Cement (Metla et al., 2014). 


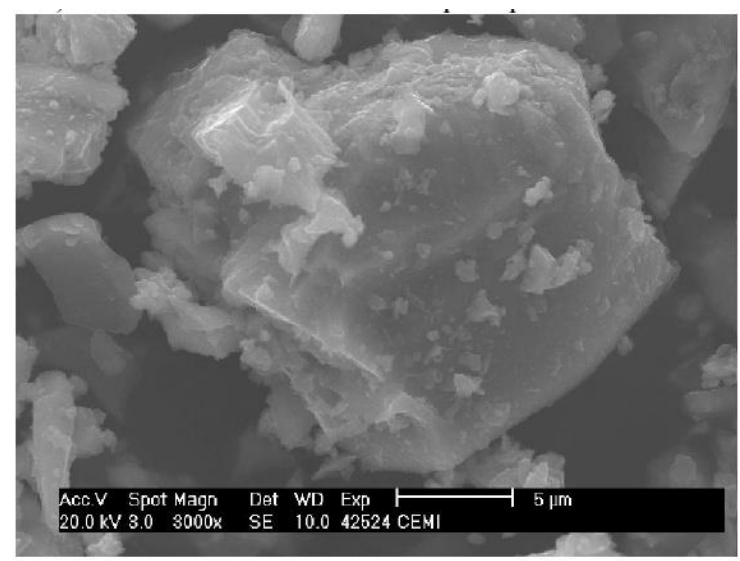

Cement particles

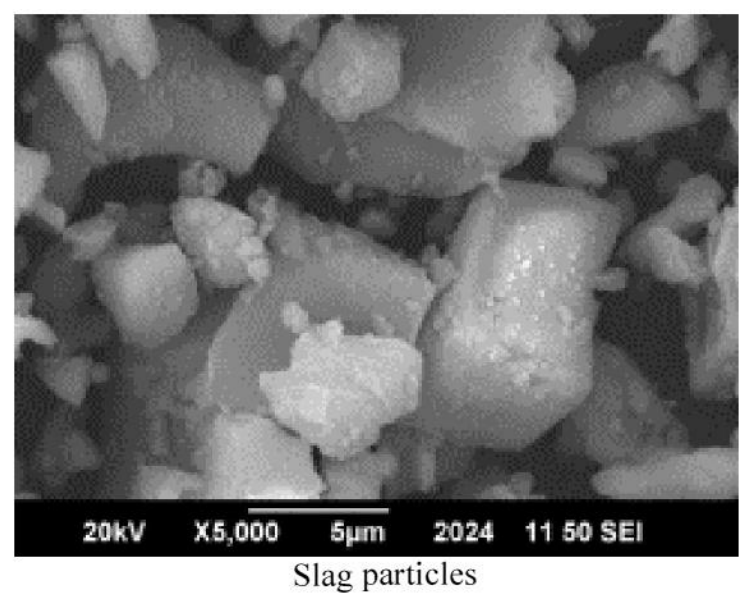

Slag particles

Figure 8-3: SEM image of cement and slag particles (Metla et al., 2014)

The chemical composition of the slag is depending on the composition of the iron ores, flux stones and fuels. The GGBFs made as cementitious material must be produced using uniform raw materials with a consistent quality. The chemical composition of GGBFs from a given source should only vary within narrow limits. In most cases, the $95 \%$ of GGBF is made of four major oxides: lime, magnesia, silica and alumina. Minor elements include sulfur, iron, manganese, alkalis, and trace amounts of several others (Lewis, 1982). There many different chemical compositions from different literatures. In summary, Lewis (1982) shows the percentage range of GGBFS chemical compositions produced in the US (updated in 1992), while Taylor (1997) shows the percentage range produced in France (Table 8-1).

Table 8-1: Chemical composition of GGBFs from US and France

\begin{tabular}{|l|c|c|}
\hline Constituent & Lewis, 1992 & Taylor, 1997 \\
\hline Lime $(\mathrm{CaO})$ & $32 \sim 45$ & $38 \sim 44$ \\
\hline Magnesia $(\mathrm{MGO})$ & $5 \sim 15$ & $3.6 \sim 8.7$ \\
\hline Silica $\left(\mathrm{SiO}_{2}\right)$ & $32 \sim 42$ & $32 \sim 37$ \\
\hline Alumina $\left(\mathrm{Al}_{2} \mathrm{O}_{3}\right)$ & $7 \sim 16$ & $10 \sim 16$ \\
\hline Sulfer $(\mathrm{S})$ & $1 \sim 2$ & $0.68 \sim 1.25$ \\
\hline Iron Oxide $\left(\mathrm{Fe}_{2} \mathrm{O}_{3}\right)$ & $0.1 \sim 1.5$ & $0.3 \sim 9.3$ \\
\hline Manganese $\mathrm{Oxide}(\mathrm{MnO})$ & $0.2 \sim 1.0$ & $0.3 \sim 1.3$ \\
\hline
\end{tabular}




\subsection{The Influence of GGBFs on Cement Hydration}

The GGBFs alone is not capable of reacting with water. In slag concrete mix, the alkalinity of OPC serves as a catalyst to activate slag reaction. When Portland cement reacts with water, it hydrates and produces calcium silicate hydrate (CSH), the main component to the cements strength, and calcium hydroxide $\left(\mathrm{Ca}(\mathrm{OH})_{2}\right)$. The chemical equation of OPC can be simplified as in R1. When GGBFs is added to the mixture, it also reacts with water and produces CSH from its available supply of calcium oxide and silica. A pozzolanic reaction also takes place which uses the excess $\mathrm{SiO}_{2}$ from the slag source, $\mathrm{CA}(\mathrm{OH})_{2}$ produced by the hydration of the Portland Cement, and water to produce more of the desirable CSH (R2). However, R2 reaction is much slower in comparison with the OPC-water reaction (R1). Therefore, a GGBFs concrete mix often results a low early age strength but an increase in later age strength. R2 also has a 'pore-blocking' effect which can lead to increased long-term hardening of the cement paste. The blocking of pores leads to higher strength, lower permeability and enhanced resistance to the sulfate attack (Macphee et al., 1989). The chemical reactions (R1 and R2) with the attendance of $\mathrm{SiO}_{2}$ from GGBFs are illustrated in Figure 8-4.

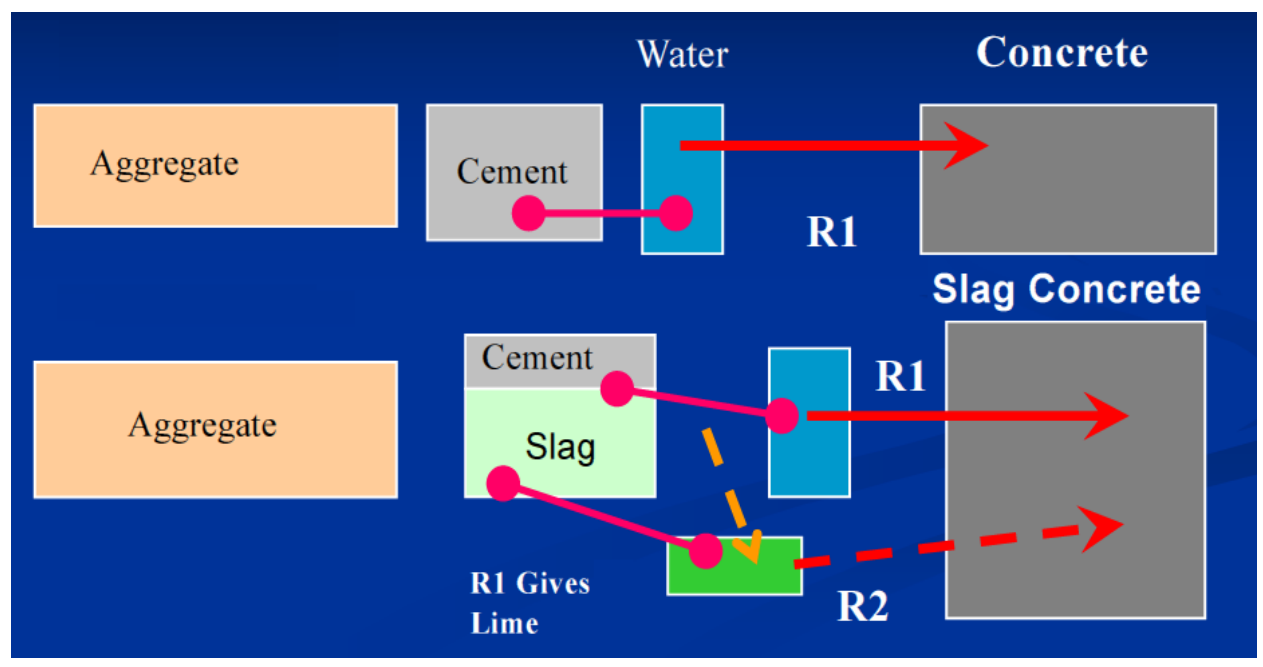

Figure 8-4: Chemical reaction of OPC and GGBFs (Anderson, 2009) 
$\mathrm{C} 3 \mathrm{~S}+\mathrm{H}_{2} \mathrm{O}-------->\mathrm{C}-\mathrm{S}-\mathrm{H}+\mathrm{Ca}(\mathrm{OH})_{2}$

Silica of GGBF Slag $+\mathrm{Ca}(\mathrm{OH})_{2}+\mathrm{H}_{2} \mathrm{O}$

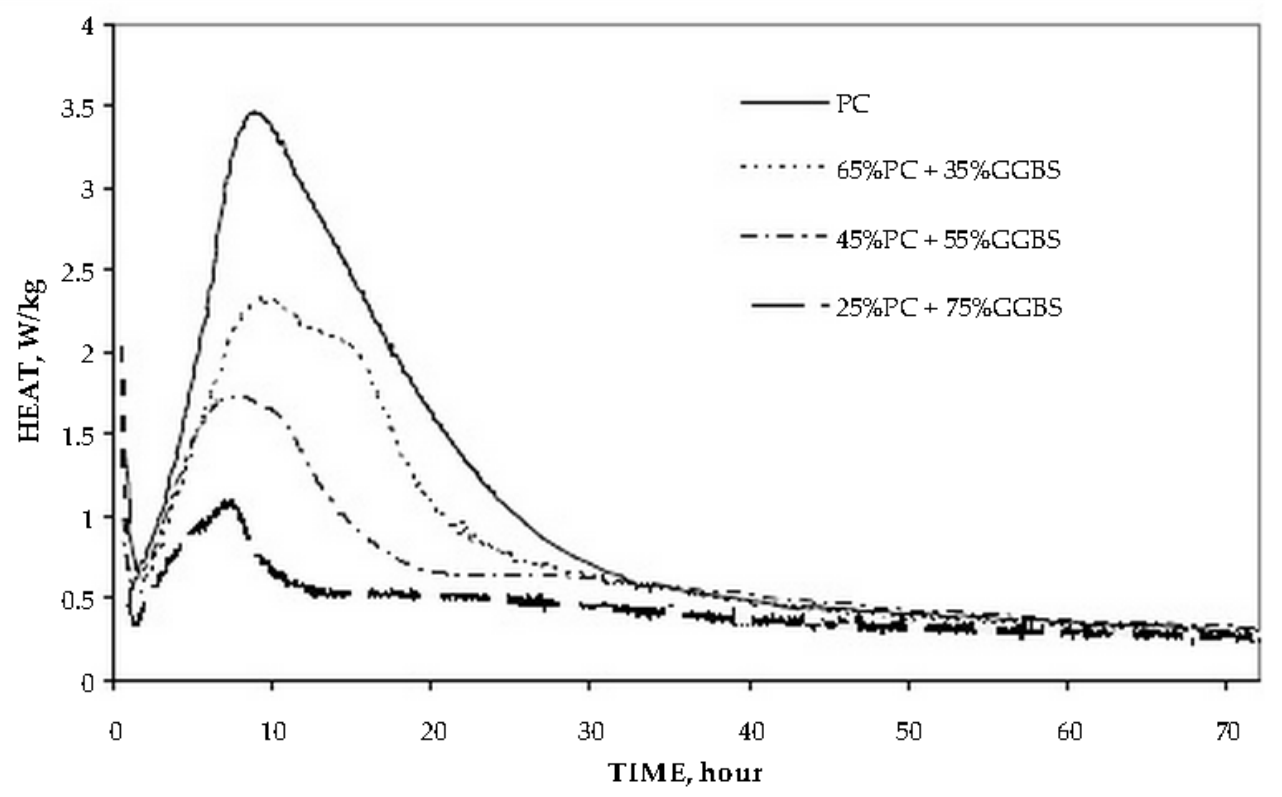

Figure 8-5: Rate of heat evolution at various GGBFs levels (Nasir et al., 2014)

\subsection{The Effect of GGBFs on Heat and Strength Development of Concrete}

The attendance of GGBFs in the cement paste decreases the hydration rate as explained in Section 8.3. The decrease in hydration rate can be reflected by the heat generation and strength development. Odler (1998) points out that the presents of GGBFs in large amount will significantly decrease the hydration rate. Nasir et al. (2014) studied the effect of GGBFs to hydration heat using calorimetry method. Figure 8-5 shows the heat generation histories of an OPC mix and three GGBFs mixes in different percentages (25\%, 45\% and 65\%). Robbins (2007) also demonstrated the same effect in terms of cumulated heat generation as the GGBFs content varies (Figure 8-6). A similar study was also conducted in WVU laboratory using the adiabatic calorimeter described in Chapter 3. Mix 4 from Table 5-2 were used as the OPC mix design. 23\% 
and $47 \%$ of the OPC were replaced with Grade 100 GGBFs from ESSROC company to create two other mix designs for comparison purposes. Other ingredients in Mix 4 were kept the same. The adiabatic temperature rises for the three mix designs were converted to energy per grams of cementitious material and presented in Figure 8-7.

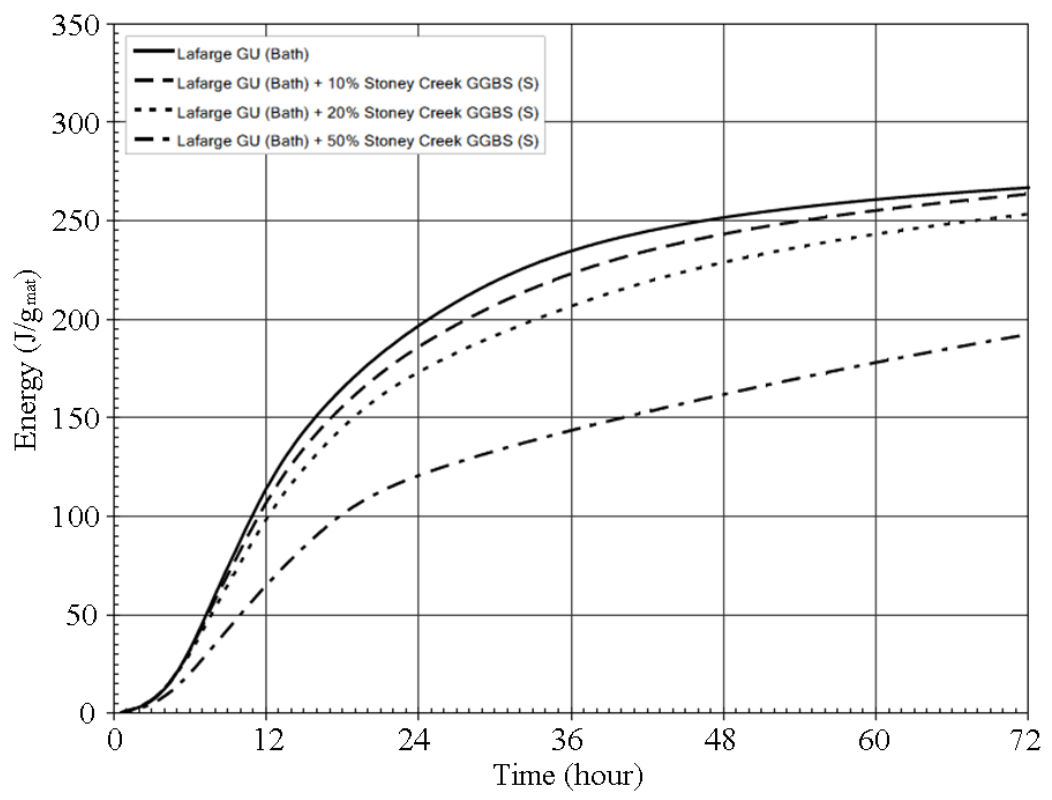

Figure 8-6: Total of heat evolution at various GGBFs levels (Robbins, 2007)

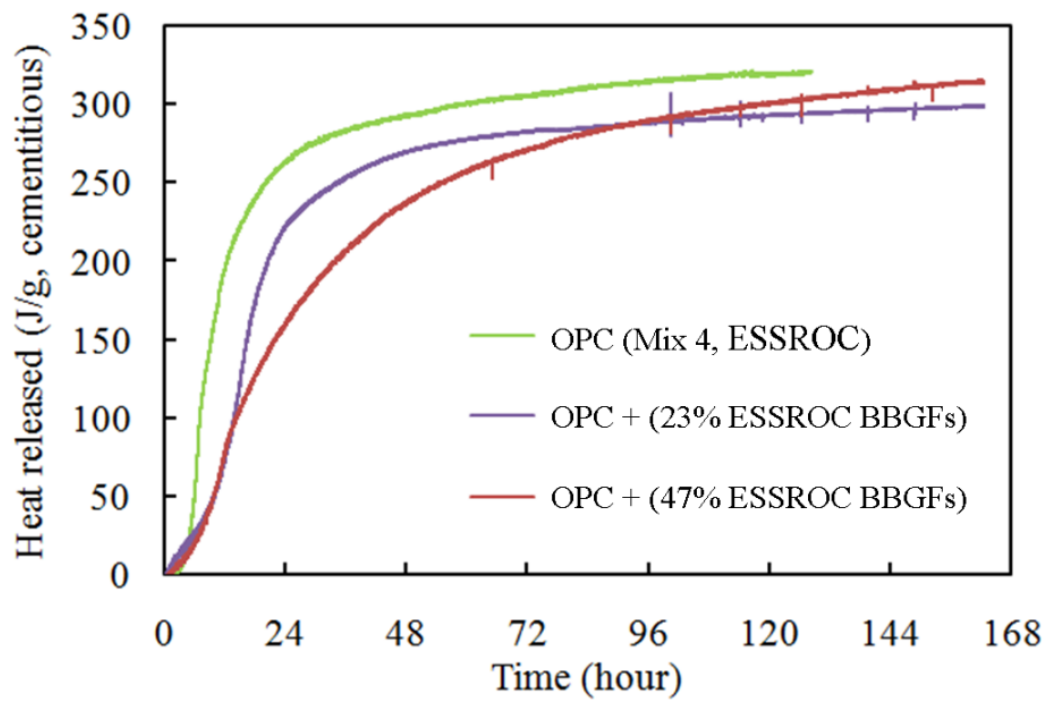

Figure 8-7: Total of heat evolution at various GGBFs levels (WVU lab testing) 
As shown in Figure 8-7, the 47\% GGBFs mix exhibited much lower heat generation rate but a maintained a higher rate in later ages (after 120 hours). The total heat release of the $47 \%$ GGBFs mix should be higher than the OPC mix. Similar effects were also found in strength development. Researchers discovered a decrease in rate of strength gain in the early age and a higher ultimate strength in concrete with GGBFs.

Hogan and Mesusel (1981) found that the compressive strength development was slow for the first three days for concrete containing 40\%-60\% of GGBFs. Similar results were obtained by Roy and Idorn (1982) for concrete with 20\%-60\% of GGBFs and Badu and Kumar (2000) for concrete with $10 \%-80 \%$ of GGBFs. The harden concrete with GGBFs (age > 28 days) is found to be denser and higher in compressive strength in comparison with OPC concrete (Basheer et al., 2002). The effect is due to the pore-filling effect during later age hydration. Daube and Bakker (1983) indicated that the addition of GGBFs modifies the products and the pore structures in a hardened cementitious material. Luo et al. (2003) studied the pore structures of a $70 \%$ GGBFs concrete mixture in comparison with OPC concrete using a water-cementitious ratio of 0.34 . He reported that the hardened $70 \%$ GGBFs concrete mixture has a better pore structure, especially after 60 day of concrete age. Better pore structure and extra CSH formed due to the existence of GGBFs can improve the later age strength. Varies researchers have reported a higher compressive strength of hardened GGBFs concrete than OPC concrete (Hogan and Meusel, 1981; Hwang and Lin, 1986; Aldea et al., 2000: Miura and Iwaki, 2000). Khatib and Hibbert (2005) studied the effect of GGBFs (0\%-80\%) on the flexural strength of concrete. They demonstrated that from $40 \%$ to $60 \%$ of GGBFs content has a benefit in terms of higher later age flexural strength (Figure 8-8). 


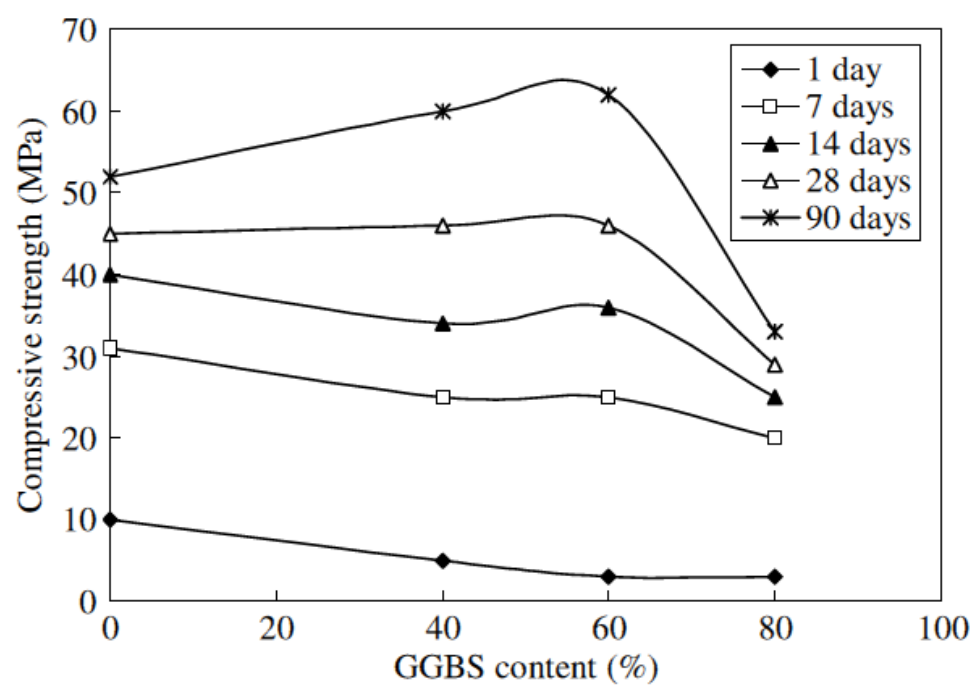

Figure 8-8: Influence of varying GGBFs contents in strength (Khatib and Hibbert, 2005)

Compressive strength development curves for the three mix design in Figure 8-7 were also tested in WVU. The early age strength decreases while later age strength increases as GGBFs content increases (23\% and 47\%). The comparison of the compressive strength of the three mix designs is shown in Figure 8-9.

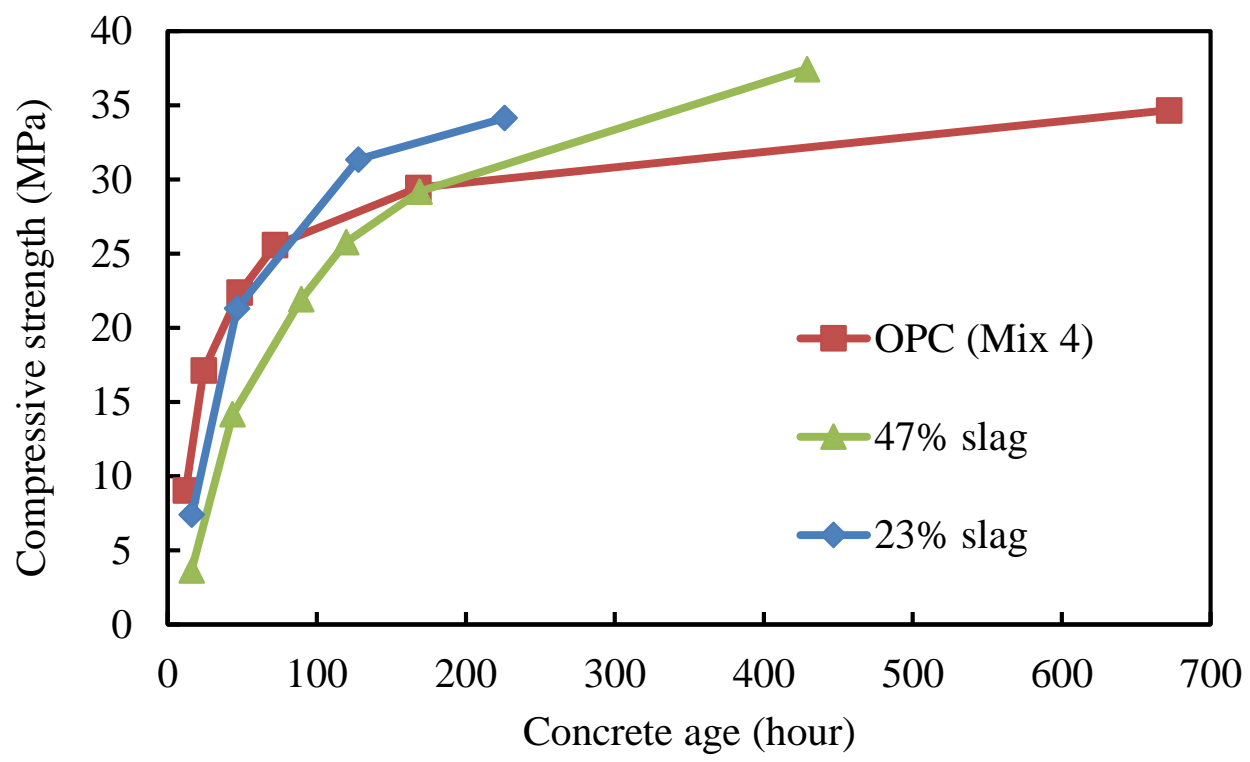

Figure 8-9: Comparison of compressive strength development (WVU lab) 


\subsection{The Effect of GGBFs on the Viscoelasticity of Concrete}

The implementation of GGBFs in concrete has a significant impact on basic creep behaviors of concrete. Researchers have performed basic creep tests on concrete containing GGBFs in comparison with OPC concrete (Nevill et al. 1983; Brooks, 1992; Ghodousi et al., 2009). Nevill et al. (1983) show that hardened concrete containing GGBFs has reduced creep deformation than OPC concrete. Brooks et al. (1992) and Ghodousi et al. (2009) showed the same findings for hardened concrete. But in the early ages, GGBFs concrete has a higher creep deformation (Figure 8-10). This phenomenon illustrated in Figure 8-10 is due to the slower reaction rate for GGBFs concrete in the early ages, because creep behavior is much more pronounced as the loading age decreases. GGBFs concrete exhibited a larger creep deformation due to a relatively smaller loading age or degree of hydration. In the later ages, GGBFs concrete has a better pore structure which caused a lower later age creep.

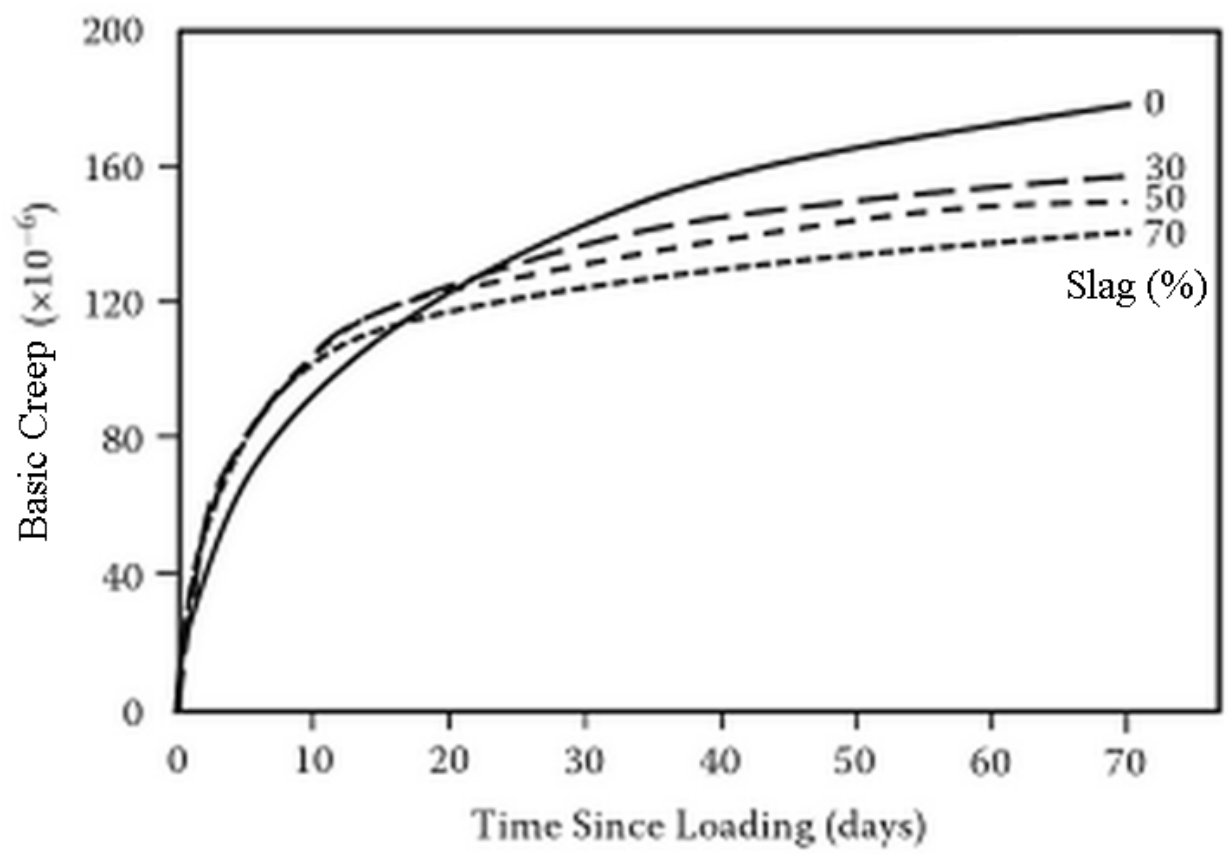

Figure 8-10: Effect of slag on basic creep of sealed concrete samples (Brooks et al. 1992) 


\subsection{The Effect of GGBFs on the Autogenous and Drying Shrinkage of Concrete}

The existence of GGBFs in concrete increases the autogenous shrinkage during concrete hydration (Tazawa and Miyazawa, 1995; Lim and Wee, 2000; Li and Yan, 2001; Lura et al., 2001; Lee et al., 2005) presented their results in different water cementitious ratios (Figure 8-11). For water cementitious ratio of 0.27 to 0.37 , the increase of GGBFs content will cause autogenous shrinkage to increase from the very early ages.

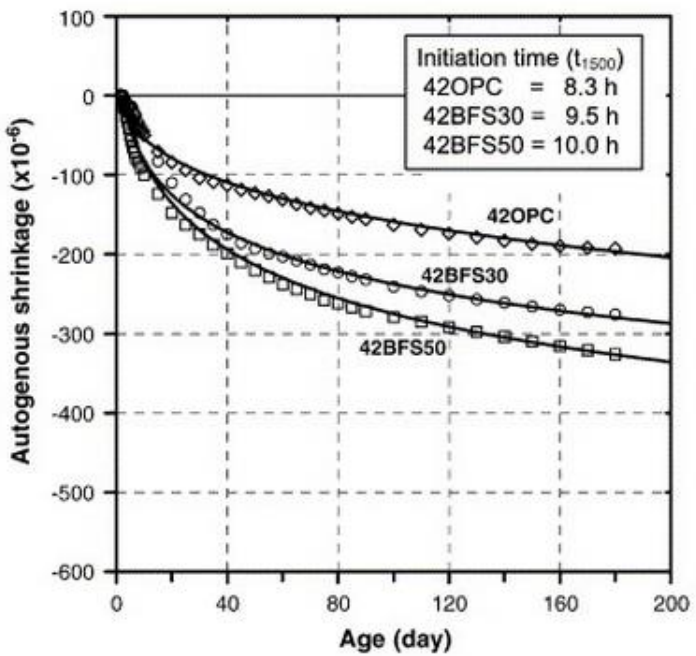

(a) $w / \mathrm{cm}=0.42$

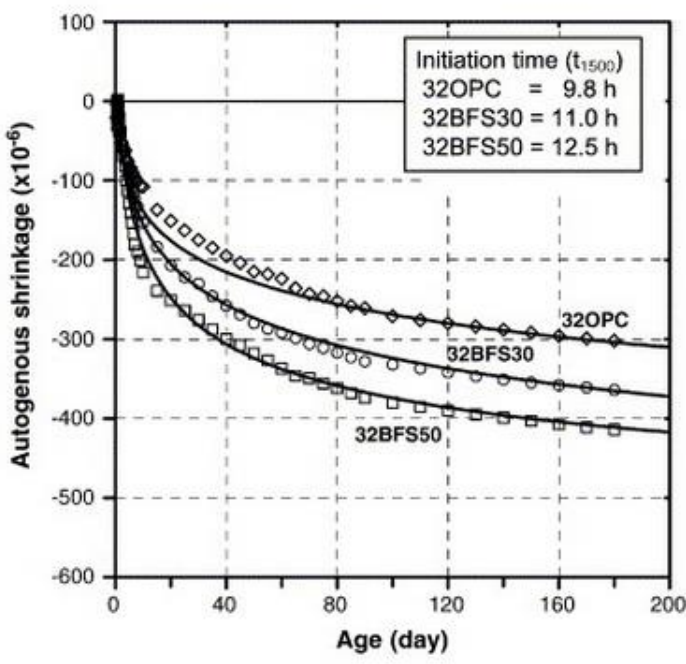

(c) $w / \mathrm{cm}=0.32$

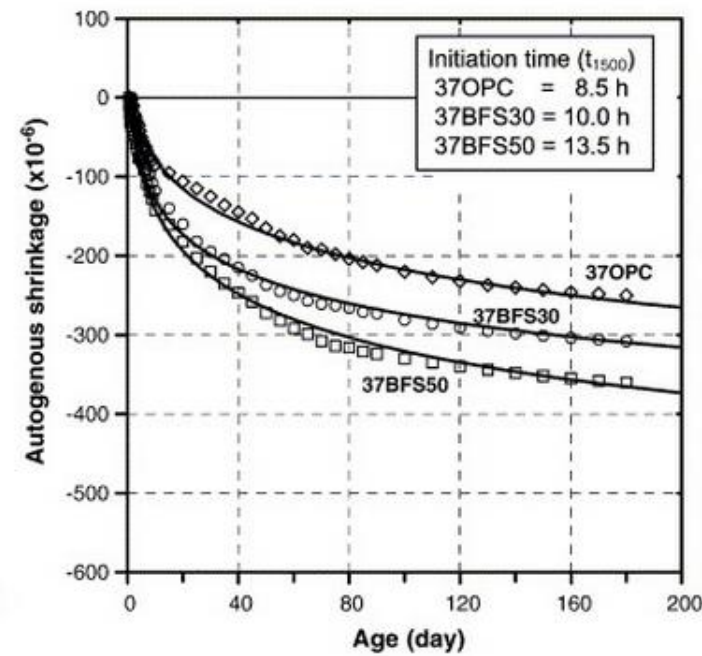

(b) $w / c m=0.37$

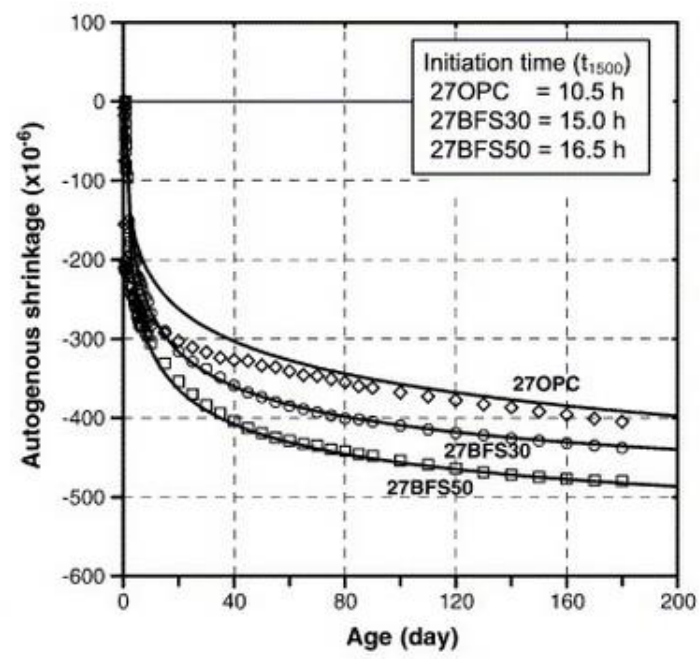

(d) $\mathrm{w} / \mathrm{cm}=0.27$

Figure 8-11: Effect of slag on autogenous shrinkage with different W/C (Lee et al., 2005) 
Drying shrinkage is more damaging to concrete durability than autogenous shrinkage. Many researchers studied the effect of GGBFs on concrete drying shrinkage. The results are listed in Table 8-2. From Table 8-2, the results are not completely consistent. The reason could be due to different starting point in measurement as mentioned by Lee et al. (2005). The majority of results show that the existence of GGBFs increases the drying shrinkage of concrete. However, the amount of drying shrinkage seems to be not affected by the percent of GGBFs.

Table 8-2: Effect of GGBFs on drying shrinkage of concrete (a summary of the findings from literature)

\begin{tabular}{lcccc} 
& w/c & \% slag & Humidity $(\%)$ & Relative Shrinkage \\
\hline Klieger and Isberner, 1967 & 0.42 & 20 & 50 & $0.8-1.0$ \\
Chojnacki, 1981 & 0.48 & 25 & 50 & 1.02 \\
& 0.38 & 25 & 50 & 0.89 \\
\hline Chern and Chan, 1989 & 0.51 & 4.5 & 50 & 1.17 \\
& 0.51 & 36 & 50 & 1.13 \\
& 0.51 & 68 & 50 & 1.08 \\
\hline Lankard, 1992 & N/A & 40 & 50 & 0.6 \\
\hline Ravindrarajah. et al., 1995 & 0.3 & $35 \%$ & 65 & 1.26 \\
\hline Chan et al., 1999 & 0.32 & 40 & 50 & 1.38 \\
& & 60 & 50 & 0.88 \\
\hline Luther, 1999 & 0.45 & 19 & 50 & 0.97 \\
& 0.45 & 23 & 50 & 0.76 \\
\hline Khatri et al., 1995 & 0.45 & 34 & 50 & 1.26 \\
\hline Brooks et al., 1992 & 0.35 & 65 & 50 & 1.37 \\
& 0.43 & 30 & 65 & 1.18 \\
& 0.43 & 50 & 65 & 1.34 \\
\hline Hogan and Meusel, 1981 & 0.43 & 70 & 65 & 1.46 \\
& 0.38 & 40 & 50 & 1.39 \\
\hline Tazawa et al., 1989 & 0.38 & 50 & 50 & 0.79 \\
\hline Nannamaker, 1996 & 0.38 & 65 & 50 & 0.74 \\
\hline & 0.51 & 35 & 50 & 50 \\
\hline & 0.51 & 55 & 50 & 50 \\
\hline
\end{tabular}

Note: relative shrinkage is the ratio of shrinkage of the OPC mix and the slag mix. 


\subsection{Conclusions}

One of the benefits of implementing GGBFs is the reduction of early age hydration heat. The mass concrete definition table was built based on Mix 4 as discussed in Chapter 7. It is recommended to study alternative mix designs with GGBFS based on which new mass concrete definition tables can be developed. The new mass concrete definition tables will have the potential of increasing minimum size of mass concrete from Table 7-1. If contractors agree to use the new proposed low heat mix designs, more concrete elements will be able to be defined as non-mass concrete so that the extra cost of the thermal control plan can be eliminated. Further research is currently being carried out by WVU researchers on studying alternative "thermal friendly" mix designs. 


\section{CHAPTER 9 SUMMARY AND RECOMMENDATIONS}

\subsection{Summary}

During this study, fourteen different elements from six bridge projects were instrumented with temperature sensors. The early age temperature distributions of these fourteen concrete elements were recorded. These elements were constructed using the common practice in West Virginia. Eleven out of the fourteen real bridge elements exceeded $20{ }^{\circ} \mathrm{C}\left(35^{\circ} \mathrm{F}\right)$ maximum allowable temperature differential limit, and one of them exceeded $70{ }^{\circ} \mathrm{C}\left(158{ }^{\circ} \mathrm{F}\right)$ maximum allowable center temperature limit. The concrete used in each member, casting time, initial temperature, maximum center concrete temperature, the maximum temperature differential between the center and the surface, as well as the time of the maximum differential appeared are tabulated in Table 4-1 (Chen et al., 2015).. In addition, four 1.8-meter (6-foot) cubes, three 1.2meter (4-foot) cubes and one 0.9-meter (3-foot) cube were constructed in WVU. The measured temperature histories were studied and used for validations of FEM results. During this study, a good understanding was established on how the temperature development can be affected by different factors including mix design, insulation and ambient temperature. It was understood that the temperature differential can be reduced by decreasing the total cementitious material, using mineral additives (slag or fly ash) to replace OPC and increase the surface insulation (Chen et al., 2015).

Using the adiabatic calorimeter developed in this study, the adiabatic temperature rises (ATR) of five different mix designs (Table 5-2) were experimentally measured which provided the shape of the hydration curve in thermal analysis. The ATR results of five different mix 
designs were used to calibrate the thermal loading functions for the finite element thermal analysis and made significant contributions to achieve accurate temperature profile predictions.

Finite element models were created using ABAQUS with the aid of FORTRAN subroutines to predict the thermal stress development for the early age of concrete members. The accuracy of the results was improved from a plain ABAQUS CAE model by adopting the following modeling techniques in both thermal analysis and stress analysis.

In thermal analysis, the goal was to predict the temperature profile history of a concrete member throughout the early age. The FEM model created in this study considered the variations of concrete properties during hydration, non-uniform heat generations inside the concrete member, interface thermal resistance and external surface convection. FORTRAN subroutines (DFLUX and USDFLD) were coded to incorporate solution-dependent material properties and thermal loading function. As a result, the FEM model was able to predict the early age temperature profile histories for seven different concrete cubes as well as a pier-cap in the new Ices Ferry Bridge. The FEM results showed accurate correlations with experimental temperature measurements.

In stress analysis, the model used the calculated temperature profile histories and the mechanical properties of early age concrete to predict the thermal stress development for early age concrete members (Chapter 6). The experiments were performed to obtain compressive strength, tensile strength elastic modulus, thermal expansion coefficient and viscoelasticity. FORTRAN subroutine (USDFLD) was developed and implemented to consider the elastic modulus change during hydration and the viscoelasticity of early age concrete. Concrete tensile creep and compressive creep behaviors were considered using a step-by-step incremental 
calculation algorithm. The influences from loading age and temperature effect were included in the creep model to increase the modeling accuracy. The calculated total strain values were also validated by experimental measurements.

\subsection{Recommendations}

Finite element models for thermal and stress analysis were created in this study to predict the temperature and stress development for early age concrete members. Potential modifications can still be made to improve the modeling accuracy. The models were made for the concrete cubes without structural steel reinforcement. For the case of the pier-cap from the new Ices Ferry Bridge (Section 5.9), the predicted center temperature seems to be decreasing slower than the measured temperature. The thermal conductivity of the steel is much higher than plain concrete. Therefore, the steel reinforcement can lead to a faster heat flow from the concrete core to the surfaces. The error in Figure 5-42 is likely because that the effect of steel reinforcement was not considered in the FEM model. It is not feasible to add each steel bar to the model for different structures. The steel reinforcement has a similar effect as the cooling pipes used for post-cooling treatment mentioned in Section 2.5. For the benefit of further reducing the thermal stresses, it is recommended to study the effect of the steel reinforcement ratio on the overall thermal conductivity of the reinforced concrete members.

Furthermore, the moisture level inside the concrete was assumed to be $100 \%$ because the concrete cubes were covered during the early age. However, formwork removal in real world constructions can be conducted in very early age. Surface drying shrinkage can increase the tensile stresses in addition to the early age thermal stress. The chance of having surface cracking can be increased due to surface moisture loss. Therefore, it is recommended to study the drying shrinkage effect due to formwork removal. It is strongly recommended that keeping the 
formwork in place for an extended period of time to prevent any surface drying or thermal shock for early age concrete members.

Further study is needed to improve the finite element model to take the external insulation layers into consideration. Adding insulation is a cost-effective solution to reduce the thermal stress. It will be beneficial to create new mass concrete definition tables considering external insulation. Therefore, the cost of thermal control plan can be eliminated for larger concrete elements when insulation is provided. For example, the thermal blanket commonly used in West Virginia can be studied in terms of thermal resistance. Furthermore, studies on the nonlinear creep behavior with high stress to strength ratio and the unloading influence of the tensile and compressive creep in stress analysis are recommended.

Finally, in order to guide engineers and contractors to effectively reduce the possibility of thermal cracking, development of a good management practice is also recommended which covers choices of mix design, surface insulation, choices of casting time, pre-cooling, postcooling, curing method and recommended time of formwork removal. 


\section{References}

ABAQUS/CAE 6.12. Providence, RI, USA: Dassault Systèmes.

ACI 301-10 Specifications for Structural Concrete. American Concrete Institute, 2010.

Aldea, C, F Young, K Wang, and S P Shah. "Effect of curing conditions on properties of concrete using slag replacement." Cement Concrete Research 30 (2000): 465-472.

Al-Manaseer, and A N Elias. Placement of Mass Concrete for Cast-in-Place Concrete Piling. CA. Department of Transportation, 2008.

Anderson, G. "Blast Furnace Slag: Concrete Benefits." Annual Concrete Seminar, Concrete for Achieving a Sustainable Environment. Hong Kong City Hall, 2009.

ASTM C 1074, Standard practice for estimating concrete strength by the, maturity method. ASTM International, 2004.

ASTM C 150, Standard Specification for Portland Cement. West Conshohocken. ASTM International, 2005.

ASTM C 1679, Standard Practice for Measuring Hydration Kinetics of Hydraulic Cementitious Mixtures Using Isothermal Calorimetry ASTM International, 2014.

Atrushi, D S. "Tensile and Compressive Creep of Early Ag." Ph.D. Dissertation, Department of Civil Engineering, The Norwegian University of Science and Technology, 2003.

Badu, K G, and V S Kumar. "Efficiency of GGBS in Concrete." Cement and Concrete Research 30 (2000): 1031-1036.

Ballim, Y. "A Numerical Model and Associated Calorimeter for Predicting Temperature Profiles In Mass Concrete." Cement and Concrete Composite 26 (2004): 589-599.

Basheer, P A, P R Gilleece, A E Long, and W J McCarter. "Monitoring electrical resistance of concretes containing alternative cementitious materials to assess their resistance to chloride penetration." Cement and Concrete Composites 24 (2002): 437-449.

Bažant, Z P. Mathematical Modeling of Creep and Shrinkage of Concrete. John Wiley \& Sons Ltd, 1988.

Bažant, Z P, and S Baweja. "Creep and shrinkage prediction model for analysis and design of concrete structures: Model B3." American Concrete Institute. Detroit, 2000. 1-83.

Bažant, Z P, and Y Xi. "Continuous retardation spectrum for solidification theory of concrete creep." Journal of Engineering Mechanics 121, no. 2 (1995).

Bobko, C P, R Seracino, P Zia, and A Edwards. "Crack Free Mass Concrete Footings on Bridges in Coastal Environments." Department of Civil, Construction, and Environmental Engineering, North Carolina State University, 2012. 
Bombich, A, S Garner, and D Norman. Evaluation of Parameters Affecting Thermal Stresses in Mass Concrete. Department of the Army, 1991.

Brooks, J J. "Proceedings of the fourth international conference on fly ash, silica fume, slag and natural pozzolans in concrete." ACI 132, no. 2 (1992): 1325-1341.

Burmeister, L C. Convective heat transfer. 2nd ed. New York: Wiley-Interscience, 1993.

Bush, E W, R W Cannon, R G Mass, and S B Tatro. Effect of Restraint, Volume Change, and Reinforcement on Cracking of Mass Concrete. ACI Committee 207, 1995.

Byfors, J. "Plain Concrete at Early Ages." Swedish Cement and Concrete Research Institute, Stockholm, Sweden, 1980.

Carino, N J. "The Maturity Method: Theory and Application." Journal of Cement, Concrete, and Aggregates 6, no. 2 (1984): 61-73.

Carino, N J, and H S Lew. "The maturity method: from theory to application." Structure Congress \& Exposition. Washington, D.C., 2001.

Chan, Y W, C Y Liu, and Y S Lu. "Effects of Slag and Fly Ash on the Autogenous." In Autogenous Shrinkage of Concrete, by E\&FN Spon, 221-228. London, 1999.

Chen, H L, Y Lin, and A Yikici. Preliminary Analysis of Use of Mass Concrete in West Virginia. West Virginia University, RP \#257 Final Report, West Virginia Department of Transportation, 2015.

Chen, W. "Hydration of Slag Cement: Theory, Modeling and Application." Ph.D. Dissertation, University of Twente, 2007.

Chern, J C, and Y W Chen. "Deformations of Concrete Made with Blast Furnace Slag Cement and Ordinary Portland Cement." ACI Materials Journal 86, no. 4 (1989): 372-382.

Chojnacki, B. Sulfate Resistance of Blended (Slag) Cement. Report No. EM-52, Downsview, Ontario: Ministry of Transportation and Communications, 1981.

Copeland, L E, D L Kantro, and G Verdeck. "Chemistry of Hydration of Portland Cement. Part III- Energetic of the Hydration of Portland Cement." Proceeding of 4th International Symposium on Chemistry of Cement. Washington D.C.: NBS Monograph , 1962. 453-468.

CRD-C. Method of test for thermal diffusivity of concrete. Handbook of Concrete and Cement, Army COE Standards, 1973, 36-73.

Daube, J, and R Bakker. Portland blast-furnace slag cement: a review: Blended Cement. ASTMSTP 897, 1983, 5.

Dusinberre, D M. "Numerical Methods for Transient Heat Flow." Transactions, American Society of Mechanical Engineers 67 (1945): 703-772. 
Espinos, A, M L Romero, and A Hospitaler. "Advanced model for predicting the fire response of concrete filled tubular columns." Journal of Construction Steel Research 66, no. 8-9 (2010): 1030-1046.

Folliard, K J, et al. "Prediction Model for Concrete Behavior." Austin, TX, 2008.

Freiesleben Hansen, P, and E J Pederson. Curing of Concrete Structures. Guide to Durable Concrete Structures, Draft DEB, 1985, Appendix 1.

Freiesleben Hansen, P, and J Pederson. "Maturity Computer for Controlled Curing and Hardening of Concrete." Nordisk Betong 1, no. 19 (1977): 19-34.

Ghodousi, P, M H Afshar, H Ketabchi, and E Rasa. "Study of Early-age Creep and Shrinkage of Concrete Containing Iranian Pozzolans: An Experimental Comparative Study." Transaction A: Civil Engineering 16, no. 2 (2009): 126-137.

Gibbon, G J, Y Ballim, and G R Grieve. "A Low-Cost, Computer Controlled Adiabatic Calorimeter for Determining the Heat of Hydration of Concrete." Journal of Testing and Evaluation 25, no. 2 (1997): 261-266.

Gutch, A, and F S Rostasy. Young concrete under high tensile stresses - creep, relaxation and cracking. Proceedings of the International RILEM Symposium, London: E \& FN Spon, 1995, 111-118.

Hauggaard, A B, L Damkilde, P F Hansen, J H Hansen, S L Christensen, and A Nielsen. "Control of Early Age Cracking in Concrete, Phase 3: Creep in Concrete." Danish Road Directorate. Lyngby, 1997.

Hilaire, A, F Benboudjema, A Darquennes, Y Berthaud, and G Nahas. "Modeling basic creep in concrete at early-age under compressive and tensile loading." The International Conference on Structural Mechanics In Reactor Technology. New Dekhi India, 2011. 222-230.

Hogan, F J, and J W Meusel. "Evaluation for durability and strength development of a ground granulated blast furnace slag." Cement Concrete Aggregate 3, no. 1 (1981): 40-52.

Hong, S, and A H Varma. "Analytical modeling of the standard fire behavior of loaded CFT columns." Journal of Construction Steel Research 65, no. 1 (2009): 54-69.

Houghton, D L. "Concrete Strain Capacity Tests-Their Economic Implications." Engineering Foundation Research Conference. Pacific Grove, 1972. 75-99.

Houghton, D L. "Determining Tensile Strain Capacity of Mass Concrete." ACI JOURNAL 73, no. 12 (1976): 691-700.

Hwang, C L, and C Y Lin. "Strength development of blended blast furnace slag cement mortars." ACI SP 91, 1986: 1323-1340.

Kalyoncu, R. "Minerals yearbook: Slag-iron and steel, Report, U.S. Geological Survey." Reston, U.S., 1998. 
Kanstad, T, Ø BjØntegaard, and E J Sellevold. "Tensile and compressive creep deformations of hardening concrete containing mineral additives." Materials and Structures 46, no. 7 (2012): 1167-1182.

Khatib, J M, and J J Hibbert. "Selected engineering properties of concrete incorporating slag and metakaolin." Construction and Building Materials 19 (2005): 460-472.

Khatri, R P, V Sirivivatnanon, and W Gross. "Effect of Different Supplementary Cementitious Materials on Mechanical Properties of High Performance Concrete." Cement and Concrete Research 25, no. 1 (1995): 209-220.

Kim, J K, S H Han, and K M Lee. "Estimation of compressive strength by a new apparent activation energy function." Cement and Concrete Research 31, no. 2 (2001): 217-225.

Kishi, T, and K Maekawa. Thermal and mechanical modeling of young concrete based on hydration process of multi component cement minerals. RILEM Symposium on Thermal Cracking in Concrete at Early Ages, London: R. Springenschmid, E \& EF Spon, 1995.

Klieger, P, Isberner, and w Albert. "Laboratory Studies of Blended Cement-Portland BlastFurnace Slag Cements." Portland Cement Association 9, no. 3 (1967): 2-22.

Lange, D A, and S A Altoubat. Early Thermal Changes, Early Age Cracking in Cementitious Systems. Report of RILEM Technical Committee 181-EAS, RILEM Publications S.A.R.I. , 2003.

Lankard, D. Evaluation of Concretes for Bridge Deck Applications. Lankard Materials, Ohio Department of Transportation, 1992.

Lawrence, A M, M Tia, C Ferraro, and M Gergin. "Effect of early age strength on cracking in mass concrete containing different supplementary cementitious materials: experimental and finite element investigation." (Journal of Material in Civil Engineering) 24, no. 4 (2012): 362-372.

Lee, K M, H K Lee, S H Lee, and G Y Kim. "Autogenous shrinkage of concrete containing granulated blast-furnace slag." Cement and Concrete Research 36, no. 7 (2005): 1279-1285.

Lee, M H, B S Khil, and H D Yun. "Influence of Cement Type on Heat of Hydration and Temperature Rise of the Mass Concrete." Indian Journal of Engineering \& Material Sciences 21 (2014): 536-542.

Lewis, D W. "National Slag Association Presented at Symposium on Slag National Institute for Transport and Road Research South Africa." 1982.

Li, J. "Predicting early-age thermal behavior of mass concrete for bridge foundation." Master's thesis, Civil, Construction, and Environmental Engineering, Iowa State University, 2012.

Li, J, and Y Yan. "A Study on Creep and Drying Shrinkage of High Performance Concrete." Cement and Concrete Research 31 (2001): 1203-1206. 
Lim, S N, and T H Wee. "Autogenous shrinkage of ground-granulated blast-furnace slag concrete." ACI Material Journal 97 (2000): 587-593.

Lin, Y, and H L Chen. "Thermal analysis and adiabatic calorimetry for early-age concrete members." Journal of Thermal Analysis and Calorimetry 122, no. 2 (2015): 937-945.

Lin, Y, and H L Chen. "Thermal analysis and adiabatic calorimetry for early-age concrete members - Part 2: Evaluation of thermally induced stresses." Journal of Thermal Analysis and Calorimetry DOI: 10.1007/s10973-015-5131-x

Lokhorst, S J. "Deformational behaviour of concrete influenced by hydration related changes of the microstructure." Technical University Delf, The Netherlands, 1998.

Lu, H, X L Zhao, and L H Han. "Fire behavior of high strength self consolidating concrete filled steel tubular stub columns." Journal of Construction Steel Research 65, no. 10-11 (2009): 1995-2010.

Luo, R, Y Cai, C Wang, and X Huang. "Study of chloride binding and diffusion in GGBS concrete." Cement and Concrete Research 33 (2003): 1-7.

Lura, P, K Breugel, and I Maruyama. "Effect of curing temperature and type of cement on earlyage shrinkage of high-performance concrete." Cement and Concrete Research 31 (2001): 1967-1872.

Luther, M. Personal Communication. Data from CTL Report to Holcim (US) Inc, 1999.

Luzio, G D, and G Cusatis. "Soli Solidification-microprestress-microplane (SMM) Theory for Concrete at Early Age: Theory, validation and Application." International Journal of Solids and Structures 50, no. 6 (2012): 957-975.

Macphee, D E, M Alkins, and F P Glasser. "Phase development and pore solution chemistry in ageing blast furnace slag-Portland cement blends." Materials Research Society. Pittsburgh, PA, 1989. 475-480.

McIntosh, J D. "Electrical Curing of Concrete." Magazine of Concrete Research 1, no. 1 (1949): 21-28.

Melta, M, R Khan, and S H Farooq. "Activation of Ground Granulated Blast Furnace Slag by Alkalis in Self-Consolidating Concrete." Life Science Journal 11, no. 12 (2014).

Mills, R H. Factors influencing cessation of hydration in water cured cement pastes. Washington: Highway Research Board, 1966.

Mindess, S, and J F Young. Concrete. New Jersey: Prentice-Hall, 1981.

Miura, T, and I Iwaki. "Strength development of concrete incorporating high levels of ground granulated blast-furnace slag at low temperatures." ACI Materials Journal 97, no. 1 (2000): 66-70. 
Nagy, A, and S Thelandersson. Material characterization of young concrete to predict thermal stresses. Thermal Cracking in Concrete at Early Ages. R. Springenschmid, E\&FN Spon, 1994.

Nasir, N A, N A Farah, A B Aziz, and N A Safiee. "Hydration of the combinations of ground granulated blast furnace slag cements." Basics \& Applications in Science. 2014. 392-396.

Neville, A M. "Properties of concrete." Nordtest: Essex, England: Prentice Hall, 1995.

Neville, A M, W H Dilger, and J J Brooks. Creep of plain and structural concrete. Construction Press, 1983.

NIST. Virtual Cement and Concrete Testing Laboratory. The National Institute of Standards and Technology, 2014.

Nurse, R W. "Steam Curing of Concrete." Magazine of Concrete Research 1, no. 2 (1949): 79-88.

Østergaard, L, D Lange, S A Altoubat, and H Stang. "Tensile basic creep of early-age concrete under constant load." Cement and Concrete Research 31, no. 12 (2001): 1895-1899.

Pane, I, and W Hansen. "Investigation Of Blended Cement Hydration By Isothermal Calorimetry And Thermal Analysis." Cement And Concrete Research 35, no. 6 (2005): 1155-1164.

Polivka, R M, and E L Wilson. "Finite Element Analysis of Nonlinear Heat Transfer Problems." University of California, Berkeley, 1976.

Poole, J L. "Modeling Temperature Sensitivity and Heat Evolution of Concrete." PhD Dissertation, University of Texas, Austin, 2007.

Radjy, F F. "An Overview of Heat Signature Technology and its Application to Proposed Concrete In-Place Thermal Cracking Field Curing Indices." ACI, SP-241, 2007.

Ravindrarajah, R S, C M Mercer, and J Toth. "Moisture-Induced Volume Changes in HighStrength Concrete." ACI SP-149, High Performance Concrete. 1995. 475-490.

Rhodes, J A. Thermal Properties. ASTM, 1978, 242-266.

Riding, K. "Early age concrete thermal stress measurement and modeling." Ph.D. Dissertation, University of Texas at Austin, Austin, Texas, 2007.

Robbins, M E. Predicting Temperature Rise and Thermal Cracking in Concrete. University of Toronto, PCA, 2007.

Ross, A D, and J W Bray. "The Prediction of Temperatures in Mass Concrete by Numerical Computation." (Magazine of Concrete Research) 1, no. 1 (1949): 9-20.

Roy, D M, and G M Idorn. "Hydration, structure, and properties of blast furnace slag cement, mortars, and concrete." American Concrete Institute Journal 79 (1982): 444-457.

Saul, A G. "Principles Underlying the Steam Curing of Concrete at Atmospheric Pressure." (Magazine of Concrete Research) 2, no. 2 (1951): 127-140. 
Schindler, A K, and K J Folliard. "Heat of hydration models for cementitious materials." ACI Materials Journal 102 (2005): 24-33.

Schutter, G D. "Fundamental study of early age concrete behavior as a basis for durable concrete structures." Materials and Structures 35 (2002): 15-21.

Shaw, J J. "A case study of mass concrete construction for Midwest boarder bridges." Master's thesis, Civil, Construction, and Environmental Engineering, Iowa State University, 2012.

Siddiqui, R A. Ground Granulated Blast Furnace Slag. Springer, 2008.

Springenschmid, R. Prevention of Thermal Cracking in Concrete at Early Ages. RILEM Technical Committee 119, London: E and FN Spon, 1998.

Tasong, W A, and R Tilley. "Mechanism by which ground granulated blast furnace slag prevents sulfate attack of lime stabilized kaolinite." Cement and Concrete Research 29 (1999): 975982.

Taylor, H F. Cement chemistry. 2nd edn. London: Thomas Telford Publishing, 1997.

Tazawa, E, A Yonekura, and S Tanaka. "Drying Shrinkage and Creep of Concrete Containing Granulated Blast Furnace Slag." ACI SP-114 Fly Ash, Silica Fume, Slag and Natural Pozzolans in Concrete: Proceedings Third International Conference. Trondheim, Norway, 1989. 1325-1343.

Tazawa, E, and S Miyazawa. "Influence of cement and admixture on autogenous shrinkage of cement paste." Cement and Concrete Research 25 (1995): 281-287.

TCE-119, RILEM Technical Committee. "Adiabatic and Semi-Adiabatic Calorimetry to Determine the temperature Increase in Concrete due to Hydration Heat of Cement. Prevention of Thermal Cracking in Concrete at Early Ages, London: E \& FN Spon, 1998, 315-330.

Tepke, D G, P J Tikalsky, and B E Scheetz. "The maturity method: from theory to application." Structure Congress \& Exposition. Washington, D.C, 2001.

Thomas, L C. Fundamentals of Heat Transfer. New Jersey: Prentice-Hall, 1980.

Tia, M, C Ferraro, A Lawrance, S Smith, and E Ochiai. Development of Design Parameters for Mass Concrete Using Finite Element Analysis. Tallahassee, FL: Florida Department of Transportation, 2010.

Tia, M, C Ferraro, T A Do, and Y Chen. Pilot project for maximum heat of mass concrete. The Florida Department of Transportation. The Florida Department of Transportation, 2013.

Ulm, F J, and O Coussy. "Modeling of thermo-mechanical couplings of concrete at early ages." Journal of Engineering and Mechanics 121, no. 7 (1995): 785-794.

Umehara, H, and T Uehara. "Effect of creep in concrete at early ages on thermal stresses, thermal cracking in concrete at early ages." Proceedings of the International RILEM Symposium. London: E\&FN Spon, 1995. 79-86. 
Van Breugel, K. Prediction of Temperature Development in Hardening Concrete. RILEM Report $15,1998$.

Waller, V, L d'Aloïa, F Cussign, and S Lecrux. "Using the Maturity Method in Concrete Cracking control at early ages." Cement and Concrete Composites, 2004: 589-599.

Wannamaker, D. "Evaluation of Alternative Concrete for Water Retaining Structures." Master's Thesis, Department of Civil Engineering, University of Toronto, 1996.

Wei, Y, and W Hansen. "Tensile Creep Behavior of Concrete Subject to Constant Restraint at Very Early Ages." Journal of Materials in Civil Engineer 25, no. 9 (2013).

West Virginia Department of Transportation, "Structural Concrete - Mass Concrete", Special Provision, Section 601, 2010.

Wight, J K, and J G MacGregor. "Reinforced Concrete: Mechanics and Design." Chap. Chapter 3. Pearson Prentice Hall, 2009.

Wilbur, R, and E Mead. The Construction Of Hoover Dam: Preliminary Investigations, Design Of Damn, And Progress Of Construction. Washington: Government Printing Office, 1933.

Wilson, E L. The Determination of Temperatures within Mass Concrete Structures. SESM Report No. 68-17, Department of Civil Engineering, University of California, Berkeley: Structures and Materials Research, 1968, 1-33.

Wu, S, D Huang, F B Lin, H Zhao, and P Wang. ""Estimation of cracking risk of concrete at early age based on thermal stress analysis." Journal of Thermal Analysis and Calorimetry 105 (2011): 171-186.

Xu, Q, J M Quiz, G K Chang, R O Rasmussen, and D K Rozycki. "Moisture transport model for enhancing FHWA HIPERPAV predictions." Journal of Transportation Research Board 2113 (2009): 1-12.

Yikici, A, and H L Chen. "Effect of temperature-time history on concrete strength in mass concrete structure." TRB 92nd annual conference proceeding. Washington, D.C., 2013. 